\title{
Characterization of infield vehicle activity data and exhaust emissions from diesel powered off-road vehicles
}

\author{
Ryan Andrew Barnett \\ West Virginia University
}

Follow this and additional works at: https://researchrepository.wvu.edu/etd

\section{Recommended Citation}

Barnett, Ryan Andrew, "Characterization of infield vehicle activity data and exhaust emissions from diesel powered off-road vehicles" (2001). Graduate Theses, Dissertations, and Problem Reports. 1150. https://researchrepository.wvu.edu/etd/1150

This Thesis is protected by copyright and/or related rights. It has been brought to you by the The Research Repository @ WVU with permission from the rights-holder(s). You are free to use this Thesis in any way that is permitted by the copyright and related rights legislation that applies to your use. For other uses you must obtain permission from the rights-holder(s) directly, unless additional rights are indicated by a Creative Commons license in the record and/ or on the work itself. This Thesis has been accepted for inclusion in WVU Graduate Theses, Dissertations, and Problem Reports collection by an authorized administrator of The Research Repository @ WVU. For more information, please contact researchrepository@mail.wvu.edu. 
Characterization of Infield Vehicle Activity Data and Exhaust Emissions from Diesel Powered Off-Road Vehicles

\author{
Ryan A. Barnett \\ Thesis submitted to the \\ College of Engineering and Mineral Resources \\ at West Virginia University \\ in partial fulfillment of the requirements \\ for the degree of \\ Masters of Science \\ In \\ Mechanical Engineering \\ Mridul Gautam, Ph.D., Chair \\ Greg Thompson, Ph.D. \\ W. Scott Wayne, Ph.D. \\ Department of Mechanical and Aerospace Engineering \\ Morgantown, WV \\ 2001
}

Keywords: Off-Road Diesel, Emissions Testing, Torque Prediction 


\section{Abstract \\ Characterization of Infield Vehicle Activity Data and Exhaust Emissions from Diesel Powered Off-Road Vehicles}

Ryan A. Barnett

A study was conducted to determine brake-specific emissions from dieselpowered off-highway heavy equipment that were exercised on steady-state and transient cycles. Two vehicles were evaluated in this study, a streetsweeper (114 hp) and a rubbertired loader $(110 \mathrm{hp})$. Due to the lack of appropriate transient cycles available for these vehicles, methods were developed to document infield operation for the creation of test cycles and strategies. These cycles were later used to mimic infield operation for the collection of emissions and performance data on a dynamometer test bed.

Brake-specific emissions data collected during the transient cycles was compared to data collected during the 8-mode test (CFR 40, Part 89; ISO $8178 \mathrm{C} 1$ ) that is currently used for engine certification, and results were found to differ significantly. For the rubber-tired loader, the weighted 8-mode brake-specific $\mathrm{HC}, \mathrm{CO}, \mathrm{CO}_{2}, \mathrm{NO}_{\mathrm{x}}$, and $\mathrm{PM}$ were $545 \%, 311 \%, 105 \%, 227 \%$, and $177 \%$ higher than the transient cycle emissions results, respectively. 


\section{Acknowledgements}

With this section, I wish to thank the people who have positively advised and influenced me over the years, not only in my education but also in life, itself. My career as a graduate student has been a relatively long one, during which I have acquired many great friends and mentors. I owe a lot to these people. Without a few of them, graduate school would have been a near impossibility for me. Without others, the experience would definitely have been considerably less fun.

I first would like to thank Dr. Mridul Gautam for initially giving me the opportunity to attend graduate school under his guidance. Thank you for being a good friend, advisor, and, most importantly, for always believing in me when even I sometimes didn't. Thank you, Dr. Greg Thompson and Dr. Scott Wayne for all the support provided during my graduate research and for caring enough to be on my committee.

The biggest influence in any young persons life is undoubtedly his parents. They are the ones that mold you in your formative years and often lay the groundwork for future interests with early encouragement. Dad, thank you for not getting too angry when I would break my toys apart just to "see how they work" inside. You recognized my interest in all things mechanical very quickly and I appreciate you not stifling them even if those toys did cost a lot of money. My toys are much more expensive now, you should be glad you're not paying for them! Thank you, mom, for teaching my siblings and me at a young age and giving us a valuable head start on our educations. Without your love and support, none of this would have been possible.

As for my friends, I would first and foremost like to thank Dan Carder. You are the one that encouraged me to go to graduate school in the first place and you have 
tirelessly provided knowledge, advice, and friendship to me over the years. I would also like to thank you for allowing the construction of the "Super Bronc" in your cramped garage. I'll finish it soon, I promise! I would also like to thank your wife, Hillarey, for cooking countless good meals for me and for generally putting up with my hijinx. I would like to thank Wes Riddle for being a good friend and for his vast technical and strengths of materials knowledge in the construction of my bronco. Also, thanks for all those beautiful aluminum welds. Andy Fuller, thank you for all those beers, good times, and spots at the gym. You have undoubtedly made graduate school a lot more bearable. I would also like to thank Ben Shade, Jason Snyder, Sorin Petreanu, Brad Bane, and Jeremy Rohrbaugh for the assistance given me in my endeavors and for being good friends. You guys will not be forgotten.

For technical support, I need to thank Richard Atkinson and Tom Spencer. I owe you two a lot for all the help on the electrical/data acquisition side of things, an area where I decidedly have very limited knowledge. Keep up the good work!

A "thank you" also needs to go out to the California Air Resources Board for supplying the funding that made my masters research possible.

I sincerely hope I have not forgotten anyone. If I have, it is surely not intentional. Upon completion of this document, I find that my memory seems a little fuzzy, my vision a bit blurry, and my nerves slightly frayed. For this reason, I wish now that I would have written this section first because my thoughts would have been clearer. For anyone I forgot to mention, thank you. 
Table of Contents

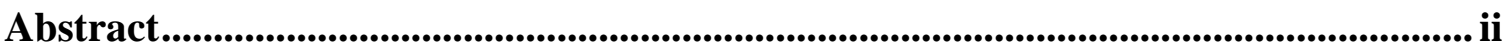

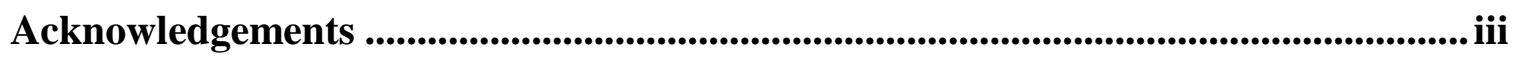

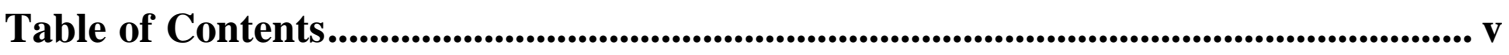

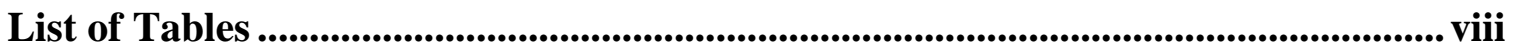

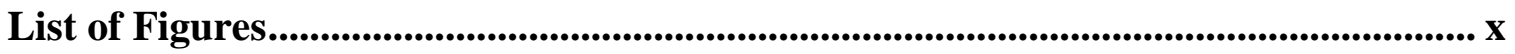

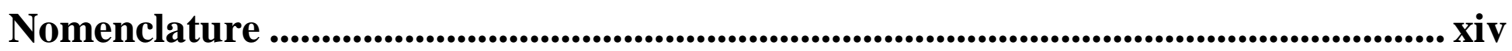

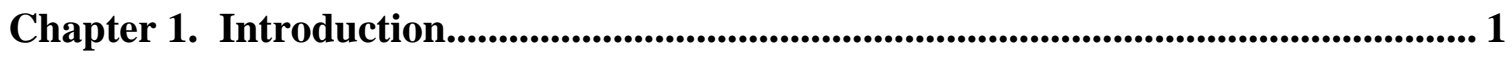

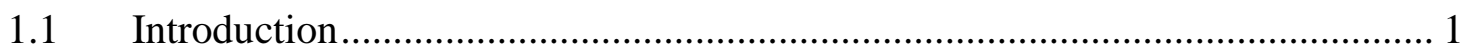

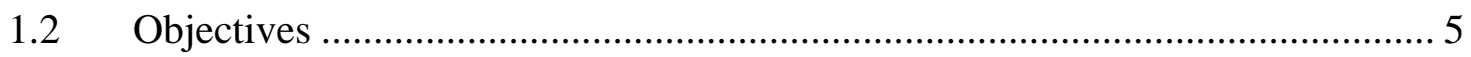

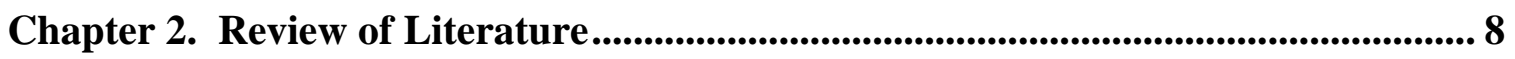

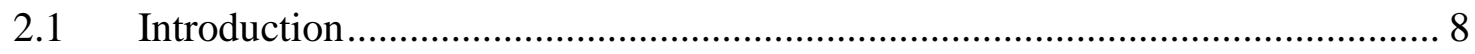

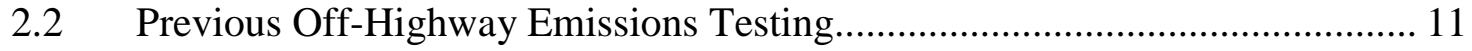

2.2.1 Northeast States for Coordinated Air Use Management — 1997 .................. 11

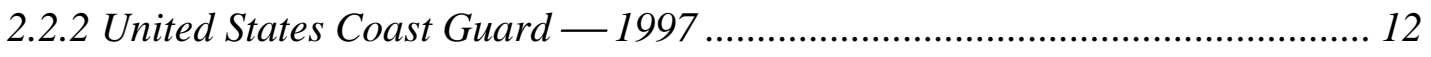

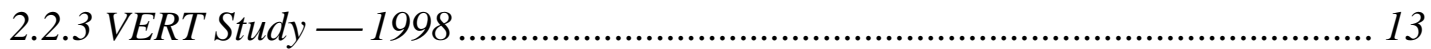

2.3 Previous On-Board Emissions Testing Devices ....................................... 15

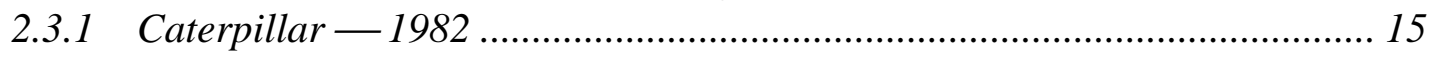

2.3.2 Southwest Research Institute - 1992 ........................................................ 15

2.3.3 General Motors — 1993 ........................................................................... 16

2.3.4 Ford Motor Company — 1994 ................................................................... 17

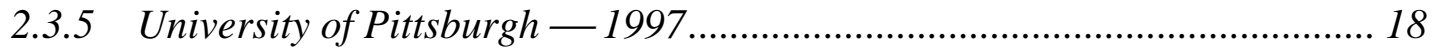

2.3.6 Flemish Institute for Technological Research - 1997 .............................. 19

2.3.7 United States Environmental Protection Agency - 1999........................... 20

2.3.8 Ford Motor Company/WPI Microprocessor Systems, Inc. — 1999............. 21

2.3.9 West Virginia University - 2000....................................................... 22

Chapter 3. Experimental Equipment and Procedures ...................................................... 25

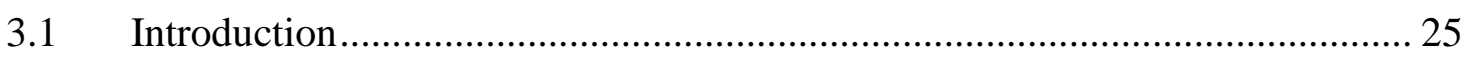

3.2 Vehicles Tested ............................................................................................... 25

3.2.1 John Deere 444 Rubber-Tired Front End Loader ..................................... 26

3.2.2 Elgin Pelican Series P Streetsweeper ....................................................... 27

3.3 Infield Data Acquisition Equipment/Procedures ............................................. 29

3.3.1 Sensors AMB-II Multigas Analyzer ....................................................... 30

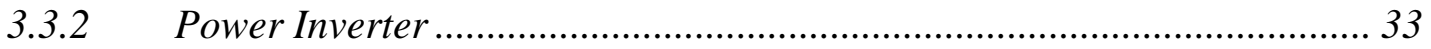


3.3.3 Exhaust Sampling System …………………….................................... 34

3.3.4 Engine Speed and Torque Measurement .............................................. 35

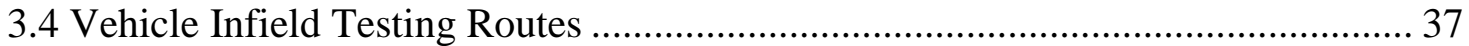

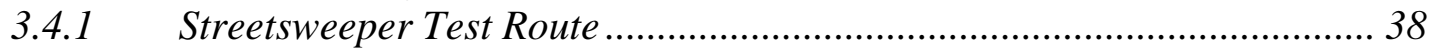

3.4.2 Rubber-Tired Loader Test Route ……………….................................... 38

3.5 In-Laboratory Data Acquisition Setup - EERL Components............................. 39

3.5.1 Full-Flow Exhaust Dilution Tunnel ........................................................ 39

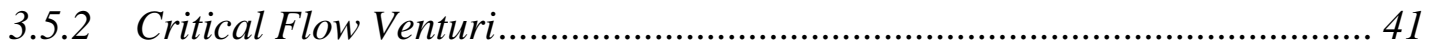

3.5.3 Particulate Sampling System …………………..................................... 42

3.5.4 Gaseous Emission Sampling System ………………................................. 43

3.5.5 Exhaust Gas Analyzers …………………………............................. 45

3.5.5.1 Oxides of Nitrogen Analyzer ............................................................... 45

3.5.5.2 Hydrocarbon Analyzer ........................................................................... 46

3.5.5.3 Carbon Monoxide/Carbon Dioxide Analyzers .................................... 46

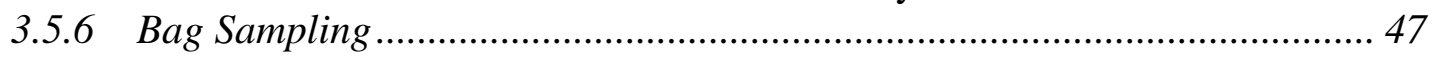

3.5.7 Fuel and Air Flow Metering .................................................................. 47

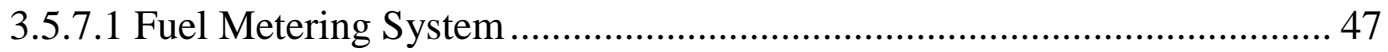

3.5.7.2 Intake Air Flow Measurement ................................................................ 49

3.5.8 Instrumentation Control/Data Acquisition ……………………................ 51

Chapter 4. Experimental Results and Discussion ................................................................. 53

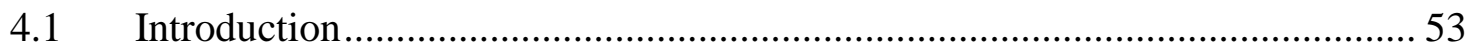

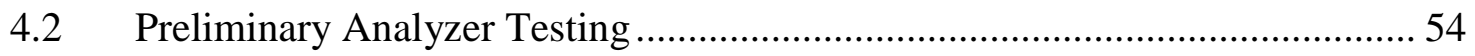

4.2.1 Steady-State Analyzer Testing............................................................ 56

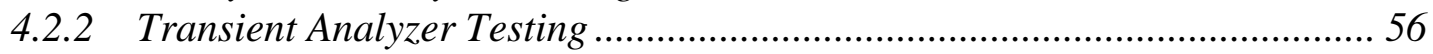

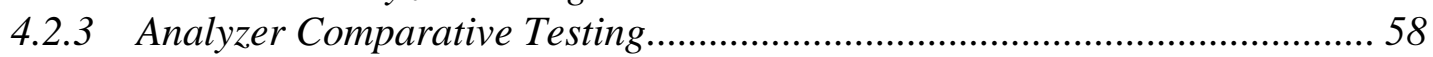

4.2.4 Torque Inference Prediction Testing ……………...................................... 59

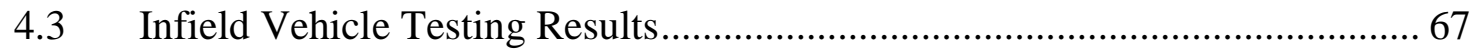

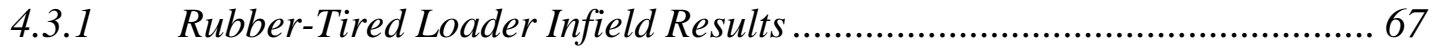

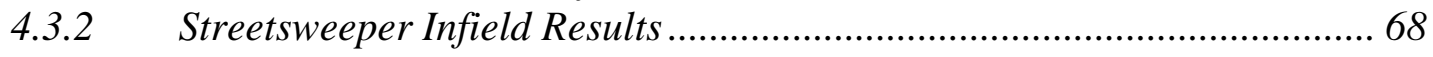

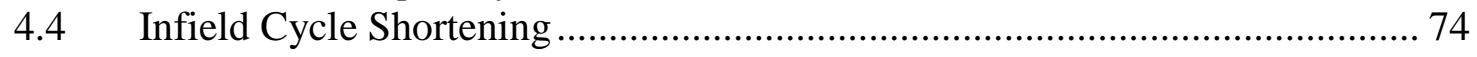

4.4.1 Infield Loader Cycle Shortening ............................................................. 75

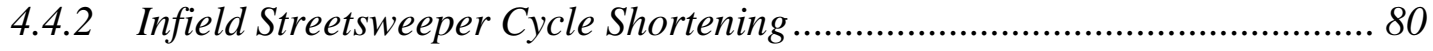

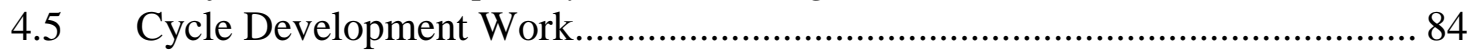

4.5.1 Rubber-Tired Loader Cycle Development .................................................. 88

4.5.1.1 Engine Map........................................................................................ 88

4.5.1.2 $\quad \mathrm{CO}_{2} \mathrm{Map}$ Matrix …………......................................................... 89

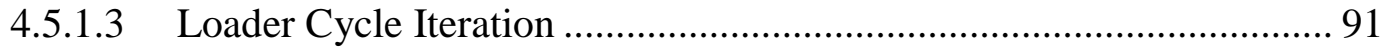

4.5.2 Streetsweeper Cycle Development …………….................................... 103

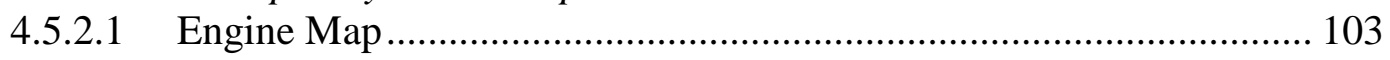

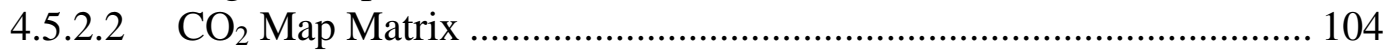

4.5.2.3 Streetsweeper Cycle Iteration ............................................................. 106

4.6 In-Laboratory Emissions Testing Results .................................................. 115

4.6.1 Rubber-Tired Loader In-Laboratory Results........................................... 116

4.6.1.1 Loader Steady-State 8-Mode Test Results....................................... 116

4.6.1.2 Loader Transient Cycle Test Results ................................................... 119 
4.6.1.3 Comparison of Loader Steady-State and Transient Test Results........ 121

4.6.2 Streetsweeper In-Laboratory Results................................................. 128

4.6.2.1 Streetsweeper Steady-State 8-Mode Test Results............................. 128

4.6.2.2 Streetsweeper Transient Cycle Test Results ..................................... 131

4.6.2.3 Streetsweeper-on-Loader Transient Cycle Test Results .................... 135

4.6.2.4 Comparison of Sweeper Steady-State and Transient Test Results ..... 137

Chapter 5. Conclusions and Recommendations...................................................... 144

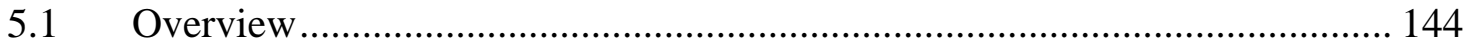

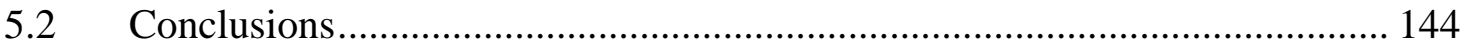

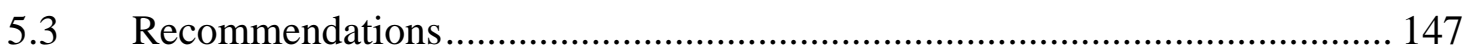

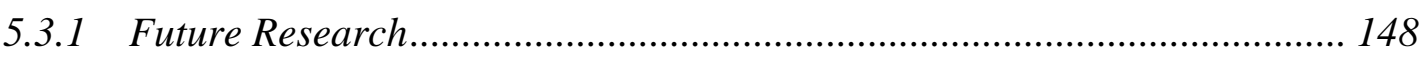

5.3.2 Test Procedure Refinement .............................................................. 152

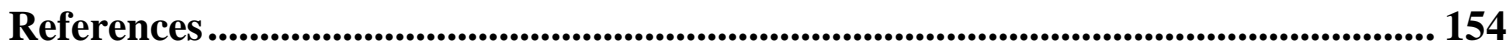

Appendix A-Additional Data for the John Deere 6059 Loader Engine..................... 157

Appendix B-Additional Data for the John Deere 4039T Streetsweeper Engine..... 161 


\section{List of Tables}

Table 1 On-Road Heavy-Duty Diesel Engine Emissions Standards [2].......................... 8

Table 2 Off-Road Diesel Engine Emissions Standards [2] ......................................... 9

Table 3 Engine Test Specifications.......................................................................... 29

Table 4 Results of Steady-State Gas Bottle Tests on Sensors AMB-II (19.9\%

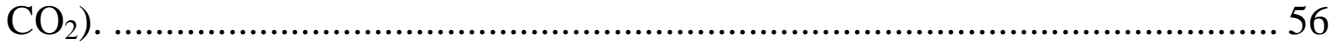

Table 5 Route Description for the Full Infield Streetsweeper Testing Route.................. 72

Table 6 Description of Sweeper Brush Drag Test. ....................................................... 73

Table 7 Comparison of Engine Speed Discretized Average Load Values between the Full and Shortened Infield Loader Cycles. ................................ 80

Table 8 Comparison of Engine Speed Discretized Average Load Values between the Full and Shortened Infield Streetsweeper Cycles. ..................... 83

Table 9 Matrix for the John Deere 6059 Loader Engine. .............................................. 91

Table 10 Matrix for the John Deere 4039T Streetsweeper Engine............................... 106

Table 11 The ISO 8-Mode Cycle........................................................................... 115

Table 12 Loader 8-Mode Engine Speed/Load Set Points........................................... 117

Table 13 Average of 8-Mode Results for the John Deere 6059 Loader Engine (g/bhp-hr)............................................................................... 117

Table 14 Transient Cycle Emissions Results for the John Deere 6059 Loader

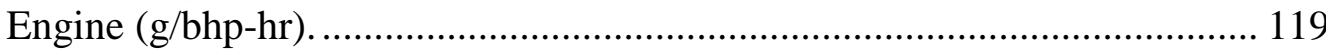

Table 15 Comparison of Transient and Weighted 8-Mode Results for the John Deere 6059 Loader Engine (g/bhp-hr).

Table 16 Regression Criteria for Transient Certification Test Validity Analysis as Outlined in the Code of Federal Regulations....

Table 17 Streetsweeper 8-Mode Engine Speed/Load Set Points.....

Table 18 Average of 8-Mode Results for the John Deere 4039T Streetsweeper Engine (g/bhp-hr).

Table 19 Transient Cycle Emissions Results for the John Deere 4039T Streetsweeper Engine Operating on the First Iteration of the Derived Test Cycle (g/bhp-hr).

Table 20 Emissions Results for the John Deere 4039T Streetsweeper Engine Operating on the Final Iteration of the Transient Cycle (g/bhp-hr).

Table 21 Comparison of Emissions Results for the John Deere 4039T

Streetsweeper Engine Operating on the First and Final Iteration of the Transient Cycle (g/bhp-hr).

Table 22 Cycle Averaged Emissions Results for the John Deere 4039T Streetsweeper Engine Operating on the Final Loader Transient Cycle (g/bhp-hr).

Table 23 Average Results Comparison of Transient Tests Performed (g/bhp$\mathrm{hr})$.

Table 24 Comparison of Transient and Weighted 8-Mode Results for the John Deere 4039T Streetsweeper Engine (g/bhp-hr).

Table 25 Comparison of Transient and Newly Weighted 8-Mode Results for the John Deere 4039T Streetsweeper Engine (g/bhp-hr). 
Table 26 Regression Criteria for Transient Certification Test Validity Analysis as Outlined in the Code of Federal Regulations.

Table 27 Comparison of Steady-State Results with the Current Off-Road Diesel Emissions Standards. 


\section{List of Figures}

Figure 1 John Deere 444 Rubber-Tired Front End Loader............................................ 26

Figure 2 John Deere 6059D Engine on Dynamometer Test Bed................................... 27

Figure 3 Elgin Pelican Series P Streetsweeper ............................................................ 28

Figure 4 John Deere 4039T Engine on Dynamometer Test Bed .................................... 28

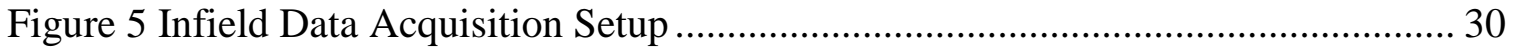

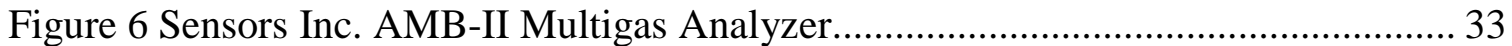

Figure 7 Tripplite Inc. Model PV1200 Power Inverter................................................ 34

Figure 8 Exhaust Gas Sampling Probe for the Sensors AMB-II Analyzer...................... 35

Figure 9 Signal Conditioning Unit for RPM Measurement on AMB-II......................... 37

Figure 10 The Gaseous Emissions Analyzer Bench at the WVU EERL........................ 45

Figure 11 Schematic of West Virginia University's Engine and Emissions

Research Laboratory Emissions Measurement System. ............................... 52

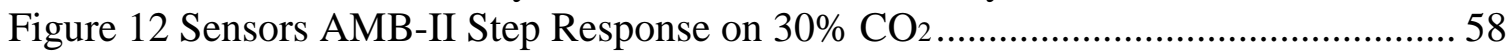

Figure 13 Rosemount 880 and Sensors AMB-II CO $\mathrm{CO}_{2}$ Measurement

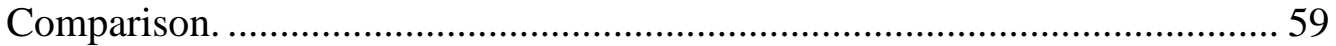

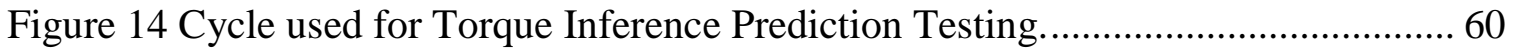

Figure 15 Engine Exhaust $\mathrm{CO}_{2}$ Concentration Map for Motored Condition.................... 61

Figure 16 Engine Exhaust $\mathrm{CO}_{2}$ Concentration Map for 0\% Applied Load...................... 61

Figure 17 Engine Exhaust $\mathrm{CO}_{2}$ Concentration Map for 25\% Applied Load.................... 62

Figure 18 Engine Exhaust $\mathrm{CO}_{2}$ Concentration Map for 50\% Applied Load................... 62

Figure 19 Engine Exhaust $\mathrm{CO}_{2}$ Concentration Map for 75\% Applied Load.................... 63

Figure 20 Engine Exhaust $\mathrm{CO}_{2}$ Concentration Map for 100\% Applied Load.................. 63

Figure 21 Interpolated $\mathrm{CO}_{2}$ vs. Engine Load Correlation for $970 \mathrm{rpm}$. .............................64 64

Figure 22 Interpolated $\mathrm{CO}_{2}$ vs. Engine Load Correlation for 1160rpm. ........................ 64

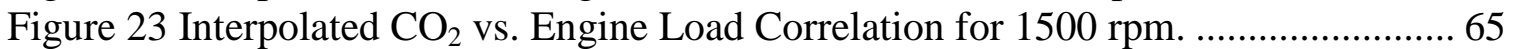

Figure 24 Interpolated $\mathrm{CO}_{2}$ vs. Engine Load Correlation for $1800 \mathrm{rpm}$......................... 65

Figure 25 Interpolated $\mathrm{CO}_{2}$ vs. Engine Load Correlation for $2200 \mathrm{rpm}$. ........................ 66

Figure 26 Torque Inference Error Estimates for Preliminary Engine Testing................. 66

Figure 27 Infield $\mathrm{CO}_{2}$ and Engine Speed vs. Time Results for the Rubber-Tired

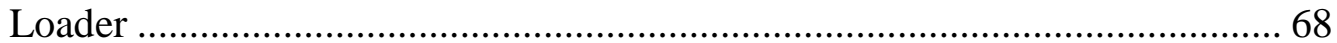

Figure 28 Infield $\mathrm{CO}_{2}$ and Engine Speed vs. Time for Series P Streetsweeper............... 70

Figure 29 Map of Route taken for Infield Streetsweeper Testing. ................................. 71

Figure 30 Effect of Sweeper Brush Drag/Inertia on $\mathrm{CO}_{2}$ Emission Levels.................... 73

Figure $31 \mathrm{CO}_{2}$ and Engine Speed vs. Time for the Shortened Infield Loader

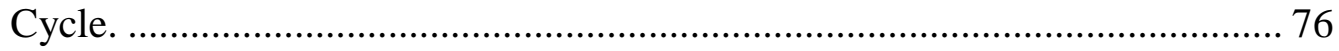

Figure $32 \mathrm{CO}_{2}$ and Engine Speed vs. Time for the Full Infield Loader Cycle................ 77

Figure 33 Normalized Engine Speed and Load for the Shortened WVU Infield

Rubber-Tired Loader Cycle. ......................................................................... 78

Figure 34 Normalized Engine Speed and Load for the EPA Rubber-Tired

Loader Cycle....................................................................................... 78

Figure $35 \mathrm{CO}_{2}$ and Engine Speed vs. Time for the Shortened Infield

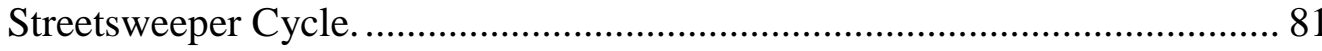

Figure $36 \mathrm{CO}_{2}$ and Engine Speed vs. Time for the Full Infield Streetsweeper

Cycle. 
Figure 37 Normalized Engine Speed and Load for the Shortened Infield

Streetsweeper Cycle.

Figure 38 Flowchart of Steps Involved in the Cycle Iteration Process........................... 86

Figure 39 Engine Map for the John Deere 6059 Loader Engine. .................................. 89

Figure 40 Comparison of Engine Speed Traces for the John Deere 6059 Loader

Engine prior to Time Alignment (First Iteration).

Figure 41 Comparison of Engine Speed Traces for the John Deere 6059 Loader

Engine after Shifting Laboratory Data by 4 Seconds for Time

Alignment (First Iteration).

Figure 42 Comparison of $\mathrm{CO}_{2}$ Traces for the first 700s of the John Deere 6059

Loader Engine Cycle After Time Alignment (First Iteration).

Figure 43 Comparison of $\mathrm{CO}_{2}$ Traces for the first 700s of the John Deere 6059

Loader Engine Cycle After Time Alignment (Final Iteration).

Figure $44 \mathrm{CO}_{2}$ Correlation Results for Two Repeat Runs of the Final Loader

Cycle.

Figure 45 Engine Speed Correlation Results for Two Repeat Runs of the Final

Loader Cycle.

Figure 46 Correlation of the Loader $\mathrm{CO}_{2}$ data Between the Infield and the

Derived In-laboratory Cycles (First Iteration).

Figure 47 Correlation of the $\mathrm{CO}_{2}$ Data Between the Infield and the First

Portion of the Final Iteration of the Derived In-Laboratory Cycle

(0s-580s).

Figure 48 Correlation of the $\mathrm{CO}_{2}$ Data Between the Infield and the Second

Portion of the Final Iteration of the Derived In-Laboratory Cycle

(580s-900s)....

Figure 49 Correlation of the $\mathrm{CO}_{2}$ Data Between the Infield and the Final

Portion of the Final Iteration of the Derived In-Laboratory Cycle

(900s-1144s).

Figure 50 Correlation of the Loader Engine Speed Data Between the Infield and the Derived In-Laboratory Cycles (First Iteration).

Figure 51 Correlation of the Loader Engine Speed Data Between the Infield and the Derived In-laboratory Cycles (Final Iteration).

Figure 52 Engine Map for the John Deere 4039T Streetsweeper Engine.

Figure 53 Comparison of $\mathrm{CO}_{2}$ Traces for the John Deere 4039T Streetsweeper

Engine After Time Alignment (First Iteration)

Figure 54 Comparison of $\mathrm{CO}_{2}$ Traces for the John Deere 4039T Streetsweeper Engine After Time Alignment (Final Iteration).

Figure $55 \mathrm{CO}_{2}$ Correlation Results for Two Repeat Runs of the Final

Streetsweeper Cycle.

Figure 56 Engine Speed Correlation Results for Two Repeat Runs of the Final

Streetsweeper Cycle.

Figure 57 Correlation of the $\mathrm{CO}_{2}$ Data Between the Infield and Derived In-

Laboratory Streetsweeper Cycles (First Iteration).

Figure 58 Correlation of the $\mathrm{CO}_{2}$ Data Between the Infield and Derived Inlaboratory Streetsweeper Cycles (Final Iteration). 
Figure 59 Correlation of the Engine Speed Data Between the Infield and

Derived In-laboratory Streetsweeper Cycles (First Iteration).

Figure 60 Correlation of the Engine Speed Data Between the Infield and the

Derived In-laboratory Streetsweeper Cycles (Final Iteration).

Figure 61 Average of 8-Mode Emissions Results for the John Deere 6059

Loader Engine (g/bhp-hr).

Figure 62 Average Weighted 8-Mode Results for the John Deere 6059 Loader

Engine (g/bhp-hr).

Figure 63 Transient Cycle Emissions Results for the John Deere 6059 Loader

Engine (g/bhp-hr).

Figure 64 Comparison of Continuous $\mathrm{CO}_{2}$ Traces for Two Repeat Tests of the

Final Loader Transient Cycle....

Figure 65 Comparison of Continuous Engine Speed Traces for Two Repeat

Tests of the Final Loader Transient Cycle.

Figure 66 Percentage of Total Cycle Time Spent In Each Speed Range for the

John Deere 6059 Loader Engine.

Figure 67 Comparison of the Time Spent at Different Load Ranges for Adjacent Speed Ranges.

Figure 68 Percent Load vs. Percent Total Intermediate Speed Time for the John

Deere 6059 Engine.

Figure 69 Percent Load vs. Percent Total Rated Speed Time for the John Deere 6059 Engine.

Figure 70 Regression Analysis for the Input vs. Achieved Torque for the John Deere 6059 loader Engine.

Figure 71 Regression Analysis for the Input vs. Achieved Engine Speed for the John Deere 6059 loader Engine.

Figure 72 Average of 8-Mode Results for the John Deere 4039T Streetsweeper Engine (g/bhp-hr).

Figure 73 Average Weighted 8-Mode Emissions for the John Deere 4039T

Streetsweeper Engine (g/bhp-hr).

Figure 74 Average of Emissions Results for the John Deere 4039T

Streetsweeper Engine Operating on the First and Final Iterations of the Transient Cycle (g/bhp-hr).

Figure 75 Comparison of Continuous $\mathrm{CO}_{2}$ Traces for Two Repeat Tests of the Final Streetsweeper Transient Cycle.

Figure 76 Comparison of Continuous Engine Speed Traces for Two Repeat

Tests of the Final Streetsweeper Transient Cycle.

Figure 77 Graphical Comparison of the Effects of the Test Cycle on Engine

Emissions (g/bhp-hr).

Figure 78 Percentage of Total Cycle Time Spent in each Speed Range. 138

Figure 79 Percent Load vs. Percent Total Intermediate Speed Time for the John Deere 4039T Engine.

Figure 80 Percent Load vs. Percent Total Rated Speed Time for the John Deere 4039T Engine.

Figure 81 Regression Analysis for the Input vs. Achieved Torque for the John Deere 4039T Engine. 
Figure 82 Regression Analysis for the Input vs. Achieved Engine Speed for the John Deere 4039T Engine.

Figure A.83 HC 8-Mode Results for the John Deere 6059 (g/bhp-hr).......................... 158

Figure A.84 CO 8-Mode Results for the John Deere 6059 (g/bhp-hr).......................... 158

Figure A.85 CO $\mathrm{CO}_{2}$ 8-Mode Results for the John Deere 6059 (g/bhp-hr)........................ 159

Figure A.86 $\mathrm{NO}_{\mathrm{x}}$ 8-Mode Results for the John Deere 6059 (g/bhp-hr)......................... 159

Figure A.87 PM 8-Mode Results for the John Deere 6059 (g/bhp-hr)......................... 160

Figure B.88 HC 8-Mode Results for the John Deere 4039T (g/bhp-hr)........................ 162

Figure B.89 CO 8-Mode Results for the John Deere 4039T (g/bhp-hr)........................ 162

Figure B.90 CO $\mathrm{CO}_{2}$ 8-Mode Results for the John Deere 4039T (g/bhp-hr)....................... 163

Figure B.91 $\mathrm{NO}_{\mathrm{x}}$ 8-Mode Results for the John Deere 4039T (g/bhp-hr). ...................... 163

Figure B.92 PM 8-Mode Results for the John Deere 4039T (g/bhp-hr)........................ 164 


\section{Nomenclature}

Alternating Current

BSFC Brake-Specific Fuel Consumption

CARB California Air Resources Board

CFR Code of Federal Regulations

CFV Critical Flow Venturi

$\mathrm{CO} \quad$ Carbon Monoxide

$\mathrm{CO}_{2} \quad$ Carbon Dioxide

CVS Constant Volume Sample

DC Direct Current

ECU Engine Control Unit

EERL Engine and Emissions Research Laboratory

EGS Electrochemical Gas Sensor

EPA Environmental Protection Agency

FTP Federal Test Procedure

GPS Global Positioning System

HC Hydrocarbon

HFID Heated Flame Ionization Detector

IR Infrared

LFE Laminar Flow Element

MEMS Mobile Emissions Measurement System

NDIR Non-dispersive Infrared

NDUV Non-dispersive Ultraviolet

NESCAUM Northeast States for Coordinated Air Use Management

NIST National Institute of Standards and Technology

NMHC Non-Methane Hydrocarbons

NO Nitric Oxide

$\mathrm{NO}_{2} \quad$ Nitrogen Dioxide

$\mathrm{NO}_{\mathrm{x}} \quad$ Oxides of Nitrogen

$\mathrm{O}_{2} \quad$ Oxygen

$\mathrm{O}_{3} \quad$ Ozone 


$\begin{array}{ll}\text { OBE } & \text { On-Board Emissions } \\ \text { PID } & \text { Proportional Integral Derivative } \\ \text { PM } & \text { Particulate Matter } \\ \text { PPM } & \text { Parts Per Million } \\ \text { PREVIEW } & \text { Portable Real-Time Emission Vehicular Integrated Engineering } \\ & \text { Workstation } \\ \text { QC/QA } & \text { Quality Control/Quality Assurance } \\ \text { ROVER } & \text { Real-time On-road Vehicle Emissions Recorder } \\ \text { RTD } & \text { Resistive Temperature Device } \\ \text { Scfm } & \text { Standard Cubic Feet Per Minute } \\ \text { SO } 2 & \text { Sulfur Dioxide } \\ \text { SOF } & \text { Soluble Organic Fraction } \\ \text { TTL } & \text { Transistor-Transistor Logic } \\ \text { UDDS } & \text { Urban Dynamometer Driving Schedule } \\ \text { VEOM } & \text { Vito On-the Road Emission and Energy Measurement } \\ \text { VOC } & \text { Volatile Organic Compounds } \\ \text { WVU } & \text { West Virginia University }\end{array}$




\section{Chapter 1. Introduction}

\subsection{Introduction}

In the past, the majority of the exhaust emissions regulations for diesel engines have focused primarily on pollution emitted by on-road applications. Diesel engines are currently powering nearly all off-highway heavy equipment, and current trends indicate that performance of these vehicles will become increasingly scrutinized by Federal Regulatory Agencies in the coming years. In comparison with on-highway diesel engines, the exhaust emissions of off-highway diesels have gone largely unregulated even though their constituents add significantly to emissions inventories. On a national scale, off-highway engines are estimated to emit nearly $20 \%$ of all $\mathrm{NO}_{\mathrm{x}}$ (oxides of nitrogen) and about half of all fine PM (particulate matter) pollution from mobile sources. As is indicated by current projections, the $\mathrm{NO}_{\mathrm{x}}$ emissions from non-road engines will surpass those of on-road engines by the year 2005 [8].

Traditionally, the majority of engine emissions testing has been aimed at on-road vehicles. A vast amount of research and thought has gone into the development of transient testing cycles that accurately represent operating conditions of these vehicles in the real-world environment. This testing has been performed in the past by either removing the engine from the vehicle and coupling it to a dynamometer and the associated emissions testing equipment on a test bed or by placing the entire vehicle on a chassis dynamometer. With the increasing attention currently being focused on the reduction of emissions from off-highway sources the development of representative testing cycles for these vehicles is of utmost importance. 
Testing of an engine with a dynamometer on a test bed is time consuming and labor intensive. The engine must be removed from the vehicle and set up on a dynamometer test bed with all the related engine subsystems (intake, exhaust, cooling, fuel, electrical) being implemented to most accurately mimic the conditions of operation of the test vehicle. The engine is connected to the dynamometer with a driveshaft and torsional damper. The damper dissipates harmonic vibrations as well as provides for the absorption of any shock loads that may be encountered during testing. This drive system has considerable rotational inertia and turns with the same angular velocity as the engine, so unbalance-induced vibration and resultant component failure are a major safety concern.

There are several different types of engine dynamometers that can be implemented for testing. These include water brake, eddy current, DC (direct current), and $\mathrm{AC}$ (alternating current) dynamometers. The direct and alternating current dynamometers are most often used for transient testing because of their ability to motor the engine to simulate coasting conditions in the test cycle. Load cells connected to the dynamometers are used to measure the torque while digital shaft encoders accurately measure the engine speed. The desired test cycle is broadcast to the dynamometer controller via computer interface. Emissions measurement results are generally reported on a brake-specific mass emissions basis ( $\mathrm{g} / \mathrm{hp}-\mathrm{hr}$ or $\mathrm{g} / \mathrm{kW}-\mathrm{hr}$ ). This is done to make emissions comparisons between engines of different power ranges a simple task.

Chassis dynamometer testing is another possible choice for testing of off-highway engines, but there are many problems associated with this method. The most difficult problem that currently exists is the lack of representative testing cycles for off-road 
equipment. Without a standardized cycle to test a particular type of vehicle with, emissions measurements cannot be compared between these vehicles because engine loading and speed would not be consistent from laboratory to laboratory. Clearly, development work needs to be performed to obtain testing cycles that accurately represent real world cycles.

Another difficult problem with chassis testing off-road equipment is the lack of the ability to properly load any attachments that the test vehicle might possess. Parameters such as the hydraulic pump drag being imposed on the engine would vary widely based upon hydraulic system pressure requirements while performing a particular task. The hydraulic pressure for a rubber-tired loader would substantially vary based on the weight of the material being lifted by the bucket. In the case of the streetsweeper, entities such as brush drag and water pump drag for the sprayers would be difficult to recreate on a chassis dynamometer. The fact that both vehicles covered in this document, as well as most other off-road equipment, are hydraulically driven makes engine power measurement very difficult to accurately quantify because of torque converter slippage and resultant heat generation. The operating style of the equipment driver can have a significant impact on the amount of power lost to heat in the automatic transmission.

An additional shortcoming of chassis dynamometer testing is that the vehicle test driver must read and accurately follow a cycle that is broadcast to a computer screen visible to him/her. This introduces the element of human error into the testing process and mandates that the same test driver be used in subsequent tests for the sake of repeatability. Even so, the level of repeatability achieved will still ultimately depend on the emotional state and fatigue level of the test driver. 
The development of portable, relatively compact on-board emissions testing equipment now makes raw exhaust gas sampling possible during the actual operation of the equipment being studied. The engine speed can be readily determined with the tachometer signal from the alternator or with some type of inductive-pickup device, such as a Hall-effect sensor. Intake and exhaust temperatures can easily be measured with thermocouples and pressure data can be obtained with miniaturized pressure transducers. The most difficult parameter to obtain infield is the measurement of torque.

Though devices are currently available for the direct measurement of torque, they are generally complex and prohibitively expensive. These devices are placed in the drive line and measure the torque transmitted through the drive shaft. The complexity of the device raises reliability concerns when exposed to the rugged conditions often encountered in the off-road environment. These torque sensors also require the modification of the vehicle drive train for implementation, which is often not permitted by the vehicle owner. Drive shafts used in off-road equipment are generally enclosed and very difficult to access, which compounds the problem.

Other common approaches to quantification of engine torque have generally relied on the measurement of the engine-fueling rate. The displacement of the rack in the injection pump determines the amount of fuel that is injected in a given cycle. This displacement has been monitored in previous testing by means of linear position sensors. The problems with this approach are measurement inaccuracies and the difficulty of instrumentation of the injector pump, as well as vibration-induced sensor problems. Using the linear position sensor to determine rack position requires the disassembly and 
modification of the injection pump, which is labor intensive and often not permitted by the owner of the test vehicle.

An additional approach for the determination of fueling rate can only be used on modern engines with electronically controlled fuel injection pumps. An interface can be used to retrieve desired fueling rate commanded by the ECU (Engine Control Unit), which is calculated based on various sensor values. The vast majority of off-highway equipment being used currently is mechanically injected and does not utilize the new electronically controlled engine management system technology. For this reason, the aforementioned method is not really viable for off-road engine testing at this time. However, as the current inventory of equipment wears out and is replaced by more modern electronically-controlled machinery, this could well become the most desirable method for power prediction inferred from engine fueling rates.

The method used to infer infield engine torque output in this study was to measure the $\mathrm{CO}_{2}$ concentration in the raw exhaust stream with a Sensors Inc. AMB-II multigas analyzer. The relationship between $\mathrm{CO}_{2}$ (carbon dioxide) output and engine power is linear, so the measured engine speed can be used with the $\mathrm{CO}_{2}$-predicted power output to calculate engine torque output.

\subsection{Objectives}

The global objective for this study was to measure the exhaust mass emission rates produced by two diesel-powered off-highway vehicles operated in a "real world" environment and to quantify the effect of particular engine use on these rates. The emissions rates of PM , $\mathrm{HC}$ (hydrocarbons), $\mathrm{CO}$ (carbon monoxide), $\mathrm{NO}_{\mathrm{x}}$, and $\mathrm{CO}_{2}$ were measured and recorded for both engines during both transient cycle and steady-state 
testing. The transient cycles recreated during testing were derived by WVU (West Virginia University), with input from US EPA (Environmental Protection Agency), by studying data logged infield, while the steady-state testing followed the ISO-8178 Cycle C1 Federal 8-mode steady-state cycle outlined in the CFR (Code of Federal Regulations) [1].

The accuracy of predicting engine power output from measured $\mathrm{CO}_{2}$ was explored as well as the suitability of the Sensors AMB-II multigas analyzer used for the infield data logging exercises. The engines were tested following the WVU-derived transient cycle as well as during steady-state conditions. Percent differences in measurement taken with the laboratory analyzers versus the Sensors AMB-II multigas analyzer were determined. The in-laboratory transient cycle emissions data was also correlated with the infield data to illustrate the level of accuracy that the derived cycle used for the laboratory testing achieved.

The objectives of this study were:

- To derive a transient cycle that accurately represents the "real world" operations for each vehicle.

- To determine if the Sensors AMB-II multigas analyzer is capable of accurate emissions measurement during transient and steady-state events.

- To use the derived transient cycle trace during the full-flow testing in the laboratory to determine full-flow mass emissions rates for both vehicles.

- To determine if the infield $\mathrm{CO}_{2}$ measurement can be used to accurately predict engine power output for future infield testing.

- To perform engine ISO-8178 Type C 8-Mode testing to measure the emission rates (g/bhp-hr) with the Sensors AMB-II analyzer (raw sampling) as well as laboratory-grade equipment (dilute sampling).

- To develop off-road vehicle test cycles to facilitate future emissions testing. 
- To determine the effects of cycle recreation accuracy and cycle nature on emissions results. 


\section{Chapter 2. Review of Literature}

\subsection{Introduction}

During the past few decades, the Environmental Protection Agency (EPA) has instated increasingly stricter standards on the allowable amount of pollution released into the environment from various sources. One area of primary concern is the pollution of the air by diesel-fueled vehicles that operate both on and off highway. Diesel engines currently power the majority of heavy equipment, and the vast and ever-increasing numbers of vehicles now in use call for these stricter standards to prevent further airquality degradation. While the main emphasis in the past has been placed squarely upon on-highway applications, the need for the testing of off-road equipment is becoming paramount as the quality of national air inventories is becoming increasingly scrutinized.

The implementation of regulations stemmed from concerns about respiratory health as air quality issues surfaced. The EPA's systematic promulgation of stricter regulations for diesel exhaust emission rates can be readily seen by viewing the standards for on-highway engines in Table 1 and for off-highway engines in Table 2.

Table 1 On-Road Heavy-Duty Diesel Engine Emissions Standards [9].

\begin{tabular}{|c|c|c|c|c||}
\hline Year & $\begin{array}{c}\text { PM } \\
(\mathbf{g} / \mathbf{b h p}-\mathbf{h r})\end{array}$ & $\begin{array}{c}\text { CO } \\
(\mathbf{g} / \mathbf{b h p}-\mathbf{h r})\end{array}$ & $\begin{array}{c}\text { HC } \\
(\mathbf{g} / \mathbf{b h p}-\mathbf{h r})\end{array}$ & $\begin{array}{c}\text { NOx } \\
(\mathbf{g} / \mathbf{b h p}-\mathbf{h r})\end{array}$ \\
\hline $\mathbf{1 9 9 0}$ & 0.60 & 15.5 & 1.3 & 6.0 \\
\hline $\mathbf{1 9 9 1}$ & 0.25 & 15.5 & 1.3 & 5.0 \\
\hline $\mathbf{1 9 9 4}$ & 0.10 & 15.5 & 1.3 & 5.0 \\
\hline $\mathbf{1 9 9 8}$ & 0.10 & 15.5 & 1.3 & 4.0 \\
\hline
\end{tabular}


Table 2 Off-Road Diesel Engine Emissions Standards [9].

\begin{tabular}{||c|c|c|c|c|c|}
\hline \hline Year & $\begin{array}{c}\text { PM } \\
(\mathbf{g} / \mathbf{b h p}-\mathbf{h r})\end{array}$ & $\begin{array}{c}\text { CO } \\
(\mathbf{g} / \mathbf{b h p}-\mathbf{h r})\end{array}$ & $\begin{array}{c}\text { HC } \\
\text { (g/bhp-hr) }\end{array}$ & $\begin{array}{c}\text { NO } \\
\text { (g/bhp-hr) }\end{array}$ & $\begin{array}{c}\text { Non-methane } \\
\text { Hydrocarbons } \\
\text { (NMHC) + NO }\end{array}$ \\
\hline $\mathbf{1 9 9 6}$ & 0.40 & 8.5 & 1.0 & 6.9 & - \\
\hline $\mathbf{2 0 0 3}$ & 0.22 & 3.7 & 1.0 & - & 4.9 \\
\hline $\mathbf{2 0 0 7}$ & TBA & 3.7 & 1.0 & - & 3.0 \\
\hline
\end{tabular}

The major constituents of concern present in diesel exhaust are $\mathrm{HC}, \mathrm{PM}, \mathrm{CO}$, and $\mathrm{NO}_{\mathrm{x}}$ with these constituents being of greatest concern in poorly ventilated work areas. Though most construction equipment is operated outdoors in well-ventilated areas, harmful emission concentrations increase dramatically when the vehicle is operated with poor ventilation, such as in the construction of a tunnel.

When inhaled, $\mathrm{NO}_{\mathrm{x}}$ and $\mathrm{CO}$ readily bond to the hemoglobin in blood and reduce the oxygen carrying capacity to cells. If exposure levels are high enough, death from suffocation is often the result. $\mathrm{NO}_{\mathrm{x}}$ has also been found to play a role in the formation of photochemical smog, which is an unsightly and unhealthy problem for many cities [11]. PM found in the exhaust stream can be inhaled deeply into the lung and cause severe respiratory problems. Significant reductions in PM in diesels has occurred in the past twenty years through intercooling, high boost supercharging, centralized injector nozzle positioning, much higher injection pressures, lower combustion chamber swirl, and piston bowl refinement measures. However, it was determined in a study that while the overall particulate emissions was only $10 \%$ of the emissions prevalent 15 to 20 years ago, the very fine nano-particle count was actually increased by these technologies at all load points, sometimes by as much as a factor of six [21]. The liquid phase HC component of diesel exhaust, which condenses onto the PM, is of great concern since these compounds 
have been shown to exhibit carcinogenic or mutagenic properties in biological testing at the cellular level [11].

Emissions researchers take various approaches during testing. Engine emissions are usually collected on a continuous basis while the engine is running. Exhaust gas samples can also be collected in special Tedlar bags and analyzed at a later time in the laboratory. While this approach may seem feasible for on-board sampling, it can only be used to determine an average of the emissions produced during a particular operation or cycle. Use of the bags makes it very difficult for the researcher to determine the effects of transient conditions on emission rates and makes cycle development work nearly impossible. Data can be reported in a variety of ways: concentration measurements (Parts per million (ppm), \% vol, etc.), in terms of engine output (g/bhp-hr, g/kW-hr), distance ( $\mathrm{g} / \mathrm{mile})$, and/or fuel-specific terms ( $\left.\mathrm{g} / \mathrm{g}_{\text {fuel used }}\right)$. Most engine dynamometer test bed results are reported in brake-specific terms ( $\mathrm{g} / \mathrm{bhp}-\mathrm{hr}, \mathrm{g} / \mathrm{kW}-\mathrm{hr})$ to make emissions comparisons from engines with different power output levels relatively simple. 


\subsection{Previous Off-Highway Emissions Testing}

A few noteworthy projects aimed at the measurement of in-use emissions levels from off-highway vehicles have been researched in the past. While countless tests have been performed on off-highway engines in a laboratory setting, far fewer have been performed infield on the vehicle as it operates in its true environment. Stationary equipment, such as that used by the mining industry, has often been tested with cumbersome testing apparatus similar to what would be found in a fully equipped emissions testing facility. While this approach cannot be faulted for stationary emissions sources, it is expensive, labor intensive, and usually impossible to utilize for any mobile sources.

\subsubsection{Northeast States for Coordinated Air Use Management — 1997}

The Northeast States for Coordinated Air Use Management (NESCAUM) conducted a study to evaluate the impact of exhaust aftertreatment devices on emission levels [19]. Four different technologies were tested on five vehicles. The devices tested were oxidation catalysts, fuel borne catalysts, and active as well as passive particulate filters. Prior to testing, representative infield test routes (cycles) were derived by collecting exhaust gas temperature data while the vehicles were operated in everyday conditions. Adherence to these cycles during testing was also monitored through the measurement of vehicle exhaust gas temperatures. A mini-dilution tunnel allowed dilute exhaust samples to be collected in Tedlar bags for future analysis with laboratory grade analyzers. PM was collected with $70 \mathrm{~mm}$ diameter Teflon coated glass fiber filters. Raw exhaust constituent concentrations were continuously monitored with a compact multigas 
analyzer. However, slow response times made all measurements, except $\mathrm{CO}_{2}$, unreliable. $\mathrm{CO}_{2}$ was monitored to determine vehicle fuel consumption during the test procedure.

The testing demonstrated that infield testing was feasible, although slow analyzer response time made continuous monitoring of emissions much less useful. The project also illustrated the need to develop representative testing cycles for off-road vehicles and showed methods were available to determine how closely the actual test cycle could follow the predetermined cycle.

\subsubsection{United States Coast Guard - 1997}

A system was developed by the United States Coast Guard to measure the emissions of three 82-ft. U.S. Coast Guard Cutters as Part of the Clean Air Act instituted in 1990 for non-road air pollution [2,3]. All three boats tested were powered by Caterpillar D3412 engines producing 750-800 hp. The test protocol used was one based on the ISO 8178 procedure. The effects of a number of variables were investigated including water depth, effect of towing another boat, water current, sea state, and wind direction. Pollution emitted was determined quantitatively as a function of power and fuel consumption. Propeller shaft speed was determined to have the greatest effect on the pollution level produced.

The system implemented for the measurement of emissions was capable of measuring nitric oxide $(\mathrm{NO}), \mathrm{CO}, \mathrm{NO}_{2}$, sulfur dioxide $\left(\mathrm{SO}_{2}\right)$, oxygen $\left(\mathrm{O}_{2}\right)$, and $\mathrm{HC}$. The system was an Enerac 2000E produced by Energy Efficiency Systems, Inc. The concentration of $\mathrm{CO}_{2}$ in the exhaust was not directly measured but inferred from the other gaseous measurements. The need for an emissions analysis system for ship testing was the driving force in the study. Other necessary testing parameters were also addressed 
during testing. The measurement of intake air flow rate was monitored digitally with the Electronic Flowhood manufactured by Shortridge instruments. Fuel consumption was measured with Hedland in-line flow meters. Engine torque was measured with driveshaft-mounted strain gauges that broadcast strain quantity through radio frequency.

The gaseous measurement system was originally designed and constructed for the monitoring of emissions from stationary exhaust stack sources, so it was large, cumbersome, and lacked portability. The research illustrated the use of strain gauges for infield torque measurement as a viable, though complex and tedious, option. The principle of testing ships with portable instruments was found to be feasible and it was later applied in the testing of larger vessels.

\subsubsection{VERT Study -1998}

A European study was conducted to quantify the effects of exhaust aftertreatment devices on emissions levels at tunnel construction sites [20]. Tunnel construction sites are an environment with conditions similar to those that would be found in an underground mining area. Ventilation is often poor and workers can be exposed to high levels of pollutants originating from construction vehicles and equipment. Therefore, methods of reducing harmful pollutants must be tested for effectiveness to improve the future air quality for worker safety.

The pollutant most focused on in the study was $\mathrm{PM}$, but $\mathrm{CO}, \mathrm{CO}_{2}$, and $\mathrm{VOC}$ levels were also investigated. An extensive sampling of thirty-two particulate filters of various types from different manufacturers were evaluated during the study. The two measurement methods for PM utilized during testing were the Switzerland VRV 59A smoke puff test used during free acceleration, and an exhaust blackening test at full 
engine load. Both tests used smoke opacity meters for the quantification of PM emission levels during testing.

The smoke puff test is an exhaust opacity test that determines the amount of overfueling the vehicle engine receives during a transient event. The engine is operated at steady load conditions and a sharp transient speed condition is administered. The opacity of the engine exhaust is then measured to determine the amount of diesel soot being emitted. The test was basically useless when the vehicles were fitted with the particulate filters because of the massive reduction in PM emission that was attained. The test was a good indication of filter damage during the testing.

The blackening measurements at full load were taken on construction vehicles equipped with torque converters that could be stalled during testing. When the stalled condition was encountered at full load, exhaust gas blackening from increased PM levels would often result. This stalled condition was usually maintained for two to three minutes to allow sufficient time for the completion of the testing.

Gaseous emissions were monitored only during steady-state loading conditions. Computer-controlled instruments operating on the principles of electrochemical reaction and IR absorption (NDIR) technologies were utilized for gas measurements. Samples were extracted using modern techniques for sampling adapted to diesel engine conditions. 


\subsection{Previous On-Board Emissions Testing Devices}

Infield data acquisition has required the development of a number of compact emissions measurements systems. For cycle development work, a system is needed that can be entirely contained on the vehicle being tested. This section describes a number of systems used previously for the on-board measurement of engine emissions.

\subsubsection{Caterpillar $-\mathbf{1 9 8 2}$}

A system was developed by caterpillar that consisted of a portable bag collection system implemented for the determination of $\mathrm{NO}_{\mathrm{x}}$ emissions from in-use diesel engines [9]. The system was designed to meet the requirements of Point-of-Use Control. This means that the manufacturer would label projected $\mathrm{NO}_{\mathrm{x}}$ emissions from engines that met regulations and the emissions measurement system was used to verify infield compliance to these regulations. The measurement system was quite compact, its size being compared to that of a small suitcase. The system consisted of an exhaust probe, prefilter, sample line, pump, air-cooled condensing coil, and two gas collection bags. Water was removed from the sample stream before it entered the bags. The system was operated remotely by the driver and was powered by its own on-board power supply. The testing performed with this system illustrated that valid data could only be obtained when the vehicle was operated at fully-loaded conditions. The results confirmed that the Caterpillar's on-board system could report $\mathrm{NO}_{\mathrm{x}}$ emissions within $10 \%$ of laboratory analyzers based on concentration.

\subsubsection{Southwest Research Institute - 1992}

A mobile system was developed by Southwest Research Institute that measured diesel exhaust emissions for inspection and maintenance of buses [12]. The system was 
used for the comparison of actual emissions data taken on buses with transient cycle testing results obtained by the EPA. The study was enacted to develop testing methods that did not require the use of a chassis dynamometer for data collection. The tests were limited to vehicles equipped with automatic transmissions, as the loading sequence required 30 second load operations on the vehicle at various throttle positions with the vehicle held stationary through locked brakes.

Gaseous emissions as well as PM were collected by the system. Raw gaseous measurements of $\mathrm{CO}, \mathrm{CO}_{2}, \mathrm{NO}_{\mathrm{x}}$, and $\mathrm{O}_{2}$ were made using an Energy Efficiency Systems, Inc. Enerac 2000E from bag samples collected during engine operation. PM was collected with a mini-dilution tunnel system. Testing showed that measurement of $\mathrm{CO}$, $\mathrm{O}_{2}$, and $\mathrm{NO}_{\mathrm{x}}$ were within $5 \%$ of measurements obtainable with laboratory grade analyzers. Rather than sample continuously, the system used the integrated bag approach to sampling and is therefore not useful for cycle development work.

\subsubsection{General Motors - 1993}

A 3.8-liter Pontiac Bonneville SSE gasoline-fueled passenger car was the vehicle tested with a portable system developed by General Motors Corporation [13]. The vehicle was driven on numerous driving routes to obtain desired representative emissions data. Data was collected along the driving routes during high-traffic rush-hour conditions as well as during lighter traffic conditions to obtain a broad array of operating conditions. The trunk of the car housed all testing equipment and instruments. The system was capable of measuring $\mathrm{HC}, \mathrm{CO}_{2}, \mathrm{CO}$, and $\mathrm{NO}$ using a variety of analyzers using NDIR technology. A Horiba MEXA-311GE analyzer was used to measure $\mathrm{CO}_{2}$ and $\mathrm{CO}$. Measurements of $\mathrm{HC}$ and $\mathrm{CO}$ were performed with a MEXA-324GE, also manufactured 
by Horiba. A Siemens Ultramat-22P analyzer was used to make another measurement of $\mathrm{HC}$ and $\mathrm{CO}$, while an additional Siemens analyzer was used to measure NO. An analyzer made by Draeger utilizing an electrochemical gas sensor (EGS) cell was used to measure CO buildup levels within the driver compartment of the vehicle. A Kurz flow meter was used for the measurement of exhaust gas flow rate. The intake air quantity was monitored using the stock air meter. Using these flowmeters, a relationship between intake and exhaust flows was derived, which illustrated effects of intake flow on exhaust flow. An ice-cooled trap was used to remove excess water vapor from the sample stream through condensation. Emissions rates of $\mathrm{HC}$ and $\mathrm{CO}$ were determined while the vehicle was loaded according to the Urban Dynamometer Driving Schedule (UDDS) with a chassis dynamometer. The inability of the system to record transient events as well as the system having slow analyzer response times were the major problems encountered.

While testing was limited to a single vehicle, it did provide useful emissions information for a spark-ignited gasoline fueled vehicle.

\subsubsection{Ford Motor Company — 1994}

The Ford Motor Company developed a sampling system that was used to quantify emissions from three spark-ignited vehicles $[4,10,14,15]$. The vehicles tested in the study were a 1992 Aerostar van, a 1991 Taurus station wagon, and a 1991 flex-fueled Taurus sedan. The objective of the study was the comparison of measurements made with the on-board Ford system with measurements obtained with remote equipment. The system was capable of monitoring and controlling various engine parameters, with the Aerostar van and the Taurus wagon also capable of measuring real-time vehicle emissions. 
The Aerostar van was equipped with an On-Board Emissions (OBE) system. The OBE system has a dilution tunnel and a Fourier Transform Infrared (FTIR) analyzer. Exhaust gases measured were $\mathrm{CO}_{2}, \mathrm{NO}_{\mathrm{x}}, \mathrm{CO}$, and $\mathrm{HC}$. The measurement results obtained with the OBE system were compared with results obtained in a laboratory environment using a chassis dynamometer. Comparative results showed a difference of $2 \%$ for $\mathrm{CO}_{2}, 10 \%$ for $\mathrm{NO}_{\mathrm{x}}, 3 \%$ for $\mathrm{CO}$, and $7 \%$ for $\mathrm{HC}$. It was found that the FTIR analyzer's response time was much too slow for transient emissions testing.

The Taurus wagon was outfitted with an infrared technology based analysis system that was capable of measuring $\mathrm{CO}_{2}, \mathrm{NO}_{\mathrm{x}}, \mathrm{CO}$, and $\mathrm{O}_{2}$ emissions. A nondispersive ultraviolet (NDUV) analyzer was used for NO measurement. The results from the NDUV analyzer and a laboratory grade chemiluminescent analyzer were compared and found to relate closely (slope of 0.8 and an $\mathrm{R}^{2}$ value of 0.97 ).

\subsubsection{University of Pittsburgh -1997}

The University of Pittsburgh developed a system to measure emissions from a fleet of 20 natural gas passenger vans [22]. A multigas analyzer produced by OTC SPX, Model No. RG240, was used for the detection of $\mathrm{CO}, \mathrm{NO}_{\mathrm{x}}, \mathrm{CO}_{2}, \mathrm{HC}$, and $\mathrm{O}_{2}$. The unit operated on $12 \mathrm{v}$ DC power and had an adapter to draw the required power from the vehicle's cigarette lighter socket. Engine operating data was collected with separate engine diagnostic equipment. The sample drawn from the exhaust stream was an undiluted raw sample. A 12 in. probe was situated in the tailpipe of the vehicle for sampling. Sample flow was adjusted to approximately $6 \mathrm{lpm}$ through a 0.25 in. diameter sample line. Water was remove from the sample stream with a coalescing filter. The total exhaust flow rate was determined with intake and fuel mass flow data collected by 
the diagnostic equipment. Data collection was performed with a laptop computer using software developed by the University of Pittsburgh.

Problems encountered with the system were a problem with data time alignment, slow analyzer response times, accuracy of mass emission rates, and analyzer auto zeroing at random, and often inopportune, times. Also, since the analyzer unit was originally developed for testing gasoline-fueled vehicles and not NGVs, an HC measurement bias was encountered. However, the system did produce some meaningful emissions data for natural-gas fueled vehicles operating in real-world applications.

\subsubsection{Flemish Institute for Technological Research - 1997}

The Flemish Institute for Technological Research, also known as VITO, conducted on-board emissions test using a system developed in-house to collect emissions data from gasoline-fueled passenger cars and diesel-fueled buses. The Vito On-the Road Emission and Energy Measurement (VEOM) was the name of the system developed by the Institute. The system operated on NDIR technology for $\mathrm{CO}$ and $\mathrm{CO}_{2}$ measurement, HFID technology for HC measurement, and used a chemiluminescent analyzer for the detection of $\mathrm{NO}_{\mathrm{x}}$. The exhaust sample was diluted by means of a nitrogen-driven ejector located in the vehicle tailpipe. The loss of heavy hydrocarbons from the sample stream was prevented with the use of a heated sampling line. Emissions were reduced and reported in either $\mathrm{g} / \mathrm{s}$ or $\mathrm{g} / \mathrm{km}$ format by combining dilute sample amounts collected with data on fuel consumption, lambda values, and engine speed. A chassis dynamometer and laboratory analyzers were used for comparative purposes. Results showed that the VEOM data differed from the laboratory data by $25 \%$ for $\mathrm{HC}$, $20 \%$ for $\mathrm{CO}$, and less than $10 \%$ for $\mathrm{CO}_{2}$ and $\mathrm{NO}_{\mathrm{x}}$. The weight of the VEOM system, 
which tipped the scales at approximately $500 \mathrm{lbs}$, made it unwieldy and difficult to use for acquiring in-use data.

\subsubsection{United States Environmental Protection Agency - 1999}

A mobile testing system has recently been developed by the Office of Mobile Sources of the United States Environmental Protection Agency (USEPA). The Real-time On-road Vehicle Emissions Recorder (ROVER) was the name given to the system. The original design of the system focused on measuring emissions from gasoline vehicles, but it was later retrofitted to make emissions analysis of diesel-fueled vehicles possible. A differential pressure device is used to determine exhaust flow rate. A Snap-On Model MT3505 emissions analyzer is used for the determination of $\mathrm{CO}, \mathrm{CO}_{2}, \mathrm{HC}$, and NO. Results are reported by the ROVER system on a distance-specific basis in grams of pollutant emitted per mile the test vehicle travels ( $\mathrm{g} / \mathrm{mile})$. Vehicle speed can be determined with a global positioning system (GPS) and interface with the vehicle's ECU.

The problems encountered with the ROVER system were that there is no $\mathrm{NO}_{\mathrm{x}}$ converter, the differential exhaust flow measurement system, and the unheated sample line and filter. Heated sampling components are desirable in an emissions measurement system to prevent condensation from occurring. This condensation can damage analyzers and produce measurement inaccuracies. The use of a $\mathrm{NO}_{2}$ to $\mathrm{NO}$ converter is necessary because most analyzers can only accurately record $\mathrm{NO} . \mathrm{NO}_{2}$ is also readily soluble in water, so any water that condensed out in the non-heated sampling components of the ROVER system also caused a loss of a significant portion of the $\mathrm{NO}_{2}$ component of $\mathrm{NO}_{\mathrm{x}}$. The differential pressure apparatus used for the determination of the exhaust flow rate is of a particular set size, so adapters must be used when measuring flow in an exhaust pipe 
of a different diameter. These adapters can increase the amount of exhaust backpressure on the engine, which can affect performance. Though the ROVER system had its share of problems, it was lightweight and compact, making it useful for mobile emissions sampling.

\subsubsection{Ford Motor Company/WPI Microprocessor Systems, Inc. — 1999}

Ford Motor Company and WPI-Microprocessor Systems, Inc. have recently developed a system known as the Portable Real-Time Emission Vehicular Integrated Engineering Workstation (PREVIEW) [5]. PREVIEW is capable of measuring wet exhaust. The unit was designed to be compact enough to allow it to fit into the passenger compartment of a sport-utility vehicle, or SUV. PREVIEW is able to measure gaseous emissions of $\mathrm{CO}_{2}, \mathrm{NO}_{\mathrm{x}}, \mathrm{CO}$, and $\mathrm{HC}$ as well as up to forty additional engine parameters. The measurement of $\mathrm{CO}, \mathrm{HC}$ and $\mathrm{CO}_{2}$ is made possible with the NDIR technology used by the PREVIEW system. The measurement of $\mathrm{NO}_{\mathrm{x}}$ is performed using ultraviolet-based technology. A number of additional sensors can be used by the system for recording of additional parameters, such as various engine temperatures or air/fuel ratio sensing devices. Control of the PREVIEW system is possible using a laptop computer and software that can record and display data simultaneously at a frequency of $1 \mathrm{~Hz}$.

Testing performed with the system included transient FTP cycle tests as well as Highway Fuel Economy tests in a laboratory setting with a dynamometer and laboratorygrade analyzers used for comparative purposes. These comparative results showed that the PREVIEW system obtained results within $1.5 \%$ for $\mathrm{CO}_{2}, 12.3 \%$ for $\mathrm{HC}, 0.4 \%$ for $\mathrm{NO}_{\mathrm{x}}$, and $3.4 \%$ for $\mathrm{CO}$ of the laboratory-grade analyzers. It should be noted that the 
instantaneous mass measurements for $\mathrm{NO}_{\mathrm{x}}$ with the system actually exhibited faster response times than the laboratory analyzer.

\subsubsection{West Virginia University -2000}

A system was recently developed at West Virginia University for the On-Board measurement of in-use emissions from heavy-duty on-road vehicles [18]. The name of the system is the Mobile Emissions Measurement System (MEMS). The system is capable of accurate measurement of $\mathrm{NO}_{\mathrm{x}}$ and $\mathrm{CO}_{2}$ in diesel exhaust. As its name implies, it is a mobile system for the measurement of raw diesel emissions from on-road heavyduty vehicles. The three primary components that make up the MEMS system are an exhaust flow measurement apparatus, the emissions box, and the data acquisition equipment.

The exhaust flow is measured with a differential pressure device known as an Annubar. The Annubar is a multi-port Pitot tube type sensor. This type of device was desirable for the measurement of the pulsing exhaust flow because of its ability to determine an average upstream and downstream pressure. This pressure drop can be related to the velocity of the exhaust gas when coupled with temperature data. With velocity and temperature data known, the cross-sectional area of the tube was used to determine exhaust gas flow rate.

The emissions sampling box consisted of a number of components. The sample first enters the system through a stainless-steel probe located in the exhaust stream. From there it travels through a heated line and filter to a heated-head pump. The sample then passes through a Horiba Model COM-11 $\mathrm{NO}_{\mathrm{x}}$ converter. The sample is then dried with a thermoelectric chiller, made by the $\mathrm{M} \& \mathrm{C}$ Products Corporation, that lowers the dew point 
of the sample to an acceptable level. The analyzer used for measurement of $\mathrm{CO}_{2}$ is a Horiba BE-140 multigas analyzer with a MEXA-120 sensor used for determination of $\mathrm{NO}_{\mathrm{x}}$ concentration. Measurement of $\mathrm{HC}$ and $\mathrm{CO}$ is possible with the Horiba analyzer, but the resolution is too coarse for accurate measurement of the concentrations found in diesel exhaust. An electrochemical cell was also utilized for an additional check of $\mathrm{NO}_{\mathrm{x}}$ levels in the exhaust. It was deemed necessary to perform two $\mathrm{NO}_{\mathrm{x}}$ measurements for quality control/quality assurance (QC/QA) purposes and to ensure that the $\mathrm{NO}_{\mathrm{x}}$ converter was performing properly. Determination of engine torque output and speed was made with a manufacturer-supplied computer interface with the ECU that controls the fuel injection duties. Vehicle speed during infield testing was measured with a Global Positioning System (GPS).

The data acquisition components of the MEMS were a computer, signal conditioning hardware, and data acquisition and control software. The MEMS data acquisition system is capable of measuring analog and digital signals from various engine sensors as well as the emissions measurement box. During testing, it was necessary to record a variety of signals from thermocouples, pressure transducers, the emissions analyzers, and numerous ECU outputs. The computer utilized for testing was a National Instruments Corp. PXI-1025 chassis unit. This computer was chosen for its robustness in the infield-testing environment. The computer ran on the Windows NT operating system because of its excellent memory and networking capabilities, software support, and reliability.

The weight (136 lbs) and large size of the original MEMS system made it somewhat unsuitable for the often space-confined testing of off-highway equipment. The 
more-compact design of the current revision of the MEMS has eliminated the weight and space concerns. The systems reliance on the ECU data is an additional strike against it for off-highway testing because the vehicles that are currently in use are often mechanically injected with no sensor feedback. However, the system was able to obtain fairly accurate measurement of diesel emissions when compared to laboratory-grade analyzers during chassis-dynamometer testing. Steady-state testing revealed that the MEMS $\mathrm{CO}_{2}$ data differed from the laboratory data by $2.5 \%, \mathrm{NO}_{\mathrm{x}}$ by $11.5 \%$ (MEXA-120) and $5.7 \%$ (Electrochemical cell). 


\section{Chapter 3. Experimental Equipment and Procedures}

\subsection{Introduction}

This chapter explains the procedures, equipment, and instruments utilized during the testing for this project. All infield data was acquired while the vehicles were operated on the streets and land of Morgantown and all in-laboratory testing was performed at the West Virginia University Engines and Emissions Research Laboratory (WVU EERL). The EERL was designed according to the specifications outlined in the CFR Title 40, Part 86, Subpart N [1] and follows other transient and steady-state testing protocols.

\subsection{Vehicles Tested}

For the infield testing, infield data was logged from a rubber-tired loader and a streetsweeper, owned and operated by the WVU physical plant. WVU owns two rubbertired loaders and one streetsweeper. Since these vehicles are used on a daily basis, measures had to be taken to limit the negative impact, as a result of downtime, on maintenance and construction on the WVU campus. For instance, in the case of the rubber-tired loader, laboratory testing was performed on the engine while the vehicle was down for drive train repairs. By doing this, the laboratory portion of the testing could be performed with no additional downtime being required for the vehicle. Similar equipment was rented or a contractor was hired for cases where it was necessary to disable the University's vehicle for laboratory testing. All infield testing was conducted in a manner that did not bias the operation of the vehicle during its everyday routine. Infield testing routes and task descriptions will be described later in this chapter. 


\subsubsection{John Deere 444 Rubber-Tired Front End Loader}

A John Deere 444 rubber-tired loader was tested infield at a landfill site on WVU property. A picture of the rubber-tired loader can be seen in Figure 1. Data was collected with a data logging system that will be described in detail later in the chapter. The loader is powered by a direct-injected, naturally aspirated, in-line six cylinder John Deere 6059 diesel engine. Detailed specifications for the 6059 engine are listed in Table 3 , while the engine, as tested in the laboratory, is illustrated in Figure 2.

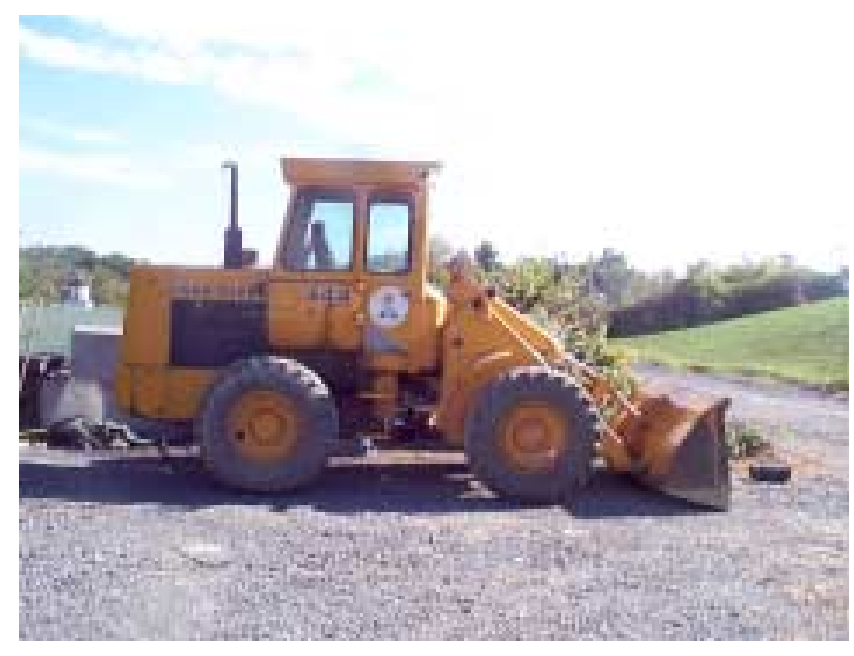

Figure 1 John Deere 444 Rubber-Tired Front End Loader 


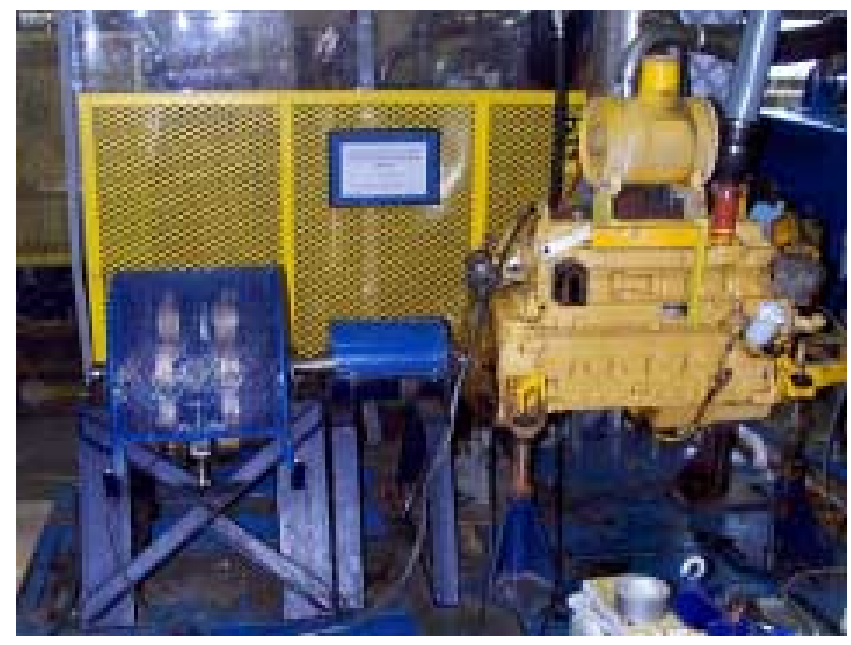

Figure 2 John Deere 6059D Engine on Dynamometer Test Bed

\subsubsection{Elgin Pelican Series P Streetsweeper}

An Elgin Series P streetsweeper was tested infield on WVU campus streets

following its normal sweeping routes. A picture of the streetsweeper can be seen in

Figure 3. The streetsweeper is powered by a John Deere 4039T diesel engine that is of a direct-injected, turbocharged (non-aftercooled), in-line four-cylinder configuration.

Specifications for the 4039T engine are given in Table 3, while the in-laboratory testing setup for this engine can be viewed in Figure 4. 


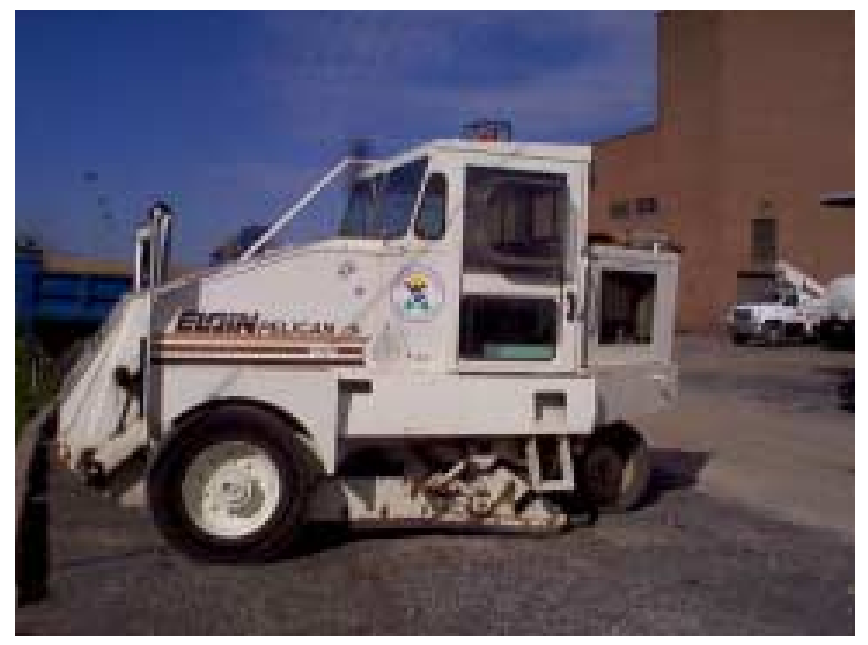

Figure 3 Elgin Pelican Series P Streetsweeper

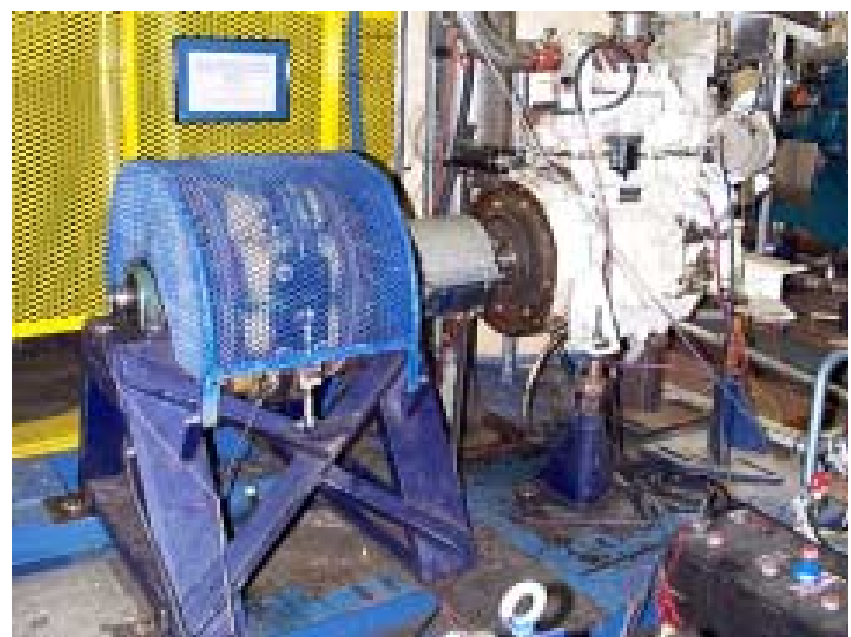

Figure 4 John Deere 4039T Engine on Dynamometer Test Bed 
Table 3 Engine Test Specifications.

\begin{tabular}{|c|c|c|}
\hline Vehicle & Elgin Pelican Streetsweeper & John Deere Loader \\
\hline Engine Manufacturer & John Deere & John Deere \\
\hline Engine Model & $4039 \mathrm{~T}$ & $6059 \mathrm{D}$ \\
\hline Displacement & $239 \mathrm{in}^{3}$ (3.92L) & $359 \mathrm{in}^{3}$ (5.9L) \\
\hline Power Rating & 110hp @ 2400rpm & $107 \mathrm{hp} \mathrm{@} \mathrm{2500rpm}$ \\
\hline Torque Rating & $339 \mathrm{ft}-1 \mathrm{bs} @ 1500 \mathrm{rpm}$ & $260 \mathrm{ft}-1 \mathrm{bs}$ @ 1400rpm \\
\hline Configuration & In-line four cylinder & In-line six cylinder \\
\hline Bore x Stroke & 4.19in x 4.33in & 4.19 in x 4.33in \\
\hline Compression Ratio & $17.2: 1$ & $17.8: 1$ \\
\hline Injection & Direct & Direct \\
\hline
\end{tabular}

\subsection{Infield Data Acquisition Equipment/Procedures}

Infield emissions were measured using four main components. A Sensors AMB-II multigas analyzer with laptop, a power inverter to provide $120 \mathrm{~V}$ AC power, an exhaust sampling probe that transferred the sample, and a signal-conditioning device for engine speed measurement. A schematic of the infield testing setup is included as Figure 5. The four components will be described in detail in the following sections. 


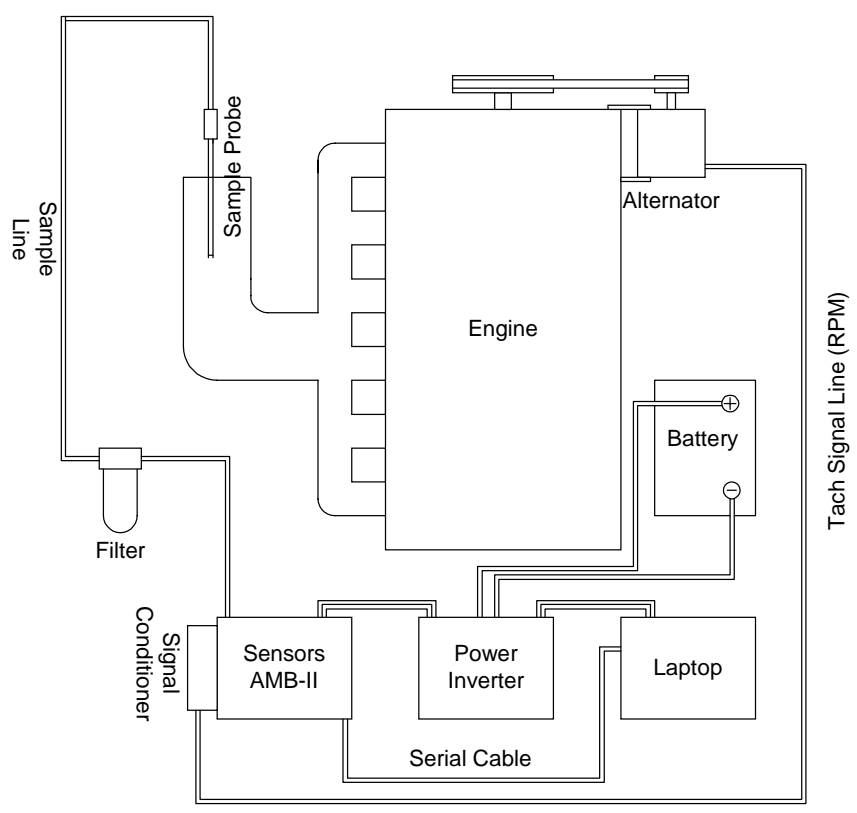

Figure 5 Infield Data Acquisition Setup

\subsubsection{Sensors AMB-II Multigas Analyzer}

Raw continuous exhaust concentration measurements were collected with a Sensors AMB-II five gas repair-grade analyzer on a continuous basis. The AMB-II utilized a solid-state detector using Non-Dispersive Infrared (NDIR) and electrochemical cell technology that was capable of measuring $\mathrm{CO}_{2}, \mathrm{CO}, \mathrm{NO}, \mathrm{O}_{2}$, and $\mathrm{HC}$. An electrochemical cell is used for the measurement of $\mathrm{NO}$ and $\mathrm{O}_{2}$ in the sample, while $\mathrm{CO}_{2}$, $\mathrm{CO}$, and $\mathrm{HC}$ are measured with the NDIR detector. The principle of operation will be briefly discussed in the following section. The analyzer can be seen in Figure 6.

NDIR detection is based upon the principle of selective absorption of a specific waveband of light in the infrared (IR) spectrum. This light is directed toward thermal detectors through a tube containing the sample gas. However, before the light can reach these thermal sensors it must first pass through optical band-pass filters. These band-pass filters transmit electromagnetic energies only within the critical IR waveband absorbed 
by the sample gas, thus increasing resolution and reducing interference caused by absorption spectrum overlap. When the sample tube is filled with sample gases, the thermal detector measures the reduction in IR energy transmitted within the waveband of each gas being measured. Pressure and temperature variations in the sample tube are accounted for with a bench-mounted microprocessor

An electrochemical or polarographic cell is used in the Sensors AMB-II analyzer for measuring concentrations of NO, in the sample stream. An electrochemical cell consists of two or more electrodes separated by an electrolyte. For a cell with two electrodes, one electrode must be porous so the gas can pass through it after diffusing through a membrane. A resistor is connected between the two electrodes and voltage drop across the resistor is converted to gas concentration. If the rate of diffusion is controlled via a membrane, the current flowing through the resistor and therefore, the voltage drop across the resistor is proportional to the concentration of candidate gas, as stated by Fick's law of diffusion. Fick's law of diffusion is as follows:

$$
i=\frac{n F A D c}{d}=k c
$$

\section{Eqn. 3.1}

where
$\mathrm{i}=$ The current
$\mathrm{n}=\quad$ The number of exchanged electrons per mole of candidate gas
$\mathrm{F}=\quad$ The Faraday constant $(96,500$ coulombs $)$
A $=$ The surface area of the electrode
$\mathrm{D}=\quad$ The diffusion coefficient of the gas through the membrane
c $=$ The gas concentration in the electrolyte 
$\mathrm{d}=\quad$ The thickness of the diffusion layer

$\mathrm{k} \quad \mathrm{A}$ constant

The oxidation reaction for an $\mathrm{NO}$ molecule at the sensing electrode of an electrochemical cell is shown below.

$$
\mathrm{NO}+2 \mathrm{H}_{2} \mathrm{O}----\mathrm{HNO}_{3}^{+}+3 \mathrm{e}^{-}
$$

Notice that water is a reactant and therefore must be available in the sample stream to avoid depletion of water from the electrolyte. The sample needs to maintain a relative humidity of between $15 \%$ and $90 \%$ to avoid this depletion. The potential of the sensing electrode must be within a certain range for the reaction to occur. If the potential of the sensing electrode is outside the design limits the response will be non-linear. Three electrodes may be used to avoid non-linearity due to the counter electrode becoming polarized as a result of high candidate gas concentrations. The third electrode is a reference electrode that is used to maintain a constant potential between itself and the sensing electrode, so the counter electrode potential is not a factor in the measurement. A fourth electrode may be added to react the products of oxidation, which can interfere with the reference electrode potential.

Electrochemical cells typically have a $\mathrm{T}_{90}$ response time of at least 5 seconds for $\mathrm{NO}$, and approximately 30-40 seconds for $\mathrm{CO}$ and $\mathrm{NO}_{2}$. Therefore, electrochemical cells could only be considered for NO measurement due to highly transient engine operation of in-use off-road vehicles. $\mathrm{A} \mathrm{NO}_{\mathrm{x}}$ converter would be required to obtain an $\mathrm{NO}+\mathrm{NO}_{2}$ measurement, which would add significantly to infield sampling system complexity. For this reason, infield $\mathrm{NO}_{\mathrm{x}}$ data is not reported in this thesis. 


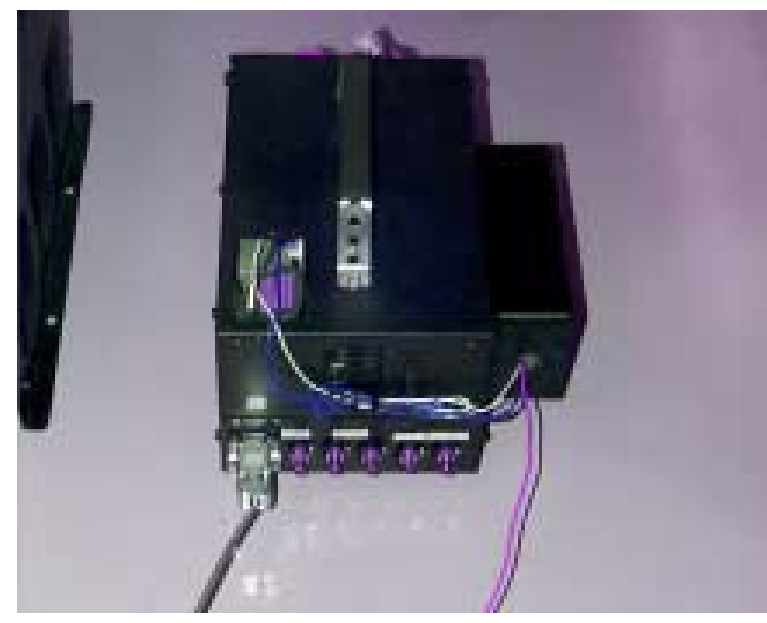

Figure 6 Sensors Inc. AMB-II Multigas Analyzer

The AMB-II has measurement ranges of 2000 parts per million (ppm) for $\mathrm{HC}, 0$ $20 \%$ for $\mathrm{CO}_{2}, 0-5000$ ppm NO, and 0-15\% for CO. The analyzer communicates with an onboard laptop computer via serial cable. Software supplied by Sensors, Inc. is used to control the calibration and data acquisition functions of the unit.

\subsubsection{Power Inverter}

In order to supply power to the analyzer and the laptop, the use of a DC to AC power inverter was required. Tripplite, Inc. manufactures the inverter, a model PV1200 shown in Figure 7, used for the infield testing. The inverter converts the $12 \mathrm{~V}$ DC power supplied by the vehicle's alternator into $110 \mathrm{~V}$ AC power that can be utilized for data acquisition. 


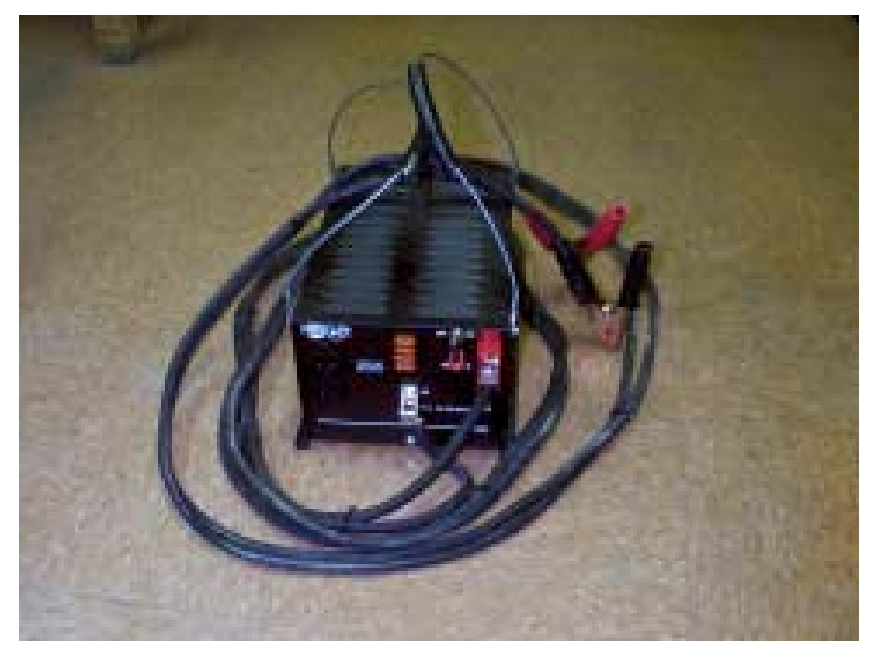

Figure 7 Tripplite Inc. Model PV1200 Power Inverter.

\subsubsection{Exhaust Sampling System}

A stainless steel exhaust probe was mounted at the end of the vehicle's exhaust system, and was connected to the gas analyzer with a flexible hose. The exhaust sample was routed through a Balston filter holder containing a high temperature glass microfiber filter and a condensate trap in order to remove particulate matter and reduce water interference effects. Since NO and HC were not reported, condensation and solubility issues inherent to the measurement of these species did not have to be addressed, and, therefore, a non-heated design was used due to its simplicity, robustness, and flexibility. The exhaust sampling system can be seen in Figure 8. 


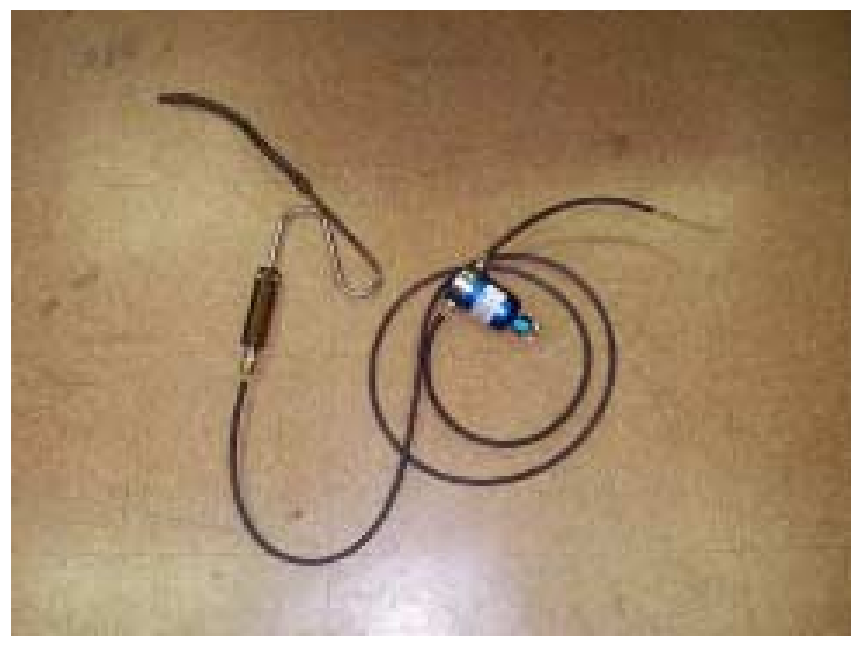

Figure 8 Exhaust Gas Sampling Probe for the Sensors AMB-II Analyzer

\subsubsection{Engine Speed and Torque Measurement}

A signal conditioning apparatus was constructed to aid in the measurement of the vehicles engine speed. Engine speed was measured by tapping into the vehicle alternator and converting the signal coming from the alternator into a transistor-transistor logic (TTL) stepped-pulse type signal. The Sensors AMB-II has the capability of measuring a TTL signal, but a problem was encountered due to the noise contained in the alternator signal. The unconverted signal, which alternates between a value near zero volts and an upper limit near one volt, required filtering to eliminate voltage spikes that were exceeding the threshold voltage of the comparator circuit and creating false triggers. A signal-conditioning device was constructed to truncate the top of the signal (voltages near one volt) and nullify the noise spikes that were significantly less than one volt, thus producing a substantially cleaner signal. The signal conditioner was mounted to the side of the AMB-II analyzer and can be viewed in Figure 9.

Engine torque is an exceedingly difficult parameter to quantify during infield testing. Conventional methods of torque measurement, such as with a dynamometer, are 
impractical for real world testing of off-highway vehicles. In-line torque transducers are currently available for torque measurement, but transmission efficiencies must be known and taken into account. An additional shortcoming of in-line transducers is that any parasitic engine losses such as water and hydraulic pump drag, alternator drag, air compressor drag, and fan windage losses cannot be accounted for. It is also often very difficult to use in-line transducers for off-highway vehicle testing because of the short drive shafts that are usually not exposed for easy access.

In its simplest form, engine torque production can be inferred from the brakespecific fuel consumption of the engine. Many modern diesel engines use electronically controlled injection strategies that maximize power output and fuel efficiency. The injection is computer (ECU) controlled and optimized with various sensors providing feedback. These modern systems provide the ability to interface with them to allow the determination of the amount of fuel injected during each engine cycle. With the aid of sensors determining parameters such as intake pressure and temperature, exhaust backpressure, coolant and fuel temperatures, and intake air humidity, an accurate estimate of torque can be acquired. Due to the fact that the vehicles tested were both mechanically controlled, this method was not an option for this research. However, this would be the method of choice for future torque determination on modern ECU-controlled vehicles. In this study, engine torque was estimated with the BSFC determined by the measured $\mathrm{CO}_{2}$ amount present in the exhaust stream. This method allows the approximation of torque based on the fuel properties, such as the hydrogen-to-carbon ratio and energy density. Many errors associated with the aforementioned parasitic loss parameters from engine accessories are eliminated with this approach. The inferred 
torque estimates were evaluated using an iterative approach while the vehicle's engine was operated on a dynamometer.

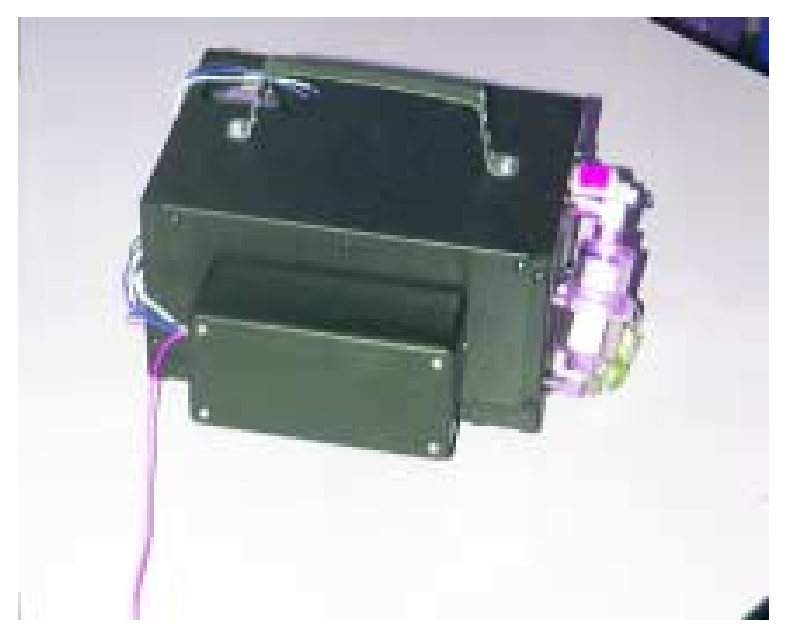

Figure 9 Signal Conditioning Unit for RPM Measurement on AMB-II.

\subsection{Vehicle Infield Testing Routes}

Emissions data was collected on the two vehicles while they followed operational cycles that closely resembled those encountered during day-to-day usage. Detailed graphs of $\mathrm{CO}_{2} / \mathrm{RPM}$ vs. time can be viewed in the results section of this document. The representative cycle developed during infield testing was later recreated in the laboratory using laboratory-grade analyzers and a dynamometer test bed. Raw emissions were measured during laboratory testing with the Sensors AMB-II analyzer and speed and load settings applied to the dynamometer were adjusted until the in-laboratory emissions data closely correlated with emissions data taken infield. Sampling system variables (flow rate, line length, etc.) and calibration techniques were kept consistent with those used during infield testing in order to reduce errors. A brief description of the testing routes, 
including approximate inclination angles of any hills encountered, is also included in Chapter 4.

\subsubsection{Streetsweeper Test Route}

Data were collected on the streetsweeper while it performed normal sweeping duties on the campus streets of WVU. In the case of the streetsweeper, it was possible for the test engineer to ride aboard the vehicle to monitor data acquisition functions during testing. A typical sweeping route was followed, - streetsweeper functions performed while data was taken included: normal sweeping, normal transport mode with brushes off, dumping of collected debris, and extended idle periods. A short test was also performed to assess the effects of brush rotation and drag on $\mathrm{CO}_{2}$ emission rates. These effects and infield emissions data are illustrated in the infield results section of Chapter 4.

\subsubsection{Rubber-Tired Loader Test Route}

Data were collected on the rubber-tired front-end loader while it performed earthmoving activities at a landfill site on the WVU campus. Though space restraints prevented the test engineer from riding aboard the machine during the end loader testing, the vehicle was stopped several times during the test session to ensure that data acquisition system was functioning properly and to recalibrate the Sensors AMB-II. Activities encountered while following the operational route include: transport from the place of origin to the landfill site on hilly terrain, loading/lifting dirt with the bucket, transporting the dirt in the bucket, and dumping the dirt. These processes were repeated numerous times during the test. Infield emissions data can be seen in the infield results section of Chapter 4. 


\subsection{In-Laboratory Data Acquisition Setup - EERL Components}

All in-laboratory testing for this research was performed at the West Virginia University Engine and Emissions Research Laboratory located on the WVU campus in Morgantown, WV. The laboratory utilizes a full-scale critical flow venturi-constant volume sampler (CFV-CVS) system with all laboratory components and equipment constructed according to the specifications outlined in the CFR 40, Part 86, Subpart N [1]. These components will be briefly discussed in this section. A schematic of the laboratory testing setup is shown in Figure 11.

\subsubsection{Full-Flow Exhaust Dilution Tunnel}

The primary goal of engine emissions testing is to determine the effects that exhaust constituents have on the environment. In order to simulate "real world" conditions and collect representative emissions data, it is necessary to simulate the dilution process that occurs when hot exhaust gases mix with ambient air. The effects of this exhaust gas dilution are threefold. The primary reason for dilution is to allow any inuse exhaust-air interactions to take place, but it also quenches post-cylinder combustion reactions and lowers the exhaust gas dew point, thus inhibiting condensation. Exhaust line quenching is necessary to prevent measurement inconsistencies. The elimination of water in the sampling stream is of utmost importance as certain gaseous components are soluble in water ( such as nitrogen dioxide $\left(\mathrm{NO}_{2}\right)$ ), which could adversely affect measurement accuracy. Water presence in sample lines can also affect certain instruments as well, such as NDIR analyzers, and particulate matter measurement accuracy could be reduced. 
Emissions data presented heirin was collected using a full-flow dilution tunnel. In a full-flow tunnel, all of the exhaust gases emitted by the test engine are routed into the tunnel where they are mixed with the required amount of air to achieve the desired dilution ratio. Mini-dilution tunnels have also been developed that dilute only a small portion of the total exhaust stream for sampling. While these systems are decidedly more compact and portable, according to the CFR only full-flow dilution tunnels are seen as certifiable means of exhaust sampling.

The full-flow system housed at the EERL is based upon the CFV-CVS principle where a large centrifugal blower draws the diluted exhaust gas mixture from the tunnel through critical flow venturis. The dilution tunnel is constructed of stainless steel to prevent oxidation contamination and degradation from occurring and is approximately 18 inches in diameter and 40 feet in length. The blower is driven by a $75 \mathrm{Hp}$ electric motor. There are four venturis that can be selected individually or in any combination necessary to achieve the required dilution ratio. There are three 1000 standard cubic feet per minute (scfm) as well as a $400 \mathrm{scfm}$ venturi, and the system can accommodate total tunnel flow rates ranging from 400-3000 scfm. Due to blower limitations, the attainment of 3400 scfm is not possible. The exhaust gases enter the tunnel at its centerline and pass through a mixing orifice plate located three feet downstream. The orifice plate is 8 inches in diameter and creates turbulence in the flow path that promotes thorough mixing. Dilute gaseous samples are collected at a distance of $15 \mathrm{ft}$. downstream of the plate with heated sampling probes. These probes transfer the sample to the analyzers via electrically heated teflon lines. The particulate sampling system utilizes a 4 in. stainless steel secondary dilution located at the end of the sampling region to provide additional dilution 
air. Air can be injected into the secondary tunnel to increase the dilution ratio, which lowers the sample temperature to less than $125^{\circ} \mathrm{F}$. The purpose of this is to keep the face of the particulate sampling filter at a sufficiently low temperature as to prevent any damage to it. After exiting the analyzers and particulate sampling system, the exhaust gases are collected and vented away.

\subsubsection{Critical Flow Venturi}

A CVS system is used to regulate the flow of diluted exhaust gases passing through the dilution tunnel for compliance with the CFR 40 [1]. When the critical flow venturi reaches sonic conditions (choked flow), a constant mass flow rate is maintained in the dilution tunnel, and the flow rate of the gas through the venturi is a function of the diameter of the throat and the pressure and temperature of the gas upstream. Pressure data was collected with a Viatran model 1042 AC3AAA20 pressure transducer while the temperature was recorded with a resistive temperature device, or RTD. With these two parameters quantified, the mass flow rate can be determined with the following equation:

$$
\mathrm{Q}=\frac{\mathrm{K}_{\mathrm{V}} \mathrm{P}}{\sqrt{\mathrm{T}}}
$$

Eqn. 3.2

Where,

$$
\begin{aligned}
& \mathrm{Q}=\text { The flow rate in scfm at standard conditions }\left(20^{\circ} \mathrm{C} \text { and } 101.3 \mathrm{Kpa}\right) \\
& \mathrm{K}_{\mathrm{V}}=\quad \text { The calibration coefficient of the venturi } \\
& \mathrm{P} \quad=\quad \text { The absolute pressure at the inlet of the venturi in Kpa } \\
& \mathrm{T} \quad=\quad \text { The absolute temperature at the inlet of the venturi in }{ }^{\circ} \mathrm{K}
\end{aligned}
$$


The venturis were calibrated with a subsonic venturi traceable to the standards set forth by the National Institute of Standards and Technology (NIST).

\subsubsection{Particulate Sampling System}

The particulate sampling system housed at the EERL incorporates a secondary dilution tunnel to provide a double dilution, proportional-sampling method for particulate matter collection and analysis. This system draws a diluted exhaust sample from the sampling region of the primary full-flow dilution tunnel into a secondary dilution tunnel. The flow rate through the secondary dilution tunnel is varied, via mass flow controllers, throughout the emissions test in order to draw a proportional sample from both dilution tunnels. Further dilution in the second tunnel can be varied with the amount of air necessary to reduce the face temperature of the sample filter to less than $125^{\circ} \mathrm{F}\left(51.7^{\circ} \mathrm{C}\right)$. The sample filter collects the PM matter from the diluted exhaust to enable the determination of the amount of PM emitted by the engine during a test cycle with a gravimetric analysis. The PM collected consists primarily of elemental carbon as well as sulfates, the soluble organic fractions (SOF), wear metals, and bound water.

In detail, the PM sampling system draws the diluted sample through a 0.5 in. diameter transfer tube, 7 in. in length that links the secondary dilution tunnel to the sampling region of the primary dilution tunnel. The secondary dilution tunnel is constructed exclusively of stainless steel and is 3 in. in diameter and approximately $30 \mathrm{in}$. long. The secondary tunnel was designed in order to provide a sufficient residence time to allow the exhaust to thoroughly mix with dilution air to cool it to less than the desired $125^{\circ} \mathrm{F}$. The sample flow exits the secondary tunnel and passes through a stainless steel filter holder that contains two Pallflex 70mm Model T60A20 flourocarbon-coated glass 
microfiber filters used for PM collection. Two filters, a primary and a secondary, are used in the filter holder to extract the maximum amount of PM from the sample stream for analysis. The total secondary dilution flow is maintained by two Gast Model 1023101Q-583X rotary vane pumps each governed by a single Sierra 740-L-1 mass flow controller. The total diluted flow possible is $0-6 \mathrm{scfm}$ with the maximum amount of air injected variable between 0 and $3 \mathrm{scfm}$. The Sierra mass flow controllers are routinely recalibrated by the manufacturer and additionally checked with a Merriam Instruments Model No. 50MW20 laminar flow element (LFE) rated at 0-23 scfm.

Filters are conditioned prior to testing in a Thermotron SM-80 Mini-Max conditioning chamber where conditions are held near $70^{\circ} \mathrm{F}$ and $50 \%$ relative humidity, as is mandated by the CFR 40. Filters are also conditioned after testing for measurement consistency. All pre and post weighing of the PM collection filters was performed using a Cahn C-32 microbalance. The balance is recalibrated periodically during filter weighing to ensure measurement consistency.

\subsubsection{Gaseous Emission Sampling System}

The EERL's gaseous sampling system consists of heated probes located in the dilution tunnel and heated sampling lines connecting the probes with the gas analyzer bench. A picture of the gas analyzer bench can be seen in Figure 10. There are three heated sampling probes located ten tunnel diameters (approximately 180 in.) downstream of the origin of the mixing zone to ensure complete turbulent mixing of the exhaust gases with the dilution air. The tips of the probes project six inches into the tunnel and are oriented so the opening is directed upstream toward the entrance of the tunnel. The connection between the sampling probes and the analyzer bench is made with electrically 
heated sampling lines. The HC sampling line was maintained at a temperature of $375^{\circ}$ $\pm 10^{\circ} \mathrm{F}$ using Fuji model No. 223-1806 temperature controller. This prevented the high molecular weight hydrocarbons from condensing in the sample line. The sample lines and probes for the $\mathrm{NO}_{\mathrm{x}}$ and $\mathrm{CO} / \mathrm{CO}_{2}$ sampling systems were maintained at $235^{\circ} \mathrm{F} \pm 10^{\circ} \mathrm{F}$ to prevent the condensation of water in the line which could induce measurement error as well as cause damage to the analyzers. A Hankison Model 8015 thermoelectric chiller was used to remove water from the $\mathrm{CO} / \mathrm{CO}_{2}$ sample line to reduce water interference effects.

The gas analysis bench houses four major analyzer components: $\mathrm{HC}$ analyzer, $\mathrm{CO}$ analyzer, $\mathrm{CO}_{2}$ analyzer, and $\mathrm{NO}_{\mathrm{x}}$ analyzer. The analyzers are all produced by the Rosemount Company and will be described in greater detail in the following sections. The bench also houses the sample flow meters, the temperature controllers for the heated sampling components mentioned previously, and a $\mathrm{NO}_{\mathrm{x}}$ efficiency tester. The efficiency tester is made by the Beckman Co. and ensures that the $\mathrm{NO}_{\mathrm{x}}$ analyzer is operating above $90 \%$ converter efficiencies, as is mandated by the CFR 40, Part 86, Subpart N [1]. 


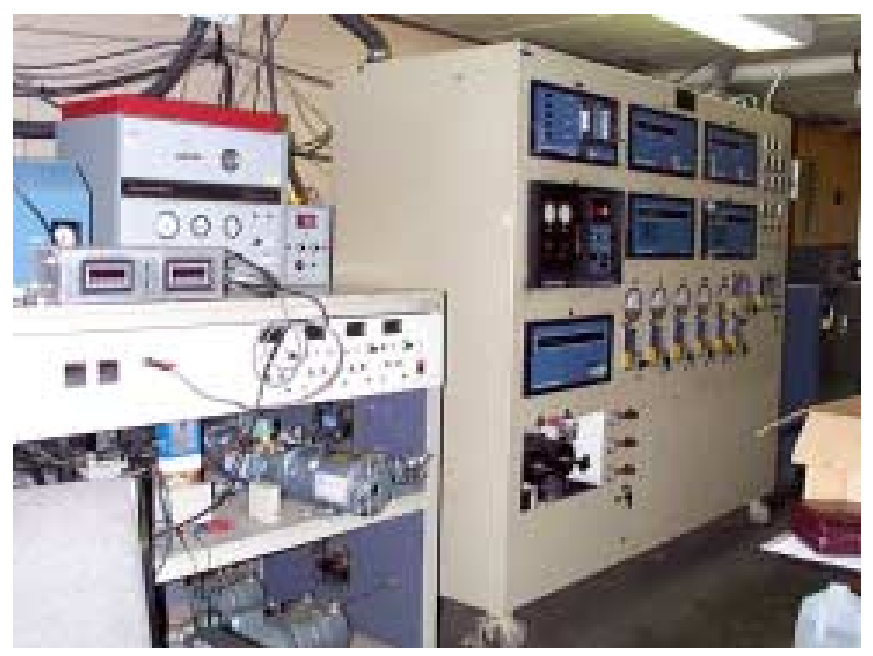

Figure 10 The Gaseous Emissions Analyzer Bench at the WVU EERL.

\subsubsection{Exhaust Gas Analyzers}

A brief description of each analyzer and its components as well as theory of operation will be given in this section. A more in depth look into operational theory can be found in the Rosemount analyzer operation manuals.

\subsubsection{Oxides of Nitrogen Analyzer}

The $\mathrm{NO} / \mathrm{NO}_{\mathrm{x}}$ analyzer used for testing was a Rosemount Model 955 Chemiluminescent analyzer. The analyzer is capable of detecting the concentration of $\mathrm{NO}$ or $\mathrm{NO}+\mathrm{NO}_{2}$, which is commonly referred to as $\mathrm{NO}_{\mathrm{x}}$. When measurement of $\mathrm{NO}$ is desired, the sample $\mathrm{NO}$ is converted into $\mathrm{NO}_{2}$ by gas-phase oxidation with molecular ozone $\left(\mathrm{O}_{3}\right)$. During this reaction, about $10 \%$ of the $\mathrm{NO}_{2}$ becomes electrically excited, followed by an immediate return to the non-excited state. This phenomenon is known as photon emission. A photon detector, or multiplier tube, is used to detect the photon emission quantity, which is proportional to the amount of NO present in the sample. For the detection of $\mathrm{NO}_{\mathrm{x}}$, the sample is first passed through a $\mathrm{NO}_{\mathrm{x}}$ converter that converts the $\mathrm{NO}_{2}$ into $\mathrm{NO}$, which is then measured with the principle described previously. If the 
determination of NO concentration only is desired, the sample can bypass the converter and be measured directly by selecting the $\mathrm{NO}$ mode of the analyzer. In the case of $\mathrm{NO}_{\mathrm{x}}$ detection, the total analyzer response would determine the amount of NO present in the original sample, as well as the $\mathrm{NO}$ created through the dissociation of $\mathrm{NO}_{2}$ in the converter. $\mathrm{A} \mathrm{NO}_{\mathrm{x}}$ efficiency tester is used to ensure that the converter in the Model 955 analyzer is operating optimally.

\subsubsection{Hydrocarbon Analyzer}

The hydrocarbon analyzer used was a Rosemount Model 402 Heated Flame Ionization Detector (HFID) analyzer. The counting of the elemental carbon atoms in the sample is used to determine the amount of hydrocarbon levels in the exhaust stream. The sample gas flow is regulated and flows through a hydrogen/helium-fueled flame that causes the production of ions. These ions are collected with polarized electrodes in the analyzer. This absorption of ions by the electrodes produces a current flow in the analyzer's measurement circuitry, which is quantified and related to the number of carbon atoms contained in the sample [17]. The measurement range of the $\mathrm{HC}$ analyzer is up to $250,000 \mathrm{ppm}$ with a linear full-scale output. A multiplier switch located on the front of the Model 402 allows selection of measurement ranges with the best resolution for the particular gas concentration being sampled.

\subsubsection{Carbon Monoxide/Carbon Dioxide Analyzers}

The gaseous constituents of $\mathrm{CO}$ and $\mathrm{CO}_{2}$ were determined with Rosemount Model 880 and Model 868 analyzers. Both of the analyzers utilize NDIR technology for gas measurement. An NDIR analyzer operates using the principle of infrared light absorption. In its simplest form, the NDIR analyzer uses the fact that a particular gas will 
absorb a certain wavelength of light somewhere within the infrared spectrum, with the other spectral wavelengths still being able to transmit through the gas. The analyzer detects the amount of infrared energy able to pass through the sample gas and uses it in the determination of the amount of the measured absorbent gas in the sample stream. An NDIR analyzer does not produce a linear output, so calibration curves were generated for the analyzers before each testing session began. The range of the $\mathrm{CO}_{2}$ analyzer is from 0$5 \%$ and from $0-20 \%$. Two analyzers are available for the sampling of CO; a high range and a low range. The low range $\mathrm{CO}$ analyzer has a range of 0-1000 ppm and 0-5000 ppm while the high range analyzer has a range of $0-2 \%$ and $0-10 \%$. For testing performed in this study, it was only necessary to use the low range $\mathrm{CO}$ analyzer.

\subsubsection{Bag Sampling}

In addition to being sampled by the analyzers during the test, a portion of the diluted exhaust is also collected in 80-liter Tedlar bags. The reason for doing this is to allow an additional gas analysis for each test. An additional bag sample of the dilution air was collected to account for any trace gas concentrations that might be contained in it. These background concentrations contained in the dilution air were subtracted from the analyzer measurements to quantify actual exhaust stream concentrations. The primary reason for using the dilute sample bag was to allow comparison between it and the integrated sample for a quality control/quality assurance check for the testing performed.

\subsubsection{Fuel and Air Flow Metering}

\subsubsection{Fuel Metering System}

In order to determine exhaust dilution ratios, it is necessary to determine total tunnel flow rates and engine exhaust mass flow rates. The total tunnel flow rate, as 
described previously, was determined with the CFV-CVS system. Such a direct measurement technique is not as straightforward for the determination of raw exhaust mass flow rates. A number of factors inhibit a direct measurement of the exhaust flow rate, such as engine backpressure limits, high temperatures, and high particulate matter concentrations. An alternative approach to estimating exhaust mass flow rate is to use a summation of the intake airflow rate and engine fuel consumption rate assuming negligible losses to piston ring blow by and system leakage.

The fuel flow rate is accurately metered and monitored with a Max Flow Media 710 Series Fuel Measurement System. The fuel supplied to the engine is first drawn from a storage tank through a filter and into a vapor elimination device that maintains a constant pressure of 30 psi with the system's transfer pump. The fuel then encounters a bypass system where excess fuel is routed via a pressure regulator through a heat exchanger and back to the storage tank. The heat exchanger uses the bypass supply fuel to cool the engine return fuel. Fuel that is not returned to the tank enters a Model 214 piston-displacement flowmeter. From there the metered fuel supply enters a levelcontrolled tank. In this tank the metered fuel is mixed with the unused engine return fuel that has already passed through and been cooled by the internal heat exchanger. The volume of the tank is kept constant, so the fuel used by the engine is the amount of metered fuel recorded during a given test period. The fuel is drawn from the tank with a secondary fuel pump. The purpose of the second pump is to further increase the pressure of the fuel to levels needed by high-pressure diesel injection systems. A bubble detector eliminates any vapors in the system by controlling a solenoid valve that connects toengine and from-engine fuel lines. The removal of any vapor bubbles in the system is 
necessary to prevent any engine performance problems or metering inaccuracies. After exiting the solenoid valve, the fuel enters an external heat exchanger that maintains a constant fuel temperature with a Fuji Model 223-1806 temperature controller.

\subsubsection{Intake Air Flow Measurement}

An LFE manufactured by Meriam Instruments was used for quantification of intake airflow rates. The LFE is made up of a series of small capillary tubes oriented parallel to the direction of airflow. The purpose of the capillary matrix is to produce a laminar flow of air from the turbulent flow entering it. A pressure drop is created in the LFE from the friction of the air passing through the tiny capillaries. Meriam Instruments supplies a calibration equation and coefficients that are unique to each LFE unit. Meriam determines these coefficients with a flow meter that is traceable to NIST standards. The absolute temperature and pressure upstream of the capillary matrix and the pressure downstream of the matrix are the only parameters needed for intake volume flow determination. The equation used for this calculation is:

$$
\underset{\text { Actual }}{\dot{V}}=\left[\mathrm{B} \times(\Delta \mathrm{P})+\mathrm{C} \times(\Delta \mathrm{P})^{2}\right] \times\left(\frac{\mu_{\mathrm{STD}}}{\mu_{\mathrm{FLOW}}}\right)
$$

Eqn. 3.3

Where,

$$
\begin{array}{lll}
\underset{\text { Actual }}{\dot{V}} & =\text { Volume flow rate of air through LFE } \\
\mathrm{B} & =\text { Coefficient supplied by Meriam Instruments } \\
\mathrm{C} & =\text { Coefficient supplied by Meriam Instruments } \\
\mu_{\mathrm{STD}} & =\text { Standard kinematic viscosity }
\end{array}
$$


$\mu_{\text {FLOW }}=\quad$ Actual flow kinematic viscosity

$\Delta \mathrm{P} \quad=\quad$ Differential pressure across LFE

A correction factor is used to account for viscosity variations and is as follows:

$$
\text { CorrectionFactor }=\left(\frac{529.67}{459.67+T\left({ }^{o} F\right)}\right) \times\left(\frac{181.87}{\mu g}\right)
$$

Eqn. 3.4

with,

$$
\mu g=\frac{14.58+\left(\frac{459.67+T\left({ }^{o} F\right)}{1.8}\right)^{1.5}}{110.4+\left(\frac{459.67+T\left({ }^{o} F\right)}{1.8}\right)}
$$

Eqn. 3.5

The LFE used for all in-laboratory testing on both engines was a Meriam Model 50MC2-4 LFE that had a 4 in. I.D. and was capable of flowing a maximum of $400 \mathrm{cfm}$. Differential pressure across the element was measured with a Omega Model PX65310DSV (0-10”WC) differential pressure transducer, while absolute upstream pressure was determined with a Viatran Model 1042ACA (0-15psi) pressure transducer. The temperature of the inlet air upstream of the LFE was recorded with a Resistive Temperature Device (RTD). The pressure transducers and the RTD were calibrated before the start of each testing session. 


\subsubsection{Instrumentation Control/Data Acquisition}

All in-laboratory data obtained during the testing undertaken in this study was collected with software and hardware previously developed and installed in the EERL

[16]. The software uses an RTI-815F data acquisition board for data collection as well as rack-mounted signal conditioning units (Analog Devices Model 3B). All data was recorded in ADC code and later converted to the proper engineering units with a reduction program developed in-house at WVU. 
Figure 11 Schematic of West Virginia University's Engine and Emissions

Research Laboratory Emissions Measurement System.

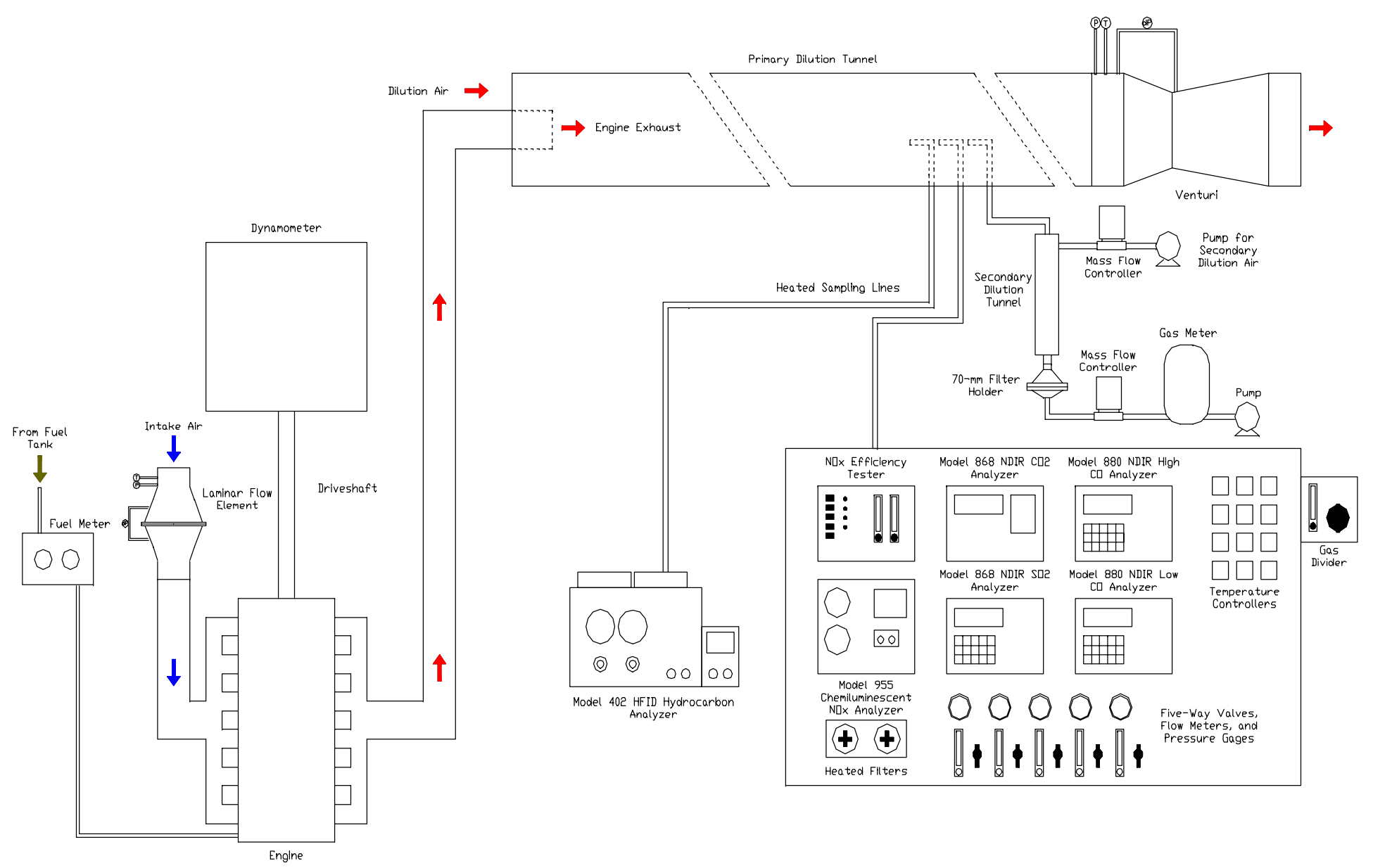




\section{Chapter 4. Experimental Results and Discussion}

\subsection{Introduction}

The objective of this study were twofold: first to develop representative testing cycles for off-road diesel-powered equipment by logging activity data while they were operating infield and second to use these cycles to exercise the engine in a dynamometer laboratory in order provide real-world emissions data from these vehicles. The task first involved some preliminary evaluative testing with the portable Sensors multigas analyzer. The analyzer was then used onboard to collect desired infield raw emissions data on the John Deere rubber-tired loader and the Elgin streetsweeper as they carried out their operational duties. The collected data were used to develop representative transient testing cycles that could then be used in a laboratory setting to accurately recreate the real-world vehicle emissions scenario. Fully diluted emissions were taken while each vehicle's engine operated on the developed transient cycle on a dynamometer test bed at the EERL. Steady-state emissions data was also collected as each engine was operated according to the ISO 8178 steady-state cycle - the current certification test cycle.

In order to compare emissions data obtained with the Sensors multigas analyzer with laboratory emissions data, a plot of $\mathrm{CO}_{2}$ data was created during each test. An integrated overall result was obtained with the following formula:

$$
I=\frac{\sum_{i=1}^{N} X_{i}\left(t_{i}-t_{i-1}\right)}{\text { TotalTime }}
$$

Eqn. 4.1

Where, 


$\begin{array}{rll}\mathrm{I} & = & \text { Integrated Result } \\ \mathrm{N} & = & \text { Number of data points } \\ \mathrm{x} & = & \text { Data point } \\ \mathrm{t} & = & \text { Time }\end{array}$

Any and all errors calculated and mentioned in this document were obtained with the formula for relative percent error given below:

$$
\% \text { error }=\frac{\text { testvalue }- \text { refvalue }}{\text { refvalue }} \times 100
$$

Eqn. 4.2

The refvalue in the above equation is considered to be the "known" value, such as the laboratory data obtained during testing. The testvalue is the value that is being compared to the "known" value, such as the data taken with the Sensors portable analyzer.

The data presented herein will be instrumental in develping protocols pertaining to the testing of off-road equipment as well as providing a more accurate description of contributors to air inventories. It also illustrates the ability to predict engine power for a particular engine family based on the amount of $\mathrm{CO}_{2}$ emitted by the vehicle, which could be very useful for future cycle development work. The infield testing data presented in this document also adds to the recent research activities focused on on-board vehicle emissions measurement.

\subsection{Preliminary Analyzer Testing}

In order to accurately measure infield vehicle emissions, a thorough evaluation of the Sensors multigas analyzer was necessary. Three areas were investigated in the testing of the analyzer. The first testing performed consisted of steady-state testing of the 
measurement accuracy of the analyzer using various known gas concentrations. The steady-state testing was followed by transient testing of the analyzer performed with a step input of a known gas to evaluate the response time, as well as the settling time of the instrument. This data was later implemented, along with line length lag time to determine total system lag time, as an aid in the recreation of the transient testing cycle in the laboratory. The final analyzer testing performed consisted of comparative tests on the detection of raw exhaust concentrations between the Sensors AMB-II analyzer and the laboratory grade analyzers housed at the EERL.

One problem encountered while using the Sensors AMB-II analyzer was the fact that it did not record data at a constant time rate for successive runs. It recorded at a rate close to one data point every 0.6 seconds, or $1.667 \mathrm{~Hz}$. This rate would vary somewhat from test to test, however. The problem arose when comparisons of the $1 \mathrm{~Hz}$ laboratory data and the slightly frequency-varying infield data were made. In order to make pointto-point correlative comparisons for the cycle development portion of the research, the data had to be of the same frequency. A program was written by Dr. Greg Thompson to convert the variable frequency Sensors AMB-II data to $1 \mathrm{~Hz}$ data for comparative purposes in the cycle iteration process.

To compound the sampling frequency problem, the Sensors AMB-II would often randomly change the sampling frequency during a test. This could be determined by performing a visual inspection of the time aligned engine speed data. This made it necessary during some tests to evaluate only the portion of the test run prior to the change in sampling frequency of the Sensors analyzer. 


\subsubsection{Steady-State Analyzer Testing}

Preliminary testing of the measurement accuracy of the Sensors AMB-II analyzer was performed using gas bottles of known concentration. A broad measurement range was investigated by diluting the test gas with nitrogen using a Stec, Inc. Model SGD710C capillary flow gas divider. This allowed the testing of the analyzer at different levels from $0 \%$ test gas concentration to $100 \%$ concentration in increments of $10 \%$. The results of the steady-state testing can be seen in Table 4. The test gas used on the AMBII was $19.9 \% \mathrm{CO}_{2}$. Gas divider viscosity effects were neglected. Results showed that the Sensors analyzer bench performed well with a range of error between $0 \%$ and $4.27 \%$.

Table 4 Results of Steady-State Gas Bottle Tests on Sensors AMB-II (19.9\% CO $\mathrm{CO}_{2}$.

\begin{tabular}{|c|c|c|c|}
\hline $\begin{array}{c}\text { Gas } \\
\text { Divider } \\
\text { Position }\end{array}$ & $\begin{array}{c}\text { Actual Gas } \\
\text { Concentration } \\
(\mathbf{\%})\end{array}$ & $\begin{array}{c}\text { Measured Gas } \\
\text { Concentration } \\
(\mathbf{\%})\end{array}$ & $\begin{array}{c}\text { Percent } \\
\text { Error }\end{array}$ \\
\hline $\mathbf{1 0 0 \%}$ & 19.9 & 19.9 & 0.00 \\
\hline $\mathbf{9 0 \%}$ & 17.91 & 18.1 & 1.06 \\
\hline $\mathbf{8 0 \%}$ & 15.92 & 16.2 & 1.76 \\
\hline $\mathbf{7 0 \%}$ & 13.93 & 14.2 & 1.94 \\
\hline $\mathbf{6 0 \%}$ & 11.94 & 12.2 & 1.18 \\
\hline $\mathbf{5 0 \%}$ & 9.95 & 10.3 & 3.52 \\
\hline $\mathbf{4 0 \%}$ & 7.96 & 8.3 & 4.27 \\
\hline $\mathbf{3 0 \%}$ & 5.97 & 6.2 & 3.85 \\
\hline $\mathbf{2 0 \%}$ & 3.98 & 4.1 & 3.02 \\
\hline $\mathbf{1 0 \%}$ & 1.99 & 2.0 & 0.50 \\
\hline $\mathbf{0 \%}$ & 0.0 & 0.0 & 0.00 \\
\hline
\end{tabular}

\subsubsection{Transient Analyzer Testing}

It was necessary to investigate the transient recording ability of the analyzer to determine if response times would be sufficient to capture the sharp transient events that would often be encountered during the infield testing. A test apparatus was developed that allowed for computer-controlled switching of a solenoid valve that routed either the 
test gas or nitrogen to the analyzer. Over-pressurization of the unit was prevented by placing an atmospheric vent in the line upstream of the analyzer sample port. A series of timed pulses were used to switch between zero and span gas streams. The pulses were tested in groups of five with the first group being 10s in length, followed by a group of 8second pulses, then 5-second, 4-second, 3-second, 2-second, and finally a group of 1second pulses. It was found that the analyzer was able to respond fast enough to allow the attainment of $100 \%$ relative concentration readings on all but the 2 -second and 1 second pulse groups. This was believed to be sufficiently fast to accurately record nearly all of the transient events that would be encountered during the infield testing. A test was then performed to determine the $\mathrm{T}_{90}$ and $\mathrm{T}_{100}$ times of the analyzer by routing $100 \%$ component gas to it and measuring the analyzer response as a function of time. It was found that the analyzer had a $\mathrm{T}_{90}$ time of 0.75 seconds and a $\mathrm{T}_{100}$ time of 2 seconds. It should be noted that these times were estimated from the graphical data and are therefore approximations. The test gas used in all of the transient testing was $30 \% \mathrm{CO}_{2}$. The graphical data can be seen in Figure 12. 


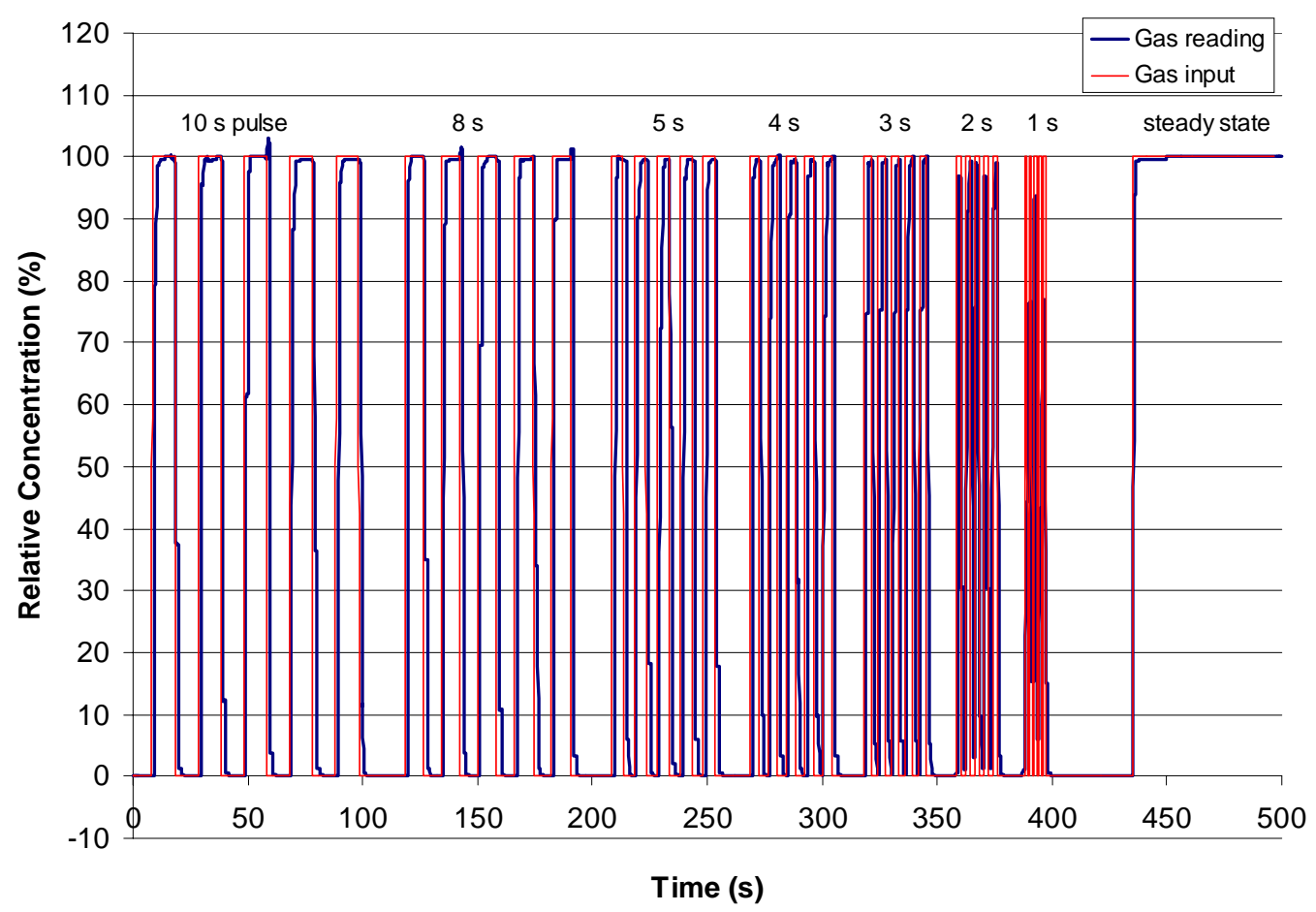

Figure 12 Sensors AMB-II Step Response on $30 \% \mathrm{CO}_{2}$

\subsubsection{Analyzer Comparative Testing}

Preliminary performance testing of the Sensors AMB-II analyzer in comparison to the EERL's laboratory-grade Rosemount $880 \mathrm{CO}_{2}$ analyzer yielded favorable results. Raw exhaust samples were collected with each analyzer from a 10.8L Cummins ISM 370 ESP diesel engine following the Federal Test Procedure (FTP) transient cycle. Percent difference between the integrated results for the two analyzers tested was less than $4 \%$ throughout the cycle. Results of the comparative testing are shown in Figure 13. 


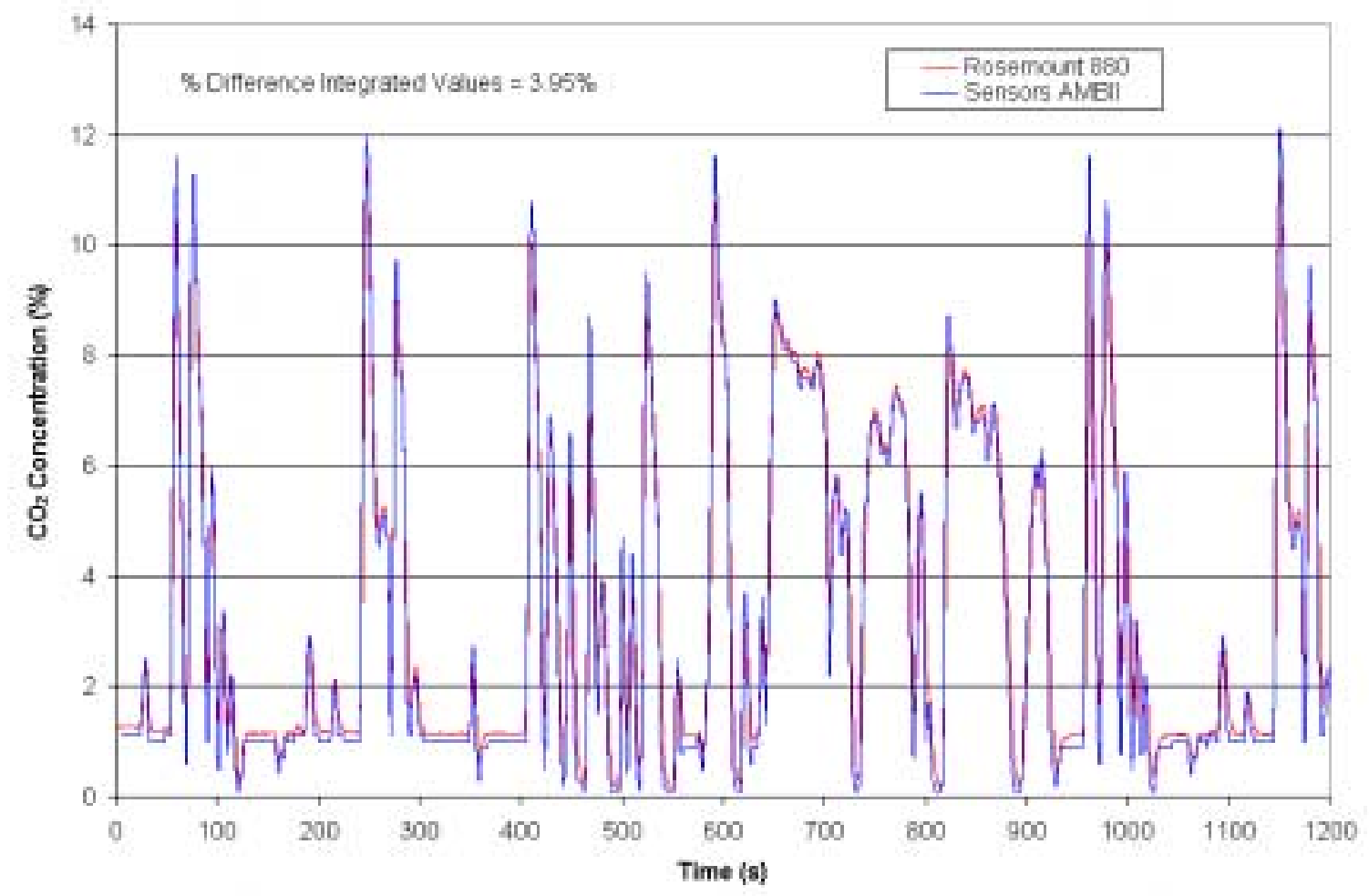

\section{Figure 13 Rosemount 880 and Sensors AMB-II $\mathrm{CO}_{2}$ Measurement Comparison.}

\subsubsection{Torque Inference Prediction Testing}

In order to evaluate the feasibility of inferring torque based on $\mathrm{CO}_{2}$ emissions, preliminary tests were performed to determine torque prediction accuracy. A Cummins ISM 370 was exercised over a series of steady-state operating conditions that spanned the engines operating range while continuous raw $\mathrm{CO}_{2}$ emissions were recorded with the Sensors AMB-II analyzer. A graphical representation of the steady-state testing cycle can be seen in Figure 14. The engine was then operated through a series of mapping exercises at motored, $0 \%, 25 \%, 50 \%, 75 \%$, and $100 \%$ load conditions while raw exhaust $\mathrm{CO}_{2}$ concentrations were again recorded using the Sensors analyzer. Graphical results of the mapping exercises can be seen in Figure 15 through Figure 20. This data was then used to develop correlation curves for the various engine speeds that were measured from 
the arbitrary test cycle (Figure 14). Correlation curves for the five selected engine speeds can be seen in Figure 21 through Figure 25. These figures show that the relationship between $\mathrm{CO}_{2}$ emissions and engine torque produced is very close to linear, as expected. Since the $\mathrm{CO}_{2}$ mapping points were discretized at $100 \mathrm{rpm}$ increments, and to further test the sensitivity to engine speed interpolation, the results for the 970 and 1160 were linearly interpolated from neighboring values. The resultant error between the inferred torques for the five randomly selected data points is shown in Figure 26, with the percent error shown in yellow, the estimated (inferred) torque in blue, and the actual torque measured by the dynamometer shown in red.

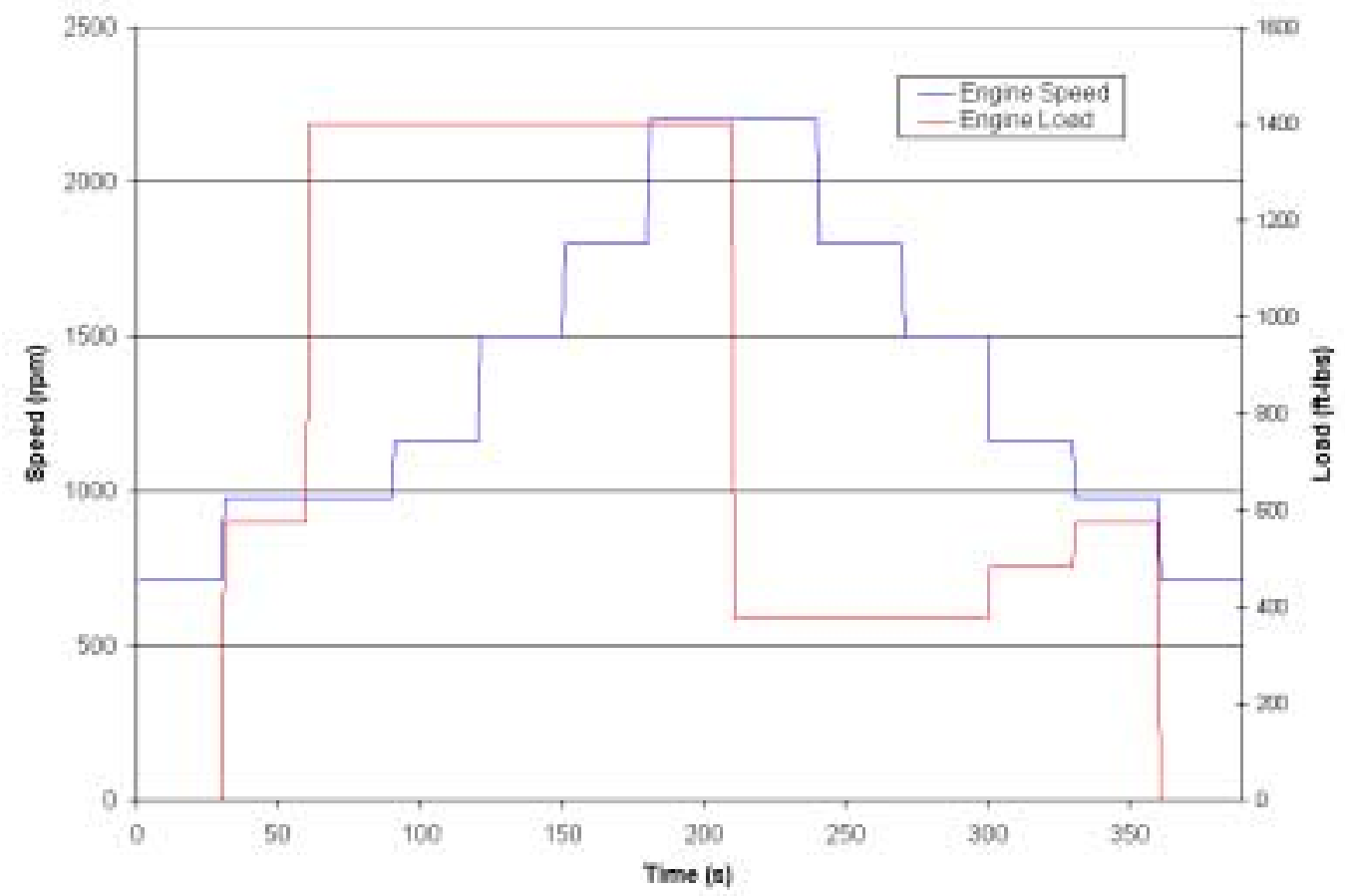

Figure 14 Cycle used for Torque Inference Prediction Testing. 


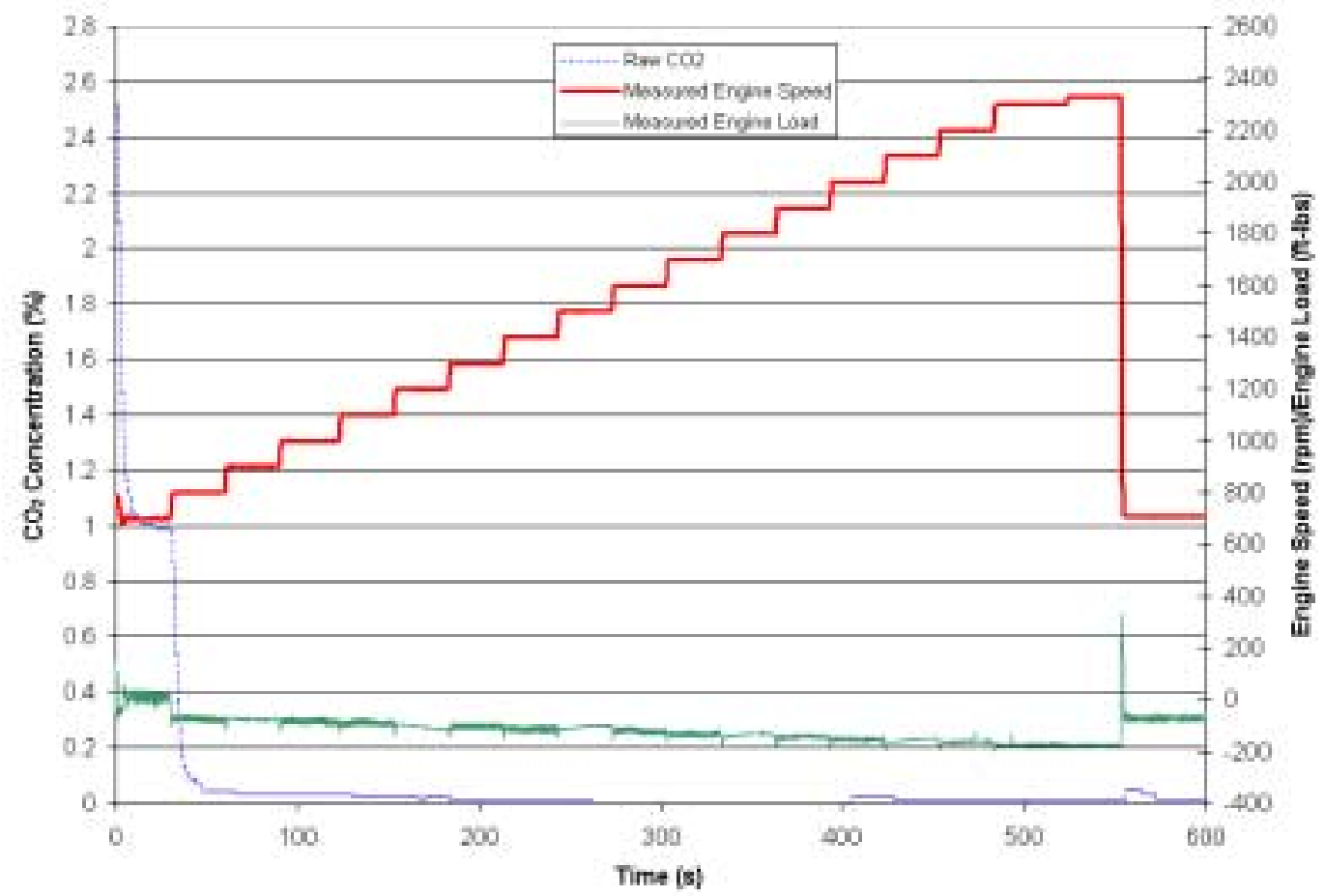

Figure 15 Engine Exhaust $\mathrm{CO}_{2}$ Concentration Map for Motored Condition.

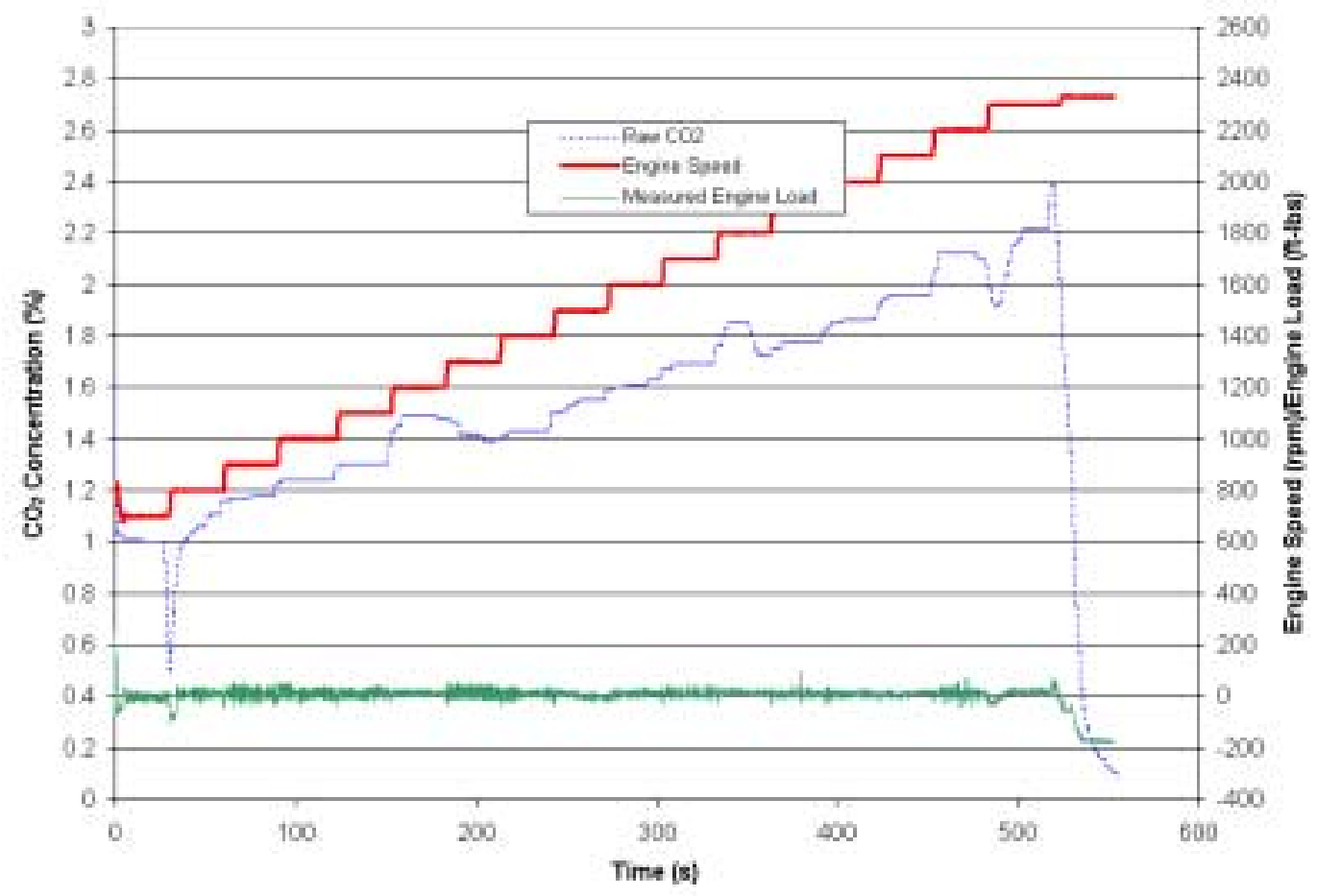

Figure 16 Engine Exhaust $\mathrm{CO}_{2}$ Concentration Map for 0\% Applied Load. 


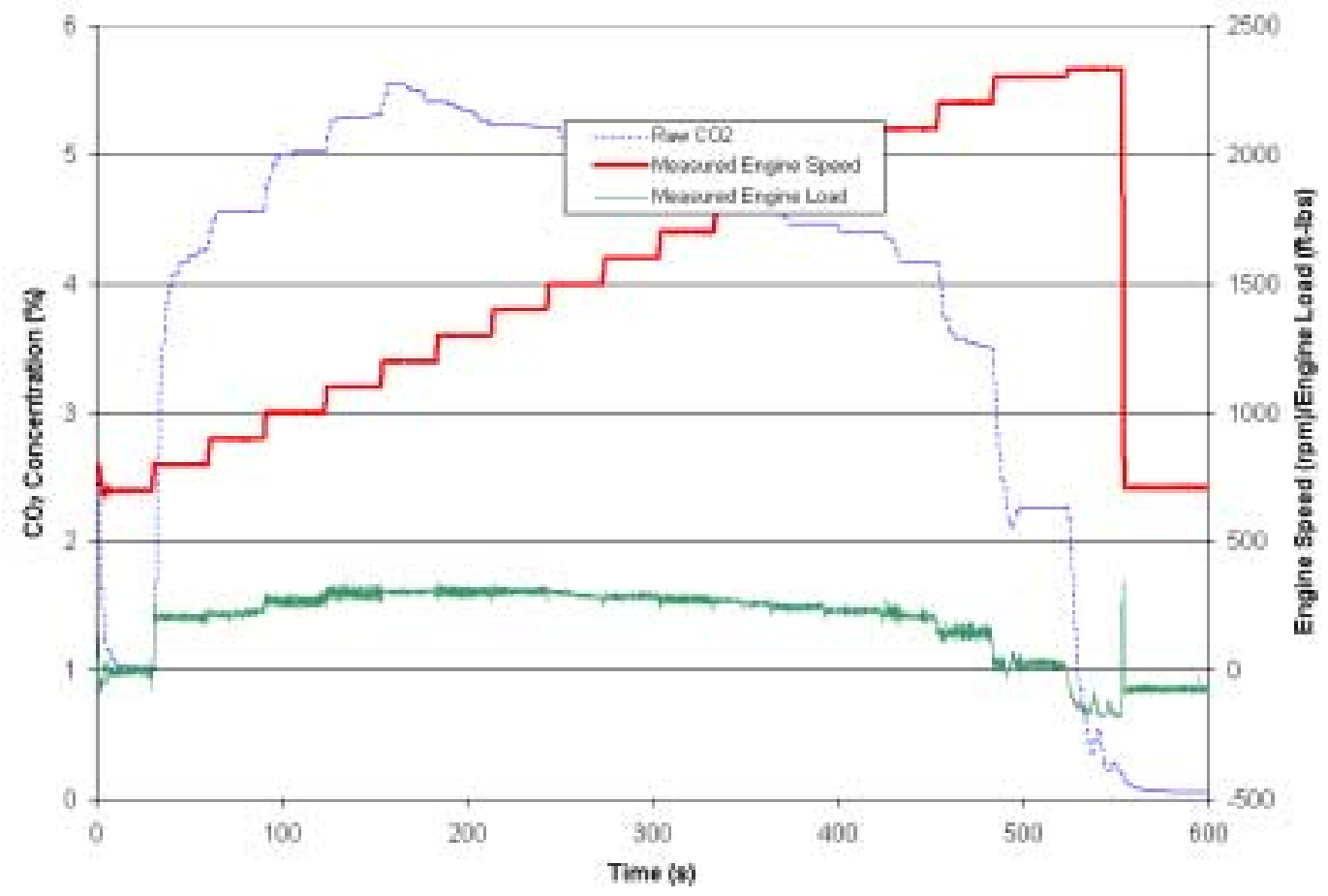

Figure 17 Engine Exhaust $\mathrm{CO}_{2}$ Concentration Map for 25\% Applied Load.

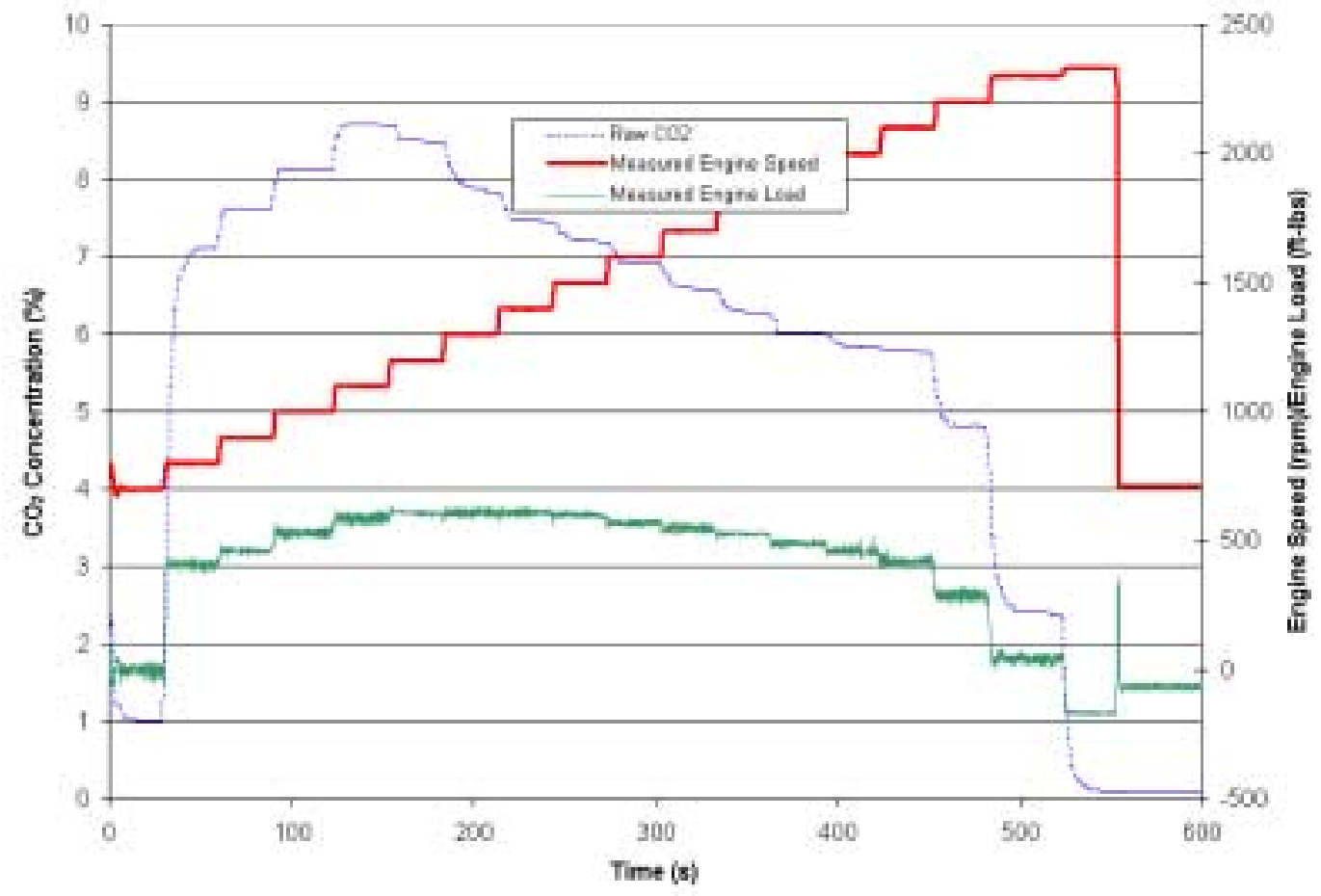

Figure 18 Engine Exhaust $\mathrm{CO}_{2}$ Concentration Map for 50\% Applied Load. 


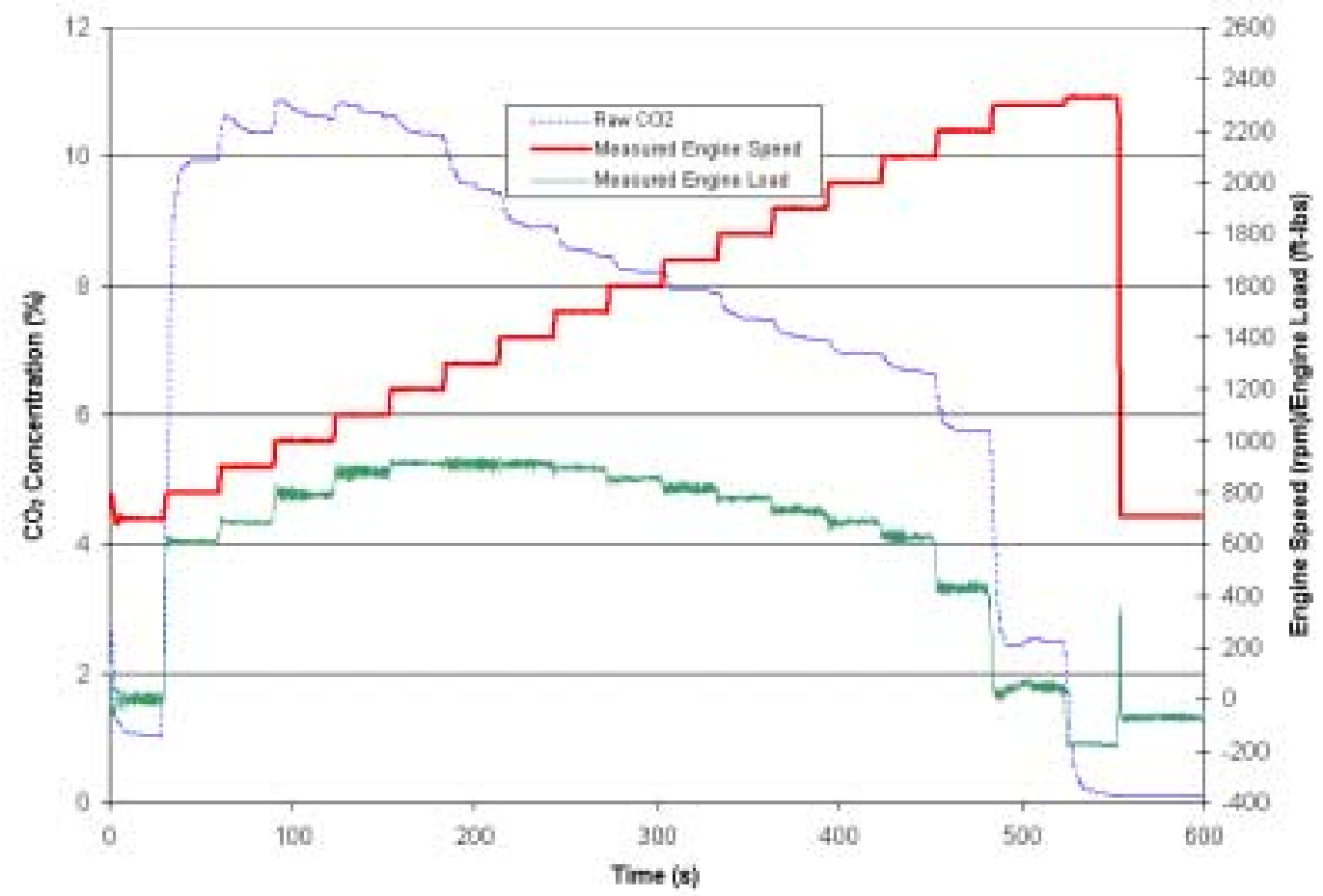

Figure 19 Engine Exhaust $\mathrm{CO}_{2}$ Concentration Map for 75\% Applied Load.

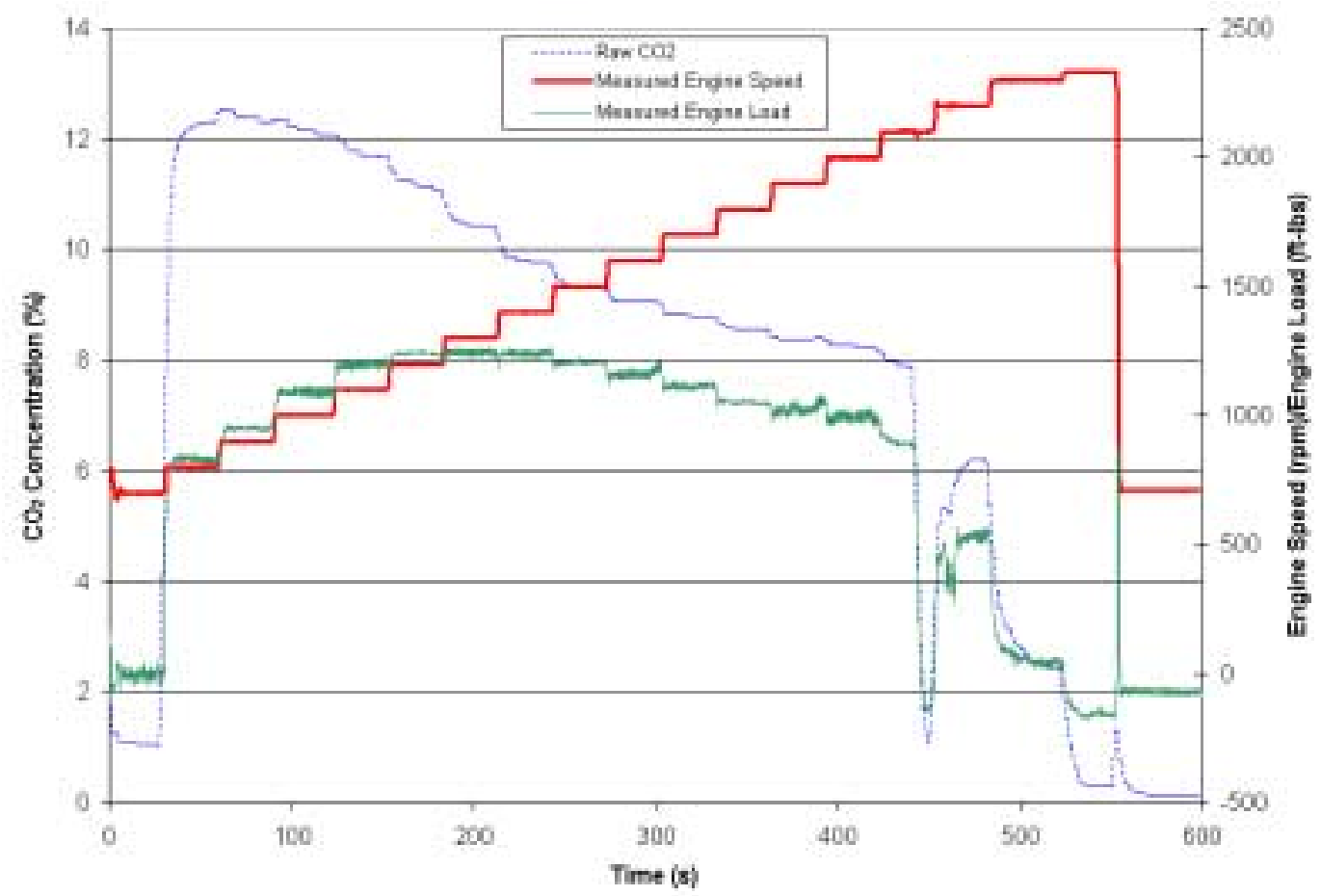

Figure 20 Engine Exhaust $\mathrm{CO}_{2}$ Concentration Map for 100\% Applied Load. 


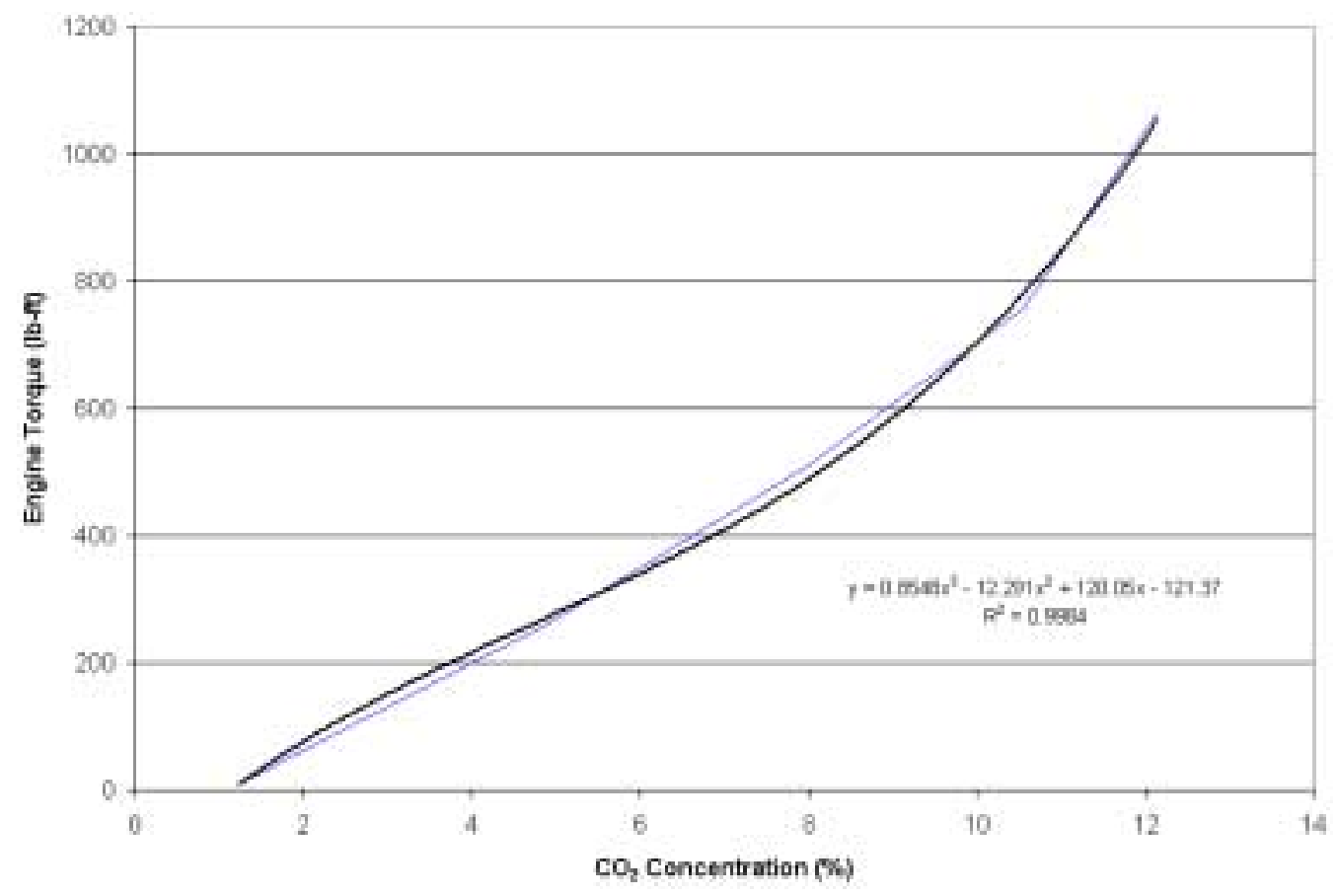

Figure 21 Interpolated $\mathrm{CO}_{2}$ vs. Engine Load Correlation for 970 rpm.

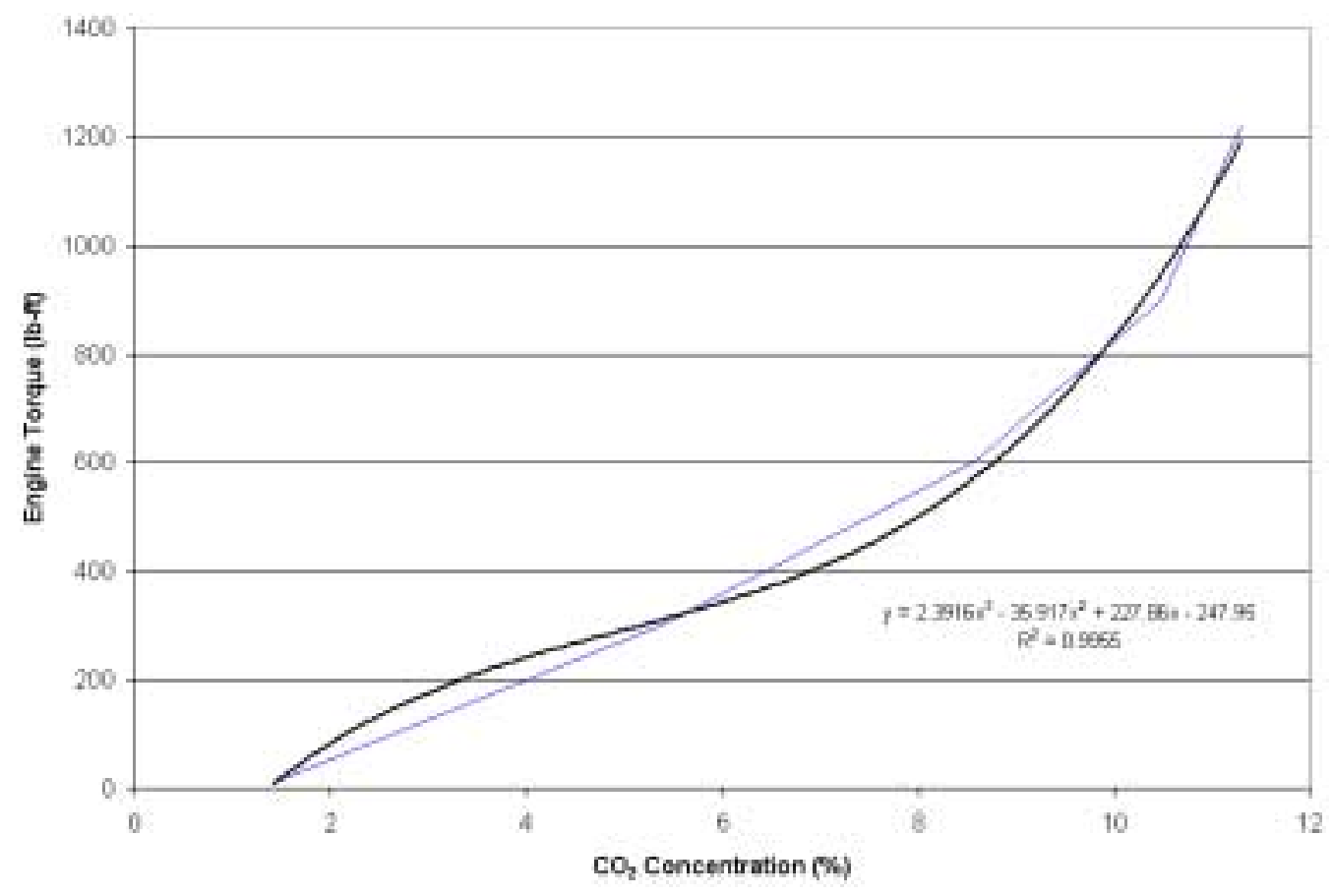

Figure 22 Interpolated $\mathrm{CO}_{2}$ vs. Engine Load Correlation for 1160rpm. 


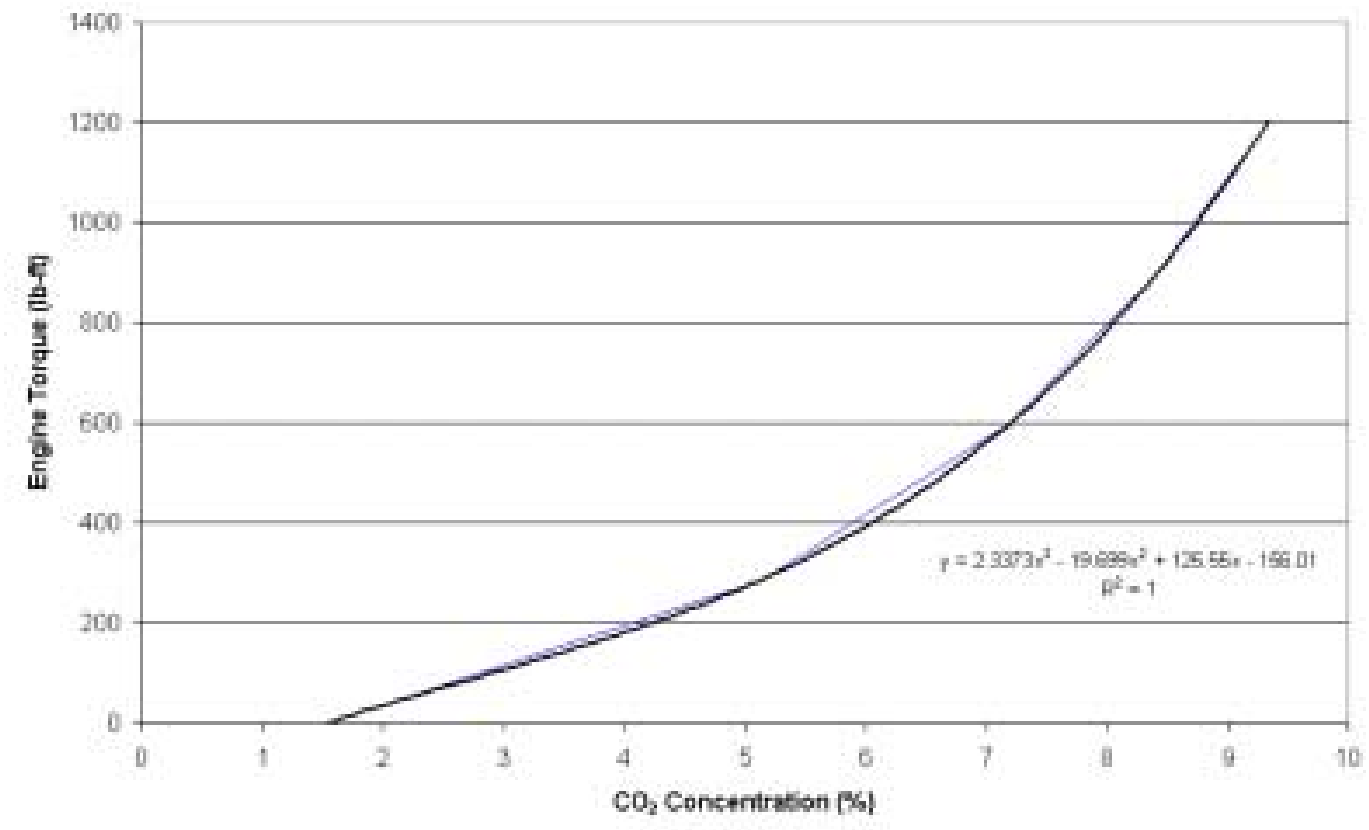

Figure 23 Interpolated $\mathrm{CO}_{2}$ vs. Engine Load Correlation for 1500 rpm.

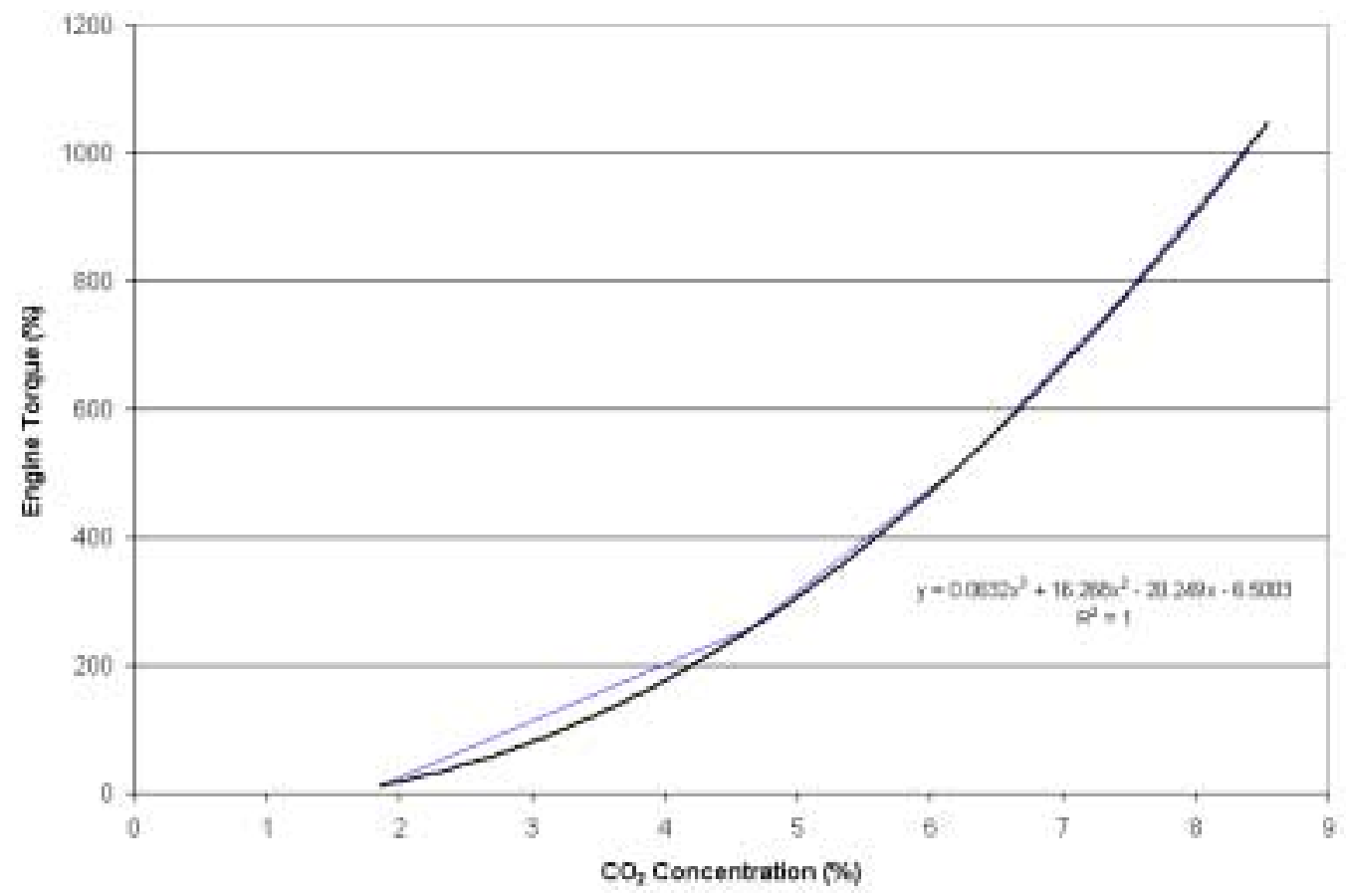

Figure 24 Interpolated $\mathrm{CO}_{2}$ vs. Engine Load Correlation for $1800 \mathrm{rpm}$. 


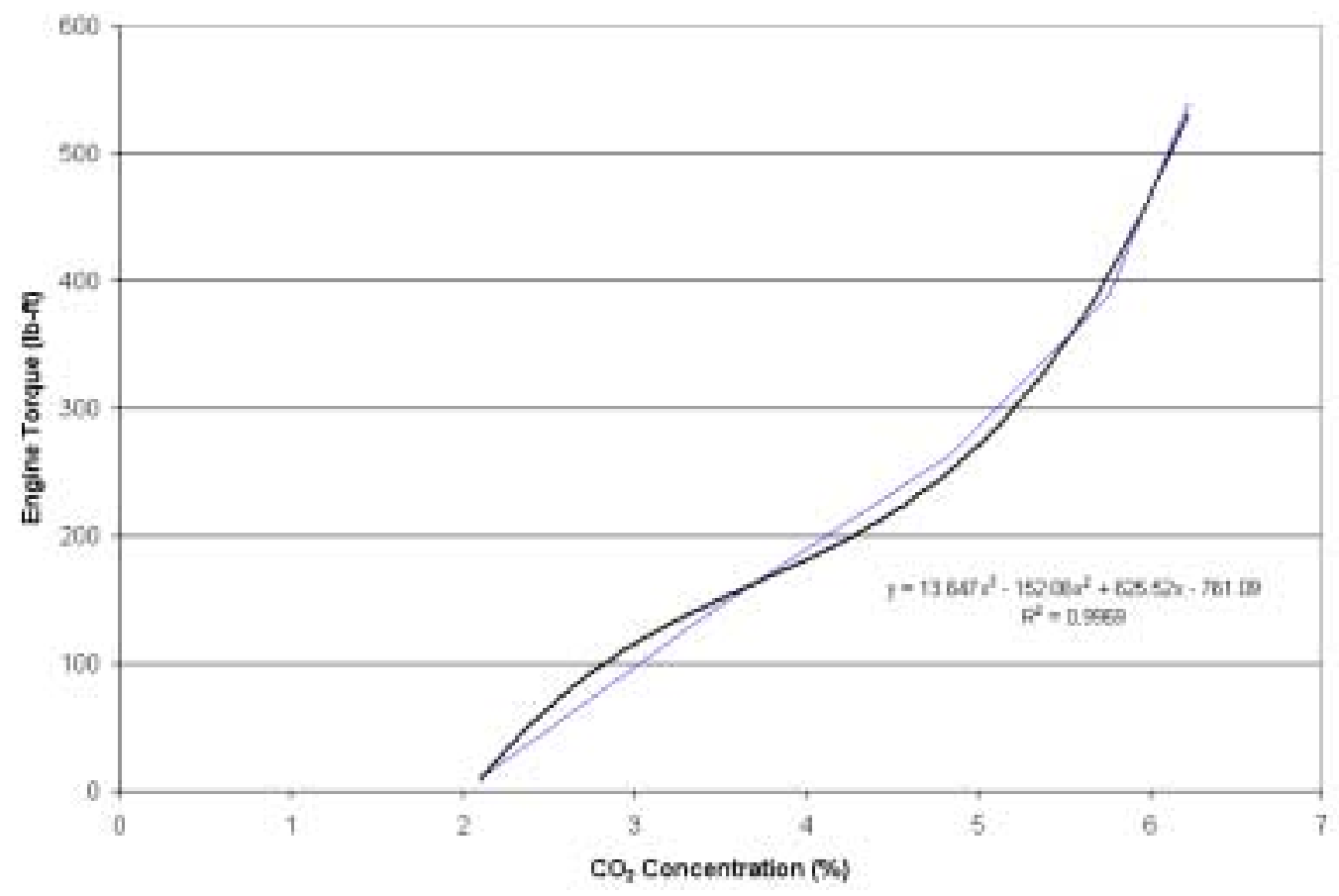

Figure 25 Interpolated $\mathrm{CO}_{2}$ vs. Engine Load Correlation for 2200 rpm.

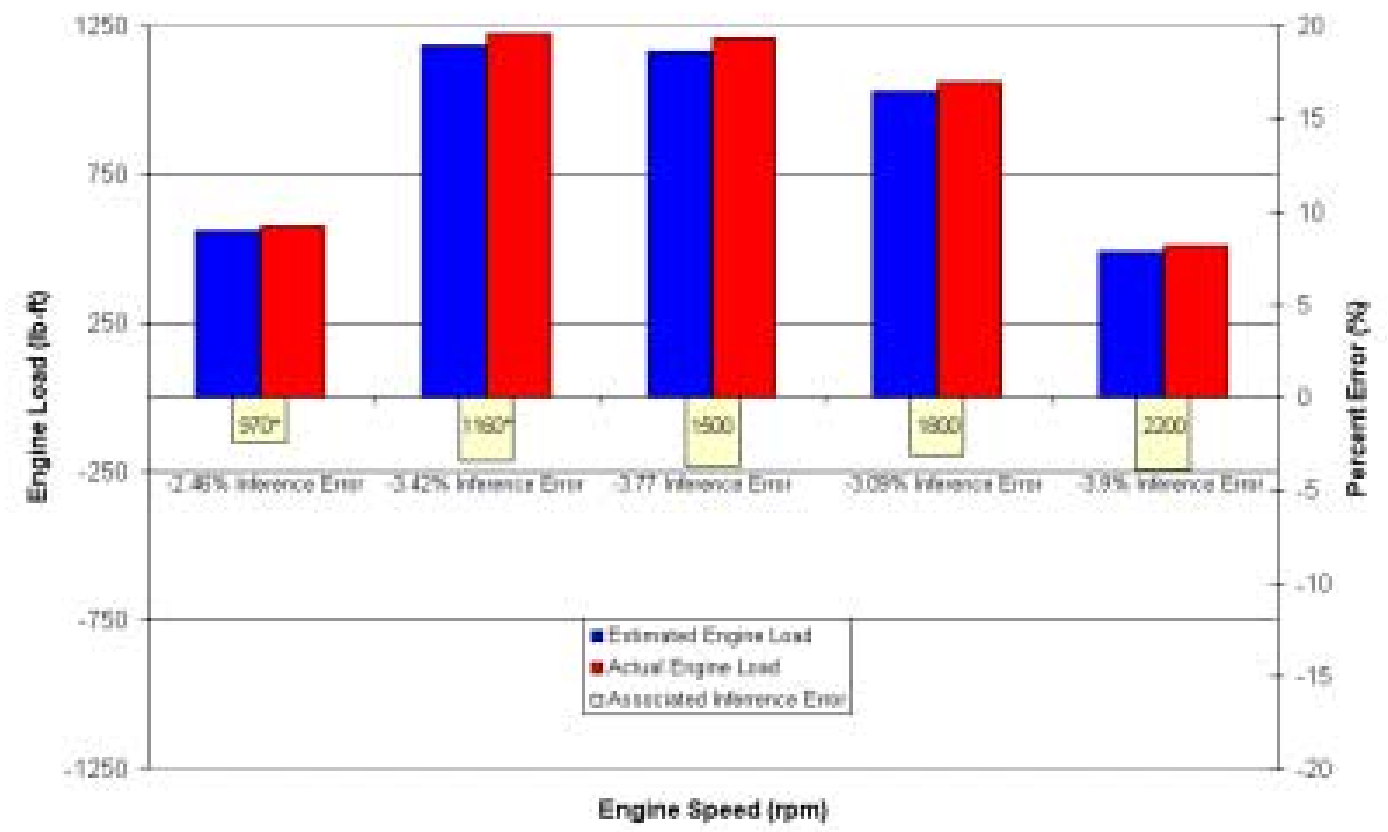

Figure 26 Torque Inference Error Estimates for Preliminary Engine Testing. 


\subsection{Infield Vehicle Testing Results}

The results of the infield data collected for the development of the representative transient testing cycles can be found in this section. All infield data were collected with the Sensors AMB-II multigas analyzer bench and associated data acquisition components. Though a number of tests were performed infield for a thorough evaluation of the "real-world" operating conditions of each vehicle, only one cycle was chosen as most representative and used in the recreation of the cycle for the in-laboratory testing. A brief description of each testing route is also given with approximate inclination angles provided for the various slopes encountered during infield data collection in the following two sections. A graphical representation of raw $\mathrm{CO}_{2}$ exhaust concentrations and engine speed for each cycle is also presented. In order to reduce the amount of dynamometer test time as well as the associated operating expenses the infield cycles were shortened, but in such a manner that they still accurately represented all activities of the full infield cycle. A detailed explanation of the cycle shortening process is described in Section 4.4.

\subsubsection{Rubber-Tired Loader Infield Results}

The testing route followed during the collection of infield $\mathrm{CO}_{2}$ emission data for the rubber-tired loader consisted of two primary operations. The two operations were a transport mode to the landfill site on hilly terrain and a scoop loading/unloading mode that was repeated numerous times during data collection. The graph of the infield $\mathrm{CO}_{2}$ emissions and engine speed versus time can be seen in Figure 27 below. The sharply transient nature of the loader cycle was somewhat more difficult to recreate in the laboratory and required a number of iterations to be performed before a satisfactory 
correlation could be achieved. This iterative process is explained in the Cycle Development section of this chapter.

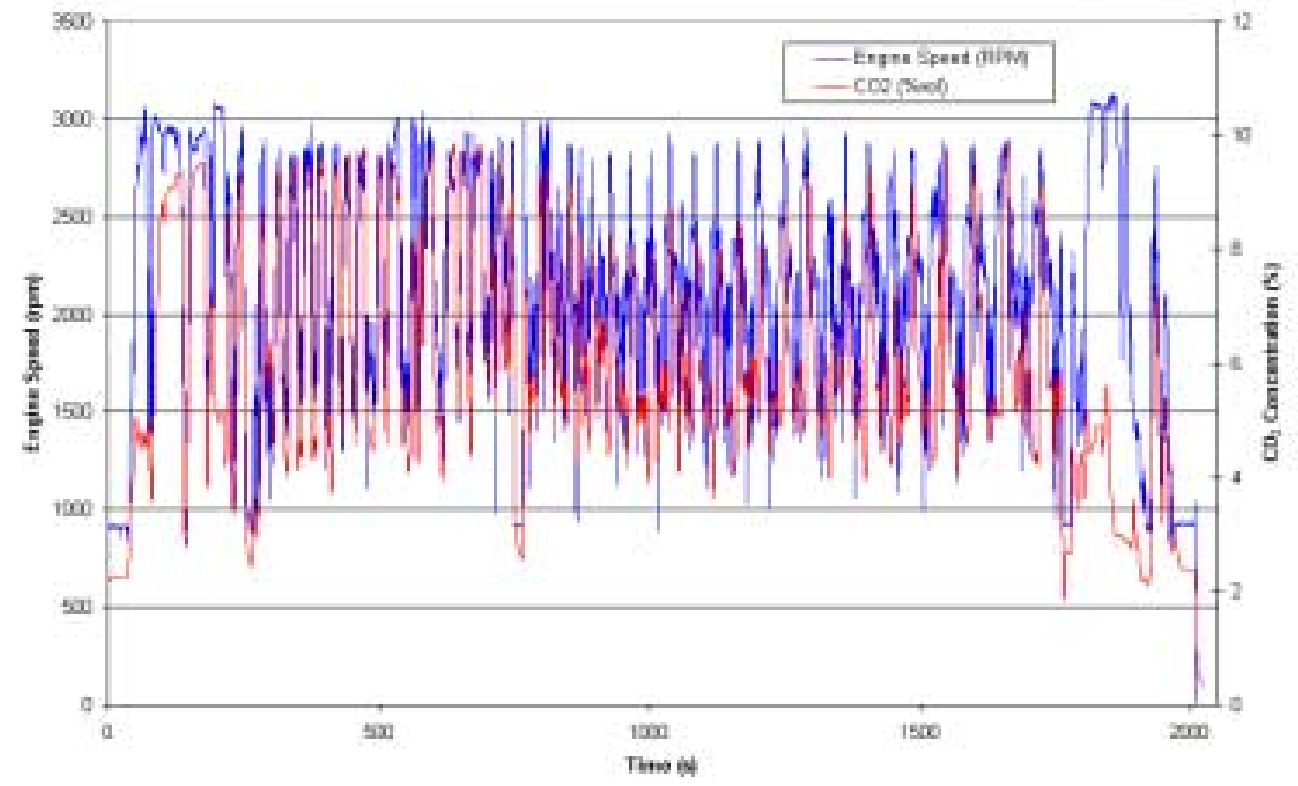

Figure 27 Infield $\mathrm{CO}_{2}$ and Engine Speed vs. Time Results for the Rubber-Tired Loader

\subsubsection{Streetsweeper Infield Results}

As stated previously, the primary goal of the infield testing was to accurately measure $\mathrm{CO}_{2}$ emissions during each vehicles routine operation. The $\mathrm{CO}_{2}$ emissions were continuously collected to allow the estimation of the engine load throughout the infield route. A description of the infield testing route with approximate inclination angles for the slopes encountered can be seen in Table 5. The inclination angles were approximated with a pendulum apparatus. The graphical representation of the streetsweeper $\mathrm{CO}_{2}$ emissions and engine speed as a function of time can be seen in Figure 28. The amount of $\mathrm{CO}_{2}$ emitted is useful because it can be directly related to the amount of fuel being 
combusted by the vehicle, which can then be used to estimate engine horsepower output. The engine speed was also continuously monitored during testing. With the estimated power derived from $\mathrm{CO}_{2}$ emissions and known engine speed, an approximation of the produced engine torque can be determined.

This estimation of engine torque output can be used to account for drive train and accessory losses during the operation of the vehicle. In the case of the streetsweeper, a test was performed to quantify the effect of brush rotation and drag on $\mathrm{CO}_{2}$ emissions. The results can be seen in Figure 30. The estimated horsepower output of the engine based on infield data was further refined during the in-laboratory portion of the testing by actually measuring engine horsepower with the dynamometer while raw $\mathrm{CO}_{2}$ data was taken with the same experimental setup and procedures used during the infield testing. The results were compared with brake-specific $\mathrm{CO}_{2}$ maps to estimate infield engine loads. 


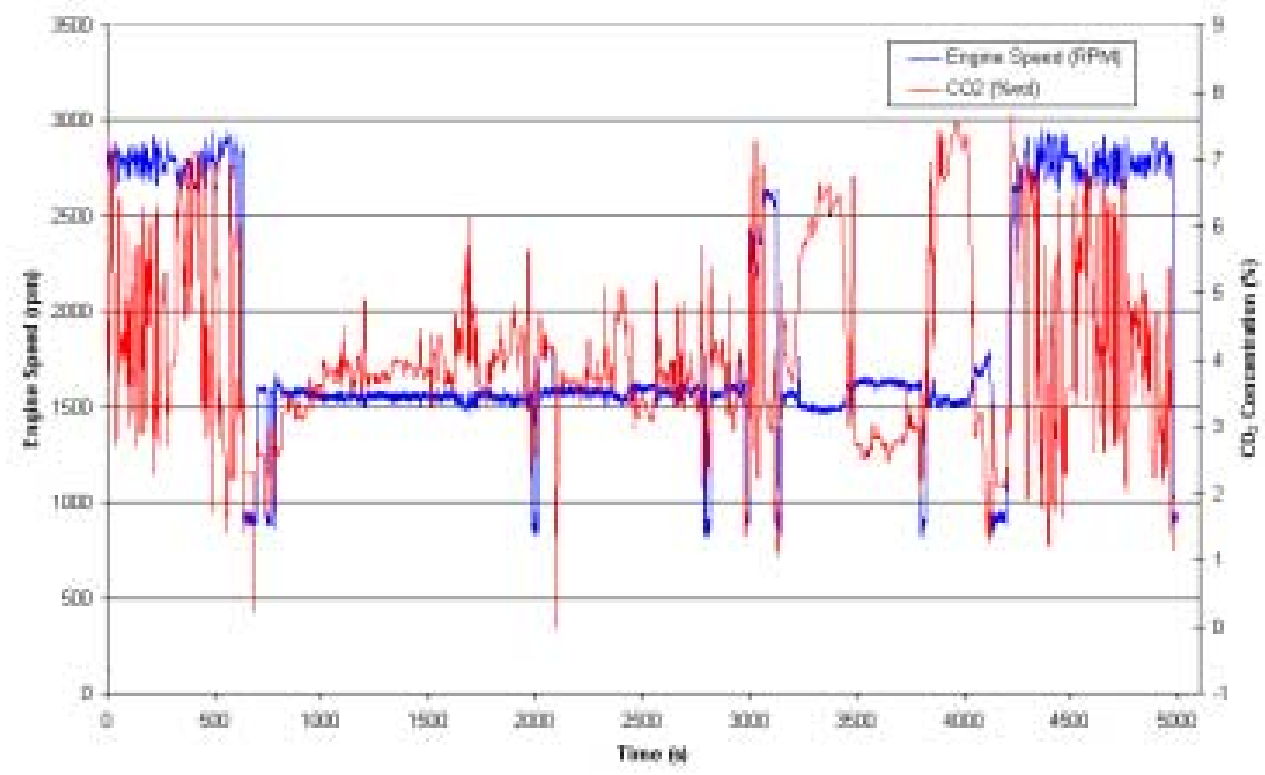

Figure 28 Infield $\mathrm{CO}_{2}$ and Engine Speed vs. Time for Series P Streetsweeper. 


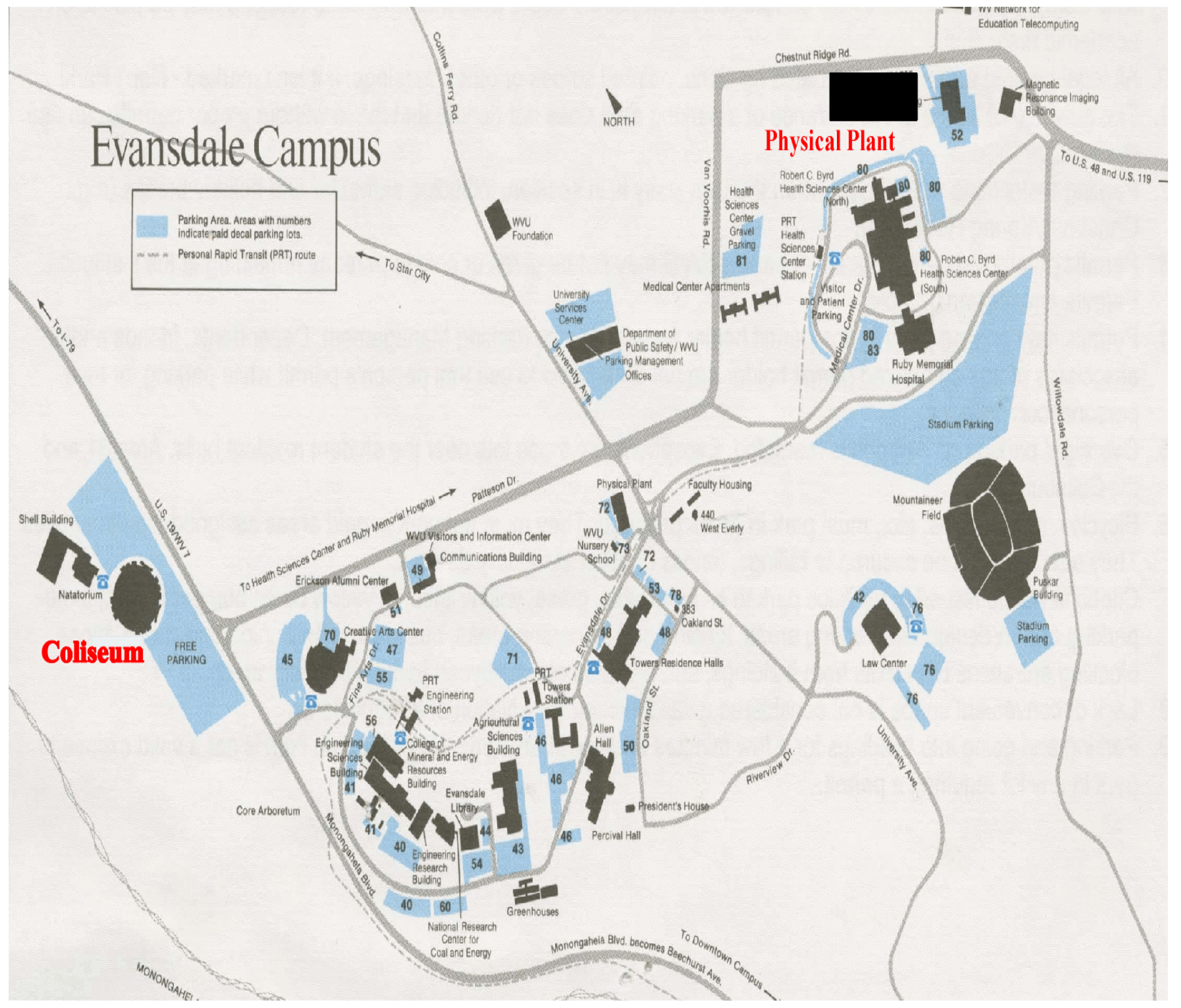

Figure 29 Map of Route taken for Infield Streetsweeper Testing. 
Table 5 Route Description for the Full Infield Streetsweeper Testing Route.

Time (s) Description

0.0 start test

228.0 end of Ruby Memorial hospital cruise (4-way)

349.5 In front of Brooke Tower

380.8 Uphill in front of ERC $(5.5 \%$ grade $)$

417.9 Uphill Percival Hall Crosswalk (5.5\% grade)

451.5 Library 4-way

529.0 bus stop turn

570.1 Downhill to CAC stoplight (4.5\% grade)

641.3 Idle

752.5 Idle

780.4 Brushes on/speed up engine

809.5 brushes down to pavement

841.4 move

857.4 $\mathrm{RPM}==1500$

991.9 around Coliseum

1192.0 turn around before Shell Building parking lot dropoff

1525.5 turn around on other side of Coliseum

1621.3 turn out of Coliseum circle

1714.2 turn around (180) at Coliseum stoplight

1791.7 turn onto Coliseum circle c-clkwise

1949.6 Shell Building turn -around

1982.7 stop/check hopper

2015.2 start again

2081.9 zero bench

2100.7 sample again

2280.3 turn around on other side of Coliseum

2428.5 turn around at light again

2778.0 stop/check hopper again

2808.7 start again

2975.8 transport mode

3061.3 down Patteson Dr. from Coliseum

3117.7 turn into Alumni Center road

3141.1 take off sweeping

3209.5 passing old Towers shortcut starting uphill ( $4.5 \%$ grade)

3363.4 pass top parking lot by PRT track uphill (4.5\% grade)

3448.9 stop at top of hill for pedestrians

3477.4 turn around and go back downhill (4.5\% grade)

3791.0 stop and check hopper at hill bottom

3819.5 turn around at Patteson Dr.--head back uphill (4.5\% grade)

4033.3 top hill turn downhill toward Beechurst Ave (4\% grade)

4118.8 check hopper at CAC parking lot (bottom of hill....full)

4184.3 transport mode back uphill on Evansdale Dr. (4.5\% grade)

4280.1 behind shop

4365.0 downhill past Percival Hall crosswalk stop (5.5\% grade)

4412.4 towers crosswalk in front of ERC

4475.1 stoplight (University Ave./Evansdale Dr.)

4564.6 hospital 4-way 
4780.6 dump debris above Physical Plant on hill

4956.2 stop to refill water tank

4976.7 stop recording data

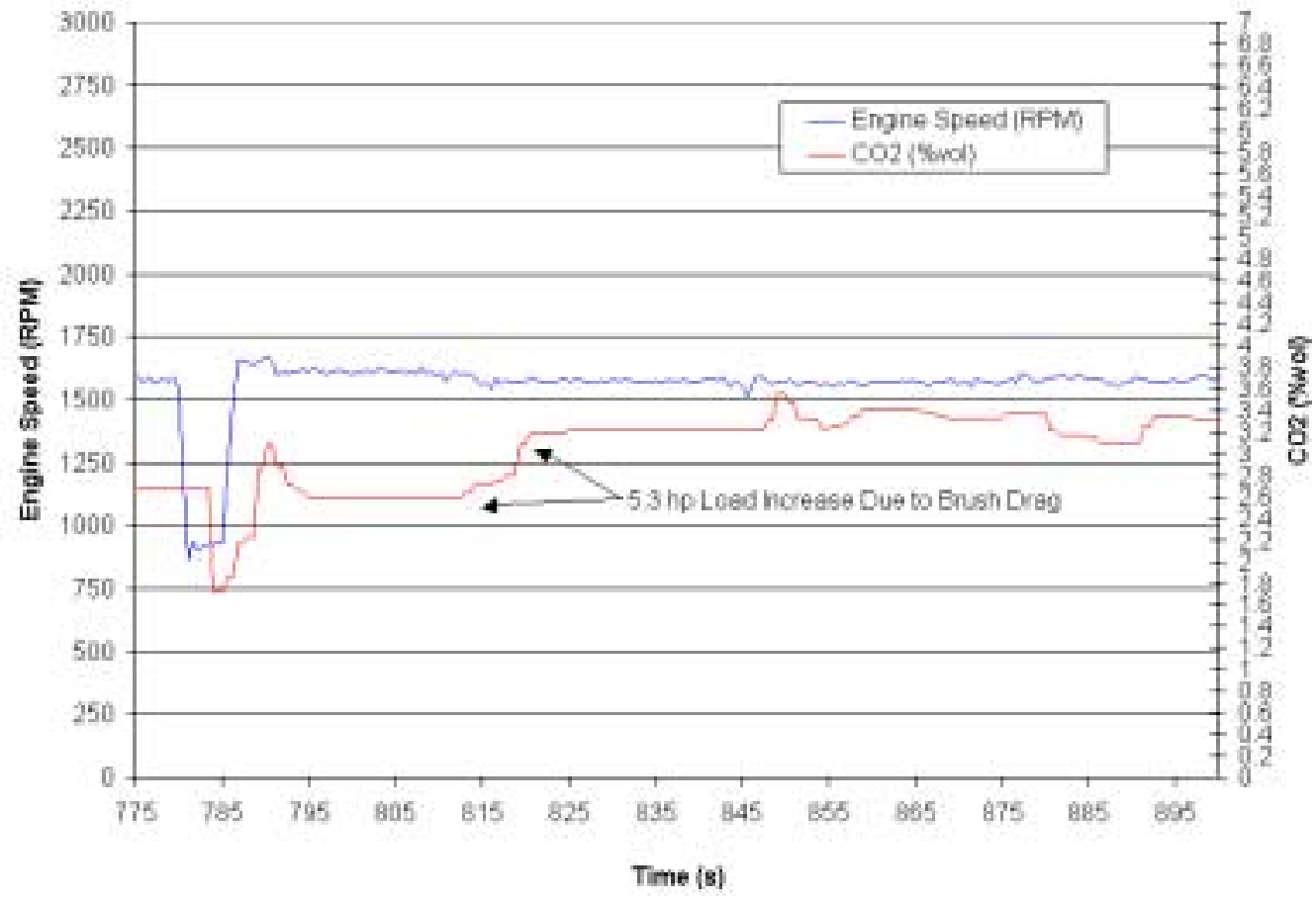

Figure 30 Effect of Sweeper Brush Drag/Inertia on $\mathrm{CO}_{2}$ Emission Levels.

Table 6 Description of Sweeper Brush Drag Test.

\begin{tabular}{|c|l|}
\hline Time (s) & Description \\
\hline 752.5 & Idle \\
\hline 780.4 & Brushes on/speed up engine \\
\hline 809.5 & brushes down to pavement \\
\hline 841.4 & move \\
\hline 857.4 & RPM $==1500$ \\
\hline 991.9 & around Coliseum \\
\hline
\end{tabular}

It can be seen from the Engine Speed/CO $\mathrm{CO}_{2}$ trace of Figure 30 and the test description of Table 6 above that sweeper brush drag and inertial forces did produce a measurable change in $\mathrm{CO}_{2}$ emissions. The small peak in $\mathrm{CO}_{2}$ emissions occurring at 
about 790 seconds is the result of the vehicles engine having to overcome the rotational inertia of the sweeper brush as it came up to speed. It can be seen from the $\mathrm{CO}_{2}$ trace that the extra load placed on the engine to overcome the rotational inertia resulted in an increase in $\mathrm{CO}_{2}$ level of about $0.5 \%$ vol over the steady-state value of about $2.6 \% \mathrm{vol}$ after the brushes were up to speed.

After the rotational inertia test was completed, a test was performed to check the effects of frictional brush drag on $\mathrm{CO}_{2}$ levels when the sweeper brush was lowered to the pavement. The added load placed on the engine in overcoming this drag resulted in an increase in $\mathrm{CO}_{2}$ emissions from about $2.6 \%$ vol to $3.2 \%$ vol. Examining the streetsweeper $\mathrm{CO}_{2}$ matrix data of Section 4.4.2.2 and noting that a $1 \%$ vol change in $\mathrm{CO}_{2}$ emissions equates to a horsepower change of about $10.6 \mathrm{hp}$, the brush drag can be quantified in terms of horsepower consumed. The increase in engine load from the frictional brush drag is approximately $5.3 \mathrm{hp}$, calculated from the $\mathrm{CO}_{2}$ level increase of $0.5 \% \mathrm{vol}$. While this is obviously a rough estimate, it illustrates the idea that vehicle drivetrain and accessory losses can be quantified through $\mathrm{CO}_{2}$ emissions measurements.

The small $\mathrm{CO}_{2}$ spike occurring at about 845 seconds is from the vehicle beginning to move to sweep the Coliseum parking area. The remainder of the $\mathrm{CO}_{2}$ trace shows data collected while sweeping the nearly flat parking area.

\subsection{Infield Cycle Shortening}

The length of the test cycle is an important consideration when developing a cycle. The researcher wants the test cycle to be long enough to provide a sufficient amount of representative emissions data while not wasting resources by being too lengthy. Laboratory dynamometer testing is expensive, and excessively long test cycles 
would add significantly to total testing costs. Limiting wear and tear on the engine as well as the testing equipment is also an important factor to consider when deciding on an appropriate test cycle length. These considerations were the driving force for shortening the infield cycles at the onset of the creation of the dynamometer test cycles.

It should be noted that the infield test cycle is only arbitrary and the strict adherence to any transient cycle is not going to be absolutely representative of all infield conditions. Many parameters influenced all infield data. Factors such as operator driving style, specific activity and load, ambient conditions, and the condition of the terrain encountered all have significant impacts on any infield cycles. The primary goal in the development of a cycle is to capture the basic nature of the modes most encountered during the test vehicle's operation. The shortened infield cycle should include all the basic operational modes of the full infield cycle with an adequate amount of time spent on each mode to allow a sufficient amount of data to be collected. For the test cycles developed, a proportional amount of time was dedicated to each of the identified modes, compared to the original infield cycle.

\subsubsection{Infield Loader Cycle Shortening}

The infield activities of the rubber-tired loader consisted of two modes of operation: a transport mode to the excavation site, and a loading/tramming/unloading mode. The infield data was examined for areas of excessive repetitiveness of operation that could be shortened. The first 240 seconds and the last 210 seconds of the infield loader data (Figure 32) consisted of the transport mode of operation. The transport mode is not of a repetitive nature because the loader was descending hills on the way back to the test origin that it ascended on the way to the excavation site and vice-versa. For this 
reason, the transport modes at the beginning and end of the full infield test cycle were kept in their entirety for the shortened test cycle (Figure 31). Sections of repetitive events in the loading/tramming/unloading mode of the infield cycle were truncated. A total of 864 seconds were removed from the full infield cycle to arrive at the shortened test length of 1144 seconds. Comparisons were made of the full infield and shortened infield cycle integrated values of continuous speed and $\mathrm{CO}_{2}$ to make sure that the shortened speed/load ranges were representative of the actual full infield ranges. Average engine speed for the full infield loader cycle was $1805.6 \mathrm{rpm}$ and the average $\mathrm{CO}_{2}$ was $5.92 \%$ vol. The shortened cycle had average engine speed and $\mathrm{CO}_{2}$ values of $1810.0 \mathrm{rpm}$ and $5.80 \%$ vol, respectively. Considering the variabilities encountered during testing, the differences in integrated values were negligible.

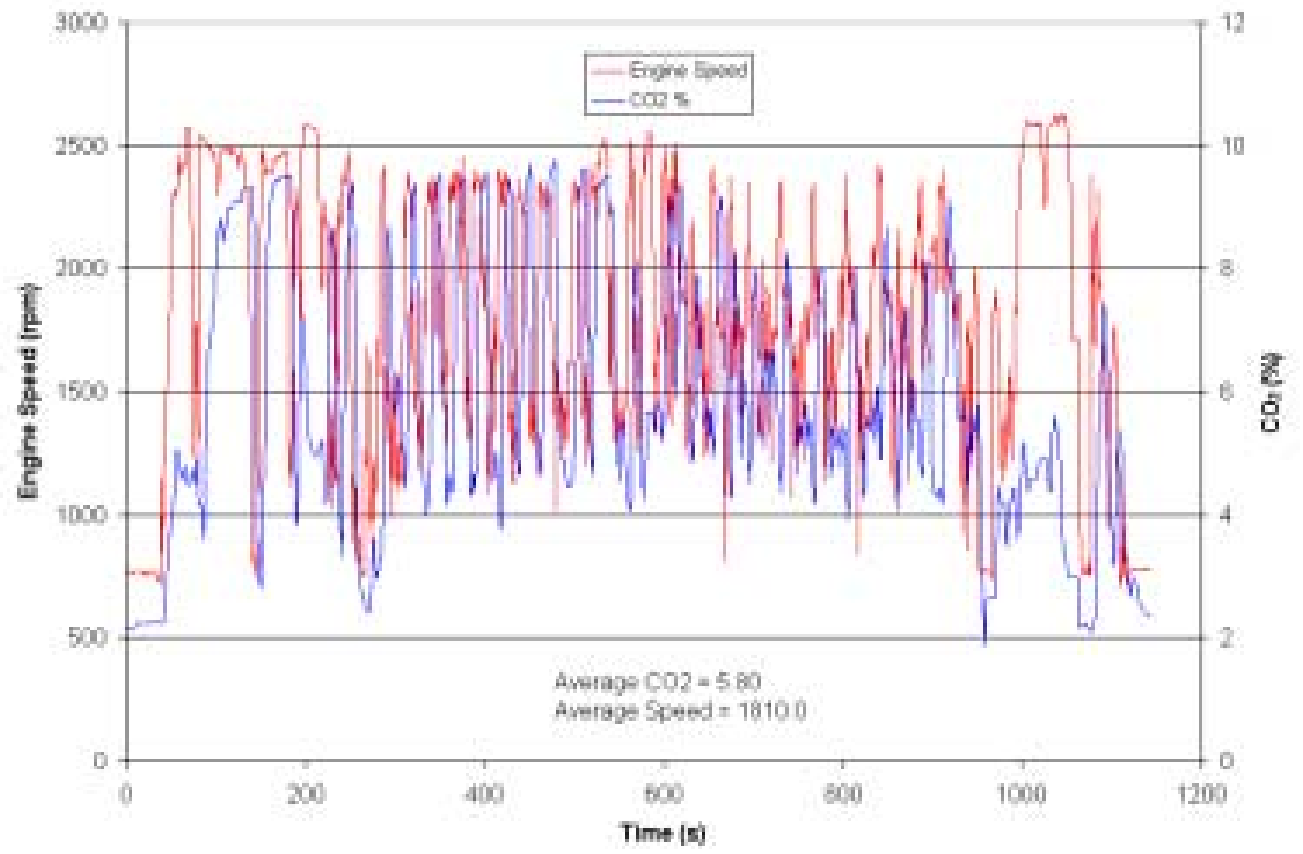

Figure $31 \mathrm{CO}_{2}$ and Engine Speed vs. Time for the Shortened Infield Loader Cycle. 


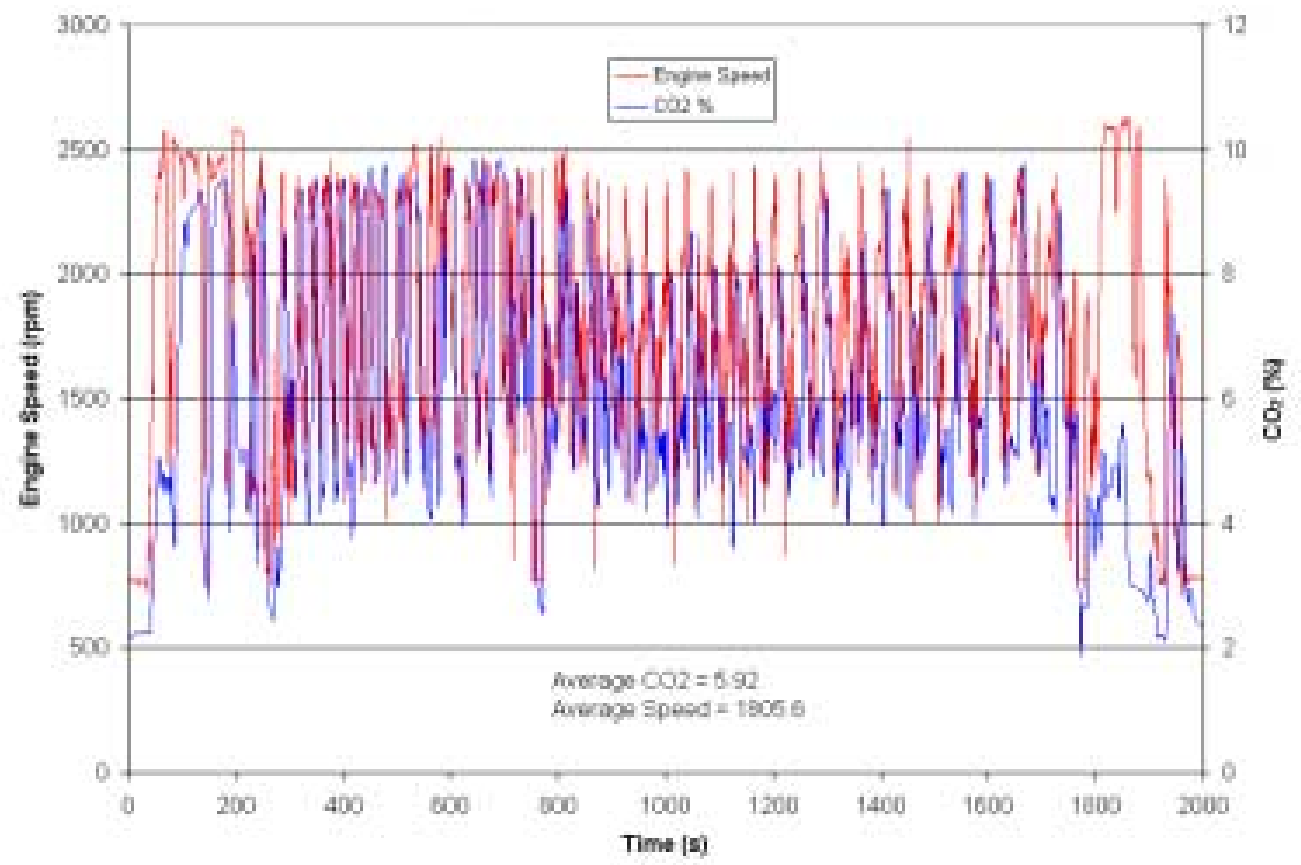

Figure $32 \mathrm{CO}_{2}$ and Engine Speed vs. Time for the Full Infield Loader Cycle.

A visual comparison was made between the normalized speed/load data of the shortened WVU loader test cycle (Figure 33) and the normalized speed/load data of a United States EPA wheel-loader transient testing cycle (Figure 34). It can be seen from comparison of the two figures that they are consistent in their repetitive nature and total test length, with the major difference being that the EPA cycle does not have a transport mode at the beginning and end of the cycle. Rubber-tired loaders can spend a significant amount of time moving from site to site, therefore it was decided that the cycle would be more representative of actual conditions encountered in the field if the transport mode data was included in the test cycle. 


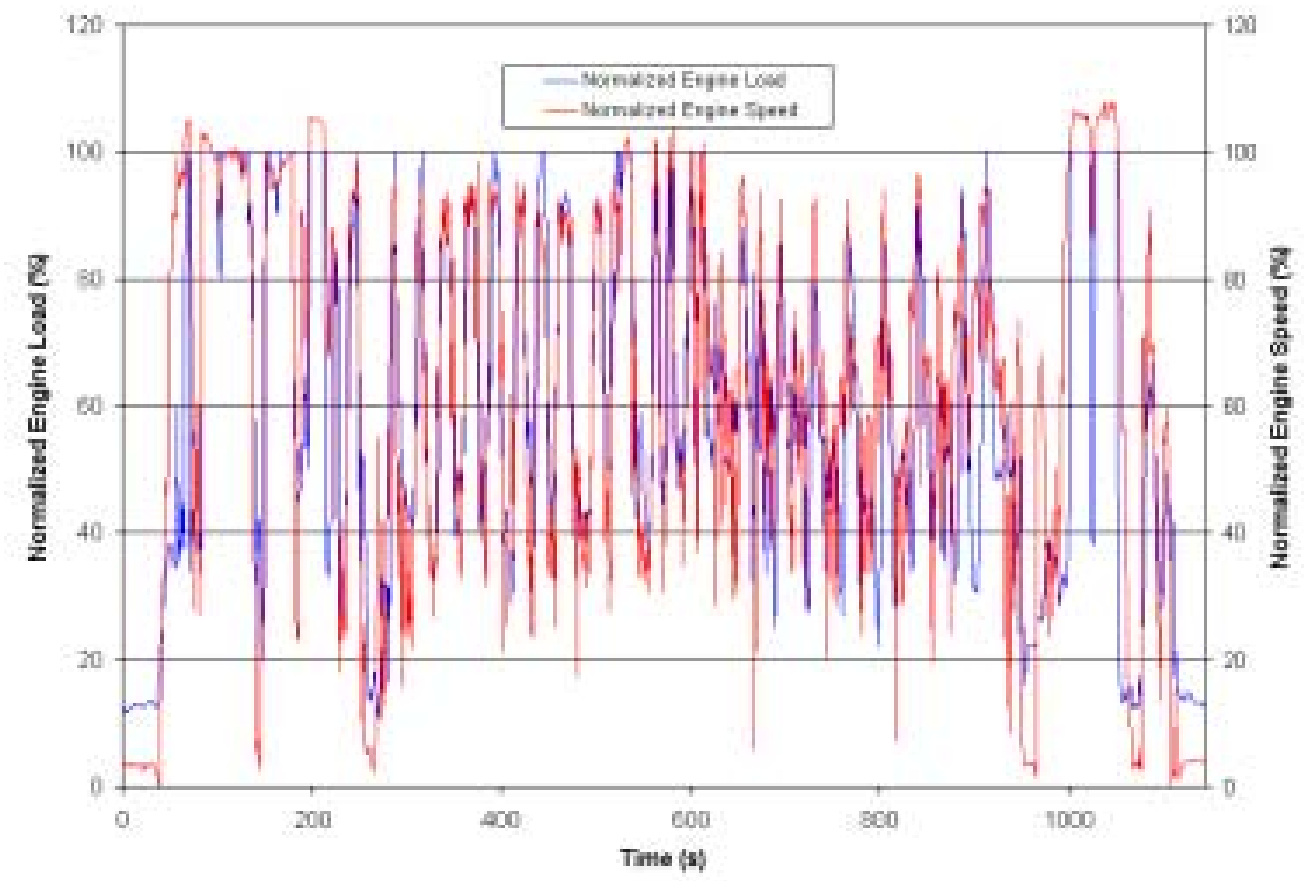

Figure 33 Normalized Engine Speed and Load for the Shortened WVU Infield Rubber-Tired Loader Cycle.

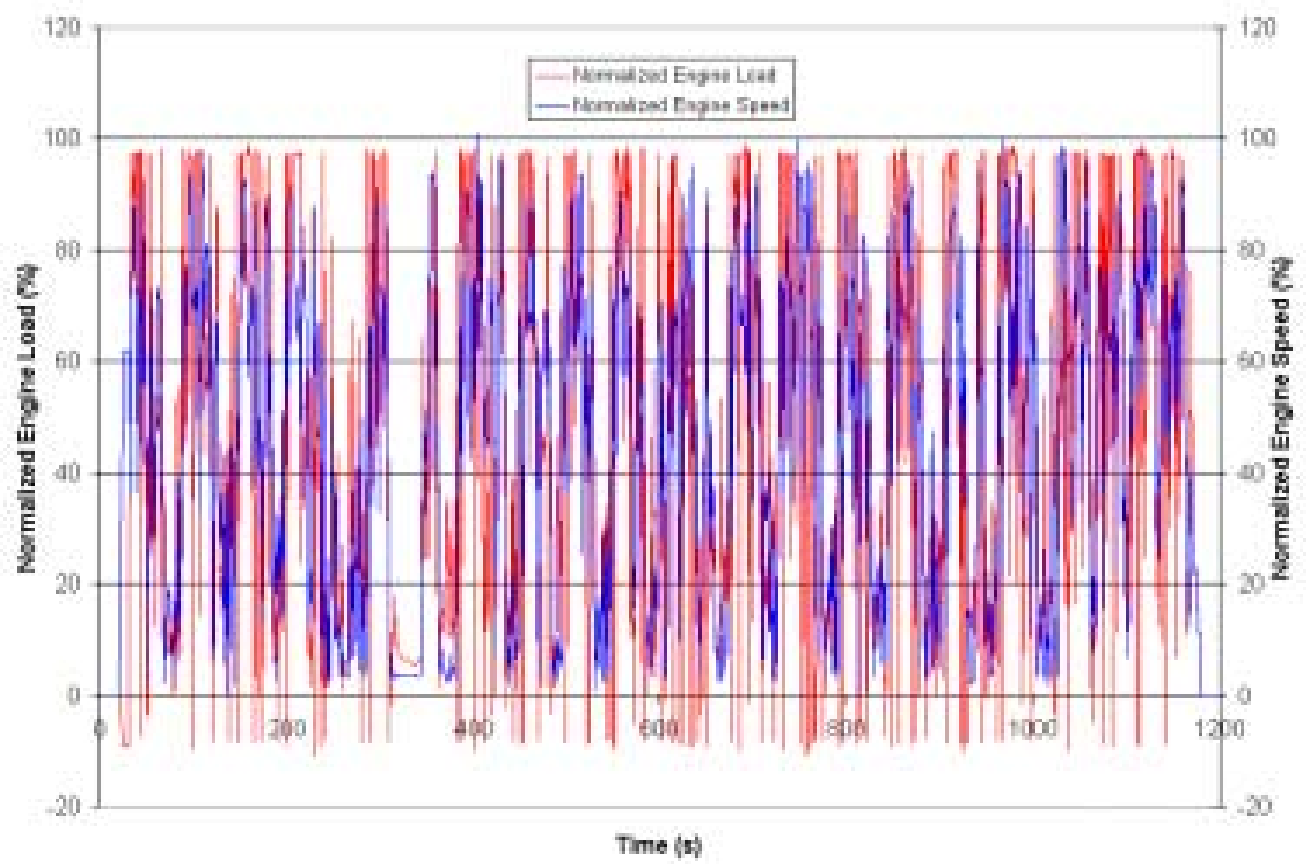

Figure 34 Normalized Engine Speed and Load for the EPA Rubber-Tired Loader Cycle. 
A much more in-depth assessment of the accuracy of the shortened cycle with respect to the full infield cycle was made by discretizing of the two cycles for small engine speed ranges and comparing normalized speed/load results. The integrated values obtained for the two cycles discussed previously are an indication of total cycle work only, and do not reflect the accuracy of recreation of transient events in the shortened cycle.

The full and shortened infield loader cycles were divided up in increments of 100rpm each from 700rpm to 2700rpm and average engine loads were estimated for each engine speed range using a normalized $\mathrm{CO}_{2}$-load inference which will be discussed thoroughly in the following sections. It was necessary to use small engine speed increments over the full range because the transient events of the loader cycle in the field indicated speed ranges from idle to full speed in rapid succession. The more steady-state operation of the streetsweeper cycle allowed the use of only three broader speed ranges for discretization purposes, as will be seen in section 4.4.2. The average engine loads were found by multiplying the average normalized $\mathrm{CO}_{2}$ values by the maximum torque found for each speed range during the creation of the loader $\mathrm{CO}_{2}$ map matrix discussed in section 4.5.1.2. This method is the most accurate indication of the differences in engine load during transient events between the shortened and full cycles. Average load values for both the full and shortened infield loader cycles as well as percent difference in average load can be seen in Table 7. 
Table 7 Comparison of Engine Speed Discretized Average Load Values between the Full and Shortened Infield Loader Cycles.

\begin{tabular}{|c|c|c|c|}
\hline $\begin{array}{c}\text { Engine Speed } \\
\text { (RPM) }\end{array}$ & $\begin{array}{c}\text { Shortened Cycle } \\
\text { Average Load } \\
\text { (ft-lbs) }\end{array}$ & $\begin{array}{c}\text { Full Cycle } \\
\text { Average Load } \\
\text { (ft-lbs) }\end{array}$ & \% Difference \\
\hline 750 & 36.1 & 41.2 & -12.47 \\
\hline 850 & 100.4 & 95.6 & 4.99 \\
\hline 950 & 73.8 & 59.5 & 24.10 \\
\hline 1050 & 128.1 & 113.8 & 12.57 \\
\hline 1150 & 109.4 & 98.8 & 10.71 \\
\hline 1250 & 106.4 & 98.6 & 7.96 \\
\hline 1350 & 115.8 & 114.3 & 1.26 \\
\hline 1450 & 123.4 & 119.4 & 3.36 \\
\hline 1550 & 116.4 & 119.5 & -2.58 \\
\hline 1650 & 124.0 & 119.8 & 3.49 \\
\hline 1750 & 114.6 & 119.2 & -3.85 \\
\hline 1850 & 125.7 & 127.1 & -1.03 \\
\hline 1950 & 114.5 & 122.5 & -6.50 \\
\hline 2050 & 117.3 & 116.1 & 1.00 \\
\hline 2150 & 95.3 & 100.3 & -5.04 \\
\hline 2250 & 100.3 & 104.7 & -4.17 \\
\hline 2350 & 103.1 & 106.0 & -2.73 \\
\hline 2450 & 140.5 & 134.6 & 4.37 \\
\hline 2550 & 94.4 & 89.0 & 6.10 \\
\hline 2650 & 1.4 & 1.4 & 0.00 \\
\hline
\end{tabular}

\subsubsection{Infield Streetsweeper Cycle Shortening}

For the infield streetsweeper cycle, the activity was divided into three main categories: transport, sweeping, and idle. The sweeping and transport activities were then subdivided by the nature of the terrain encountered. These subdivisions were identified based on whether the sweeping/transport activity was performed on level ground, uphill, or downhill, with approximate percent grades assigned to the respective activity. The three basic operational modes of the full infield sweeper cycle were examined for repetitiveness and excessive length and shortened accordingly. A total of 3760 seconds were removed from the lengthy infield cycle to arrive at the shortened cycle length of 1221 seconds. The $\mathrm{CO}_{2}$ and engine speed traces for the shortened infield sweeper cycle can be seen in Figure 35 with the average $\mathrm{CO}_{2}$ values of $4.14 \% \mathrm{vol}$ and 
1716rpm, respectively. The $\mathrm{CO}_{2} /$ speed traces for the full infield cycle can be seen in Figure 36 with an average $\mathrm{CO}_{2}$ value of $4.06 \% \mathrm{vol}$ and average engine speed of $1855.8 \mathrm{rpm}$

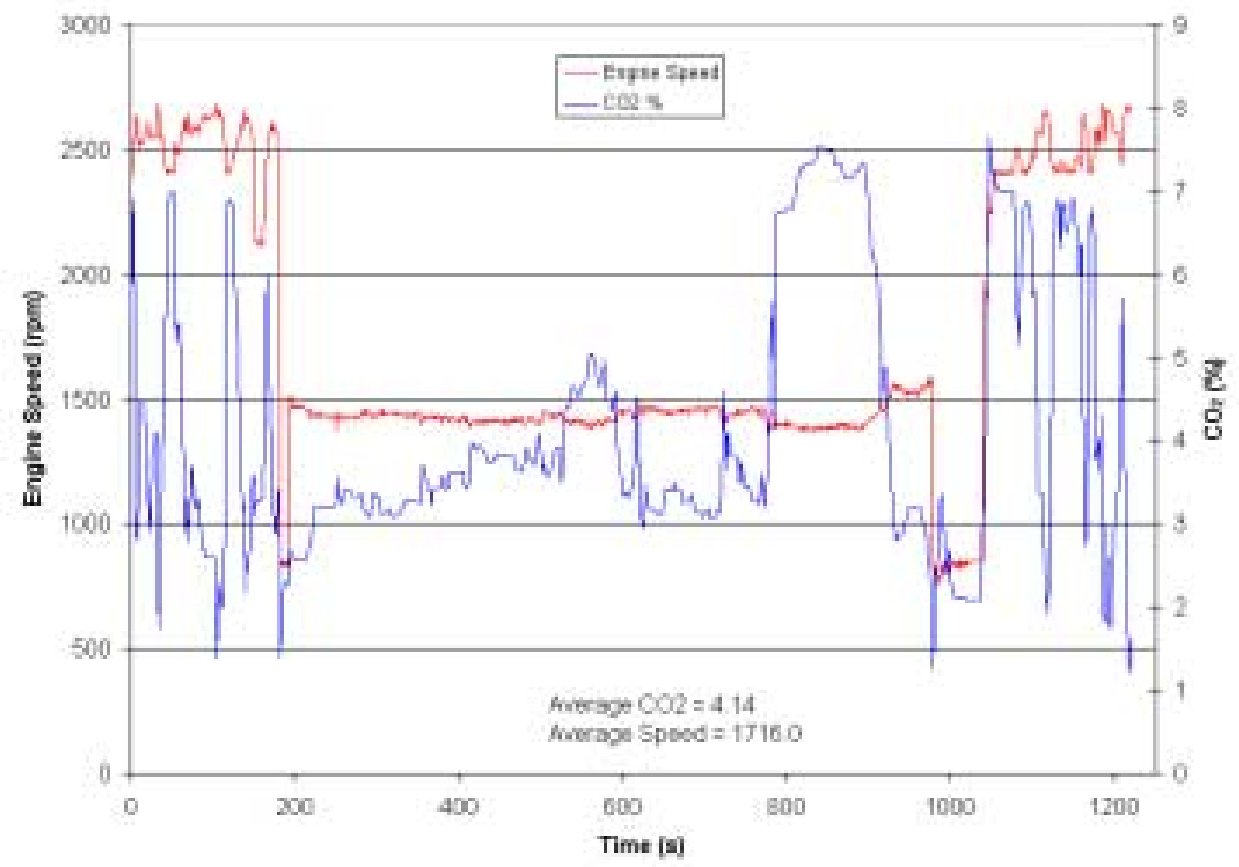

Figure $35 \mathrm{CO}_{2}$ and Engine Speed vs. Time for the Shortened Infield Streetsweeper Cycle. 


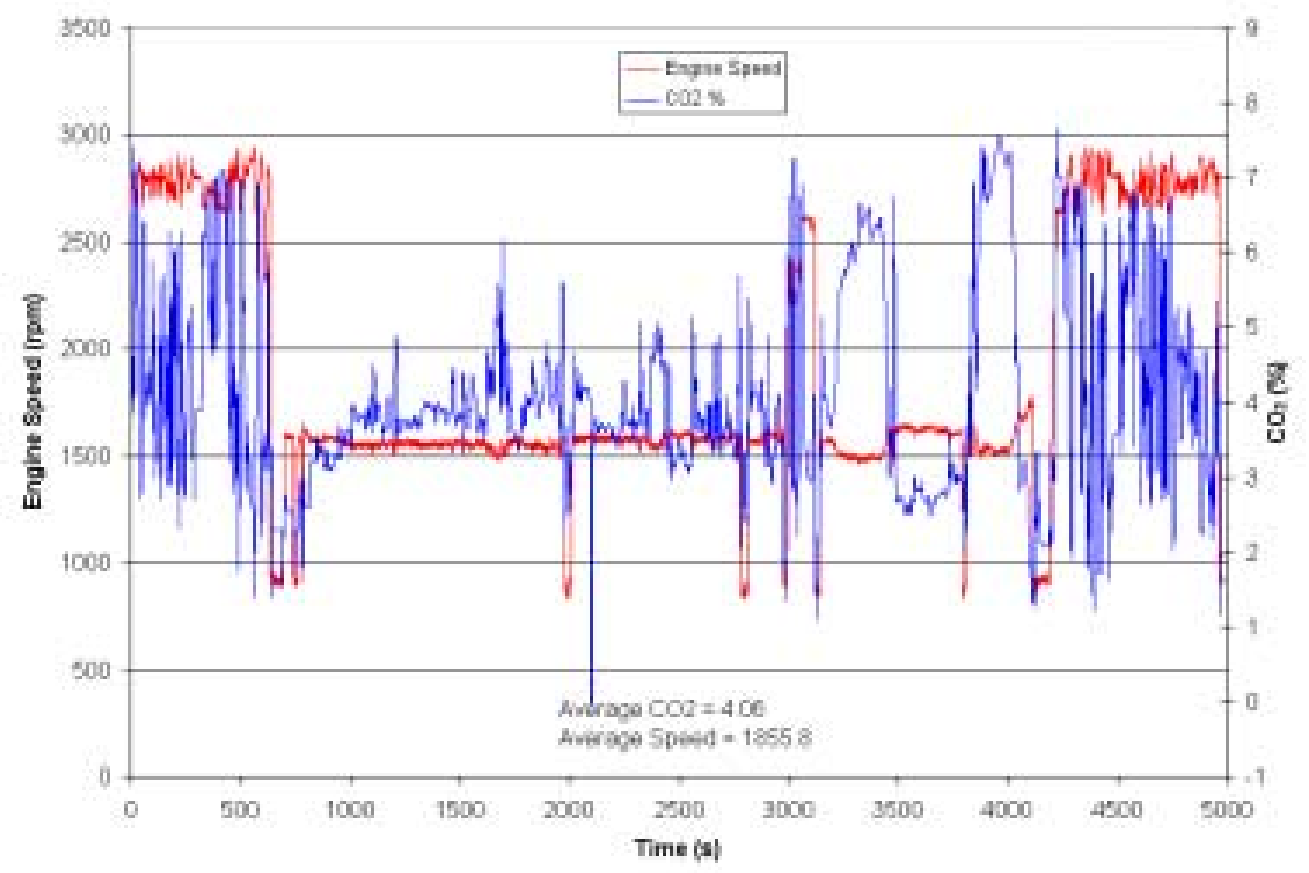

Figure $36 \mathrm{CO}_{2}$ and Engine Speed vs. Time for the Full Infield Streetsweeper Cycle.

The activities of the streetsweeper were closely related to discrete ranges of engine speeds, therefore the infield cycle was characterized according to the percent of total time allotted to each activity. The full and shortened infield streetsweeper cycles were divided into three engine speed ranges: 700rpm-1000rpm, 1200rpm-1600rpm, and 2300rpm-2700rpm. In contrast with the loader, the use of larger speed ranges for the sweeper was possible because it operated within these three ranges in the field. The idle mode (700-1000rpm), the sweeping mode (1200-1600rpm), and the transport mode (2300-2700rpm) were all covered by the selected ranges. The average engine loads were then found for each engine speed range. These average loads were found by multiplying the average normalized $\mathrm{CO}_{2}$ values by the maximum torque found for each speed range during the creation of the streetsweeper $\mathrm{CO}_{2}$ map matrix discussed in section 4.5.2.2. This method is the most accurate indication of the differences in engine load during 
transient events between the shortened and full cycles. A graphical representation of the normalized engine speed and load can be seen in Figure 37. No comparison was made between the shortened WVU cycle and other transient sweeper testing cycles because no equivalent cycles for streetsweepers were found in the literature searched. Average load values for both the full and shortened infield loader cycles as well as percent difference in average load can be seen in Table 8 .

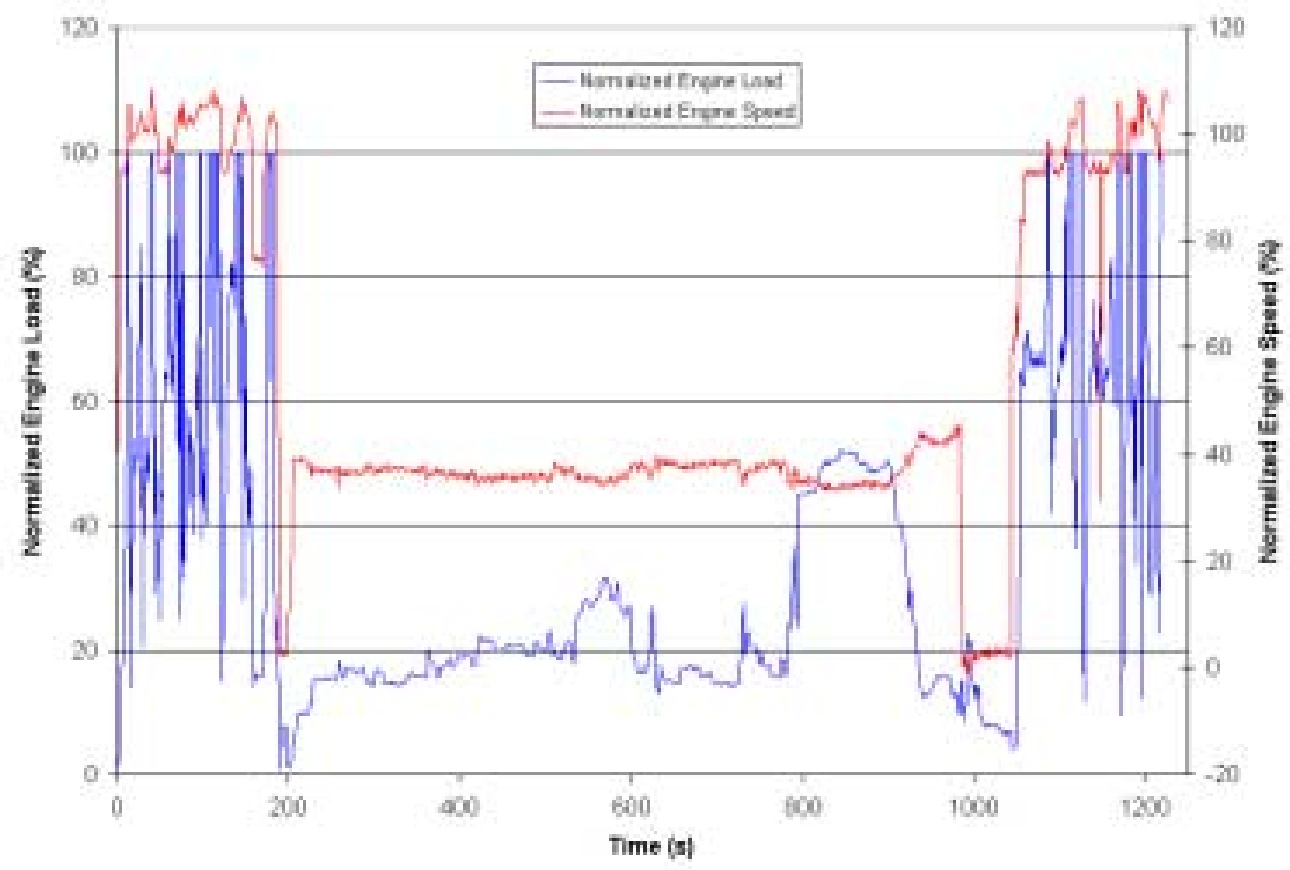

Figure 37 Normalized Engine Speed and Load for the Shortened Infield Streetsweeper Cycle.

Table 8 Comparison of Engine Speed Discretized Average Load Values between the Full and Shortened Infield Streetsweeper Cycles.

\begin{tabular}{|c|c|c|c|}
\hline $\begin{array}{c}\text { Engine Speed } \\
\text { (RPM) }\end{array}$ & $\begin{array}{c}\text { Shortened Cycle } \\
\text { Average Load } \\
\text { (ft-lbs) }\end{array}$ & $\begin{array}{c}\text { Full Cycle } \\
\text { Average Load } \\
\text { (ft-lbs) }\end{array}$ & \% Difference \\
\hline $700-1000$ & 143.9 & 89.2 & 61.34 \\
\hline $1200-1600$ & 145.9 & 134.0 & 8.88 \\
\hline $2300-2700$ & 75.3 & 81.3 & -7.47 \\
\hline
\end{tabular}


The large percent difference for the 700-1000rpm range can most likely be attributed to the operation being performed by the streetsweeper. The vehicle could have been idling in the field, it could have had the brushes up and rotating, or it could have had the brushes rotating and contacting the road surface. It should also be noted that the amount of friction-related load the brushes place on the engine will change depending on the nature of the surface being swept.

\subsection{Cycle Development Work}

The data taken in the field was used to develop a representative cycle for each vehicle that would ultimately be used to load the engine during full-flow transient emissions testing at the EERL. The lengths of the infield tests for both vehicles were too long to recreate in their entirety, so the infield data was examined and representative portions of each infield cycle were compiled to produce a single shorter test cycle.

The task of creating a shorter dynamometer test cycle that truly represented the infield cycle was a difficult and time-consuming one. The infield operating cycles for each engine are very specific to the vehicle used and the operating site and, therefore, a blind adherence to a cycle measured in the field provides only limited information regarding that vehicle operating during the specific conditions that were present during data logging. To overcome this obstacle, the infield cycle was characterized according to "micro trips" and specific activities. This process allows the researcher to be able to apply such activity data to a broader range of engines/vehicles. The infield raw $\mathrm{CO}_{2}$ emissions data traces were used to infer the speed/load traces followed by the engine while on the dynamometer. The full cycle for each vehicle, as measured in the field, was characterized and specific "micro trips" were identified. Once the infield cycle is 
characterized based on speed/load ranges, the micro-trips can be combined in order to produce alternative transient cycles that more accurately represent the actual duty cycle corresponding to a particular off-highway vehicle. A detailed explanation of the infield cycle shortening process can be found in the Infield Cycle Shortening Sections 4.4.1 for the rubber-tired loader and 4.4.2 for the streetsweeper.

The method for deriving the load points for each iteration of the test cycle consisted of exercising the engine in the laboratory on a dynamometer test bed according to the initial speed/load setpoints that were linearly interpolated. During the test, the infield data measurement system was used to compare the continuous $\mathrm{CO}_{2}$ laboratory data to the data collected in the field. The torque levels placed on the engine were then adjusted in an attempt to make the infield and in-laboratory $\mathrm{CO}_{2}$ data correlate more closely. The test was then repeated with the updated adjusted cycle and emissions data was again compared. This iterative process was continued until the laboratory cycle data and the infield cycle data met correlation criteria described in this chapter. A flowchart of the steps involved for cycle iteration can be viewed in Figure 38. 


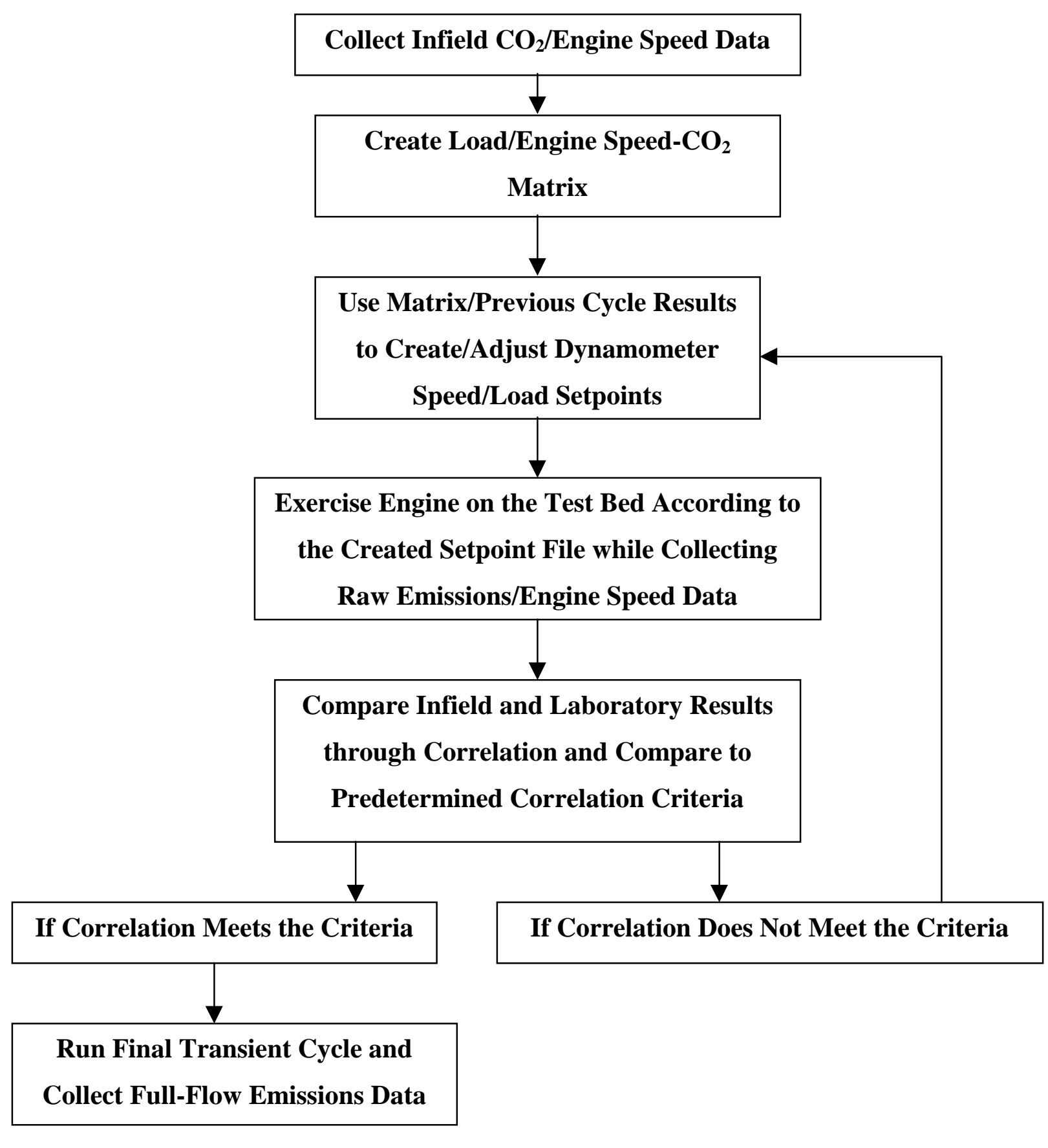

Figure 38 Flowchart of Steps Involved in the Cycle Iteration Process.

In order to provide a starting point for the development of the cycle, a torque step map was performed on each engine while raw $\mathrm{CO}_{2}$ emissions were collected with the AMB-II. During the map, the engine was loaded in increments of 50\% of maximum 
engine torque from $0 \%$ to $100 \%$ while $\mathrm{CO}_{2}$ emissions data were collected. This map was then repeated at different engine speeds from idle to maximum speed in increments of $100 \mathrm{rpm}$. A table of the values for each engine in matrix form can be seen in the " $\mathrm{CO}_{2}$ Map Matrix" portions of this chapter. The data was then examined to determine how engine torque levels and $\mathrm{CO}_{2}$ levels compared at the various engine speeds. A Visual Basic program was written by Dr. Greg Thompson that linearly interpolated engine load by comparing infield engine speed and $\mathrm{CO}_{2}$ versus time traces with a raw $\mathrm{CO}_{2}$ versus engine speed matrix. The engine load versus $\mathrm{CO}_{2}$ matrix was developed by exercising the engine through several steady-state (30s) speed/load setpoints. The engine was loaded according to the torque estimates generated by the program to produce the first iteration of the transient cycle for each vehicle.

A significant amount of time was needed for the proper setup of the Dyn-Loc IV Dynamometer Controller and the DTC-1 Digital Throttle Controller. There are several hard-coded Proportional Integral Derivative (PID) parameter settings on both systems that govern the ability of the engine to accurately follow the desired cycle. The PID settings must be set up based on the nature of the transient events encountered in the cycle and on the rotational inertia of the system. Aspects such as signal overshoot and throttle opening speed must be optimized with the settings.

The Proportional (P) parameter tells the Dyn-Loc how far the actual engine speed/torque values are from the desired values, the Integral (I) parameter allows the Dyn-Loc to close in on the desired values, and the Derivative (D) parameter dictates the speed at which the controller can close in on the desired value. Separate settings could be entered in for each of the three parameters of the PID and it was found during the setup 
process that the Derivative parameter was the most sensitive parameter to set up. If the Derivative was set too high (quick closing on the desired value) signal overshoot was the result. If it were set too low, the engine would not be able to quickly follow any sharp transient events in the cycle. There are separate PID parameters for the dynamometer controller and the throttle controller, so care must be taken during the setup process to ensure harmonious operation. Several cycle iterations were run consecutively in the laboratory for both engines in order to optimize the PID settings of both controllers for each test cycle. This setup was further complicated due to the independent PID controls for both units. If one global PID was used it is anticipated that the transient control would have been greatly improved.

\subsubsection{Rubber-Tired Loader Cycle Development}

The fact that the John Deere 6059 loader engine was tested first made the recreation of its infield cycle more time consuming. While inexperience in the whole cycle recreation process was largely to blame, many "bugs" had to be eliminated from the dynamometer setup, such as the PID settings discussed previously. However, it could be expected from the examination of the infield loader data that its cycle would be the more difficult to recreate in the laboratory than the streetsweeper cycle because of its sharply transient nature. This point is illustrated by the fact that correlation results between infield and in-laboratory data for the streetsweeper were much better than those for the rubber-tired loader.

\subsubsection{Engine Map}

An engine mapping procedure, outlined in the CFR 40 Part 86 Subpart N [1], was performed on the John Deere 6059 engine to determine at what engine speeds the 
horsepower peak (rated speed) and torque peak (intermediate speed) occur, and what values they had. Quantifying these two points is necessary to determine the set points to be run during the steady-state 8 -mode cycle and to allow the compilation of the $\mathrm{CO}_{2}$ map matrix used for development of the transient cycle. The results were corrected with the eddy current dynamometer windage loss information supplied by Mustang Dynamometers, Inc. It was found that the horsepower peak of the John Deere 6059 engine was approximately $110.5 \mathrm{hp}$ at $2375 \mathrm{rpm}$. The torque peak occurred at $1010 \mathrm{rpm}$ and was about $280.5 \mathrm{ft}-\mathrm{lbs}$. The engine lug curve for the John Deere 6059 can be seen in Figure 39.

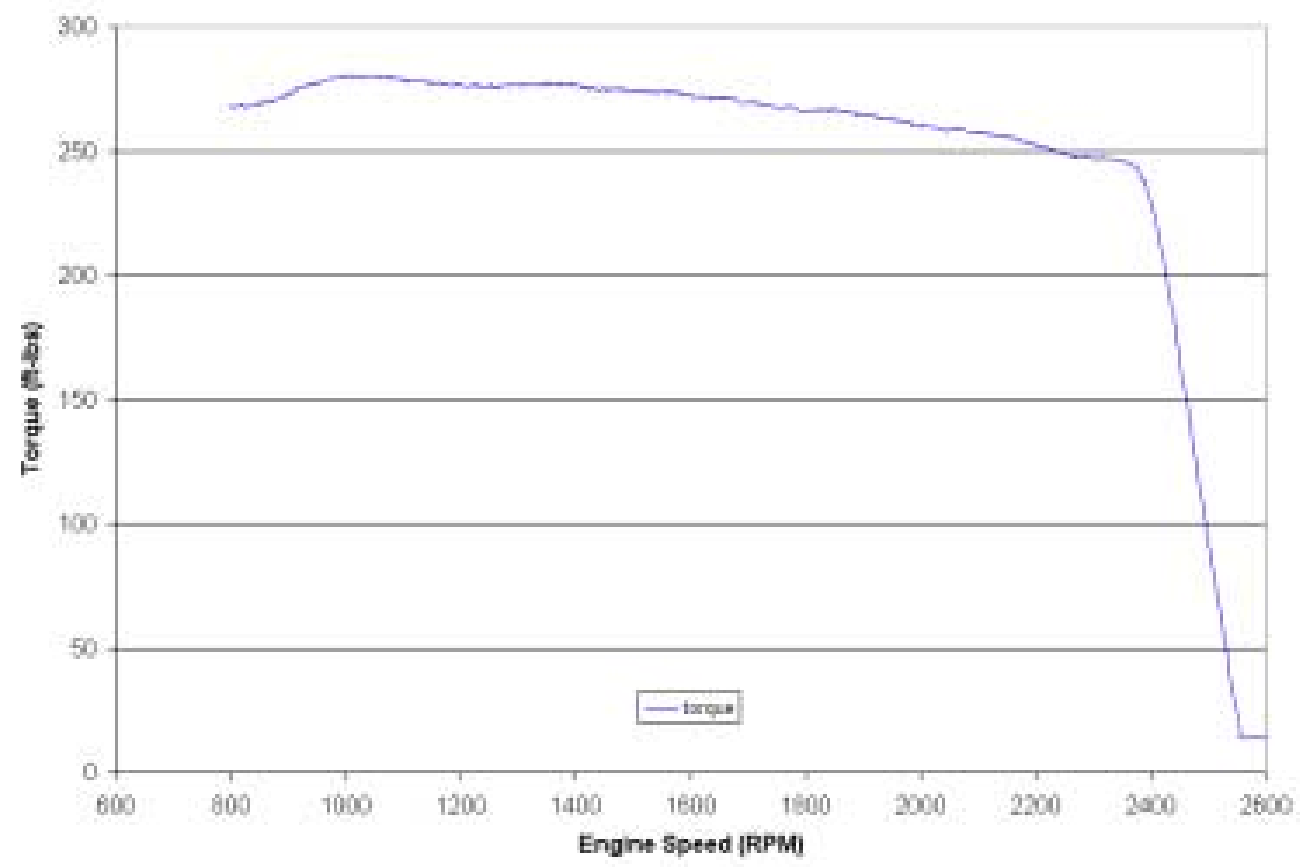

Figure 39 Engine Map for the John Deere 6059 Loader Engine.

\subsubsection{2 $\mathrm{CO}_{2}$ Map Matrix}

The engine was operated according to a series of speed-load setpoints and $\mathrm{CO}_{2}$ levels were recorded with the infield data collection system. The $\mathrm{CO}_{2}$ levels were 
recorded in the laboratory for the loader engine at speeds from 700rpm to 2700rpm in increments of 100rpm. Engine loadings used ranged from $0 \%$ to $100 \%$ load in increments of $10 \%$ load during the recording of $\mathrm{CO}_{2}$ emissions. The system was allowed to stabilize for 30s at each speed/load point to ensure that the $\mathrm{CO}_{2}$ data had time to reach a value of at least $90 \%$ of the fully stabilized steady-state value. The system was not allowed to stabilize for more than 30 s to prevent skewing of the often-quick transient events encountered during cycle testing. The full load value was determined from the engine map discussed in section 4.4.1.1 and was approximately 110.5hp. The data collected was used to develop the first iteration of the loader transient cycle via the computer matrix interpolation program mentioned previously. Raw exhaust $\mathrm{CO}_{2}$ data from the infield testing was used by the program to develop a torque estimate by interpolating the data collected in the laboratory and is shown in Table 9 below. The raw exhaust $\mathrm{CO}_{2}$ data taken during the first iteration of the cycle was compared to the infield data and a correlation of the data was performed. A manual process was then used to adjust the speed and load set points of the previous transient cycle iteration to make it match the infield data more closely. A graphical representation of continuous $\mathrm{CO}_{2}$ /engine speed traces for the first and final iterations of the recreated in-laboratory cycle for the loader can be seen in Figure 42 and Figure 43 along with graphical correlation data. 
Table 9 Matrix for the John Deere 6059 Loader Engine.

\begin{tabular}{|c|c|c|c||}
\hline Engine Speed & $\begin{array}{c}\mathbf{C O}_{\mathbf{2}} \text { (\% vol) @ 0\% } \\
\text { Engine Load }\end{array}$ & $\begin{array}{c}\mathbf{C O}_{\mathbf{2}} \text { (\% vol) @ 50\% } \\
\text { Engine Load }\end{array}$ & $\begin{array}{c}\mathbf{C O}_{\mathbf{2}} \text { (\% vol) @ 100\% } \\
\text { Engine Load }\end{array}$ \\
\hline $\mathbf{7 0 0}$ & 1.29 & 6.06 & 11.77 \\
\hline $\mathbf{8 0 0}$ & 1.31 & 5.82 & 12.24 \\
\hline $\mathbf{9 0 0}$ & 1.34 & 5.85 & 12.29 \\
\hline $\mathbf{1 0 0 0}$ & 1.35 & 5.95 & 12.43 \\
\hline $\mathbf{1 1 0 0}$ & 1.39 & 5.94 & 12.21 \\
\hline $\mathbf{1 2 0 0}$ & 1.43 & 5.84 & 12.19 \\
\hline $\mathbf{1 3 0 0}$ & 1.46 & 5.83 & 12.08 \\
\hline $\mathbf{1 4 0 0}$ & 1.51 & 5.77 & 11.86 \\
\hline $\mathbf{1 5 0 0}$ & 1.55 & 5.77 & 11.99 \\
\hline $\mathbf{1 6 0 0}$ & 1.60 & 5.77 & 11.84 \\
\hline $\mathbf{1 7 0 0}$ & 1.66 & 5.80 & 11.75 \\
\hline $\mathbf{1 8 0 0}$ & 1.72 & 5.82 & 11.63 \\
\hline $\mathbf{1 9 0 0}$ & 1.81 & 5.84 & 11.61 \\
\hline $\mathbf{2 0 0 0}$ & 1.88 & 5.85 & 11.49 \\
\hline $\mathbf{2 1 0 0}$ & 1.97 & 5.94 & 11.28 \\
\hline $\mathbf{2 2 0 0}$ & 2.10 & 5.87 & 11.21 \\
\hline $\mathbf{2 3 0 0}$ & 2.23 & 5.86 & 11.02 \\
\hline $\mathbf{2 4 0 0}$ & 2.28 & 5.60 & 10.15 \\
\hline $\mathbf{2 5 0 0}$ & 2.35 & 3.36 & 4.65 \\
\hline $\mathbf{2 6 0 0}$ & 2.50 & 3.52 & 3.81 \\
\hline $\mathbf{2 7 0 0}$ & 2.50 & 3.52 & 3.81 \\
\hline
\end{tabular}

\subsubsection{Loader Cycle Iteration}

As stated previously, a number of cycle iterations were needed for the rubbertired loader engine before the $\mathrm{CO}_{2}$ and engine speed data sufficiently matched the infield data. The repetitive nature of the loader cycle allowed a much shorter cycle to be run (about 600 seconds) for many of the iterations in order to save time and equipment wear. The first step performed after running each iteration of the cycle was to time-align the laboratory data with the infield data. This was done by examining a portion of the graphical continuous engine speed data from the laboratory and overlaying it on the infield data and adjusting the time of the laboratory data until the two engine speed traces aligned as closely as possible. The continuous $\mathrm{CO}_{2}$ data was used for time alignment 
purposes. To minimize differences in analyzer time lag between laboratory and field tests the same sampling system and sampling line were used for all testing in an attempt to keep sample transfer time and overall system lag time nearly constant. The same time difference, if any, determined by comparing the graphical engine speed data was applied to the $\mathrm{CO}_{2}$ data as well. An example of the time alignment difference for the initial portion of the first iteration of the loader cycle can be seen from the continuous engine speed data in Figure 40. The same data after time alignment can be seen in Figure 41. It should be noted that the time difference for the data of the first loader iteration was found to be about four seconds.

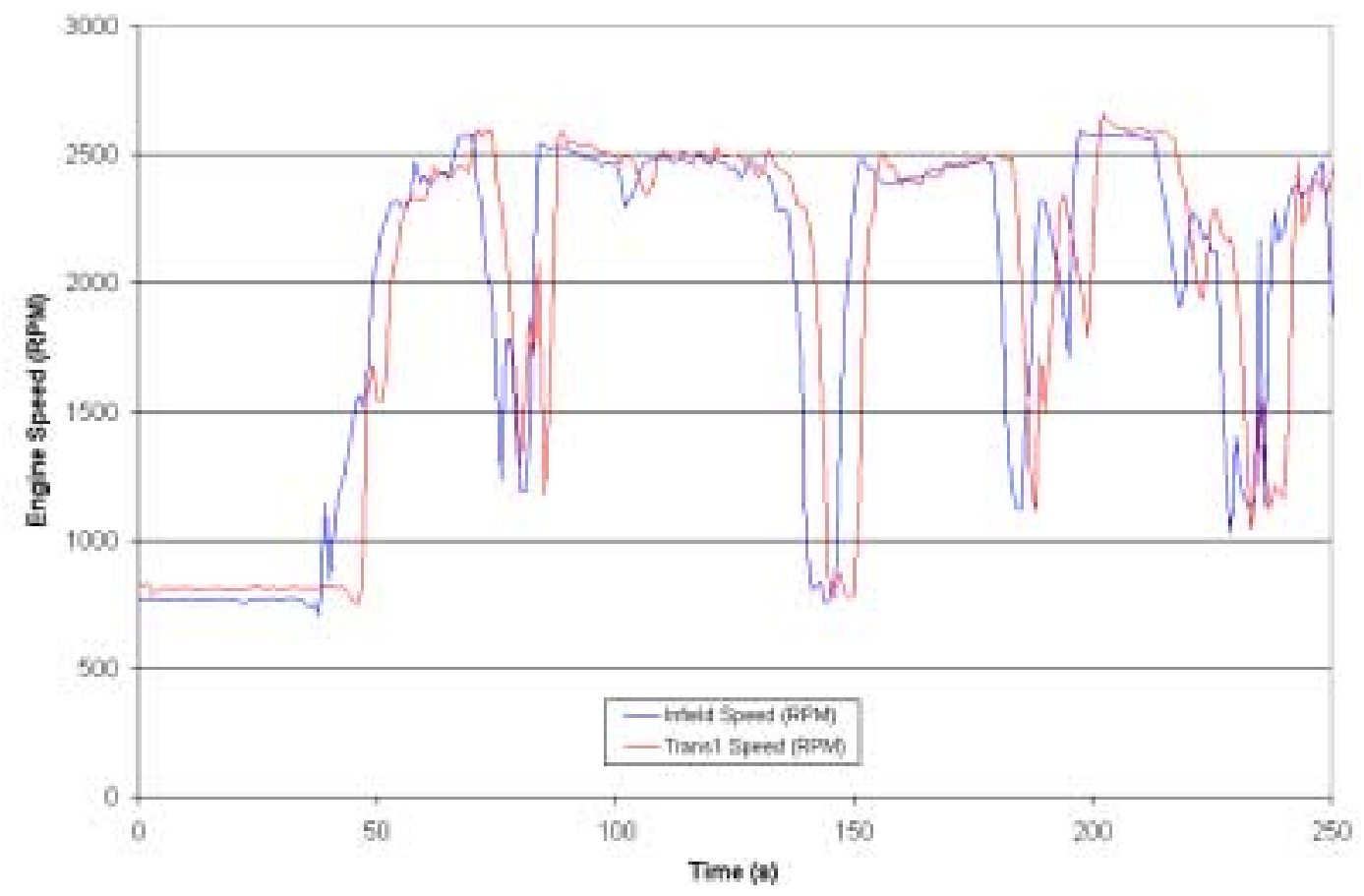

Figure 40 Comparison of Engine Speed Traces for the John Deere 6059 Loader Engine prior to Time Alignment (First Iteration). 


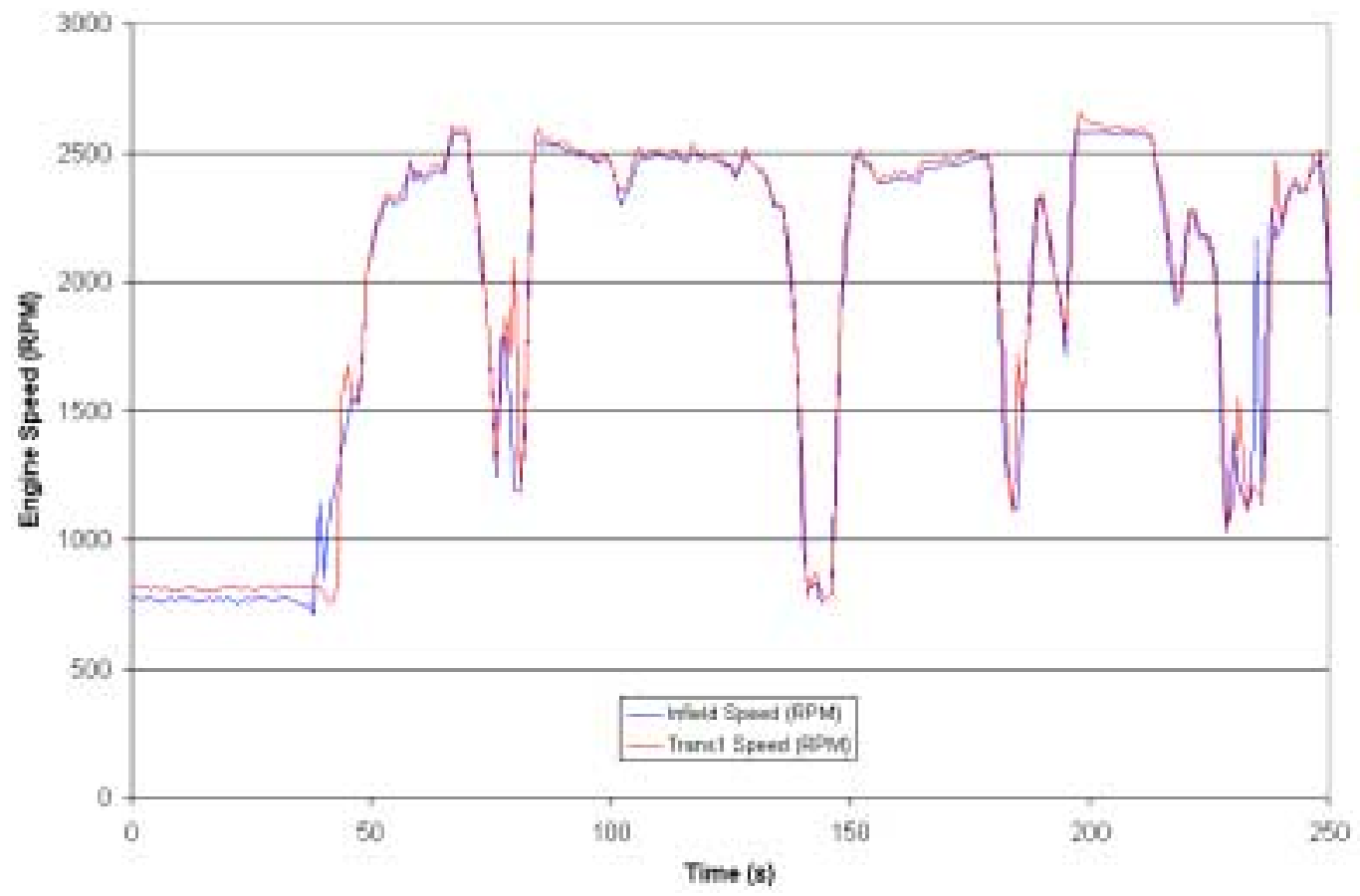

Figure 41 Comparison of Engine Speed Traces for the John Deere 6059 Loader Engine after Shifting Laboratory Data by 4 Seconds for Time Alignment (First Iteration).

After the required time shift was determined from the engine speed traces, it was applied to the $\mathrm{CO}_{2}$ data as well. The aligned infield and in-laboratory $\mathrm{CO}_{2}$ traces for the initial portion of the first iteration of the loader cycle can be seen in Figure 42. 


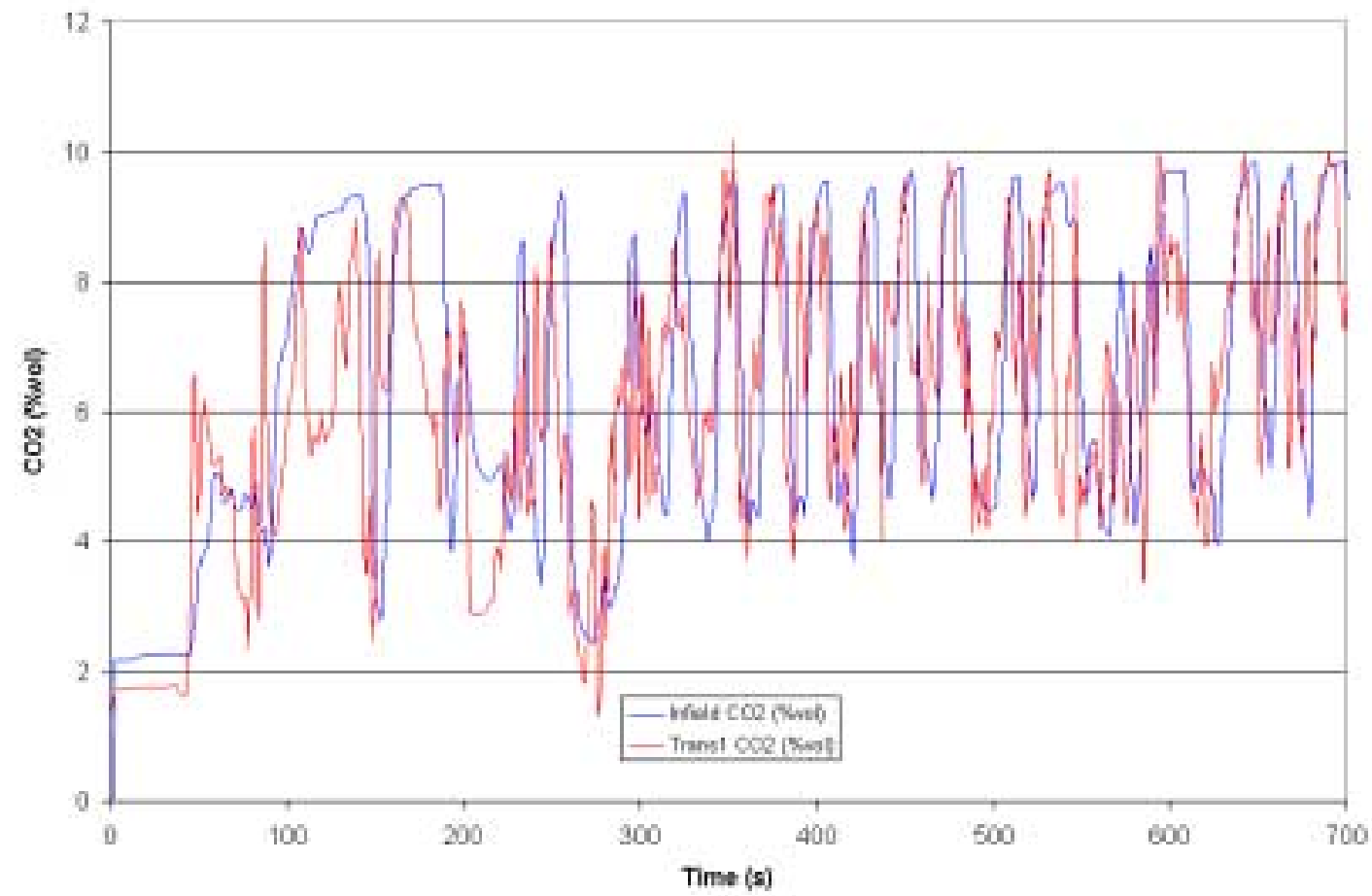

Figure 42 Comparison of $\mathrm{CO}_{2}$ Traces for the first 700s of the John Deere 6059 Loader Engine Cycle After Time Alignment (First Iteration).

It can be seen from Figure 42 that a considerable amount of setpoint refinement was necessary to make the laboratory $\mathrm{CO}_{2}$ data match the infield data. Through iteration, a manual inspection of the graphical data with appropriate adjustment to the load points of the rubber-tired loader setpoint file produced the final iteration $\mathrm{CO}_{2}$ trace seen in Figure 43. 


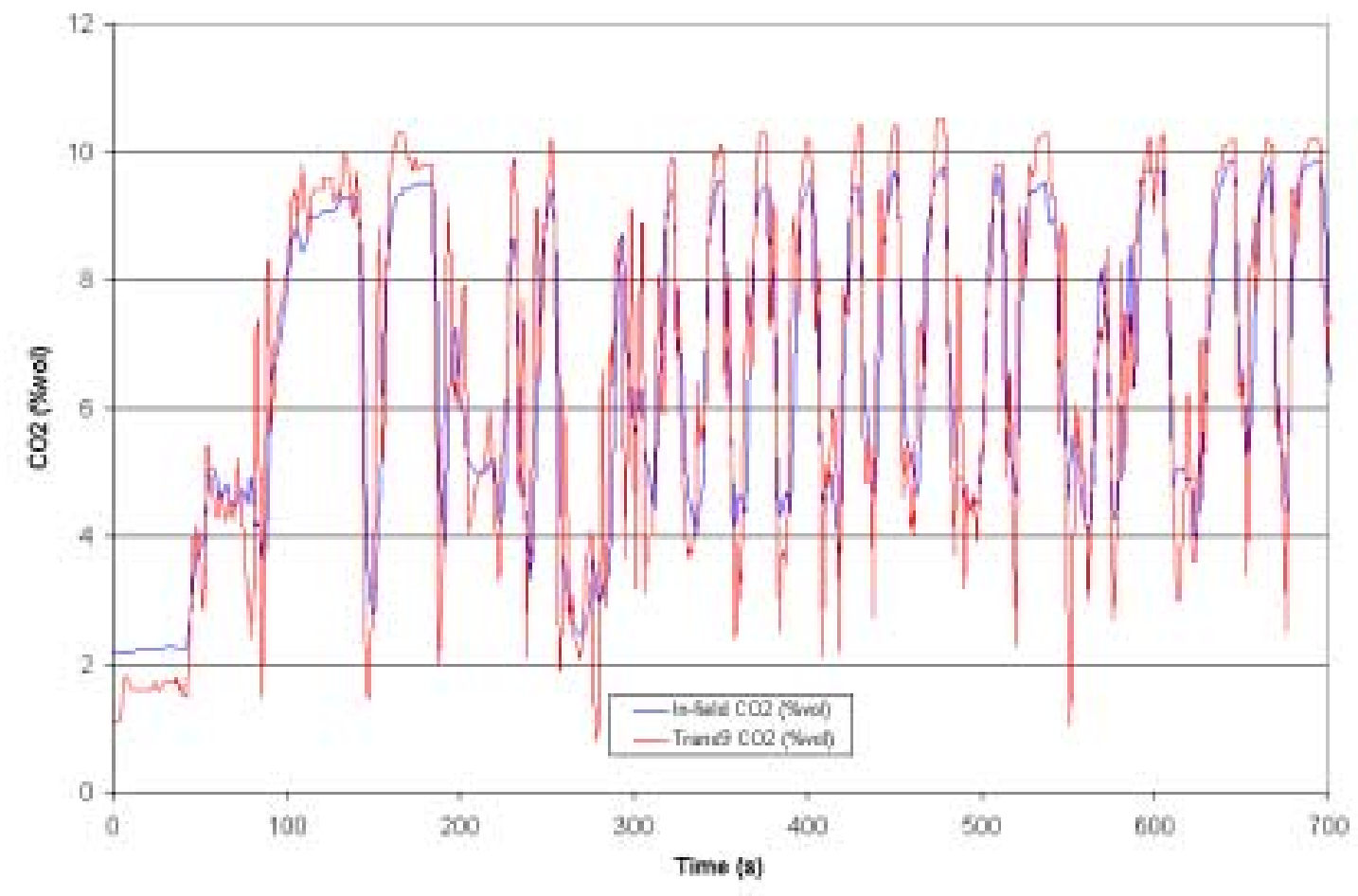

Figure 43 Comparison of $\mathrm{CO}_{2}$ Traces for the first 700s of the John Deere 6059 Loader Engine Cycle After Time Alignment (Final Iteration).

A number of repeat tests were run using the setpoints from the final iteration of the loader cycle for QC/QA purposes. A correlation was performed between two of the repeat tests to determine the best-expected correlation. While a perfect correlation would yield an $\mathrm{R}^{2}$ value of 1 and a trendline equation with slope $=1$ and a y-intercept of zero, many small factors present during testing prevent a perfect correlation from ever being obtained. The correlation results for repeat runs 1 and 2 using the setpoint file from the final iteration of the loader cycle can be seen in Figure 44 for the $\mathrm{CO}_{2}$ data, while the engine speed data can be seen in Figure 45. 


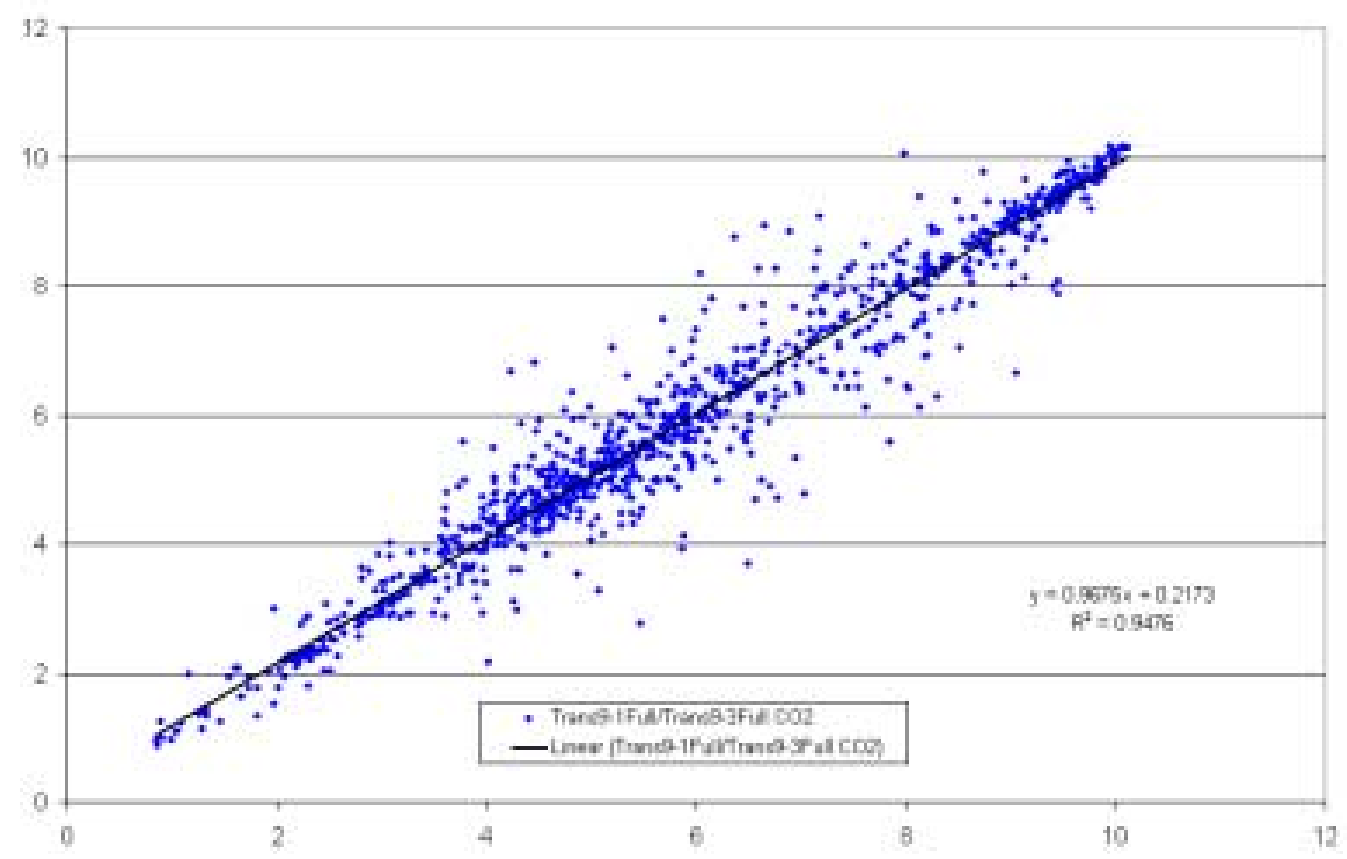

Figure $44 \mathrm{CO}_{2}$ Correlation Results for Two Repeat Runs of the Final Loader Cycle.

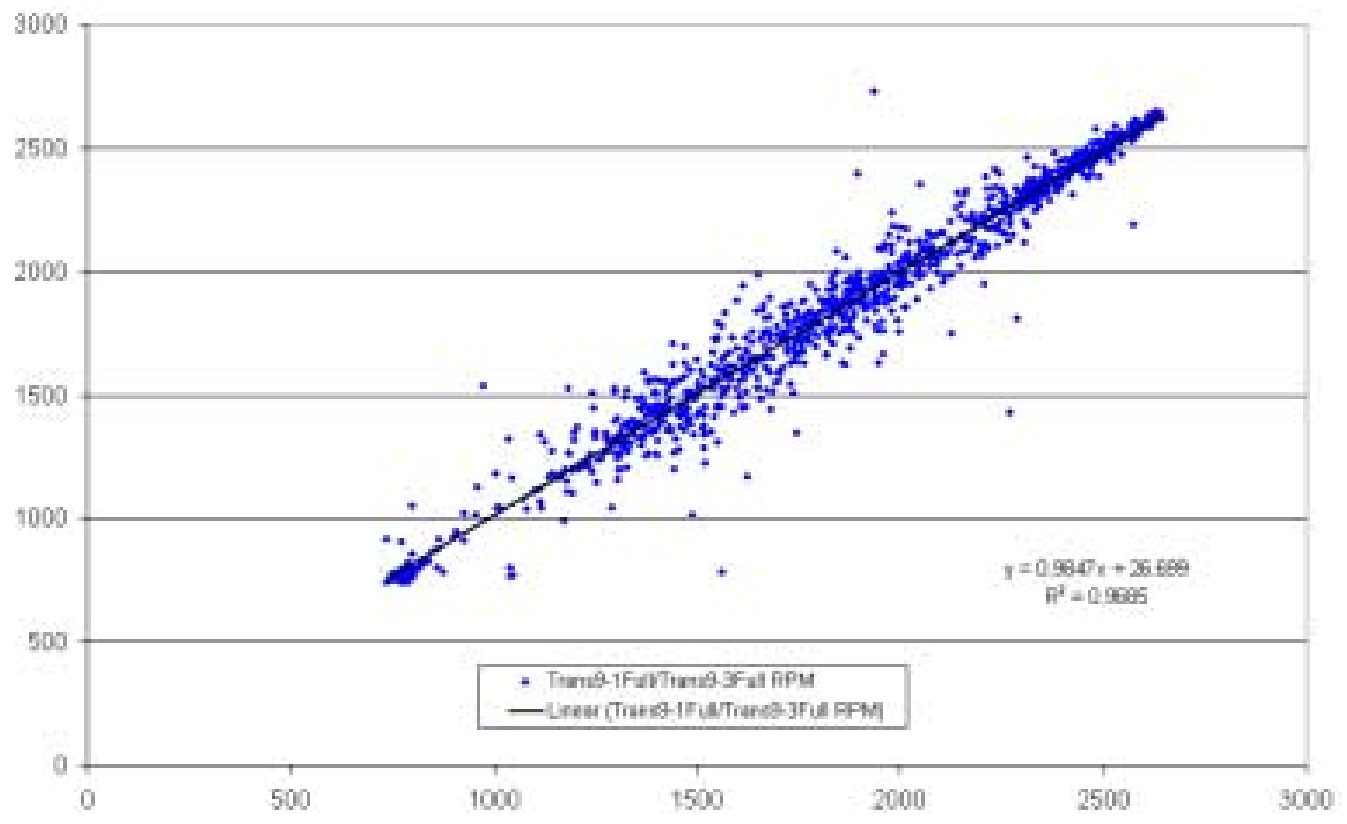

Figure 45 Engine Speed Correlation Results for Two Repeat Runs of the Final Loader Cycle. 
It can be seen from the preceding two charts the best correlation of the results that can be expected between any two tests. For the $\mathrm{CO}_{2}$ data, an $\mathrm{R}^{2}$ value of about 0.9476 with a trendline slope of 0.9675 and y-intercept of 0.2173 was the test-to-test correlation established for the loader engine dynamometer system. The engine speed data correlated with an $\mathrm{R}^{2}$ value of approximately 0.9695 with a trendline slope of 0.9647 and y-intercept of 26.7. While these numbers could slightly vary for any two runs of the same test, other test comparisons support the above correlation criteria. These criteria served as the target criteria for the infield to derived cycle comparisons. Obviously with inherent differences between the response characteristics of the engine-in-vehicle and engine-dynamometer these criteria were likely not to be satisfied. However, iteration was conducted until asymptotic values were achieved. Moreover, exhaust emissions results between the first and final iterations are presented in Section 4.6 in order to illustrate the effect of cycle refinement on cycle-integrated emissions.

A graphical correlation illustrates the large discrepancy between the desired infield $\mathrm{CO}_{2}$ trace and the in-laboratory trace collected during the running of the complete first cycle iteration. A perfect correlation, considering the test-to-test $\mathrm{CO}_{2}$ variability discussed in the preceding paragraph, would yield an $R^{2}$ value of about 0.9476 and a trendline with a slope of 0.9675 and a y-intercept of around 0.2173 , which is far from the first iteration regression values of $\mathrm{R}^{2}=0.497$ with trendline slope of 0.697 and $\mathrm{y}-$ intercept of 1.966. Clearly much more work is needed on the cycle load setpoints of the first cycle iteration. The $\mathrm{CO}_{2}$ correlation for the first iteration can be seen in Figure 46 . 


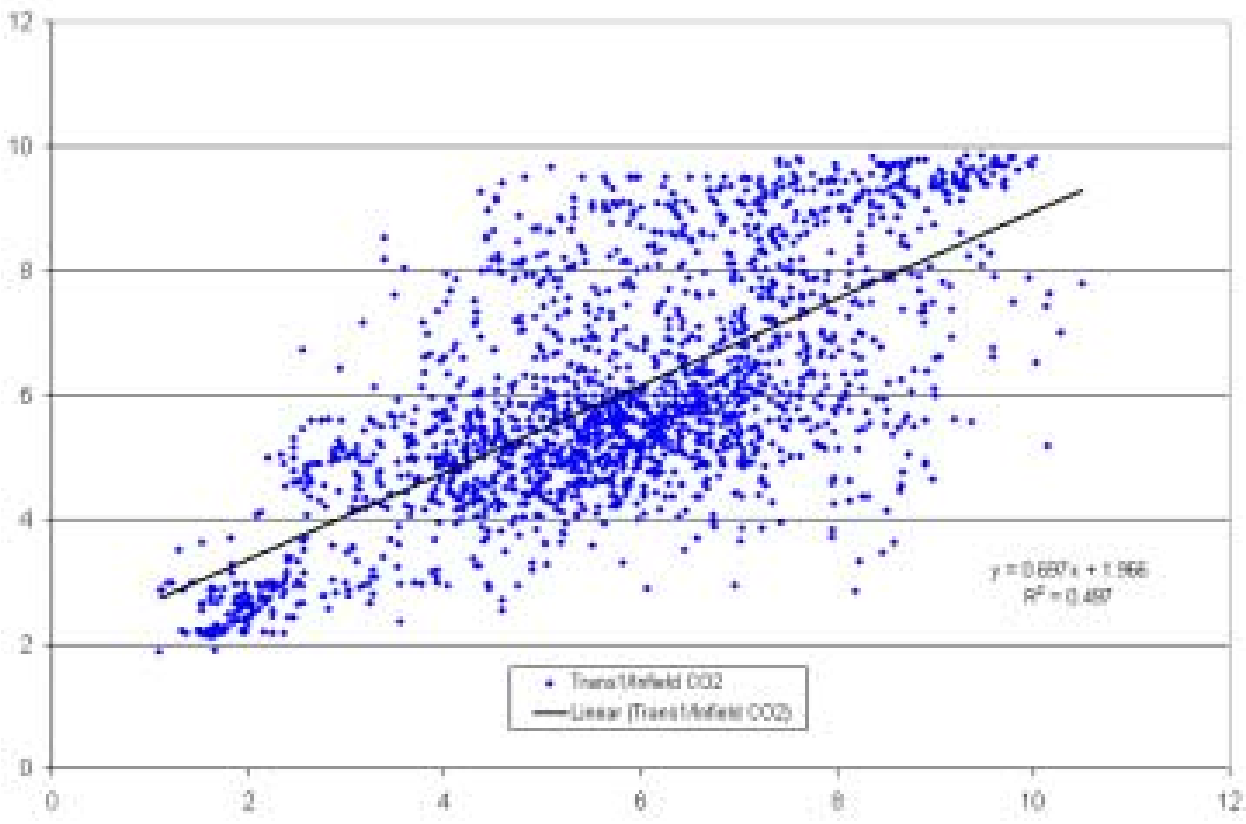

Figure 46 Correlation of the Loader $\mathrm{CO}_{2}$ data Between the Infield and the Derived In-laboratory Cycles (First Iteration).

It was determined early in the testing that the most efficient approach for recreation of the shortened infield cycle would be to divide it into smaller tests that could be repeated and modified (iterated) quickly. The rubber-tired loader shortened infield cycle was divided up into three parts: 0s-580s, 580s-900s, and 900s-1144s. $\mathrm{CO}_{2}$ correlation results for each portion of the final iteration of the loader cycle can be seen in Figure 47 through Figure 49. 


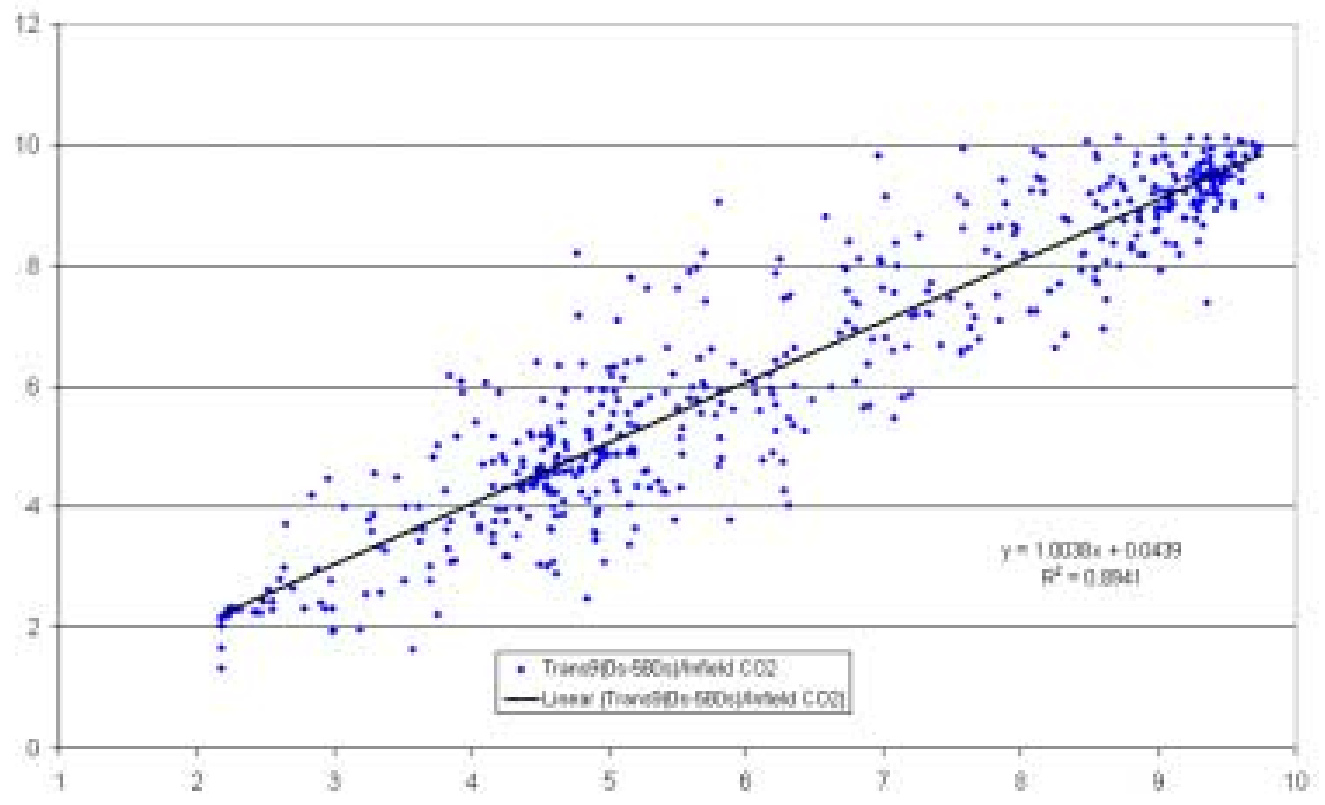

Figure 47 Correlation of the $\mathrm{CO}_{2}$ Data Between the Infield and the First Portion of the Final Iteration of the Derived In-Laboratory Cycle (0s-580s).

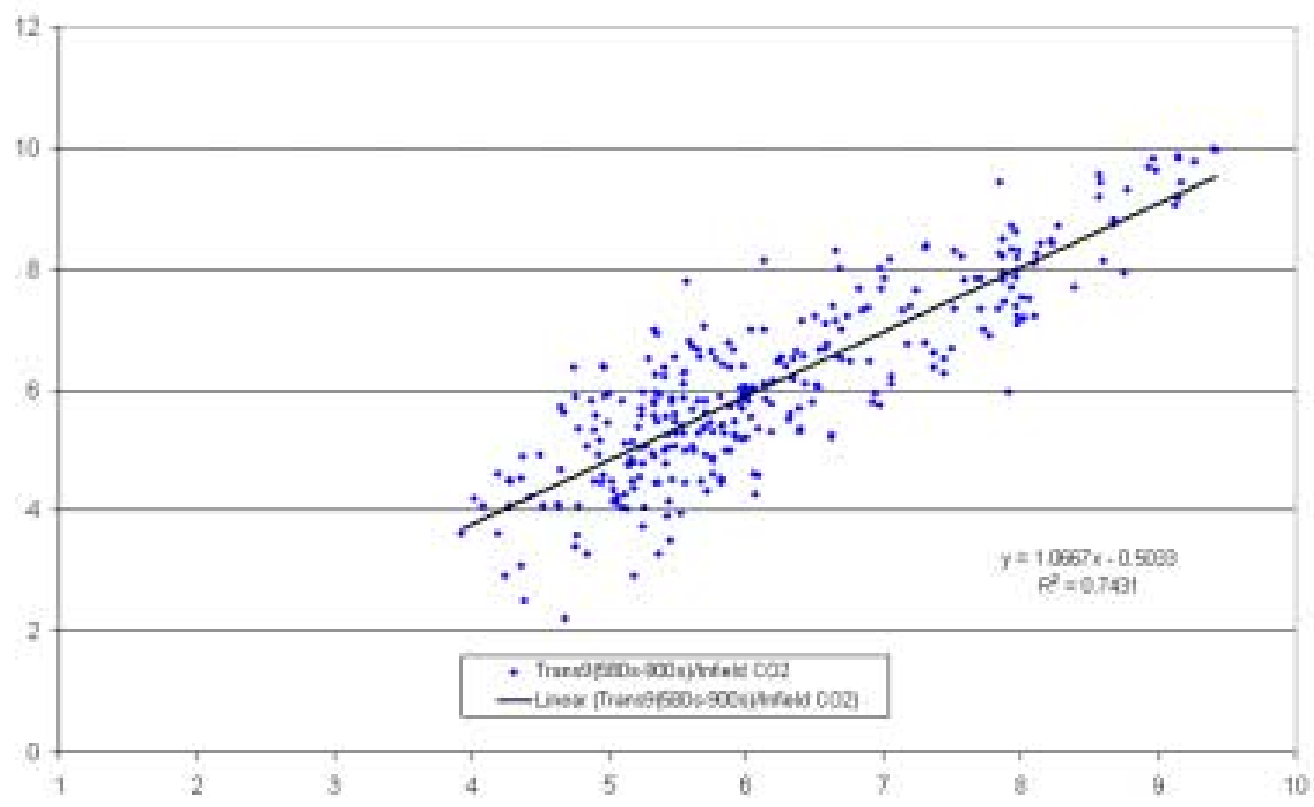

Figure 48 Correlation of the $\mathrm{CO}_{2}$ Data Between the Infield and the Second Portion of the Final Iteration of the Derived In-Laboratory Cycle (580s-900s). 


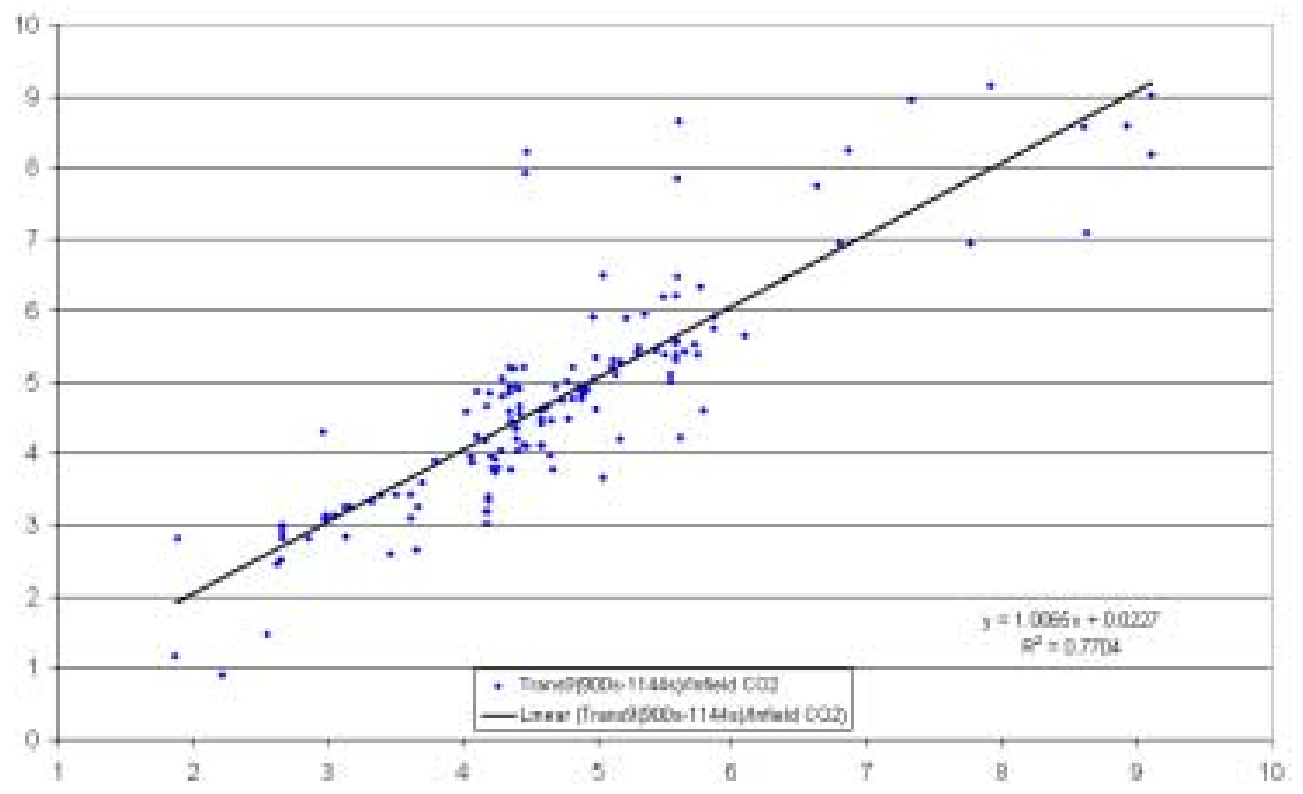

\section{Figure 49 Correlation of the $\mathrm{CO}_{2}$ Data Between the Infield and the Final Portion of the Final Iteration of the Derived In-Laboratory Cycle (900s-1144s).}

It can be seen from the performed correlations that a significant improvement was achieved through the iterative cycle development process. The $\mathrm{R}^{2}$ value improved from 0.497 for the first iteration to $0.8941,0.7431$, and 0.7704 for the first, second, and third portions of the final loader cycle iteration, respectively. The trendline slope improved from 0.697 to a value very close to 1 for each portion, with slope value of 1 being a "perfect" correlation. The y-intercept improved from 1.966 to a value of $0.0439,0.5033$, and 0.0227 for the first, second, and third portions of the final loader cycle iteration, respectively. The y-intercept has a "perfect" value of 0 for exact correlation. While vast improvement was made through the iterative process as a whole, the changes made to the cycle for some iterations actually reduced positive correlation. When this occurred, the speed/load setpoints from the previous iteration were returned to and modified again. 
The new cycle was then run and checked for improvement over the previous iteration. The iterative process was continued until adjustment of the system produced no further enhancement of results.

Engine speed data was also compared during the cycle development process. It can be seen from the engine speed traces of Figure 50 and Figure 51 that the dynamometer control system was able to recreate the infield engine speed trace much more accurately than the $\mathrm{CO}_{2}$ trace. This is due to the fact that the engine speed signal is a direct electronic measurement with near zero lag time or calibration differences. The accuracy of engine speed recreation was improved slightly through the iteration process, mainly through adjustment of PID settings for the throttle controller. The $\mathrm{CO}_{2}$ data, on the other hand, is affected by a number of parameters that can significantly alter results. The torque controlling aspect of the Dyn-Loc IV dynamometer controller relies on feedback from the dynamometer load cell to determine if more or less current needs to be supplied to the eddy-current dynamometer to achieve the desired torque demanded by the setpoint file. This feedback system produces the largest contribution to the difficulty in recreating the $\mathrm{CO}_{2}$-derived load cycle from the field. Other things such as sample line length, sample filter loading, barometric pressure, humidity, gas calibration accuracy, etc. are sources of possible deviations, but their impact was likely minimal when compared to the dynamometer torque control issues. While significant effort was put forth to minimize or eliminate the effects of these parameters, correlation results for the $\mathrm{CO}_{2}$ traces were not as good as they were for the engine speed traces. Correlation data for the first and final cycle iterations can be seen in Figure 50 and Figure 51, respectively. 


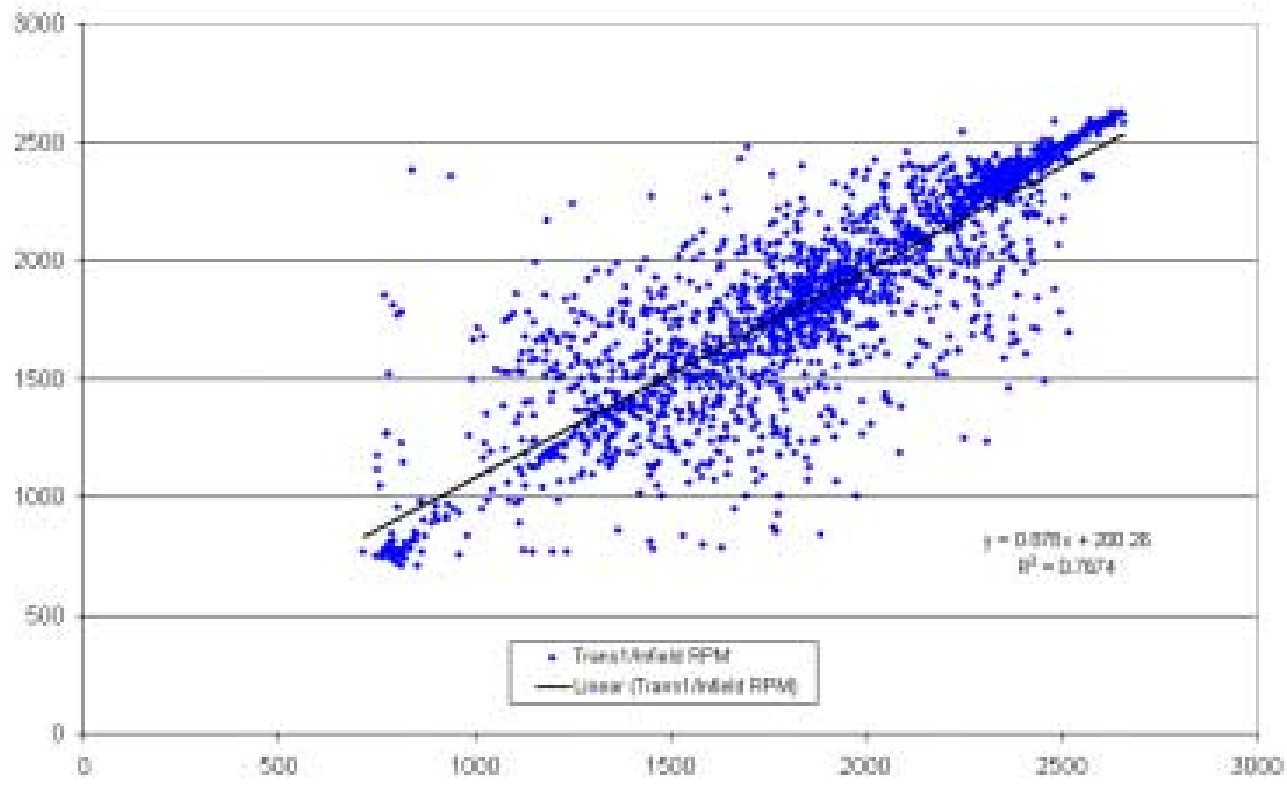

Figure 50 Correlation of the Loader Engine Speed Data Between the Infield and the Derived In-Laboratory Cycles (First Iteration).

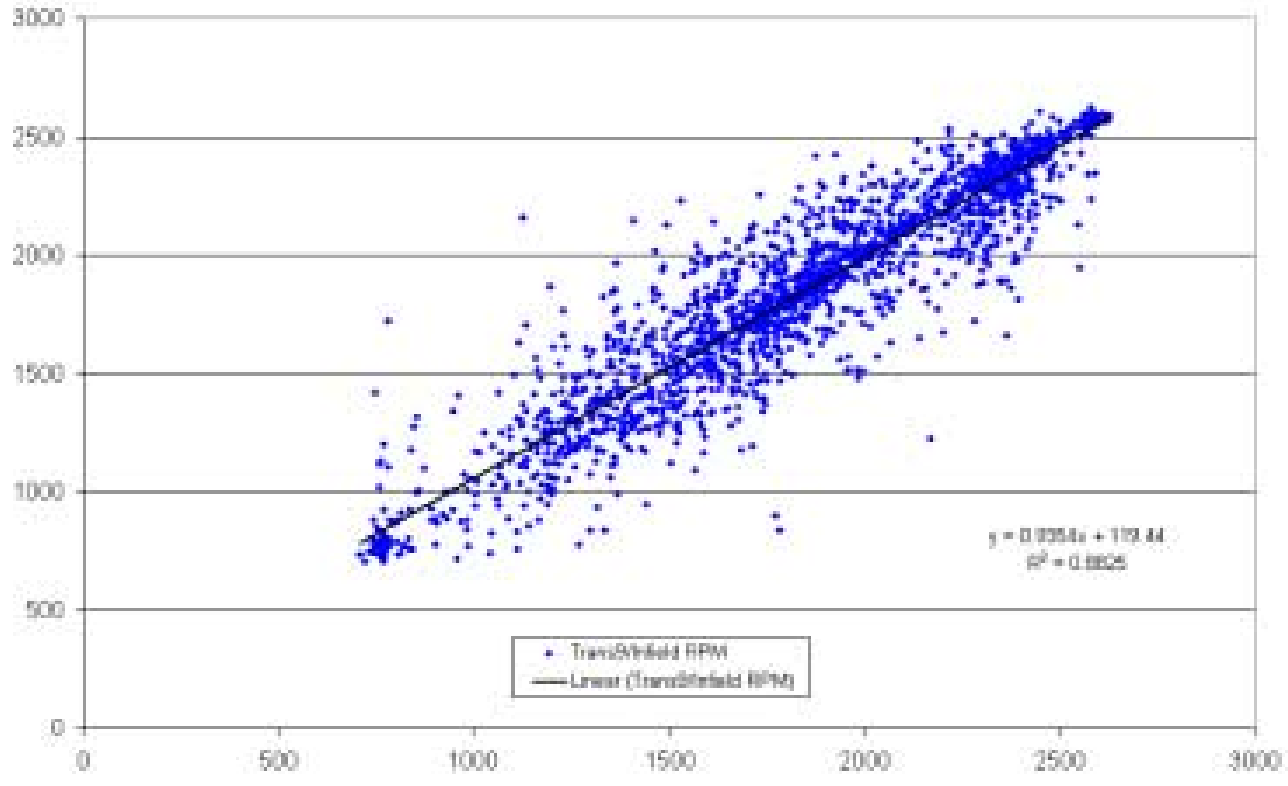

Figure 51 Correlation of the Loader Engine Speed Data Between the Infield and the Derived In-laboratory Cycles (Final Iteration). 


\subsubsection{Streetsweeper Cycle Development}

The streetsweeper cycle was easier to accurately recreate in the laboratory than the loader cycle because of its more steady-state characteristics. The very nature of the sweeping process, which was less transient, resulted in less drastic ramps of the $\mathrm{CO}_{2}$ trace during operation. In contrast, the loader operation was relatively high-speed and very transient in nature because of the bucket loading/unloading process. Additionally, the engine speed for the streetsweeper was set with a hand-twist knob during the sweeping process and an intermediate-speed governor kept engine speed relatively constant by adjusting fueling rate to compensate for differences in demanded engine load. The fueling rate of the loader, on the other hand, was controlled with a pedal operated directly by the operator's foot. For these reasons, the loader created much sharper transient events in both speed and load traces during its operation.

\subsubsection{Engine Map}

An engine mapping procedure, outlined in the CFR 40 Part 86 Subpart N [1], was performed on the John Deere 4039T streetsweeper engine to determine at what engine speeds the horsepower peak (rated speed) and torque peak (intermediate speed) occur, and what values they had. The results were corrected with information supplied by Mustang Dynamometers, Inc. quantifying windage losses versus rotational speed of the eddy current dynamometer. It was found that the horsepower peak of the John Deere 4039T engine was approximately $114.0 \mathrm{hp}$ at $2100 \mathrm{rpm}$. The torque peak occurred at $1710 \mathrm{rpm}$ and was about $300.3 \mathrm{ft}$-lbs. The engine lug curve for the John Deere 6059 can be seen in Figure 52. 


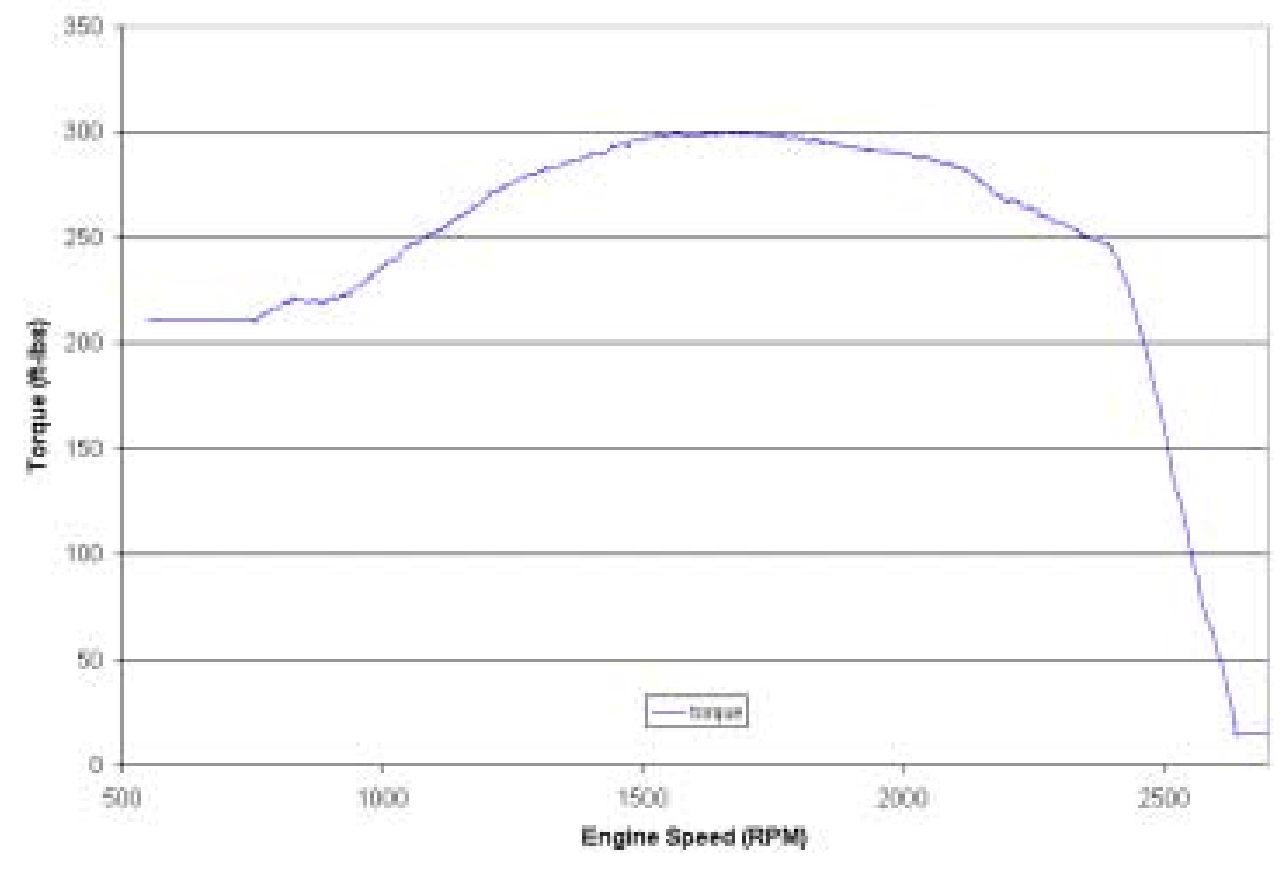

Figure 52 Engine Map for the John Deere 4039T Streetsweeper Engine.

\subsubsection{2 $\mathrm{CO}_{2}$ Map Matrix}

Just as was the case for the loader engine, the streetsweeper engine was operated according to a series of speed-load setpoints and $\mathrm{CO}_{2}$ levels were recorded with the infield data collection system. For this testing, the same setup and procedures used for the infield testing were followed. The $\mathrm{CO}_{2}$ levels were recorded in the laboratory for the 4039T streetsweeper engine at speeds from 700rpm to 2700rpm in increments of 100rpm. Three different engine loadings were used during data collection. Load levels of $0 \%$, $50 \%$, and $100 \%$ of full load were used during the recording of $\mathrm{CO}_{2}$ emissions. The system was allowed to stabilize for 30s at each speed/load point to ensure that the $\mathrm{CO}_{2}$ data had time to reach a value of at least $90 \%$ of the fully stabilized steady-state value. The system was not allowed to stabilize for more than 30 s to prevent skewing of the 
often-quick transient events encountered during cycle testing. The full load value was determined from the engine map discussed in section 4.4.2.1 and was approximately 114hp. The data collected was used to develop the first iteration of the streetsweeper transient cycle using the computer matrix interpolation program. Raw exhaust $\mathrm{CO}_{2}$ data from the field was used by the program to develop a torque estimate by interpolating the data collected in the laboratory and shown in Table 10 below. The $\mathrm{CO}_{2}$ data taken during the first iteration of the cycle was compared to the infield data and a correlation of the results was performed. A manual process was then used to adjust the speed and load set points of the previous transient cycle iteration to make the $\mathrm{CO}_{2}$ data match the infield $\mathrm{CO}_{2}$ data more accurately. A graphical representation of $\mathrm{CO}_{2}$ data for the first and final iterations of the recreated in-laboratory cycle for the streetsweeper can be seen in Figure 53 and Figure 54 along with correlations with the infield data. 
Table 10 Matrix for the John Deere 4039T Streetsweeper Engine.

\begin{tabular}{|c|c|c|c||}
\hline Engine Speed & $\begin{array}{c}\mathbf{C O}_{\mathbf{2}}(\% \text { vol) @ 0\% } \\
\text { Engine Load }\end{array}$ & $\begin{array}{c}\mathbf{C O}_{\mathbf{2}} \text { (\%) vol) @ 50\% } \\
\text { Engine Load }\end{array}$ & $\begin{array}{c}\mathbf{C O}_{\mathbf{2}} \text { (\%) vol) @ 100\% } \\
\text { Engine Load }\end{array}$ \\
\hline $\mathbf{7 0 0}$ & 1.50 & 6.22 & 10.67 \\
\hline $\mathbf{8 0 0}$ & 1.55 & 6.42 & 10.67 \\
\hline $\mathbf{9 0 0}$ & 1.59 & 6.63 & 10.67 \\
\hline $\mathbf{1 0 0 0}$ & 1.64 & 6.83 & 11.26 \\
\hline $\mathbf{1 1 0 0}$ & 1.69 & 7.04 & 11.91 \\
\hline $\mathbf{1 2 0 0}$ & 1.74 & 7.25 & 12.55 \\
\hline $\mathbf{1 3 0 0}$ & 1.80 & 7.45 & 12.89 \\
\hline $\mathbf{1 4 0 0}$ & 1.85 & 7.66 & 12.53 \\
\hline $\mathbf{1 5 0 0}$ & 1.91 & 7.76 & 12.17 \\
\hline $\mathbf{1 6 0 0}$ & 1.97 & 7.73 & 11.81 \\
\hline $\mathbf{1 7 0 0}$ & 2.03 & 7.71 & 11.44 \\
\hline $\mathbf{1 8 0 0}$ & 2.09 & 7.66 & 11.08 \\
\hline $\mathbf{1 9 0 0}$ & 2.15 & 7.55 & 10.72 \\
\hline $\mathbf{2 0 0 0}$ & 2.22 & 7.39 & 10.36 \\
\hline $\mathbf{2 1 0 0}$ & 2.28 & 7.21 & 9.99 \\
\hline $\mathbf{2 2 0 0}$ & 2.35 & 7.04 & 9.63 \\
\hline $\mathbf{2 3 0 0}$ & 2.43 & 6.84 & 9.27 \\
\hline $\mathbf{2 4 0 0}$ & 2.50 & 6.49 & 8.50 \\
\hline $\mathbf{2 5 0 0}$ & 2.58 & 5.71 & 5.95 \\
\hline $\mathbf{2 6 0 0}$ & 2.65 & 4.00 & 3.39 \\
\hline $\mathbf{2 7 0 0}$ & 2.73 & 2.73 & 2.73 \\
\hline & & & \\
\hline & & & \\
\hline
\end{tabular}

\subsubsection{Streetsweeper Cycle Iteration}

The John Deere 4039T Streetsweeper infield cycle proved to be much easier to recreate, largely due to the experience gained through testing of the John Deere 6059 loader engine. The system setup was established during the loader engine testing and a better understanding of the effects of the PID settings on the dynamometer controller were known from previous loader testing. Another important reason for the relative ease of streetsweeper cycle recreation was in the cycle, itself. The shortened infield streetsweeper cycle was much less transient in nature than the loader cycle due to a number of reasons discussed previously in this document. Just as was the case in the loader testing, the first step performed after running each iteration of the cycle was to 
time-align the laboratory data with the infield data. This was done by examining a portion of the graphical continuous engine speed data from the laboratory and overlaying it on the field data and adjusting the time of the laboratory data until the two engine speed traces aligned as closely as possible. To minimize differences in analyzer time lag between laboratory and field tests the same sampling system and sampling line were used for all testing in an attempt to keep sample transfer time and overall system lag time nearly constant. The same time difference, if any, determined by comparing the graphical engine speed data was applied to the $\mathrm{CO}_{2}$ data as well. The aligned infield and in-laboratory $\mathrm{CO}_{2}$ traces for the full first iteration of the streetsweeper cycle can be seen in Figure 53.

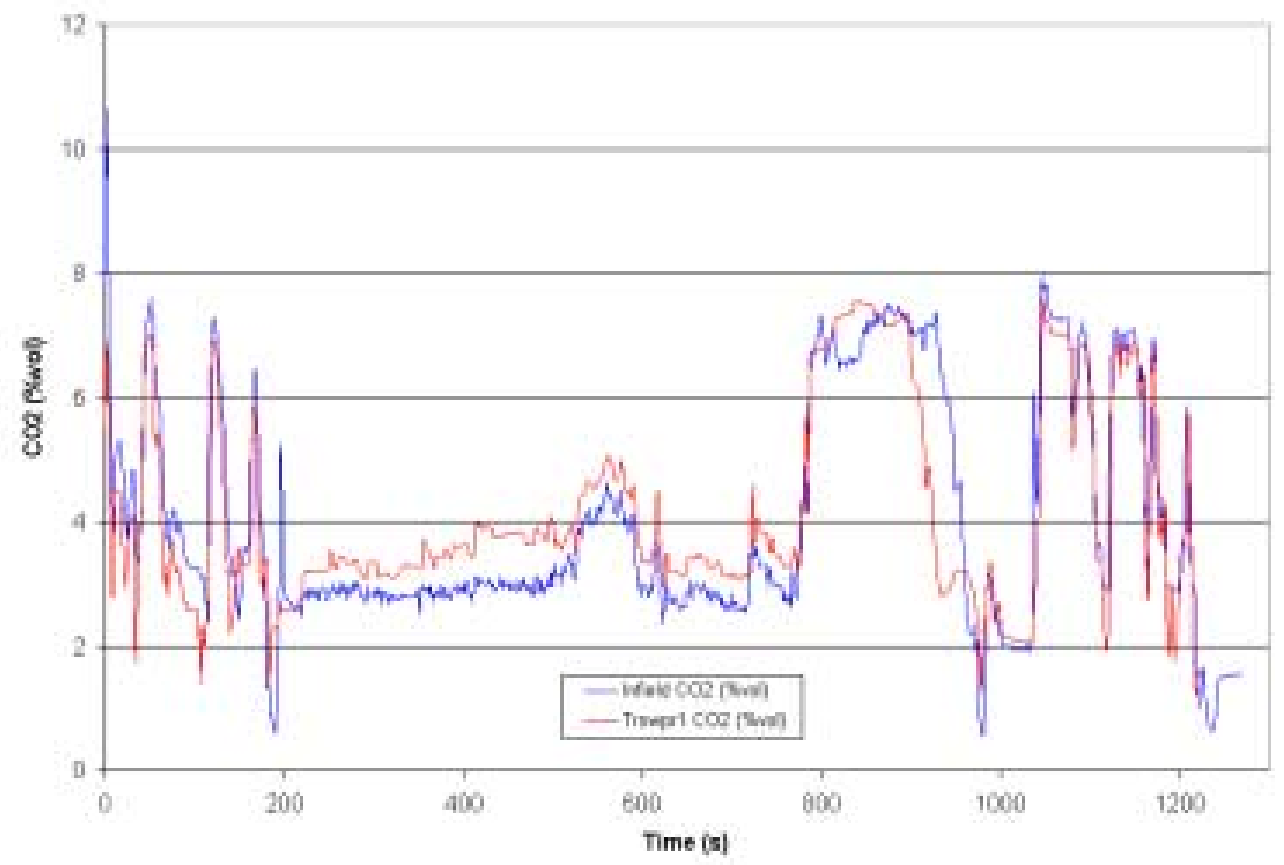

Figure 53 Comparison of $\mathrm{CO}_{2}$ Traces for the John Deere 4039T Streetsweeper Engine After Time Alignment (First Iteration). 
It can be seen from Figure 53 that a considerable amount of effort needed to be afforded in order to make the laboratory $\mathrm{CO}_{2}$ data match the infield data. Through iteration, a manual inspection of the graphical data with appropriate adjustment to the load points of the sweeper setpoint file produces the final iteration $\mathrm{CO}_{2}$ trace seen in Figure 54.

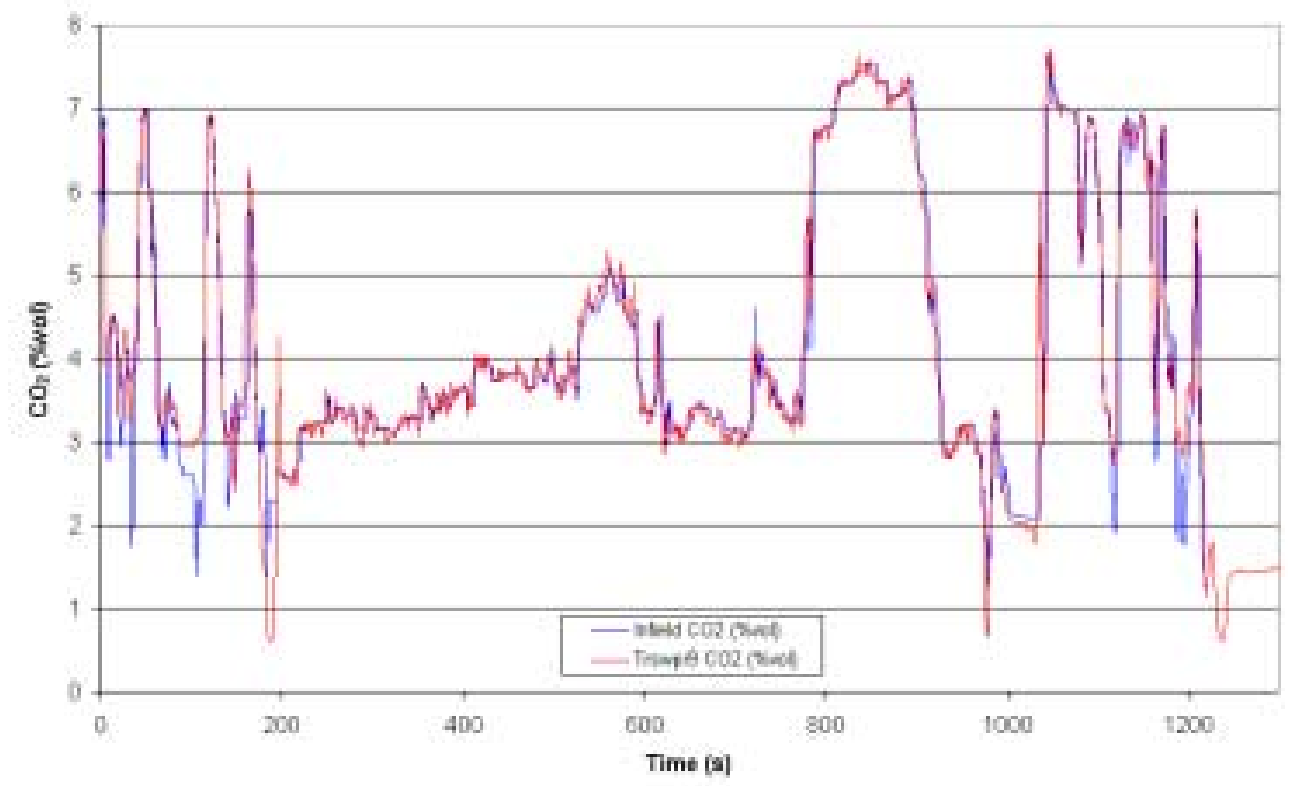

Figure 54 Comparison of $\mathrm{CO}_{2}$ Traces for the John Deere 4039T Streetsweeper Engine After Time Alignment (Final Iteration).

A number of repeat tests were run using the setpoints from the final iteration of the streetsweeper cycle to check test-to-test variation of the $\mathrm{CO}_{2}$ and engine speed data. A correlation was performed between two of the repeat tests to see what the best expected correlation could be. While a perfect correlation would yield an $\mathrm{R}^{2}$ value of 1 and a trendline equation with slope $=1$ and a y-intercept of zero, many small factors present during testing prevent a perfect correlation from ever being obtained. A 
repetitive test was performed using the setpoints from the final iteration of the streetsweeper cycle to estimate what the expected "best fit" values for the linear regression could be. The correlation results for repeat runs 1 and 2 using the setpoint file from the final iteration of the streetsweeper cycle can be seen in Figure 55 for the $\mathrm{CO}_{2}$ data, while the engine speed data can be seen in Figure 56.

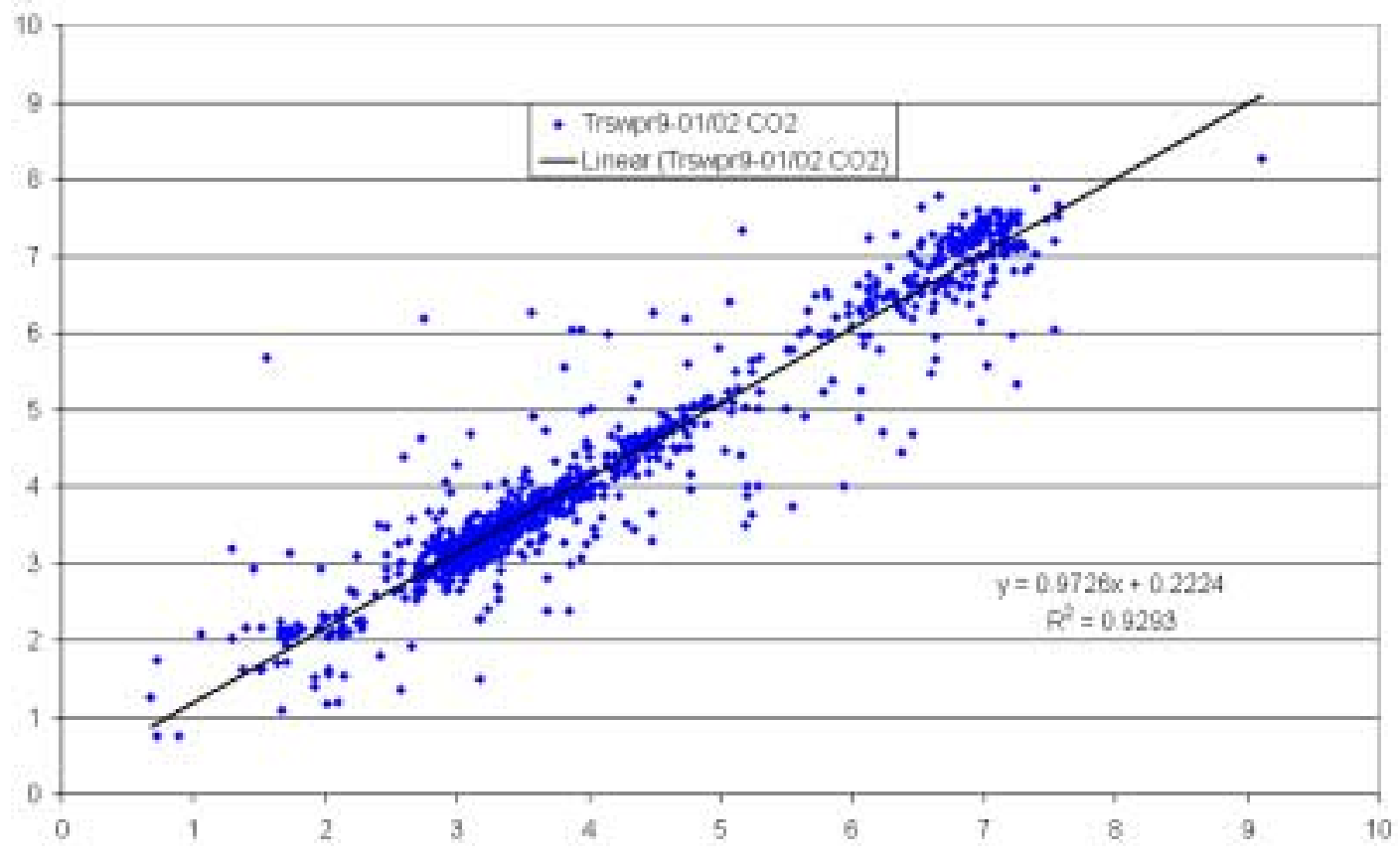

Figure $55 \mathrm{CO}_{2}$ Correlation Results for Two Repeat Runs of the Final Streetsweeper Cycle. 


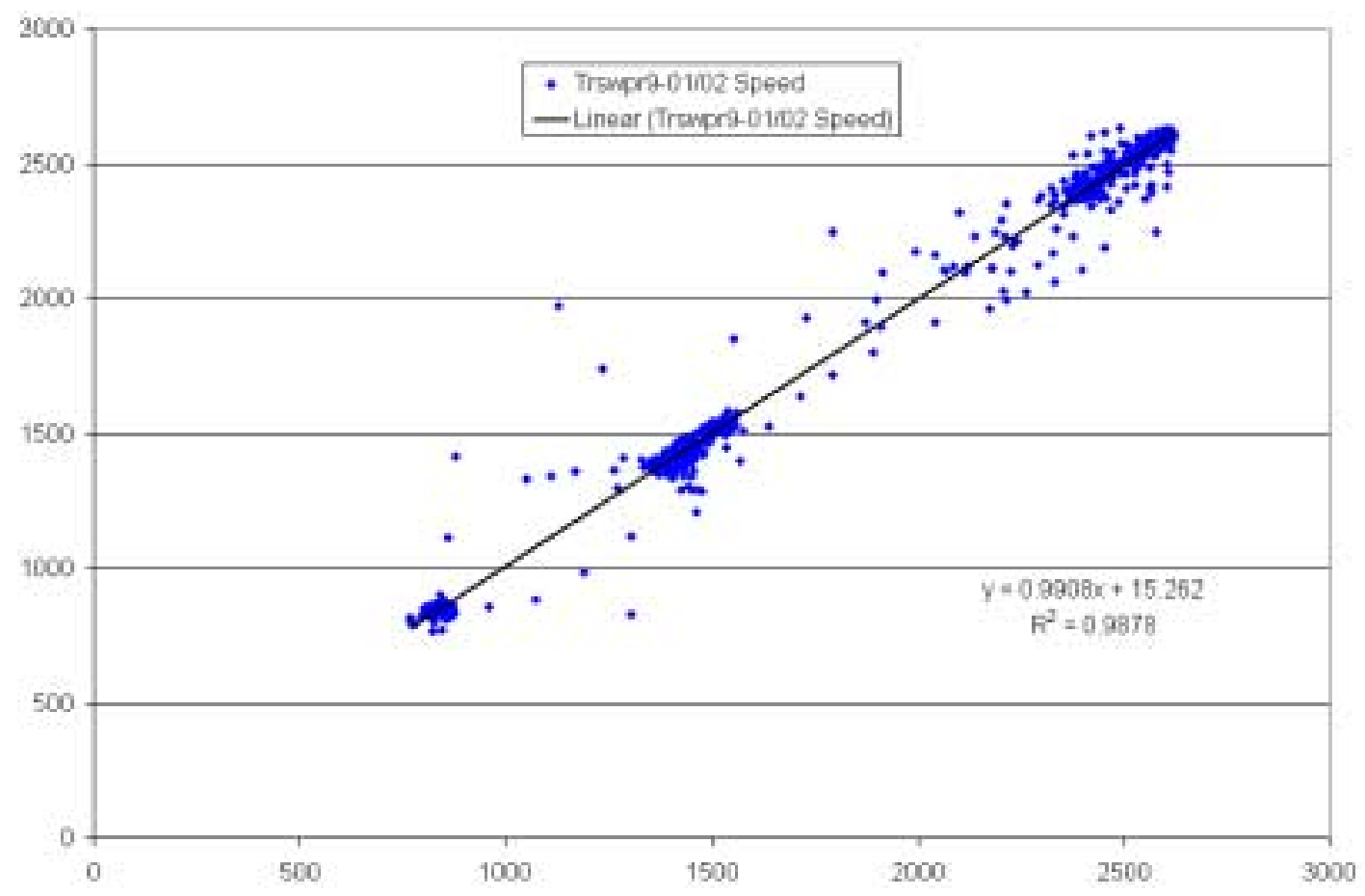

\section{Figure 56 Engine Speed Correlation Results for Two Repeat Runs of the Final Streetsweeper Cycle.}

A graphical correlation (Figure 57) illustrates the large discrepancy between the desired infield $\mathrm{CO}_{2}$ trace and the in-laboratory trace collected during the running of the complete first cycle iteration. The first iteration regression values of $R^{2}=0.7653$ with trendline slope of 0.7695 and y-intercept of 0.9849 were obtained. While these results are considerably better than the first iteration values for the loader cycle $\left(R^{2}=0.497\right.$, slope $=$ 0.697, y-intercept $=1.966$ ), more work was needed on the first iteration streetsweeper cycle load setpoints. The $\mathrm{CO}_{2}$ correlation for the first iteration of the streetsweeper cycle can be seen in Figure 57. 


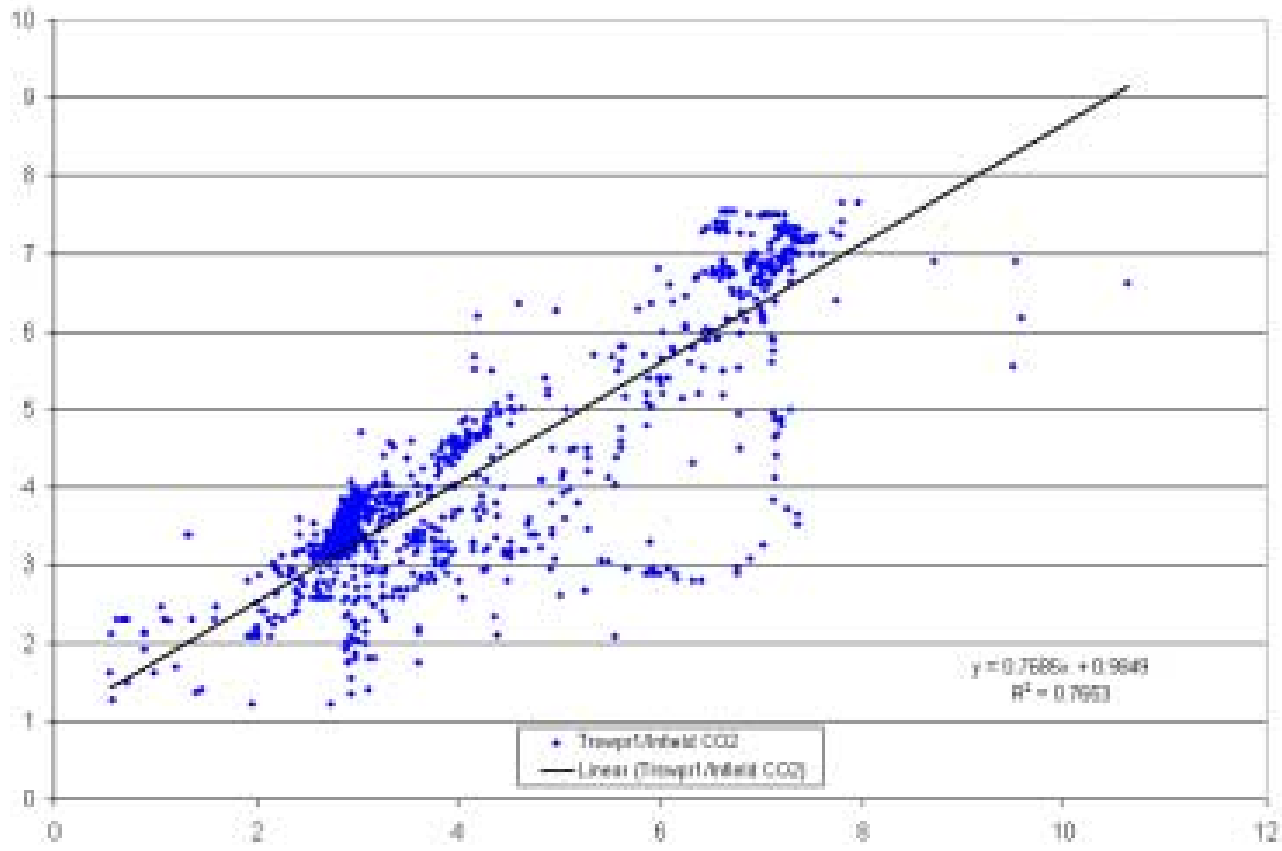

Figure 57 Correlation of the $\mathrm{CO}_{2}$ Data Between the Infield and Derived InLaboratory Streetsweeper Cycles (First Iteration).

Significant improvement was made through cycle development with the streetsweeper cycle. An $\mathrm{R}^{2}$ value for the data of 0.8968 was obtained as well as a trendline slope of 0.9481 and a y-intercept of 0.2504 . Graphical correlation results for the final iteration of the streetsweeper cycle can be seen in Figure 58. 


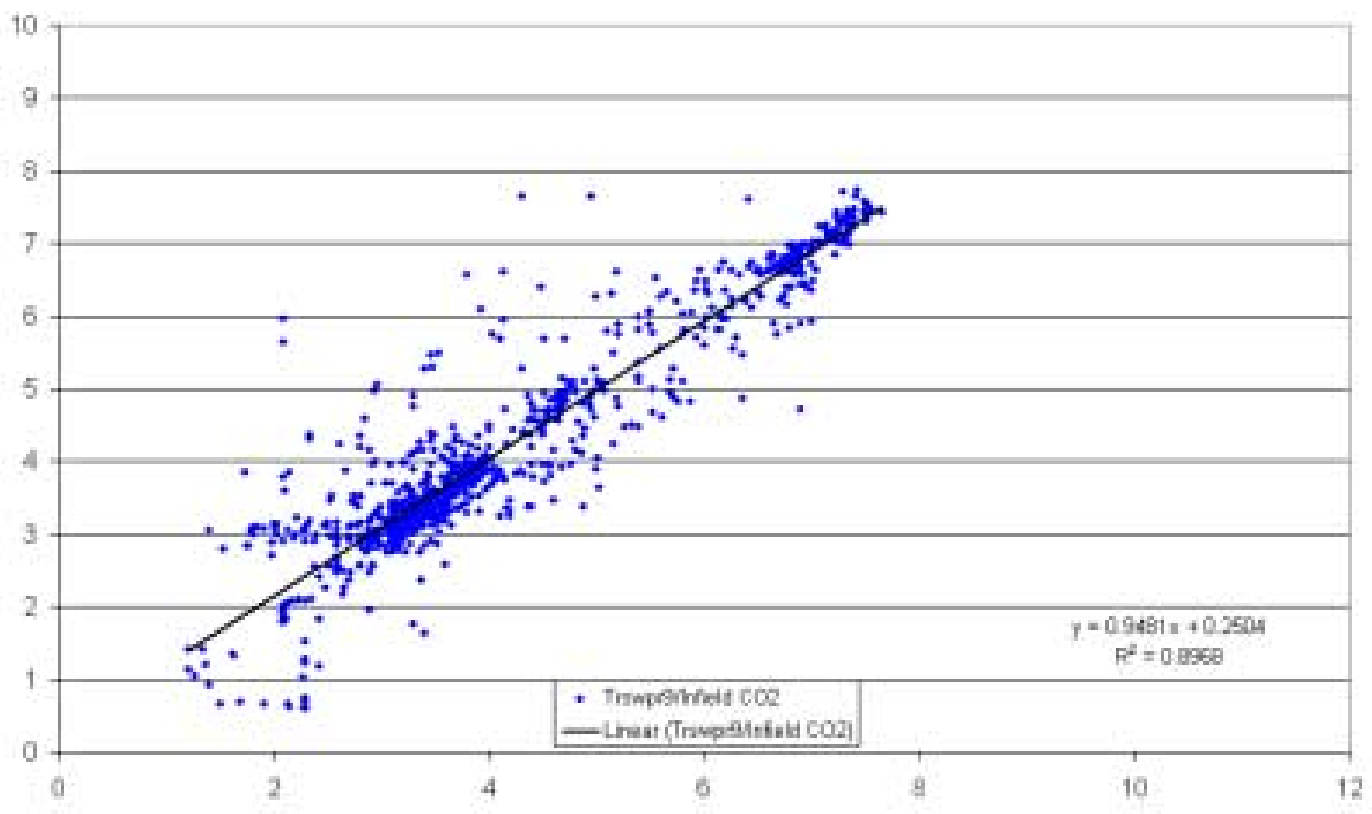

\section{Figure 58 Correlation of the $\mathrm{CO}_{2}$ Data Between the Infield and Derived In- laboratory Streetsweeper Cycles (Final Iteration).}

Engine speed data was also compared during the cycle development process. It can be seen from the engine speed traces of Figure 59 and Figure 60 that the dynamometer control system was able to recreate the infield engine speed trace much more accurately than the $\mathrm{CO}_{2}$ trace. This was due to the fact that the engine speed signal was a direct electronic measurement with no lag time or calibration differences. The accuracy of engine speed recreation was improved slightly through the iterative process, mainly through adjustment of PID settings for the throttle controller. The $\mathrm{CO}_{2}$ data, on the other hand, was affected by a number of parameters that can significantly alter results. The torque controlling aspect of the Dyn-Loc IV dynamometer controller relied on feedback from the dynamometer load cell to determine if more or less current needed to 
be supplied to the eddy-current dynamometer to achieve the desired torque demanded by the setpoint file. This feedback system produced the largest contribution to the difficulty in recreating the $\mathrm{CO}_{2}$-derived load cycle from the field. Other things such as sample line length, sample filter loading, barometric pressure, humidity, gas calibration accuracy, etc. were also other sources of possible deviation. While significant effort was put forth to minimize or eliminate the effects of these parameters, correlation results for the $\mathrm{CO}_{2}$ traces were not as good as they were for the engine speed traces. Linear regression results for the first iteration engine speed data were $R^{2}=0.9688$, trendline slope $=$ 1.0097 , and $\mathrm{y}$-intercept $=-4.9756$ and were $\mathrm{R}^{2}=0.9559$, trendline slope $=0.9624$, and $\mathrm{y}$ intercept $=45.484$ for the final streetsweeper cycle iteration. The apparently less desirable engine speed correlation results for the final iteration of the streetsweeper cycle can best be explained by the backlash in the mechanical throttle linkage and the fuel injection pump. However, both engine speed correlations meet even the stringent certification transient test validity criteria outlined in the CFR 40 and listed in Table 16. Graphical engine speed correlation data for the first and final cycle iterations can be seen in Figure 59 and Figure 60, respectively. 


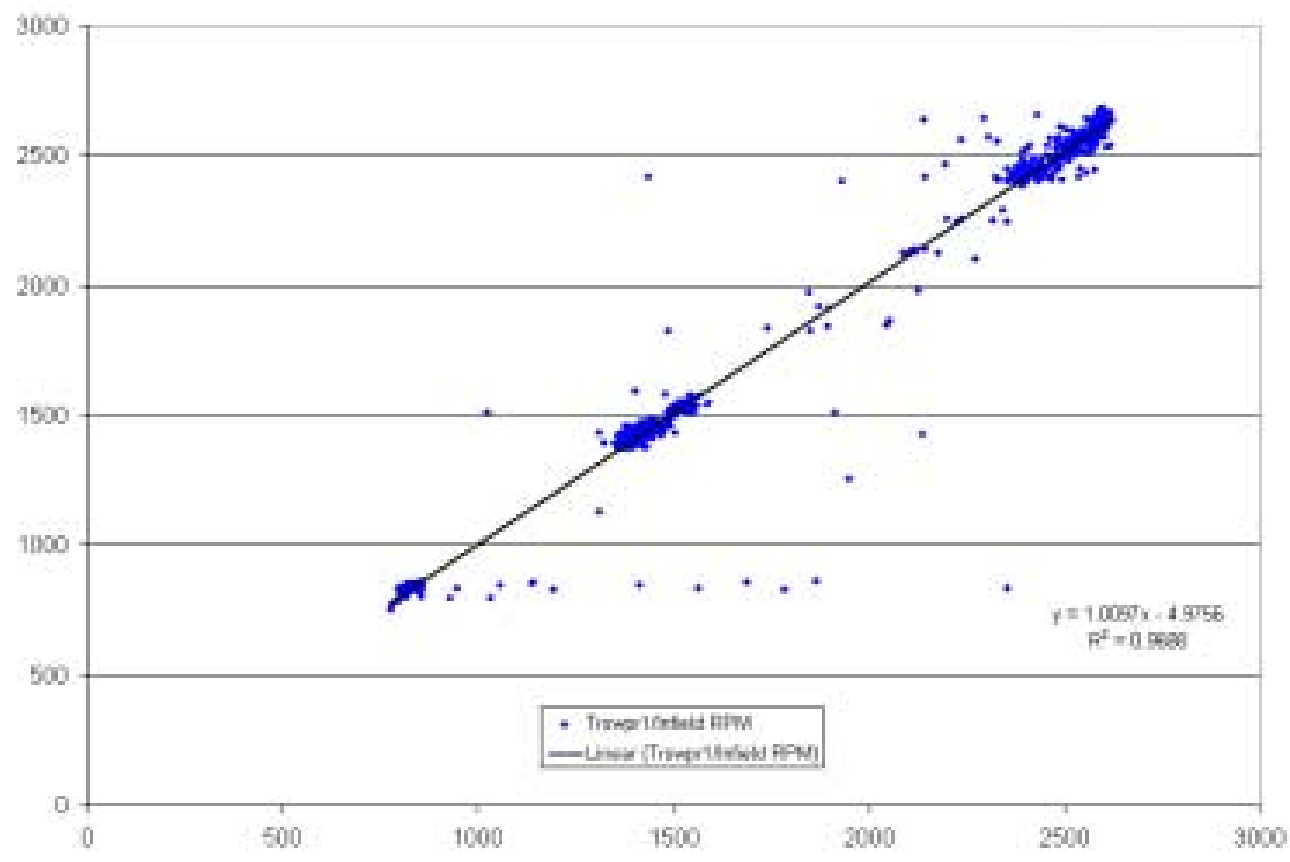

Figure 59 Correlation of the Engine Speed Data Between the Infield and Derived Inlaboratory Streetsweeper Cycles (First Iteration).

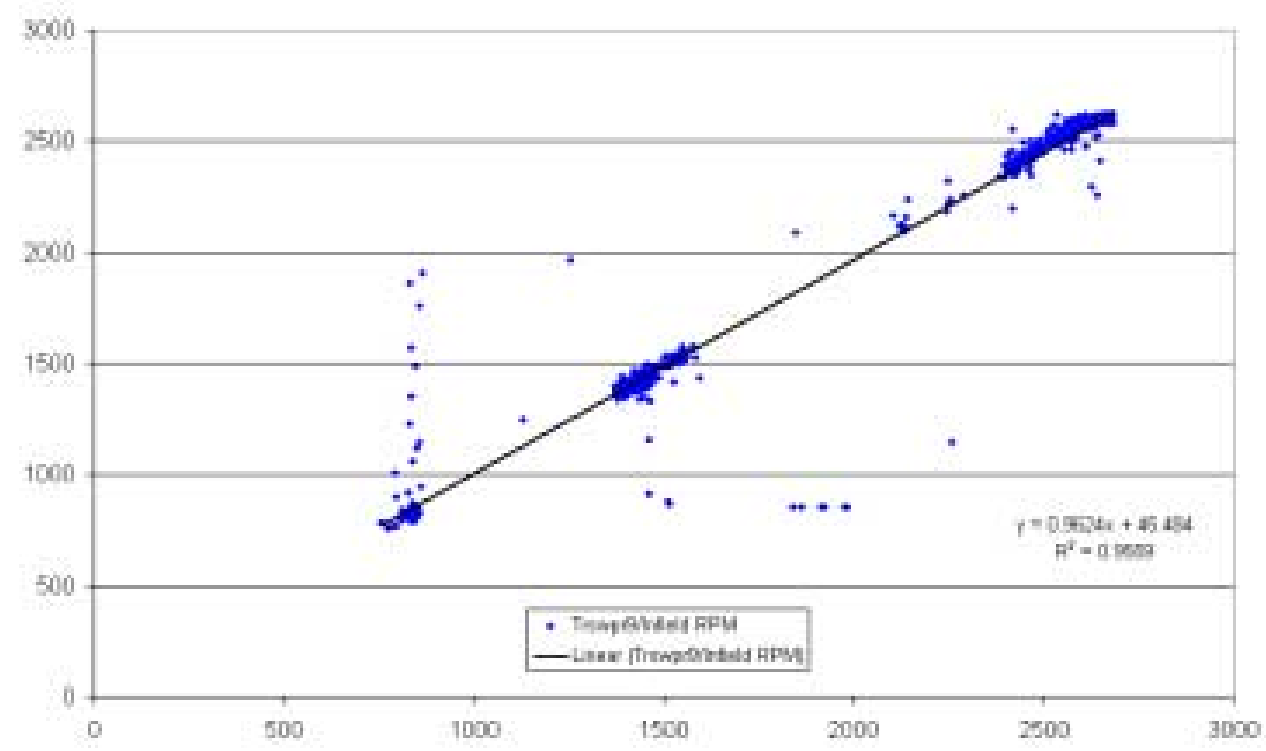

Figure 60 Correlation of the Engine Speed Data Between the Infield and the Derived In-laboratory Streetsweeper Cycles (Final Iteration). 


\subsection{In-Laboratory Emissions Testing Results}

In-laboratory testing for both engines consisted of measuring full-flow emissions during steady-state 8-Mode testing and transient testing with speed/load set points dictated by the cycles developed from the infield data and discussed in detail in Section 4.4.

Both engines tested operated at eight different modes for the steady-state portion of the laboratory testing. The engine speed and load factors of the 8-Mode test are shown in Table 11. The operating speeds and loads are obtained from the ISO/DIS 8178-4 Section 6.3.1.1 standards entitled "Test Cycles Type C - Off-Road Vehicles and Industrial Equipment," and resemble the set points outlined by CFR 30, Part 7 [1]. The weighted 8-mode data given in Chapter 4 of this document was reduced based on the associated weighting factors outlined in the Table 11.

Table 11 The ISO 8-Mode Cycle.

\begin{tabular}{|c|c|c|c|}
\hline Mode Number & Engine Speed & $\begin{array}{c}\text { Load Factor } \\
\text { (Percent Load) }\end{array}$ & Weighting Factor \\
\hline $\mathbf{1}$ & Rated & 100 & 0.15 \\
\hline $\mathbf{2}$ & Rated & 75 & 0.15 \\
\hline $\mathbf{3}$ & Rated & 50 & 0.15 \\
\hline $\mathbf{4}$ & Rated & 10 & 0.10 \\
\hline $\mathbf{5}$ & Intermediate & 100 & 0.10 \\
\hline $\mathbf{6}$ & Intermediate & 75 & 0.10 \\
\hline $\mathbf{7}$ & Intermediate & 50 & 0.10 \\
\hline $\mathbf{8}$ & Idle & 0 & 0.15 \\
\hline
\end{tabular}




\subsubsection{Rubber-Tired Loader In-Laboratory Results}

Two types of in-laboratory testing were performed on the loader engine. The first tests performed were steady-state emissions tests that followed the ISO-8178 Test C 8mode test cycle. The second series of testing consisted of final transient cycle emissions tests that followed the speed/load setpoints derived from the infield data and discussed in detail in the Cycle Development section of this thesis.

\subsubsection{Loader Steady-State 8-Mode Test Results}

The ISO-8178 8-mode steady-state tests that were conducted consisted of four modes run at rated speed, three modes run at intermediate speed, and a "no-load" idle mode. Parasitic windage losses of the eddy current dynamometer were determined for all 8-mode testing speeds and the data was corrected for these losses when reduced. Mustang Dynamometers, the dynamometer manufacturer, provided estimates of the windage losses (in ft-lbs) of the dynamometer at any speed point. The rated and intermediate speeds were obtained from the engine maps run on the engines prior to testing. The setpoints were determined using the rated and intermediate speed from the engine map and the percentages of maximum torque described in Table 11 of Section 4.6 of this document. A graphical representation of the engine map for the loader engine can be seen in Figure 39. The 8-mode speed and load set points for the 6059 loader engine can be seen in Table 12 .

The average emissions results for all gases and PM of the three 8-mode repeat tests performed can be seen in Table 13 with a graphical representation seen in Figure 61. The weighted results illustrated in Figure 62 were determined by multiplying the average 
results of Table 13 by the weighting factors outlined in Table 11 of Section 4.6. Results for all three runs of the 8-mode test are shown in table form in the appendix of this thesis.

Table 12 Loader 8-Mode Engine Speed/Load Set Points.

\begin{tabular}{||c|c|c|c||}
\hline Mode Number & Engine Speed (RPM) & Torque (ft-lbs) & Horsepower (hp) \\
\hline $\mathbf{1}$ & 2375 & 232.3 & 105.0 \\
\hline $\mathbf{2}$ & 2375 & 174.2 & 78.8 \\
\hline $\mathbf{3}$ & 2375 & 116.2 & 52.5 \\
\hline $\mathbf{4}$ & 2375 & 23.2 & 10.5 \\
\hline $\mathbf{5}$ & 1010 & 277.9 & 53.4 \\
\hline $\mathbf{6}$ & 1010 & 208.4 & 40.1 \\
\hline $\mathbf{7}$ & 1010 & 139.0 & 26.7 \\
\hline $\mathbf{8}$ & $\approx 800$ & 0.0 & 0.0 \\
\hline
\end{tabular}

Table 13 Average of 8-Mode Results for the John Deere 6059 Loader Engine (g/bhphr).

\begin{tabular}{|l|c|c|c|c|c|c|c|c|}
\hline & $\begin{array}{c}\text { Mode } \\
\mathbf{1}\end{array}$ & $\begin{array}{c}\text { Mode } \\
\mathbf{2}\end{array}$ & $\begin{array}{c}\text { Mode } \\
\mathbf{3}\end{array}$ & $\begin{array}{c}\text { Mode } \\
\mathbf{4}\end{array}$ & $\begin{array}{c}\text { Mode } \\
\mathbf{5}\end{array}$ & $\begin{array}{c}\text { Mode } \\
\mathbf{6}\end{array}$ & $\begin{array}{c}\text { Mode } \\
\mathbf{7}\end{array}$ & $\begin{array}{c}\text { Mode } \\
\mathbf{8}\end{array}$ \\
\hline $\mathbf{H C}$ & 0.33 & 0.48 & 0.99 & 9.74 & 0.48 & 0.40 & 0.73 & 22.48 \\
\hline $\mathbf{C O}$ & 2.02 & 2.86 & 3.18 & 18.48 & 4.17 & 0.30 & 1.09 & 35.32 \\
\hline $\mathbf{C O}_{\mathbf{2}}$ & 483.7 & 497.3 & 556.0 & 1236 & 471.3 & 334.6 & 483.0 & 4235 \\
\hline $\mathbf{N O}_{\mathbf{x}}$ & 11.72 & 10.32 & 7.90 & 9.21 & 20.78 & 13.03 & 16.64 & 107.1 \\
\hline $\mathbf{P M}$ & 0.188 & 0.367 & 0.347 & 0.849 & 0.172 & 0.083 & 0.094 & 1.641 \\
\hline
\end{tabular}




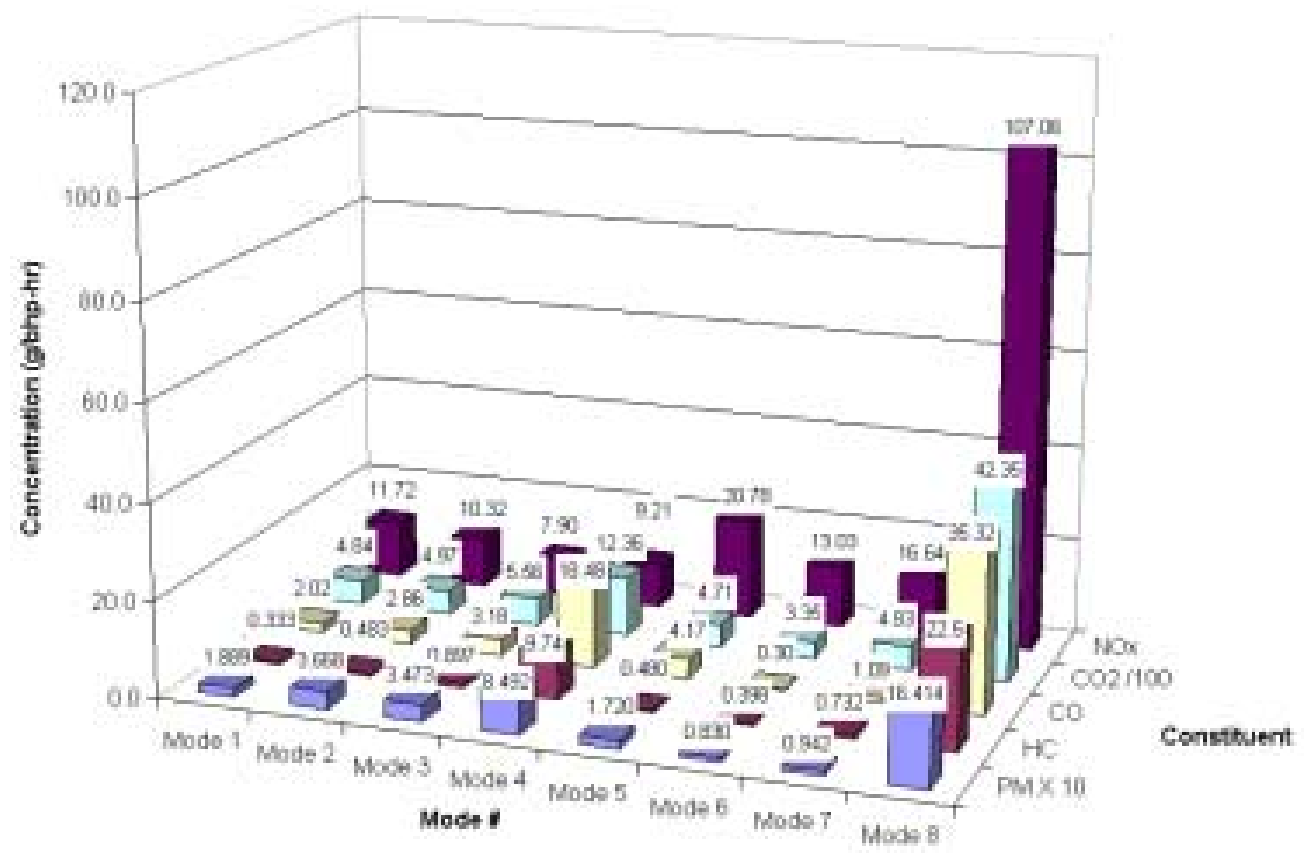

Figure 61 Average of 8-Mode Emissions Results for the John Deere 6059 Loader Engine (g/bhp-hr).

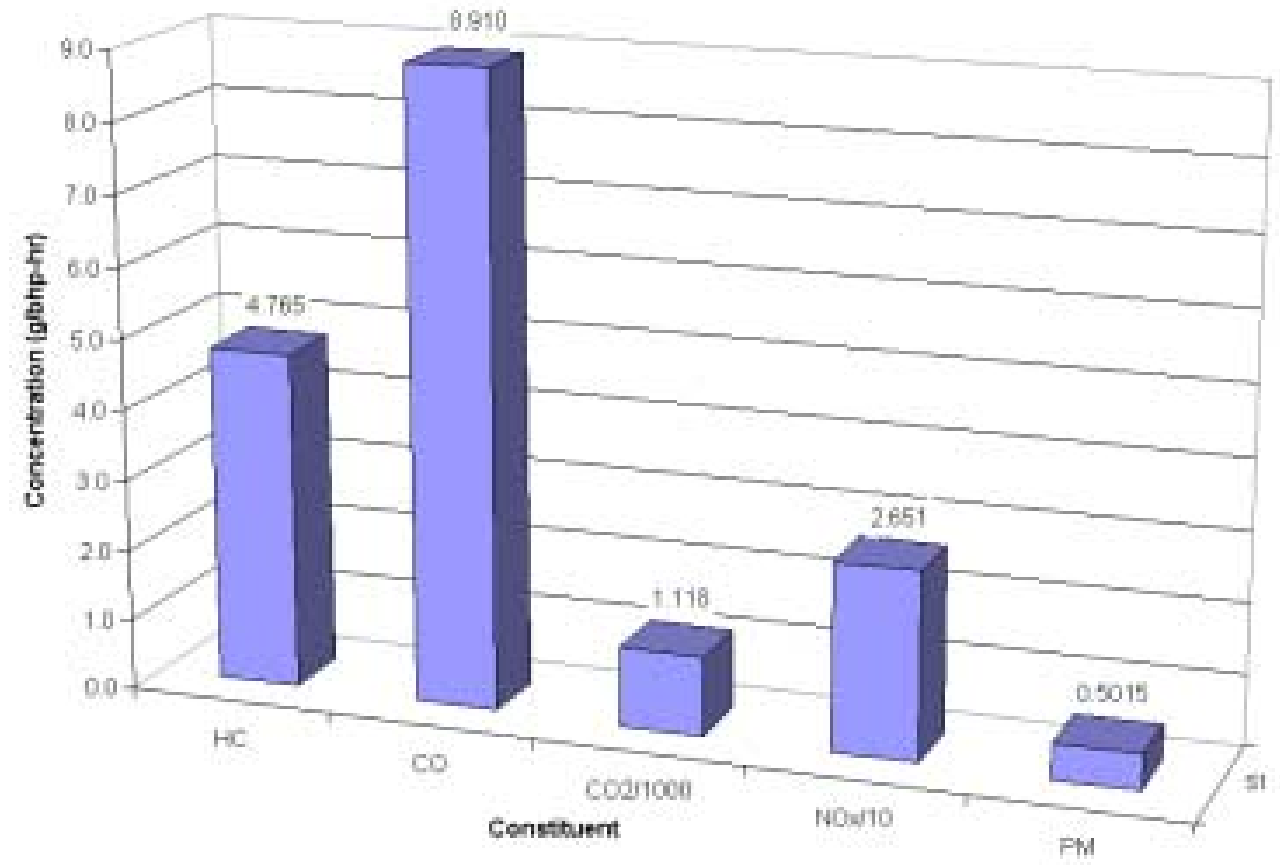

Figure 62 Average Weighted 8-Mode Results for the John Deere 6059 Loader Engine (g/bhp-hr). 


\subsubsection{Loader Transient Cycle Test Results}

In-laboratory transient cycle results for the John Deere 6059 loader engine can be seen in Table 14 with a graphical representation shown in Figure 63. All gaseous emissions data was found to be repeatable, with PM varying slightly from test to test. A total of five emissions tests were performed using the final iteration of the loader cycle for repeatability analysis. A graph of two repeated continuous $\mathrm{CO}_{2}$ data traces can be seen in Figure 64 while the repeat engine speed traces are illustrated in Figure 65. A correlation of the $\mathrm{CO}_{2}$ and engine speed data can be seen in Section 4.5.1.2 in Figure 44 and Figure 45, respectively. In the case of the loader, no full flow emissions data was collected in the laboratory during any of the previous cycle iterations with the laboratorygrade analyzers. Full-flow laboratory data was collected for the first and final iterations of the streetsweeper cycle in order to investigate the effects of cycle refinement on emission levels, the results of which are included in Section 4.6.2.2.

Table 14 Transient Cycle Emissions Results for the John Deere 6059 Loader Engine (g/bhp-hr).

\begin{tabular}{|l|c|c|c|c|c|c|}
\hline & Test 1 & Test 2 & Test 3 & Test 4 & Test 5 & Average \\
\hline HC & 0.70 & 0.76 & 0.72 & 0.75 & 0.78 & 0.74 \\
\hline CO & 2.05 & 2.17 & 2.19 & 2.17 & 2.27 & 2.17 \\
\hline CO $_{2}$ & 543.8 & 547.7 & 547.7 & 545.8 & 547.6 & 546.4 \\
\hline NO $_{\mathbf{x}}$ & 8.15 & 8.12 & 8.05 & 8.03 & 8.13 & 8.10 \\
\hline PM & 0.183 & 0.168 & 0.174 & 0.199 & - & 0.181 \\
\hline
\end{tabular}




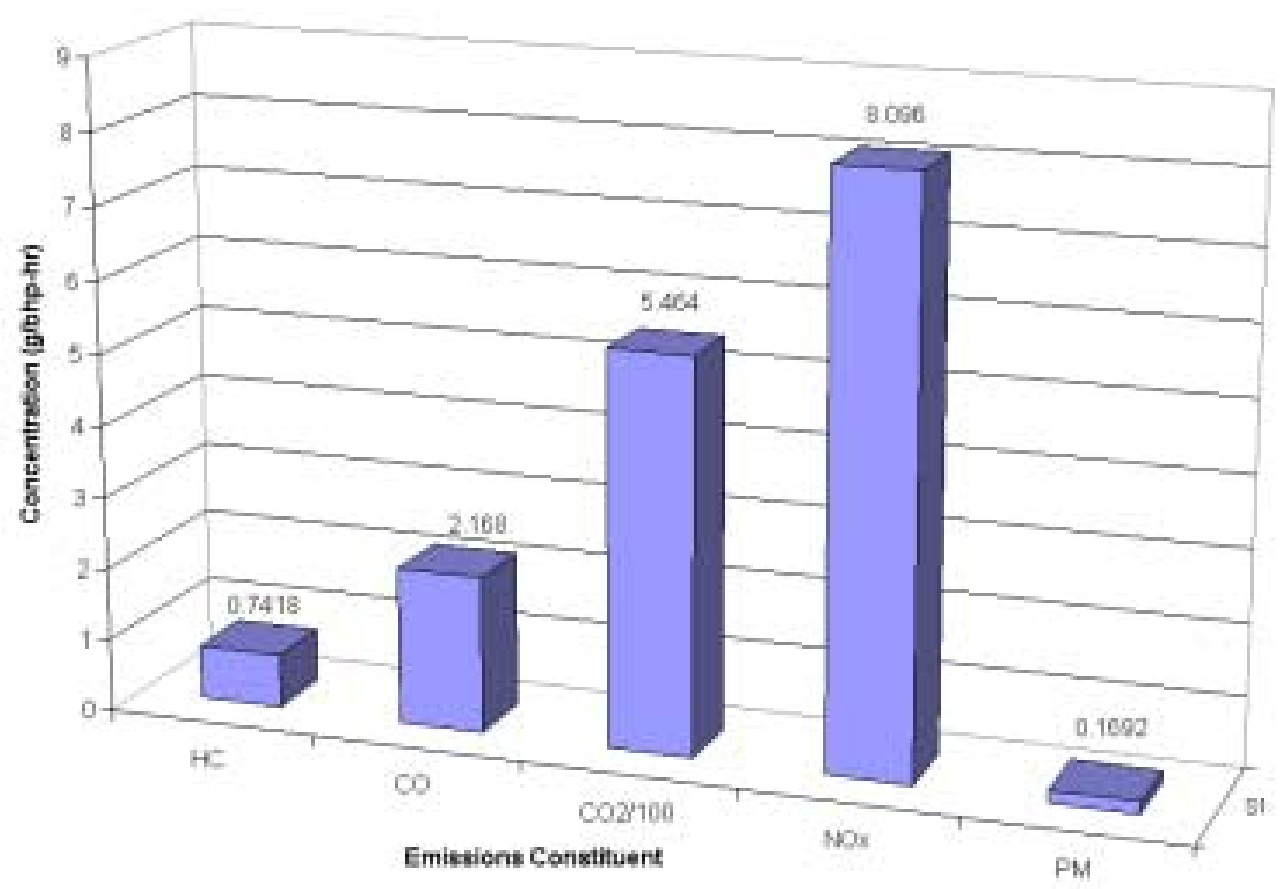

Figure 63 Transient Cycle Emissions Results for the John Deere 6059 Loader Engine (g/bhp-hr).

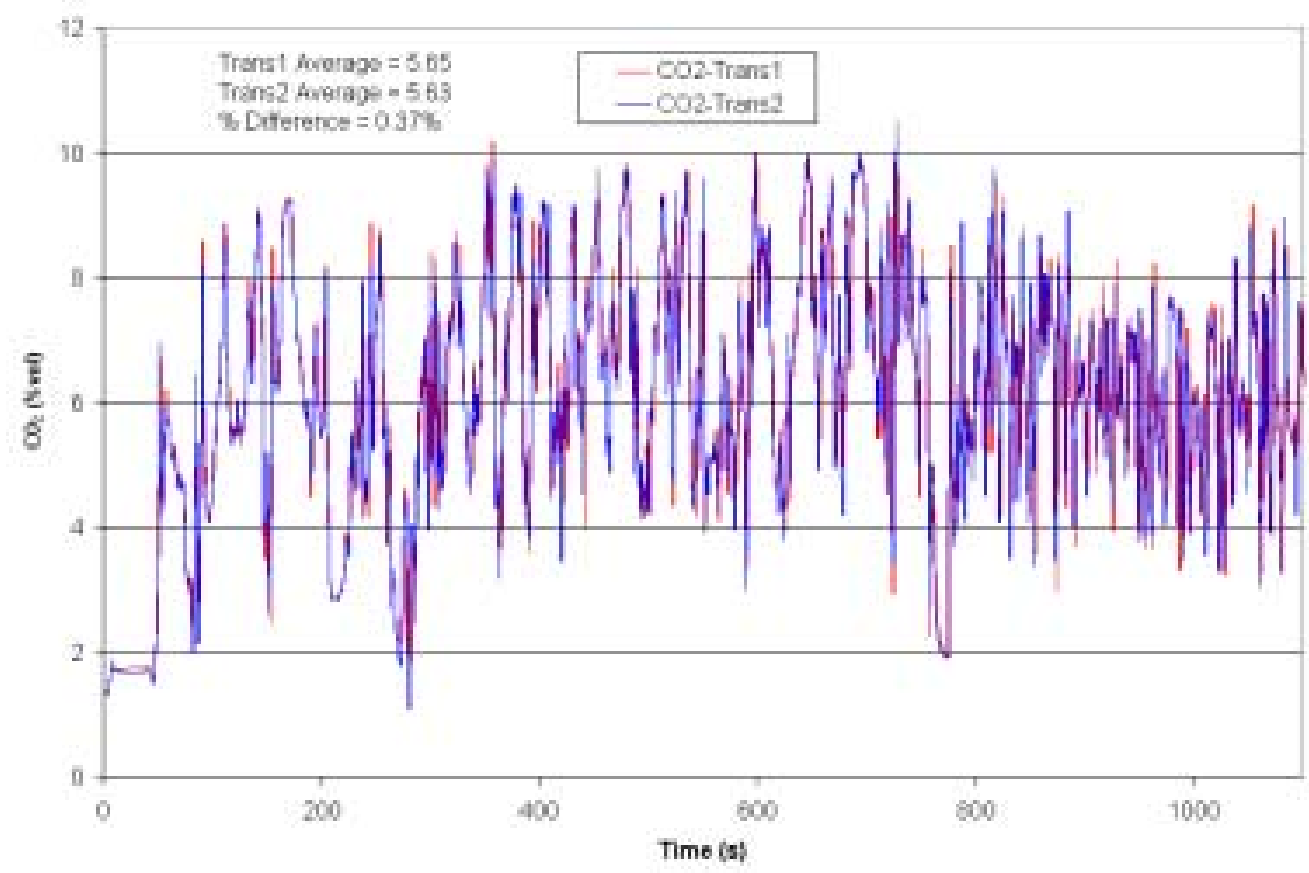

Figure 64 Comparison of Continuous $\mathrm{CO}_{2}$ Traces for Two Repeat Tests of the Final Loader Transient Cycle. 


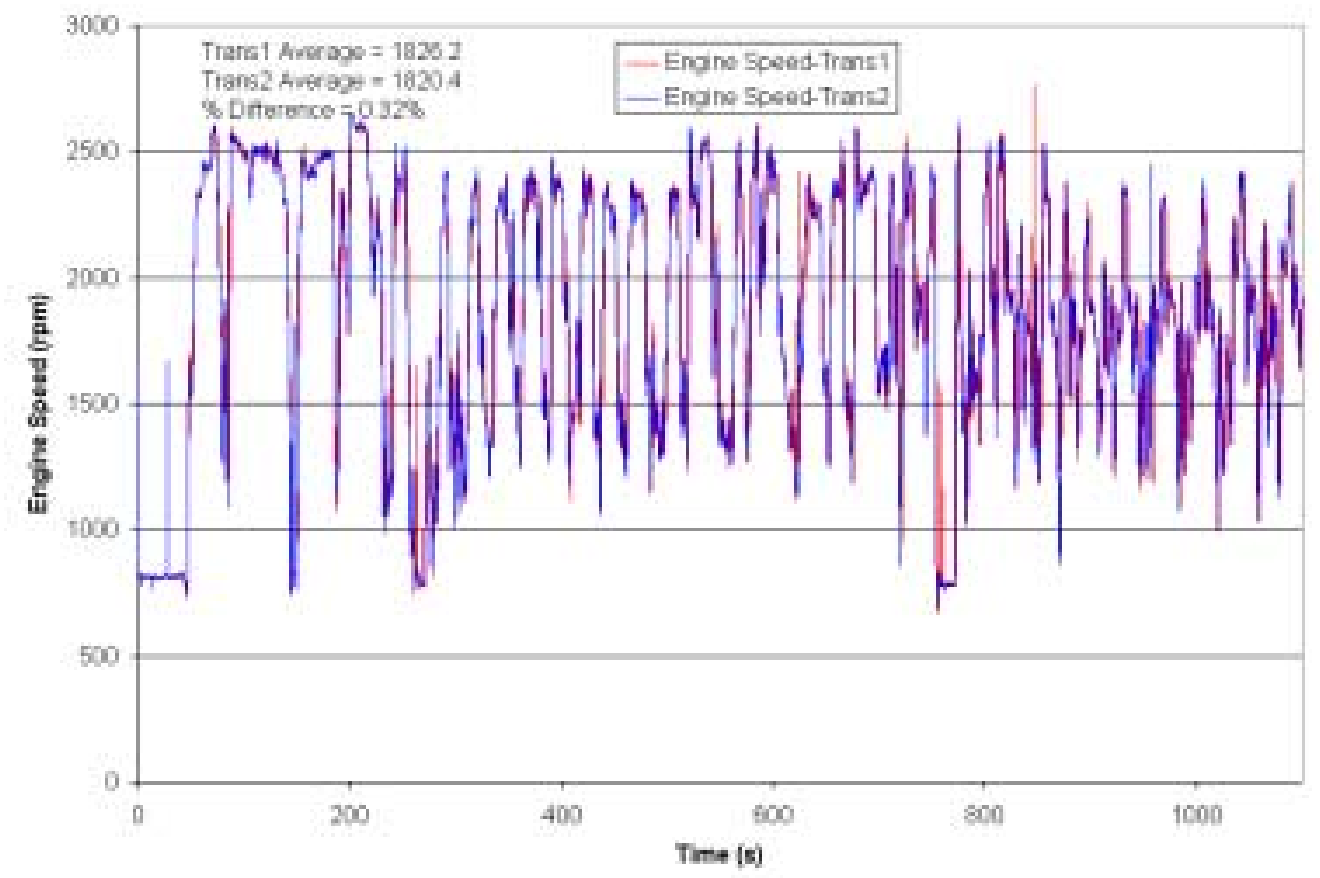

Figure 65 Comparison of Continuous Engine Speed Traces for Two Repeat Tests of the Final Loader Transient Cycle.

\subsubsection{Comparison of Loader Steady-State and Transient Test Results}

A comparison was made between 8-mode and transient results to determine how representative the 8-mode test cycle is of actual real world emissions. Brake-specific transient and weighted 8-mode results can be seen in Table 15.

Table 15 Comparison of Transient and Weighted 8-Mode Results for the John Deere 6059 Loader Engine (g/bhp-hr).

\begin{tabular}{|c|c|c|c|}
\hline Mode Number & $\begin{array}{c}\text { Weighted 8-Mode } \\
\text { Results }\end{array}$ & $\begin{array}{c}\text { Transient } \\
\text { Results }\end{array}$ & \% Difference \\
\hline HC & 4.77 & 0.74 & 544.6 \\
\hline CO & 8.91 & 2.17 & 310.6 \\
\hline CO $_{2}$ & 1118.0 & 546.4 & 104.6 \\
\hline NO $_{\mathbf{x}}$ & 26.51 & 8.10 & 227.3 \\
\hline PM & 0.502 & 0.181 & 177.3 \\
\hline
\end{tabular}


The feasibility of creating weighting factors that more accurately represent actual infield emissions was investigated. The setpoint file for the finalized streetsweeper cycle was first discretized in 100rpm increments from 700 to $2800 \mathrm{rpm}$. The percentage of the total cycle time that the vehicle spent in each 100rpm speed range was determined and can be seen in Figure 66.

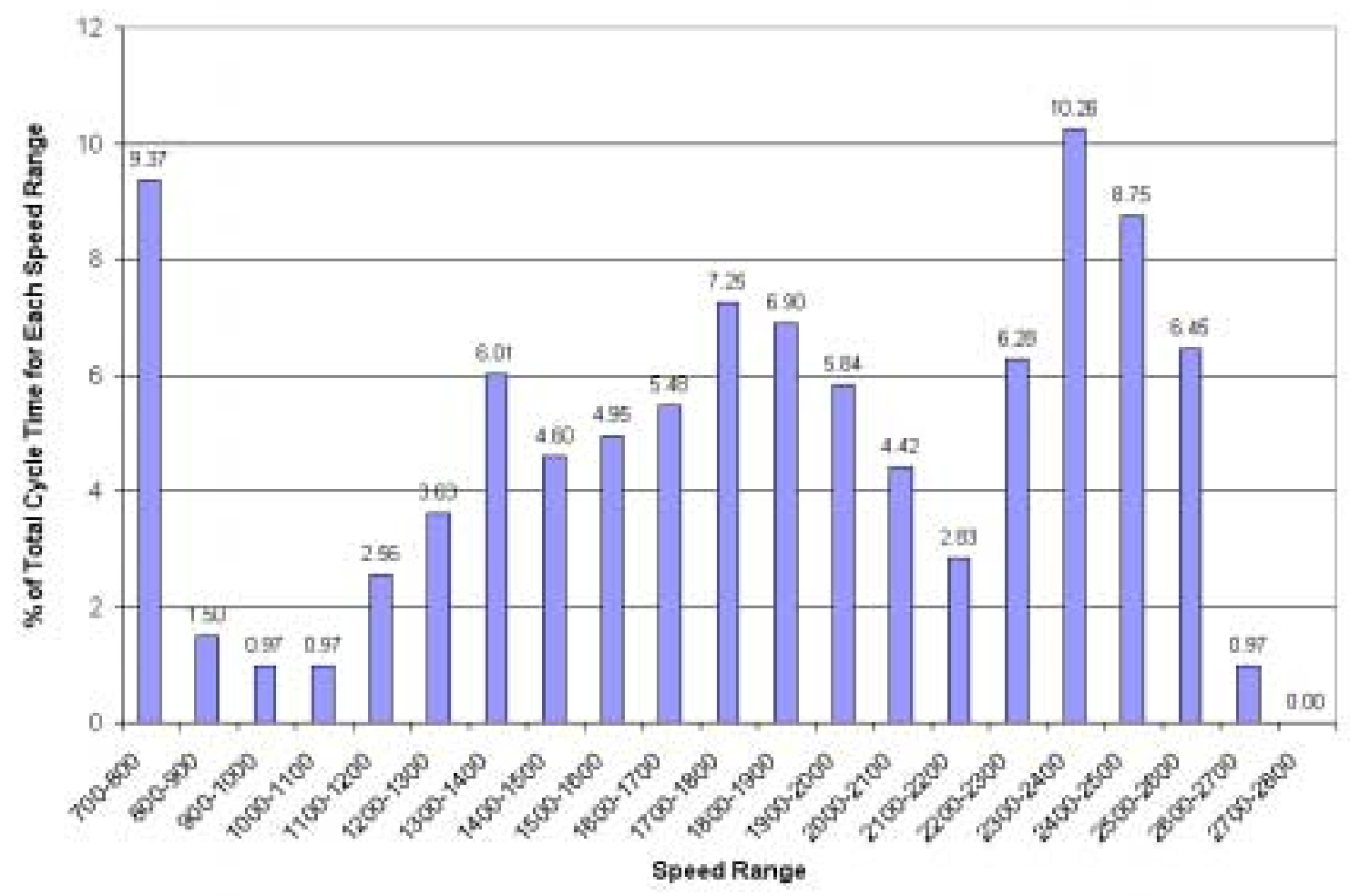

\section{Figure 66 Percentage of Total Cycle Time Spent In Each Speed Range for the John Deere 6059 Loader Engine.}

The speed discretization indicates a "tri-modal" distribution with idle, intermediate, and rated engine speed operating peaks. The data of Figure 66 was then examined for an approximate rated and intermediate speed range for the streetsweeper. Due to the local maximas at 1700-1800rpm and 2300-2400rpm, these were chosen as 
representative of intermediate and rated speed conditions for comparative purposes. Both the intermediate and rated speed ranges were then discretized from 0 to $100 \%$ load in increments of $5 \%$ and the percentage of the selected speed range time the vehicle spent at each load range was plotted. Other speed bands before and after the selected intermedate and rated speed bands were also discretized for the percentage of time spent in each load range to see how they compared to the intermediate and rated load range time percentages. A graphical representation of the results for the speed ranges adjacent to the selected intermediate and rated speed ranges can be seen in Figure 67. The results of this operation for the intermediate speed range can be seen in Figure 68 while the rated speed range is illustrated in Figure 69.

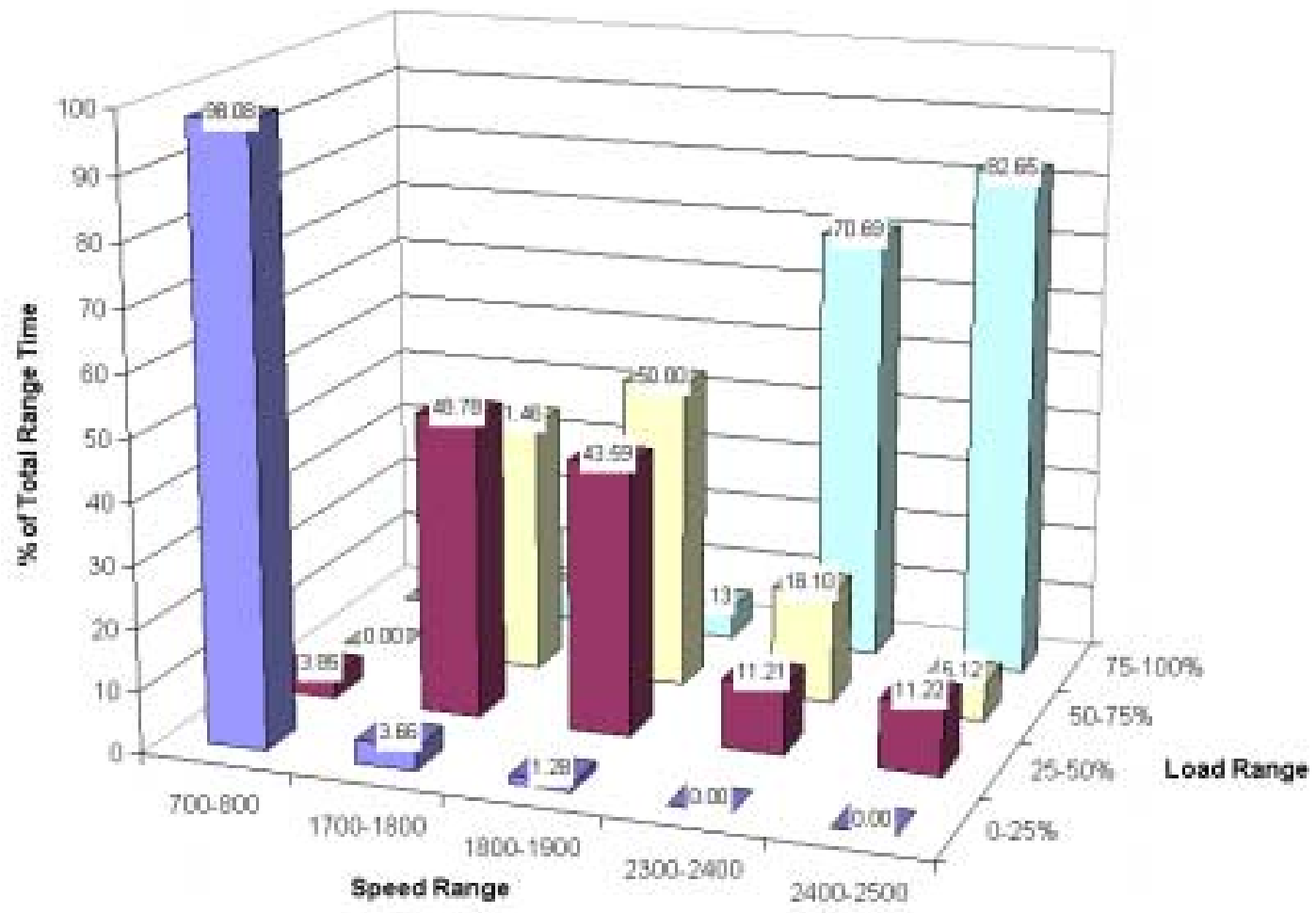

Figure 67 Comparison of the Time Spent at Different Load Ranges for Adjacent Speed Ranges. 


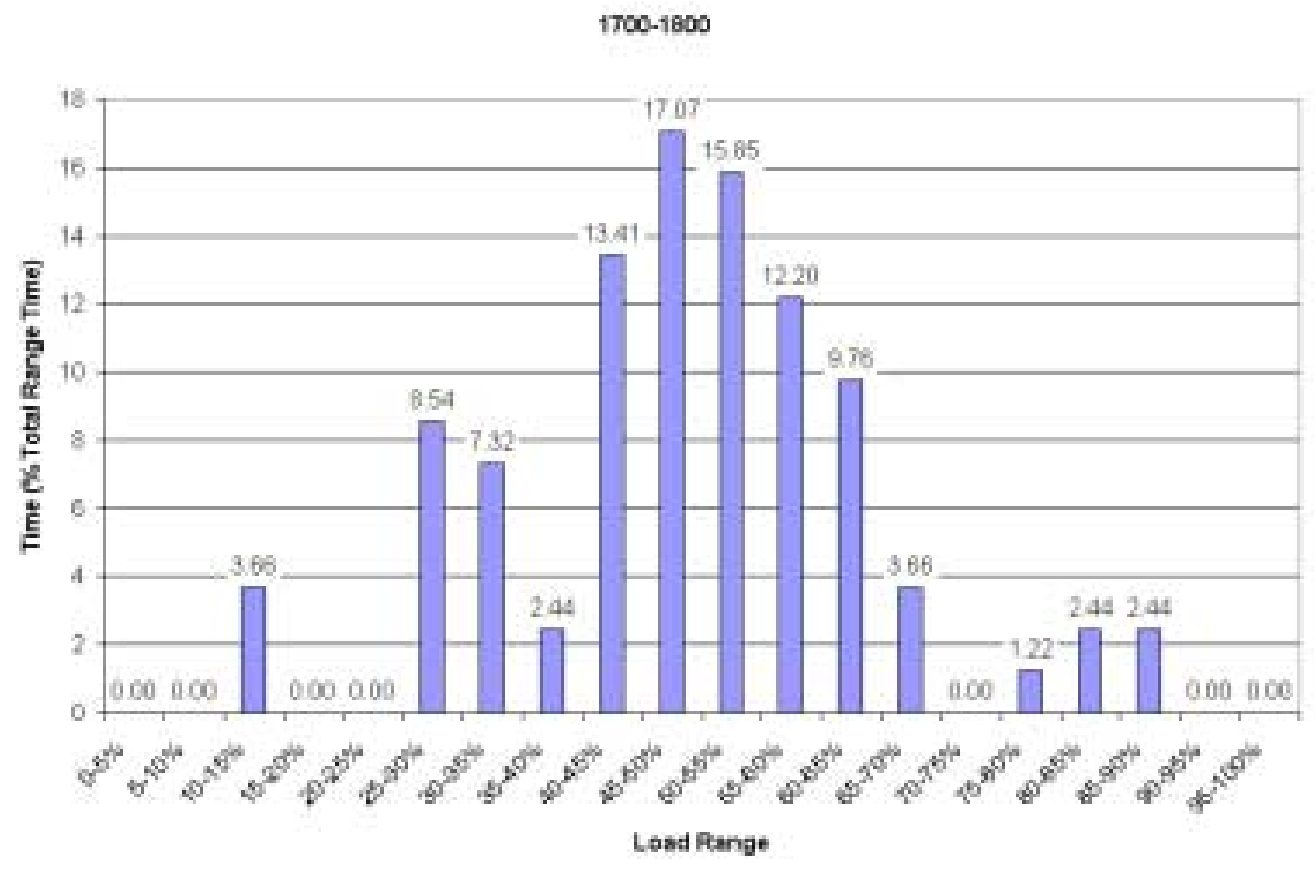

Figure 68 Percent Load vs. Percent Total Intermediate Speed Time for the John Deere 6059 Engine.

It can be seen from Figure 68 that the load range that the engine operated at most in the field for an intermediate speed range (1700-1800rpm) was 50-55\%. This would be comparable to the Intermediate $50 \%$ load point in the 8-mode cycle, which has a weighting factor of only 0.1 . It can also be deduced that the loader does not operate in the field at the other 8-mode intermediate points of $75 \%$ and $100 \%$ load, which both also have weighting factors of 0.10 . This indicates that the intermediate speed percent load points in the 8-mode cycle may be unrepresentative of actual "real world" load levels and, therefore, emissions data would also be unrepresentative. 
$2300-2400$

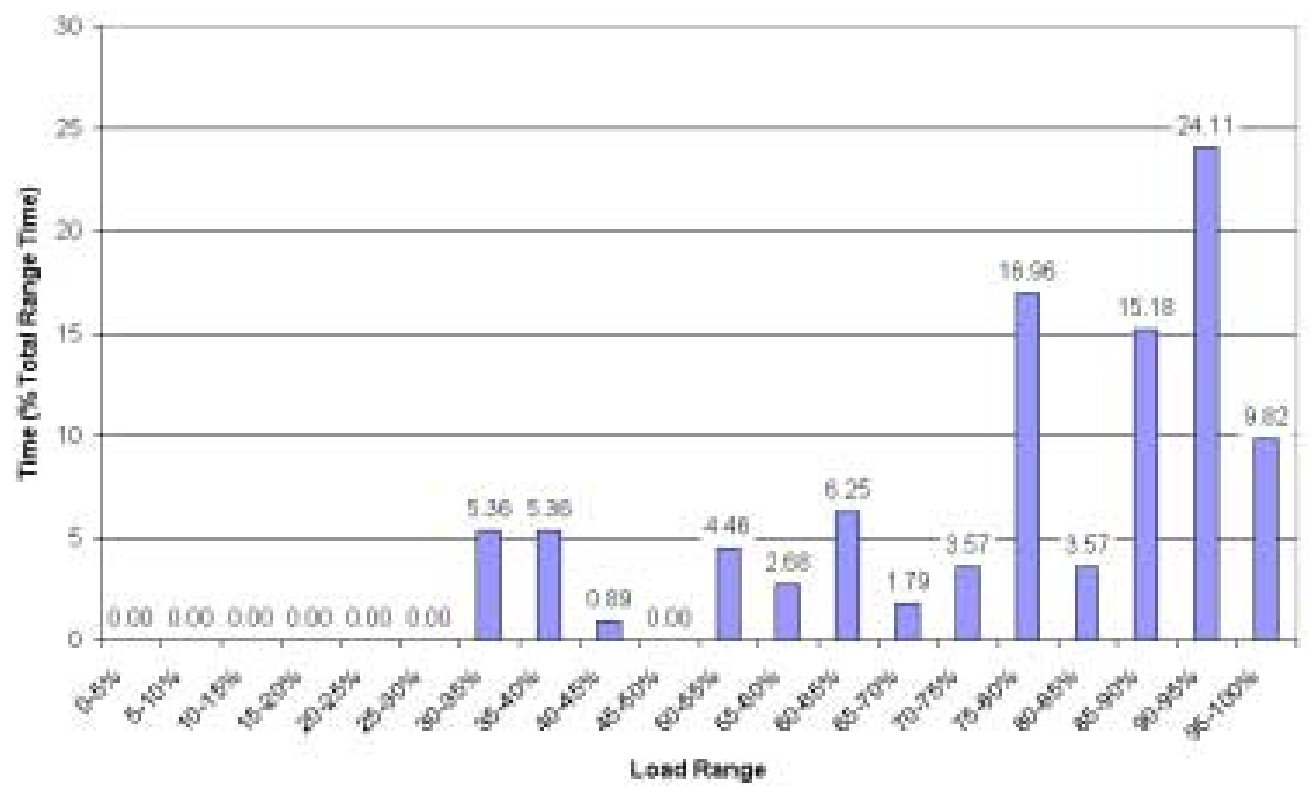

Figure 69 Percent Load vs. Percent Total Rated Speed Time for the John Deere 6059 Engine.

It can be seen from Figure 69 that the load range that the engine most operated in during infield testing was the rated speed range (2300-2400rpm) and was primarily above $75 \%$ full load. This would be comparable to the rated $75 \%$ and $100 \%$ load points in the 8-mode cycle, which both have a weighting factor of 0.15 . It can be deduced that the loader does not operate much in the field at the other rated 8-mode points of $10 \%$ and $50 \%$ load, which have 8-mode weighting factors of 0.10 and 0.15 , respectively. This indicates that the rated speed percent load points in the 8-mode cycle may be unrepresentative of actual "real world" load levels and, therefore, emissions data would also be unrepresentative.

It should be noted that the transient cycle setpoint file was used for this analysis rather than the actual measured speed/load data. A regression was performed between 
the speed/load commanded by the setpoint file and the actual speed/load levels achieved. The CFR 40 Part 86 [1] provides regression analysis criteria to assess the validity of a transient cycle with respect to its setpoint file. These criteria can be seen in Table 26.

Table 16 Regression Criteria for Transient Certification Test Validity Analysis as Outlined in the Code of Federal Regulations.

\begin{tabular}{|c|c|c|}
\hline Criteria & Speed & Torque \\
\hline Slope of Regression Line, $\mathbf{m}$ & $0.970-1.030$ & $0.83-1.03$ \\
\hline Coefficient of Determination, $\mathbf{R}^{\mathbf{2}}$ & 0.9700 & 0.8800 \\
\hline Regression line y intercept, $\mathbf{b}$ & $+-50 \mathrm{rpm}$ & $+-15 \mathrm{ft}-\mathrm{lb}$ \\
\hline
\end{tabular}

It can be concluded from viewing Figure 70 that the loader engine met the criteria for torque outlined in Table 26. The coefficient of determination for the torque was 0.8973 , the slope of the regression line was 0.94 , and the y-intercept was $8.02 \mathrm{ft}-1 \mathrm{~b}$. For the speed regression analysis performed, the results did not meet the criteria. The coefficient of determination for the speed was 0.7252 , the slope of the regression line was 0.8322, and the y-intercept was $307.24 \mathrm{rpm}$. The speed regression criteria could not be achieved with the eddy-current dynamometer and throttle controller setup used for the transient testing. The criteria listed in Table 26 are meant for engine certification purposes and were merely used as guidelines in this research as they did not have to be strictly adhered to. 


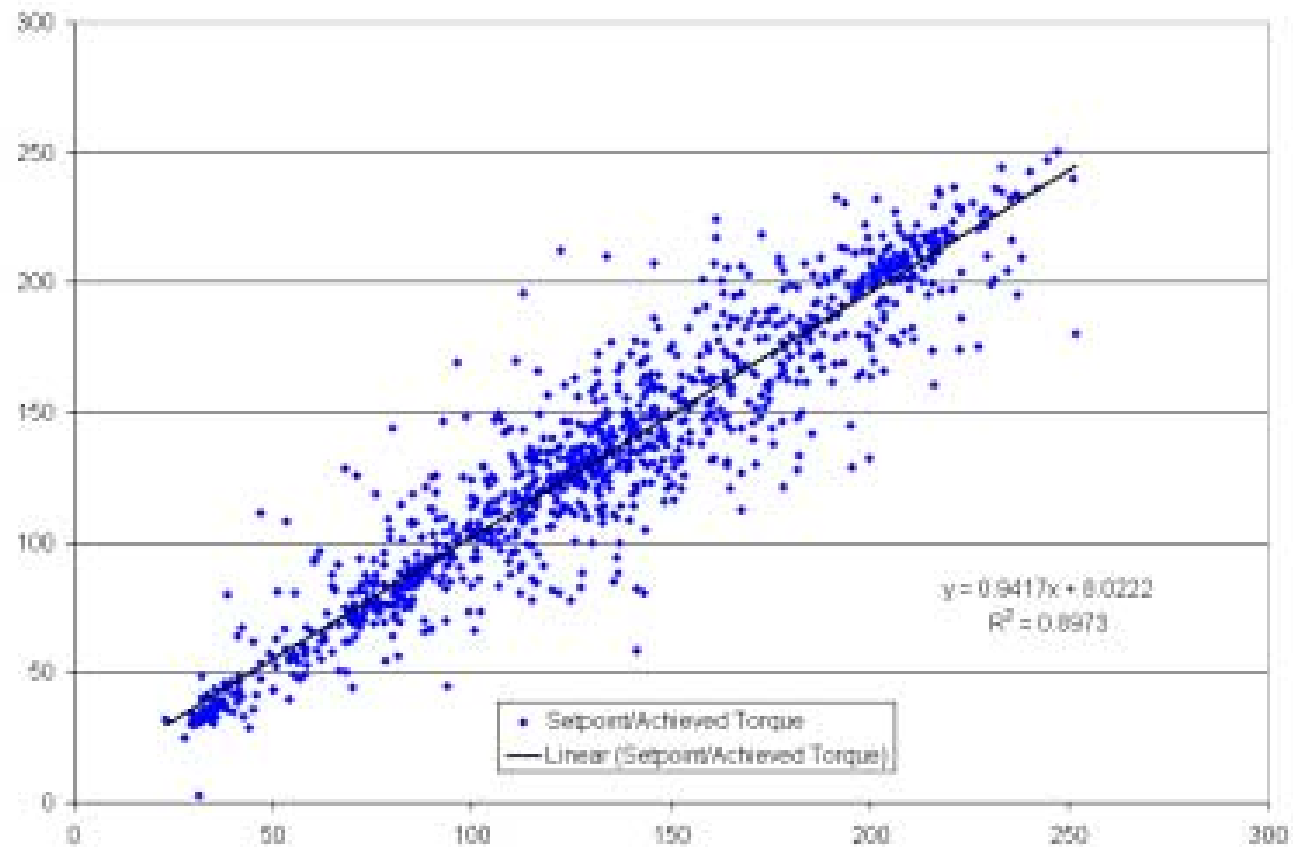

Figure 70 Regression Analysis for the Input vs. Achieved Torque for the John Deere 6059 loader Engine.

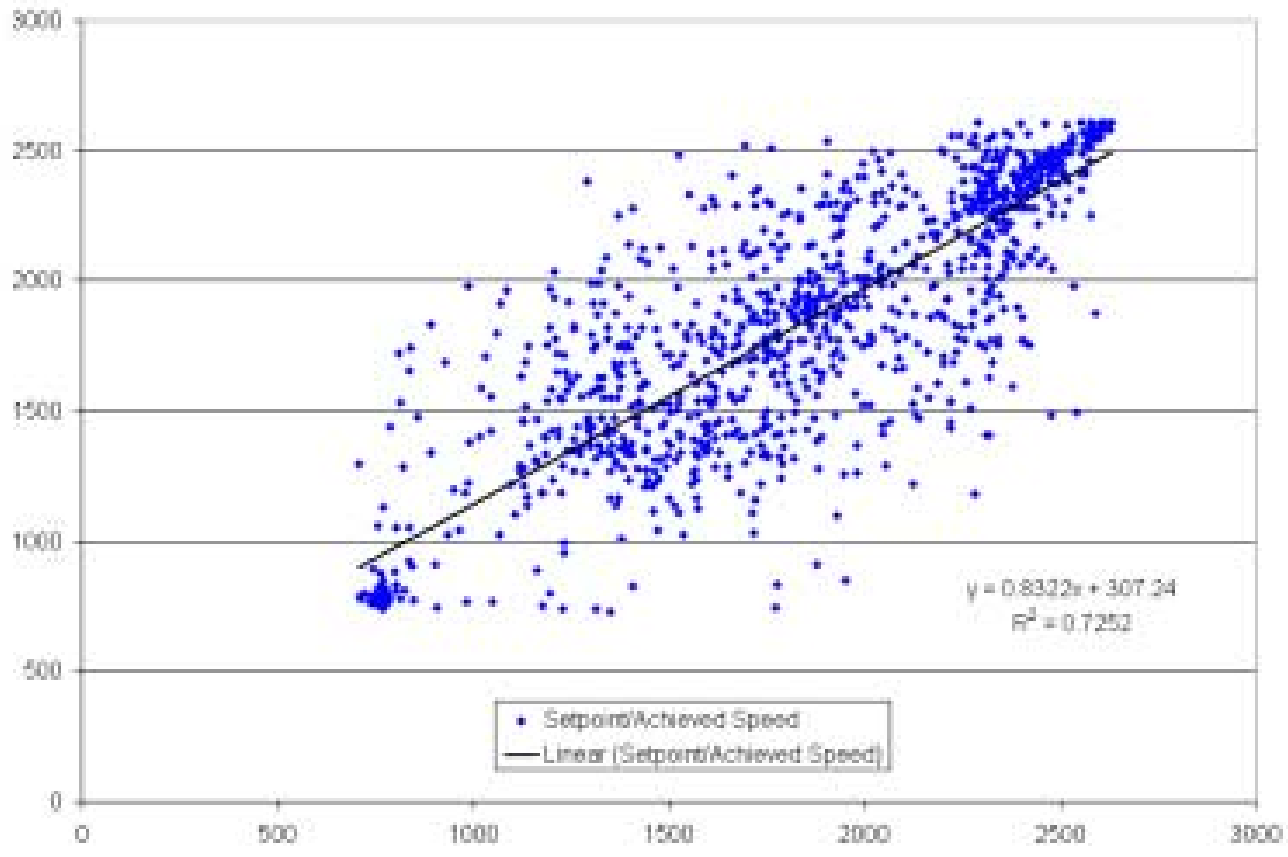

Figure 71 Regression Analysis for the Input vs. Achieved Engine Speed for the John Deere 6059 loader Engine. 


\subsubsection{Streetsweeper In-Laboratory Results}

Three types of in-laboratory testing were performed on the streetsweeper engine. The first tests performed were steady-state emissions tests that followed the ISO-8178 8mode testing protocols. The second series of testing consisted of final transient cycle emissions tests that followed the speed/load setpoints derived from the infield data and discussed in detail in the Cycle Development section of this thesis. The third test performed was a transient test that consisted of the streetsweeper engine being operated according to the normalized cycle that was developed for the loader engine.

\subsubsection{Streetsweeper Steady-State 8-Mode Test Results}

The ISO-8178 8-mode steady-state tests that were conducted consisted of four modes run at rated speed, three modes run at intermediate speed, and a "no-load" idle mode. Parasitic windage losses of the eddy current dynamometer were determined for all 8-mode testing speeds and the data was corrected for these losses when reduced. A sheet was procured from Mustang Dynamometers, the manufacturer of the eddy current dynamometer, which provided estimates of the windage losses (in ft-lbs) of the dynamometer at any speed point. The rated and intermediate speeds were obtained from the engine maps run on the engines prior to testing. The setpoints were determined using the rated and intermediate speed from the engine map and the percentages of maximum torque described in Table 11 of Section 4.6 of this document. A graphical representation of the engine map for the streetsweeper engine can be seen in Figure 52. The 8-mode speed and load set points for the 4039T streetsweeper engine can be seen in Table 17. 
The average emissions results for all gases and PM of the three 8-mode repeat tests performed can be seen in Table 18 with a graphical representation seen in Figure 72. The weighted results illustrated in Figure 73 were determined by multiplying the average results of Table 18 by the weighting factors outlined in Table 11 of Section 4.6. Results for all three runs of the 8-mode test are shown in table form in the appendix of this thesis.

Table 17 Streetsweeper 8-Mode Engine Speed/Load Set Points.

\begin{tabular}{|c|c|c|c|}
\hline Mode Number & Engine Speed (RPM) & Torque (ft-lbs) & Horsepower (hp) \\
\hline $\mathbf{1}$ & 2100 & 274.7 & 109.8 \\
\hline $\mathbf{2}$ & 2100 & 206.0 & 82.4 \\
\hline $\mathbf{3}$ & 2100 & 137.4 & 54.9 \\
\hline $\mathbf{4}$ & 2100 & 27.5 & 11.0 \\
\hline $\mathbf{5}$ & 1712 & 295.4 & 96.2 \\
\hline $\mathbf{6}$ & 1712 & 221.6 & 72.2 \\
\hline $\mathbf{7}$ & 1712 & 147.7 & 48.1 \\
\hline $\mathbf{8}$ & $\approx 760$ & 0.0 & 0.0 \\
\hline
\end{tabular}

Table 18 Average of 8-Mode Results for the John Deere 4039T Streetsweeper Engine (g/bhp-hr).

\begin{tabular}{|l|c|c|c|c|c|c|c|c||}
\hline & $\begin{array}{c}\text { Mode } \\
\mathbf{1}\end{array}$ & $\begin{array}{c}\text { Mode } \\
\mathbf{2}\end{array}$ & $\begin{array}{c}\text { Mode } \\
\mathbf{3}\end{array}$ & $\begin{array}{c}\text { Mode } \\
\mathbf{4}\end{array}$ & $\begin{array}{c}\text { Mode } \\
\mathbf{5}\end{array}$ & $\begin{array}{c}\text { Mode } \\
\mathbf{6}\end{array}$ & $\begin{array}{c}\text { Mode } \\
\mathbf{7}\end{array}$ & $\begin{array}{c}\text { Mode } \\
\mathbf{8}\end{array}$ \\
\hline HC & 0.13 & 0.16 & 0.27 & 2.17 & 0.04 & 0.20 & 0.23 & 9.82 \\
\hline $\mathbf{C O}$ & 1.60 & 0.59 & 0.53 & 4.96 & 11.31 & 2.04 & 0.34 & 16.29 \\
\hline $\mathbf{C O}_{\mathbf{2}}$ & 508.4 & 514.3 & 545.2 & 974.7 & 527.4 & 516.4 & 521.6 & 3297.0 \\
\hline $\mathbf{N O}_{\mathbf{x}}$ & 9.33 & 8.29 & 5.49 & 4.51 & 8.37 & 9.78 & 7.54 & 24.49 \\
\hline PM & 0.181 & 0.134 & 0.143 & 0.228 & 0.882 & 0.269 & 0.117 & 1.207 \\
\hline
\end{tabular}




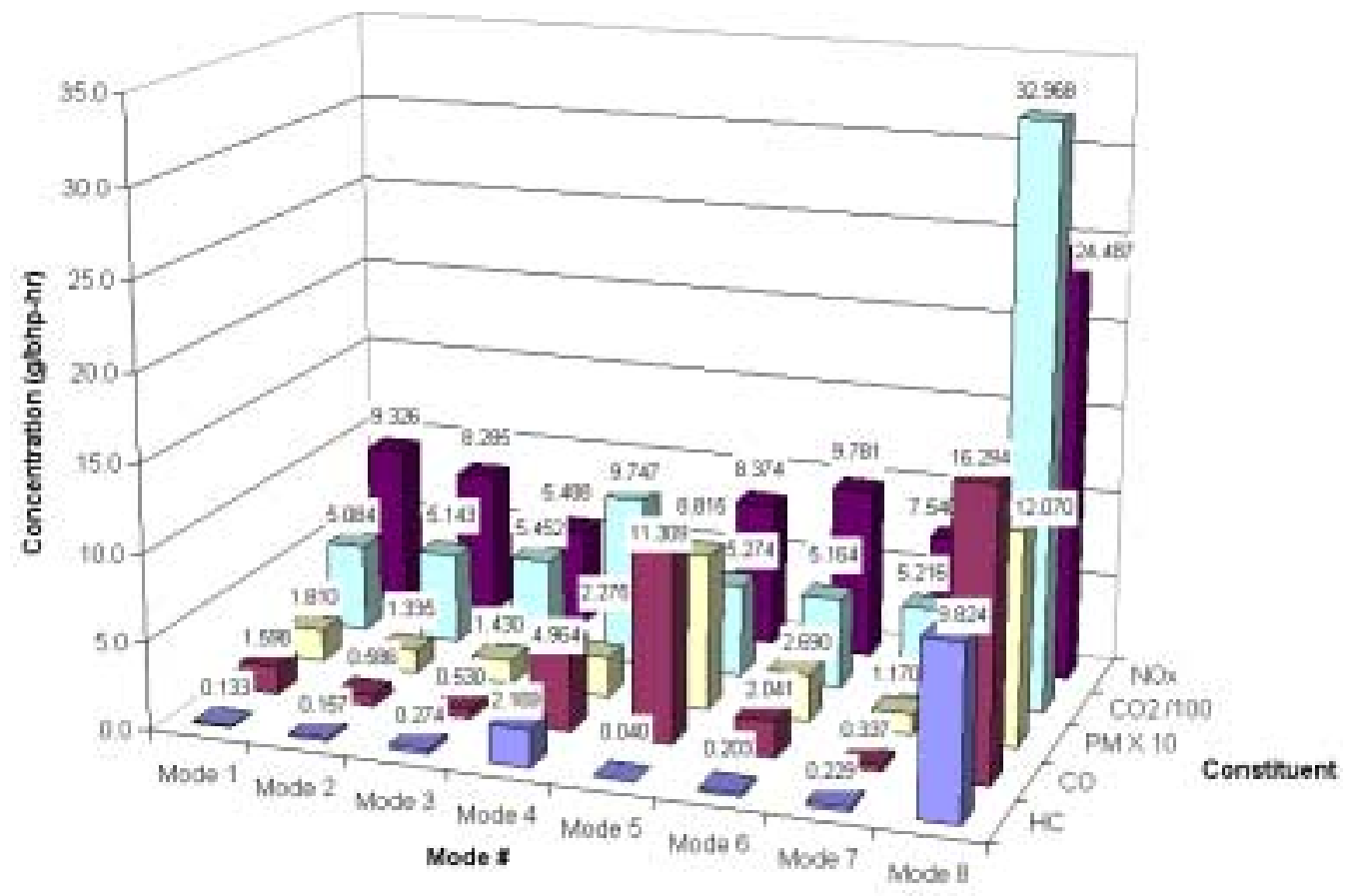

\section{Figure 72 Average of 8-Mode Results for the John Deere 4039T Streetsweeper Engine (g/bhp-hr).}

It should be noted that the results for mode 8 are higher than all the other modes because of the brake-specific format. During mode 8, the "no load" idle mode, the horsepower produced by the engine is very low, which makes any data specified on a “per horsepower” basis have a disproportionately higher value. For brake-specific (g/bhp-hr) data, there is some load on the engine even at idle. If there were actually no load on the engine, the emissions for the "no load" idle mode (mode 8) would be infinite. For this reason, presentation of 8-mode data would most accurately be presented in a time-based format, such as g/cycle, g/test, or g/mode. 


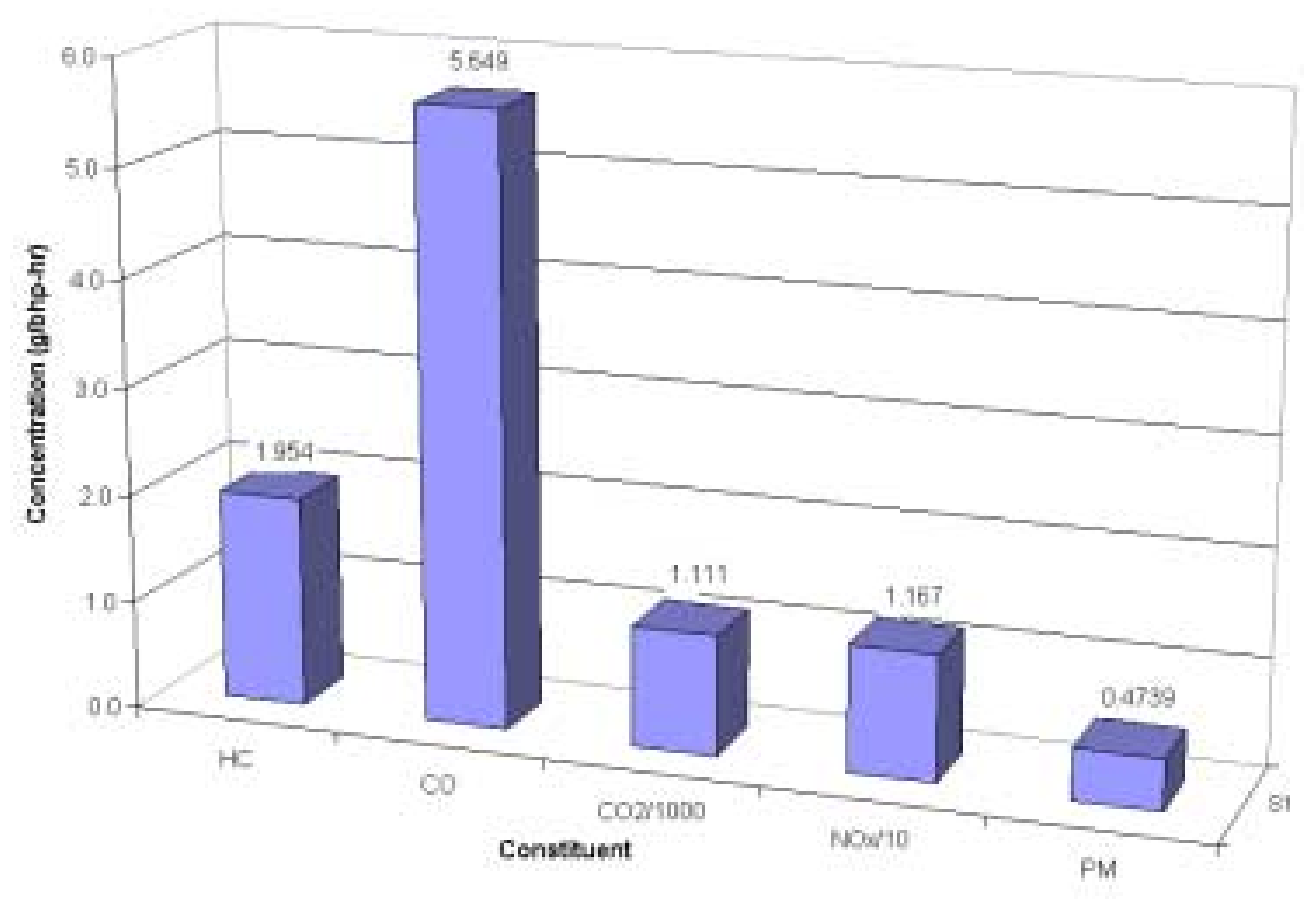

\section{Figure 73 Average Weighted 8-Mode Emissions for the John Deere 4039T Streetsweeper Engine (g/bhp-hr).}

\subsubsection{Streetsweeper Transient Cycle Test Results}

Several iterations were performed on the streetsweeper cycle before the final transient cycle emissions data were collected. Two tests were conducted with the first cycle iteration and two were run with the final iteration for repeatability purposes. A graph of two final cycle repeated continuous $\mathrm{CO}_{2}$ data traces can be seen in Figure 75 while the repeat engine speed traces are illustrated in Figure 76. A correlation of the $\mathrm{CO}_{2}$ and engine speed data can be seen in Section 4.5.2.3 in Figure 55 and Figure 56, respectively. The data collected for the first cycle iteration can be seen in Table 19 while the data collected for the final iteration can be seen in Table 20. A graphical representation for the data of Table 19 and Table 20 can be seen in Figure 74. A 
comparison of average results between the emissions values from both test cases can be seen in Table 21.

Table 19 Transient Cycle Emissions Results for the John Deere 4039T Streetsweeper Engine Operating on the First Iteration of the Derived Test Cycle (g/bhp-hr).

\begin{tabular}{||c|c|c|c|c|}
\hline & Trswpr1-Run 1 & Trswpr1-Run 2 & Trswpr1-Run 3 & Average \\
\hline HC & 0.55 & 0.573 & 0.351 & 0.491 \\
\hline CO & 1.97 & 1.93 & 1.95 & 1.95 \\
\hline CO $_{2}$ & 623.8 & 631.4 & 635.7 & 630.3 \\
\hline NO $_{\mathbf{x}}$ & 5.69 & 5.70 & 5.65 & 5.68 \\
\hline PM & 0.261 & 0.264 & 0.267 & 0.264 \\
\hline
\end{tabular}

Table 20 Emissions Results for the John Deere 4039T Streetsweeper Engine Operating on the Final Iteration of the Transient Cycle (g/bhp-hr).

\begin{tabular}{|c|c|c|c|c|}
\hline & Trswpr9-Run 1 & Trswpr9-Run 2 & Trswpr9-Run 3 & Average \\
\hline HC & 0.44 & 0.58 & 0.47 & 0.50 \\
\hline CO & 1.86 & 1.86 & 1.84 & 1.85 \\
\hline CO $_{2}$ & 624.7 & 623.9 & 629.4 & 626.0 \\
\hline NO $_{\mathbf{x}}$ & 5.64 & 5.54 & 5.60 & 5.59 \\
\hline PM & 0.243 & 0.242 & 0.248 & 0.245 \\
\hline
\end{tabular}

Table 21 Comparison of Emissions Results for the John Deere 4039T Streetsweeper Engine Operating on the First and Final Iteration of the Transient Cycle (g/bhp-hr).

\begin{tabular}{|c|c|c|c||}
\hline & $\begin{array}{c}\text { Trswpr1 } \\
\text { Average }\end{array}$ & $\begin{array}{c}\text { Trswpr9 } \\
\text { Average }\end{array}$ & $\begin{array}{c}\text { \% } \\
\text { Difference }\end{array}$ \\
\hline HC & 0.49 & 0.50 & 1.83 \\
\hline CO & 1.95 & 1.85 & -4.83 \\
\hline CO $_{2}$ & 630.3 & 626.0 & -0.68 \\
\hline NO $_{\mathbf{x}}$ & 5.68 & 5.59 & -1.51 \\
\hline PM & 0.264 & 0.245 & -7.350 \\
\hline
\end{tabular}

It can be concluded from the data of Table 21 that the refinement of the cycle through the use of the manual speed/load adjusting process does have a fairly significant impact on emissions results. As can be seen, percent difference values between the averages of data collected for the two tests ranged from $-7.53 \%$ to $1.83 \%$. However, 
cycle appropriateness for the particular vehicle being tested plays a much more significant role in cycle-averaged results. It can be seen in the next section that when the streetsweeper was run on the loader cycle, a large difference in cycle-averaged emissions results occurred.

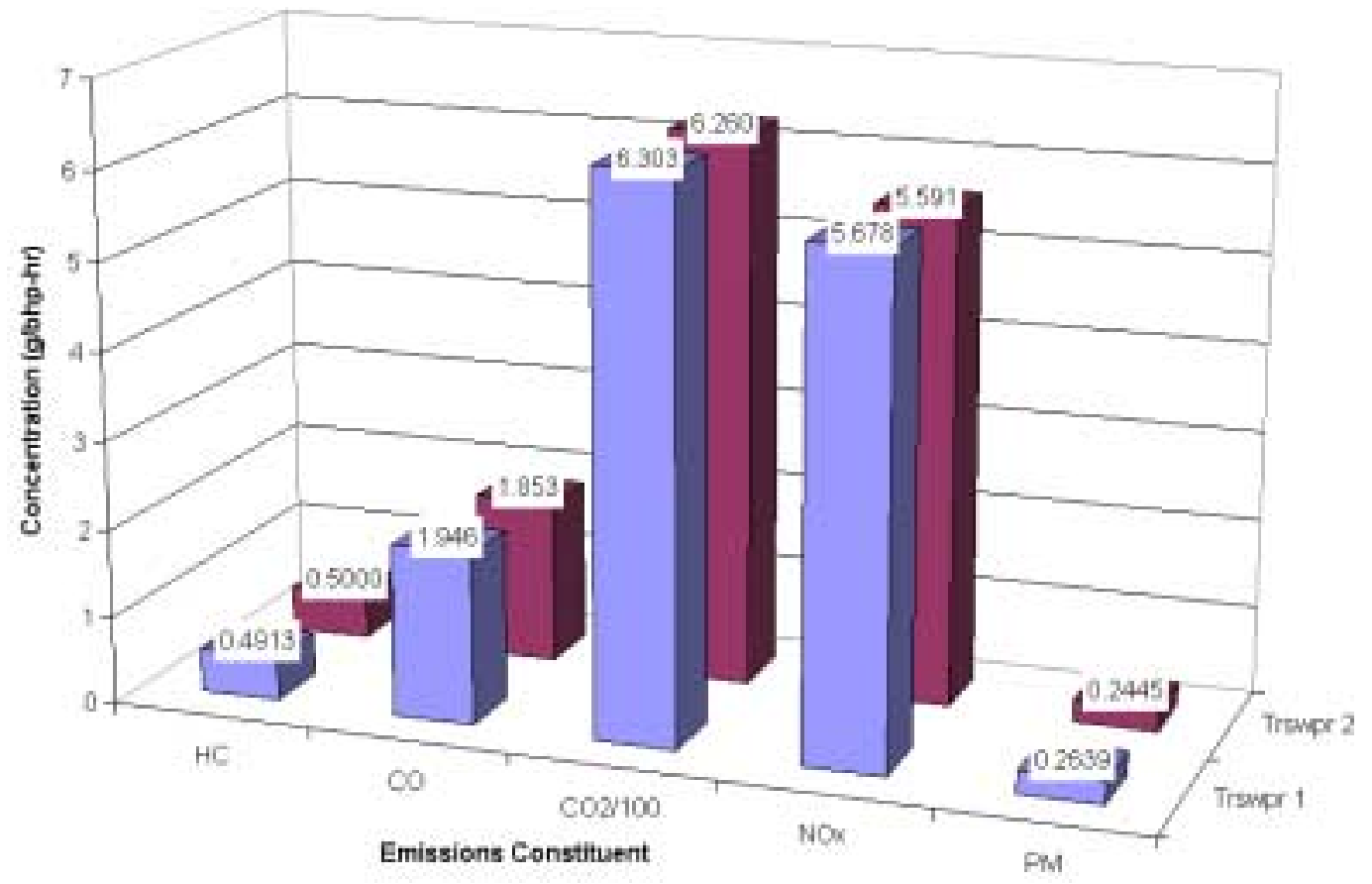

Figure 74 Average of Emissions Results for the John Deere 4039T Streetsweeper Engine Operating on the First and Final Iterations of the Transient Cycle (g/bhphr). 


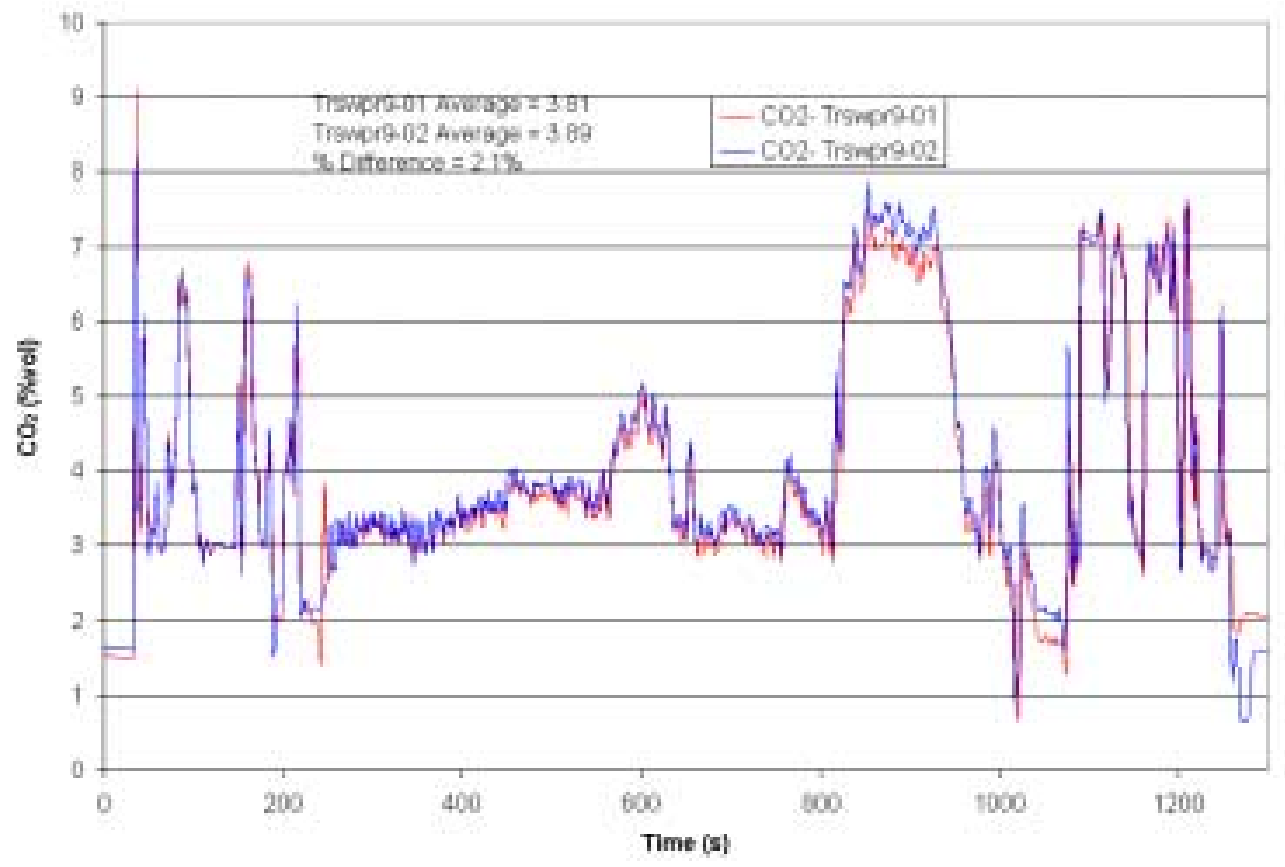

Figure 75 Comparison of Continuous $\mathrm{CO}_{2}$ Traces for Two Repeat Tests of the Final Streetsweeper Transient Cycle.

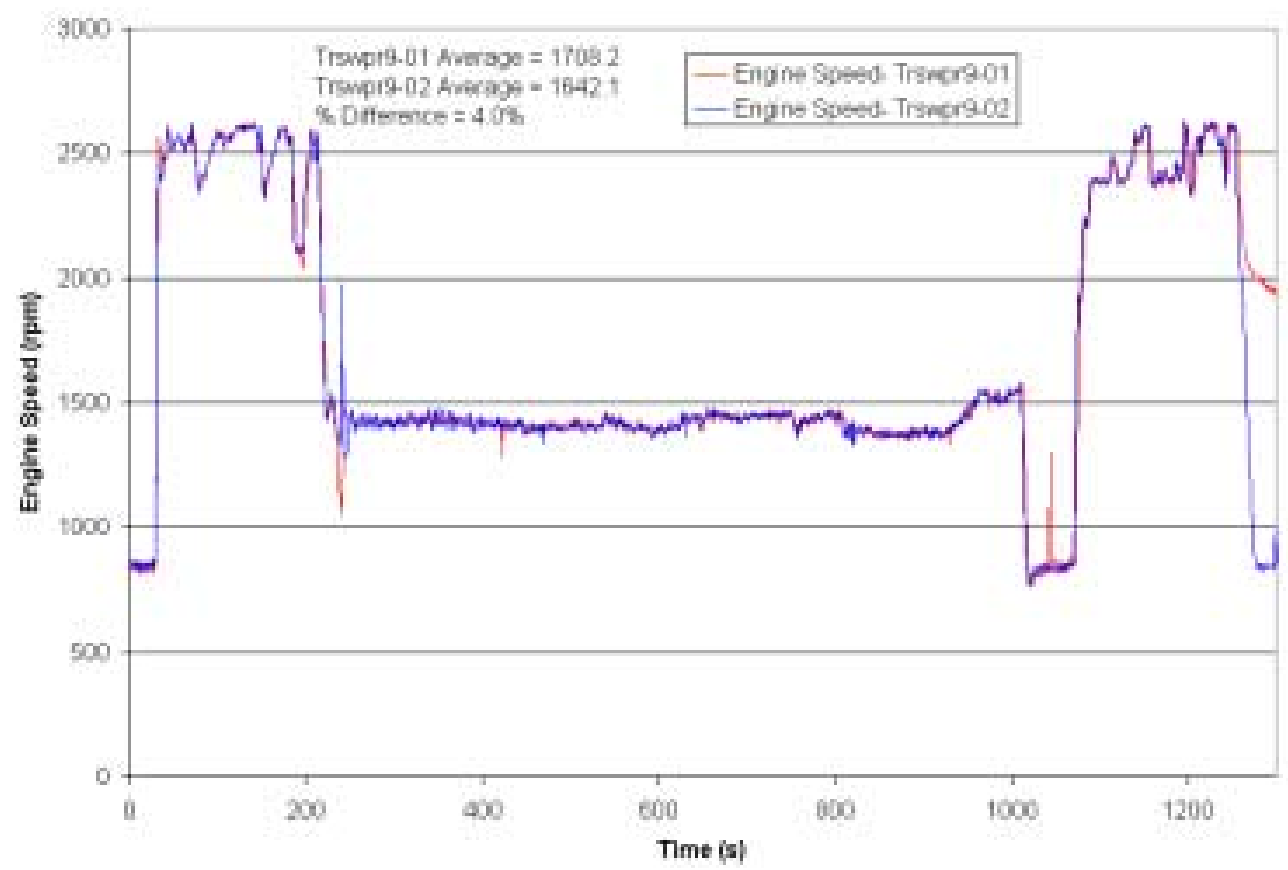

Figure 76 Comparison of Continuous Engine Speed Traces for Two Repeat Tests of the Final Streetsweeper Transient Cycle. 


\subsubsection{Streetsweeper-on-Loader Transient Cycle Test Results}

The streetsweeper was operated according to a normalized cycle developed previously for the rubber-tired loader. This test was performed to determine the feasibility of using the same cycle to test engines of different displacements but similar power levels and to determine the dependence of emissions levels on the cycles used. The turbocharged 4039T streetsweeper engine, even though of smaller displacement, made slightly more horsepower than the 6059 loader engine. The test illustrates the need to create cycles that accurately represent the "real world" operating conditions of the vehicle in the field.

Table 22 Cycle Averaged Emissions Results for the John Deere 4039T Streetsweeper Engine Operating on the Final Loader Transient Cycle (g/bhp-hr).

\begin{tabular}{||c|c|c|c|c|}
\hline & $\begin{array}{c}\text { Sweeper-on- } \\
\text { Loader Run 1 }\end{array}$ & $\begin{array}{c}\text { Sweeper-on- } \\
\text { Loader Run 2 }\end{array}$ & $\begin{array}{c}\text { Sweeper-on- } \\
\text { Loader Run 3 }\end{array}$ & Average \\
\hline HC & 0.39 & 0.35 & 0.36 & 0.37 \\
\hline CO & 3.66 & 3.56 & 3.50 & 3.57 \\
\hline CO $_{\mathbf{2}}$ & 561.9 & 561.1 & 562.4 & 561.8 \\
\hline NO $_{\mathbf{x}}$ & 7.37 & 7.34 & 7.38 & 7.36 \\
\hline PM & 0.389 & 0.376 & 0.343 & 0.370 \\
\hline
\end{tabular}

Table 23 Average Results Comparison of Transient Tests Performed (g/bhp-hr).

\begin{tabular}{|c|c|c|c||}
\hline \hline & $\begin{array}{c}\text { Sweeper-on- } \\
\text { Sweeper Cycle }\end{array}$ & $\begin{array}{c}\text { Sweeper-on- } \\
\text { Loader Cycle }\end{array}$ & \% Difference \\
\hline HC & 0.50 & 0.37 & -26.54 \\
\hline CO & 1.85 & 3.57 & 92.61 \\
\hline CO $_{2}$ & 626.0 & 561.8 & -10.26 \\
\hline NO $_{\mathbf{x}}$ & 5.59 & 7.36 & 31.60 \\
\hline PM & 0.245 & 0.370 & 51.19 \\
\hline
\end{tabular}




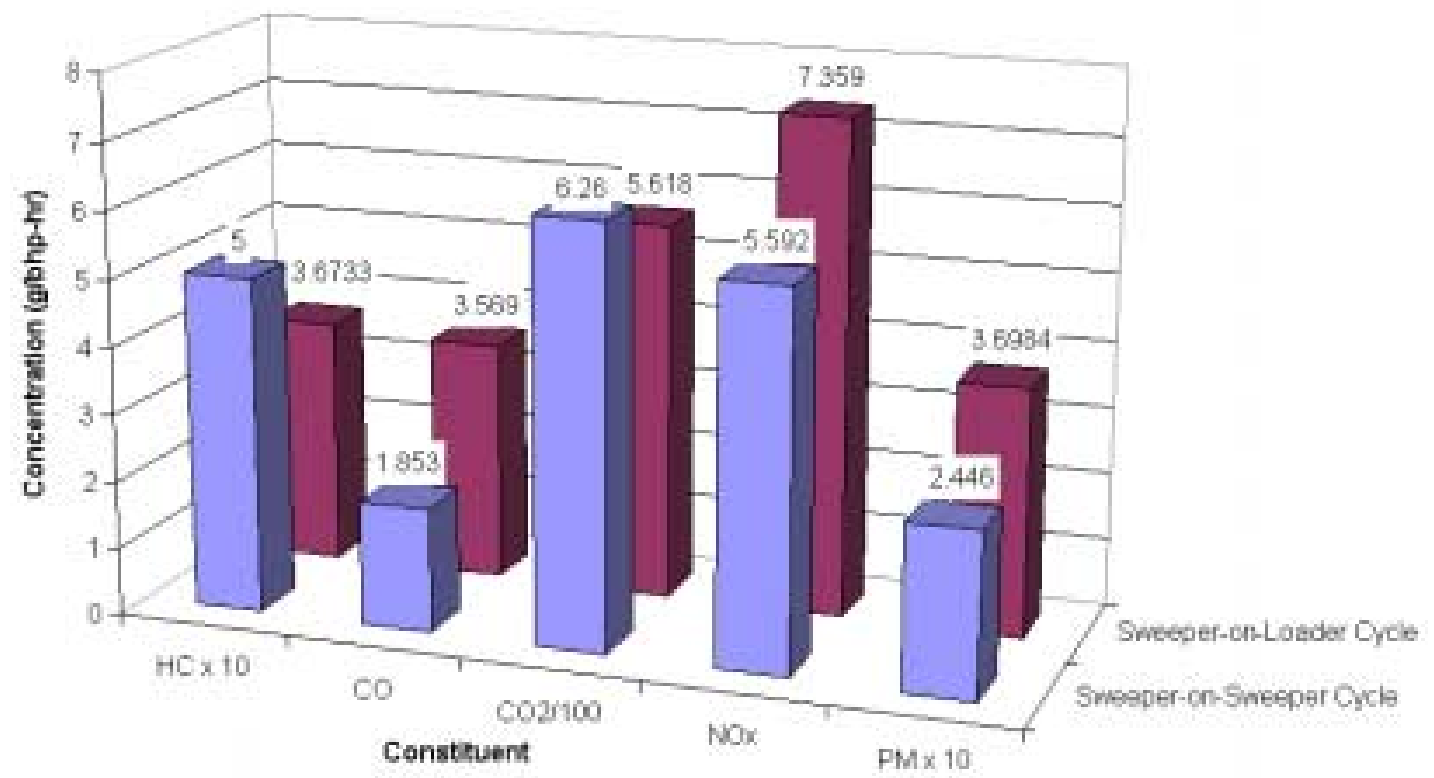

Figure 77 Graphical Comparison of the Effects of the Test Cycle on Engine Emissions (g/bhp-hr).

It can be seen from the data of Table 23 and Figure 77 that the nature of the cycle followed during testing had a dramatic effect on emission levels. In comparison with the Sweeper-on-Sweeper Cycle test, the Sweeper-on-Loader Cycle test yielded substantially higher $\mathrm{CO}(92.61 \%)$ and PM (51.19\%) levels coupled with lower $\mathrm{CO}_{2}(-10.26 \%)$ levels, which is an indication of less thorough combustion of the fuel consumed. This result can be explained in terms of the number of transient events encountered in the running of each cycle. The smoother, more steady-state sweeper cycle exhibited more complete combustion because of the more steady engine speed and much less transient torque demands placed on the engine during the sweeping process. In contrast, the drastic engine speed changes and quick torque transients of the loader cycle combine to produce 
a less complete combustion of the fuel and the resultant increase of the undesirable $\mathrm{CO}$ and PM emissions.

It can be concluded from the data of this section that "real world" representation of test cycle activity plays a much larger role in emissions results than the accurate repeatability of the infield cycle does. While the laborious and time-consuming process of cycle iteration changed the streetsweeper cycle averaged $\mathrm{CO}_{2}$ results by only $0.68 \%$, running the streetsweeper on the unrepresentative loader cycle changed cycle averaged $\mathrm{CO}_{2}$ results by $-10.26 \%$ on a brake-specific basis.

\subsubsection{Comparison of Sweeper Steady-State and Transient Test Results}

A comparison was made between 8-mode and transient results to determine how representative the 8-mode test cycle is of actual real world emissions. Differences between brake-specific transient and weighted 8-mode results can be seen in Table 24 .

Table 24 Comparison of Transient and Weighted 8-Mode Results for the John Deere 4039T Streetsweeper Engine (g/bhp-hr).

\begin{tabular}{|c|c|c|c|}
\hline Mode Number & $\begin{array}{c}\text { Weighted 8-Mode } \\
\text { Results }\end{array}$ & $\begin{array}{c}\text { Transient } \\
\text { Results }\end{array}$ & \% Difference \\
\hline HC & 1.95 & 0.50 & 290.0 \\
\hline $\mathbf{C O}$ & 5.65 & 1.85 & 205.4 \\
\hline $\mathbf{C O}_{\mathbf{2}}$ & 1111.0 & 626.0 & 77.5 \\
\hline $\mathbf{N O}_{\mathbf{x}}$ & 11.67 & 5.59 & 108.8 \\
\hline PM & 0.474 & 0.245 & 93.5 \\
\hline
\end{tabular}

The feasibility of creating weighting factors that more accurately represent actual infield emissions was investigated. The setpoint file for the finalized streetsweeper cycle was first discretized in 100rpm increments from 700 to 2800rpm. The percentage of the total cycle time that the vehicle spent in each 100rpm speed range was determined and can be seen in Figure 78. 


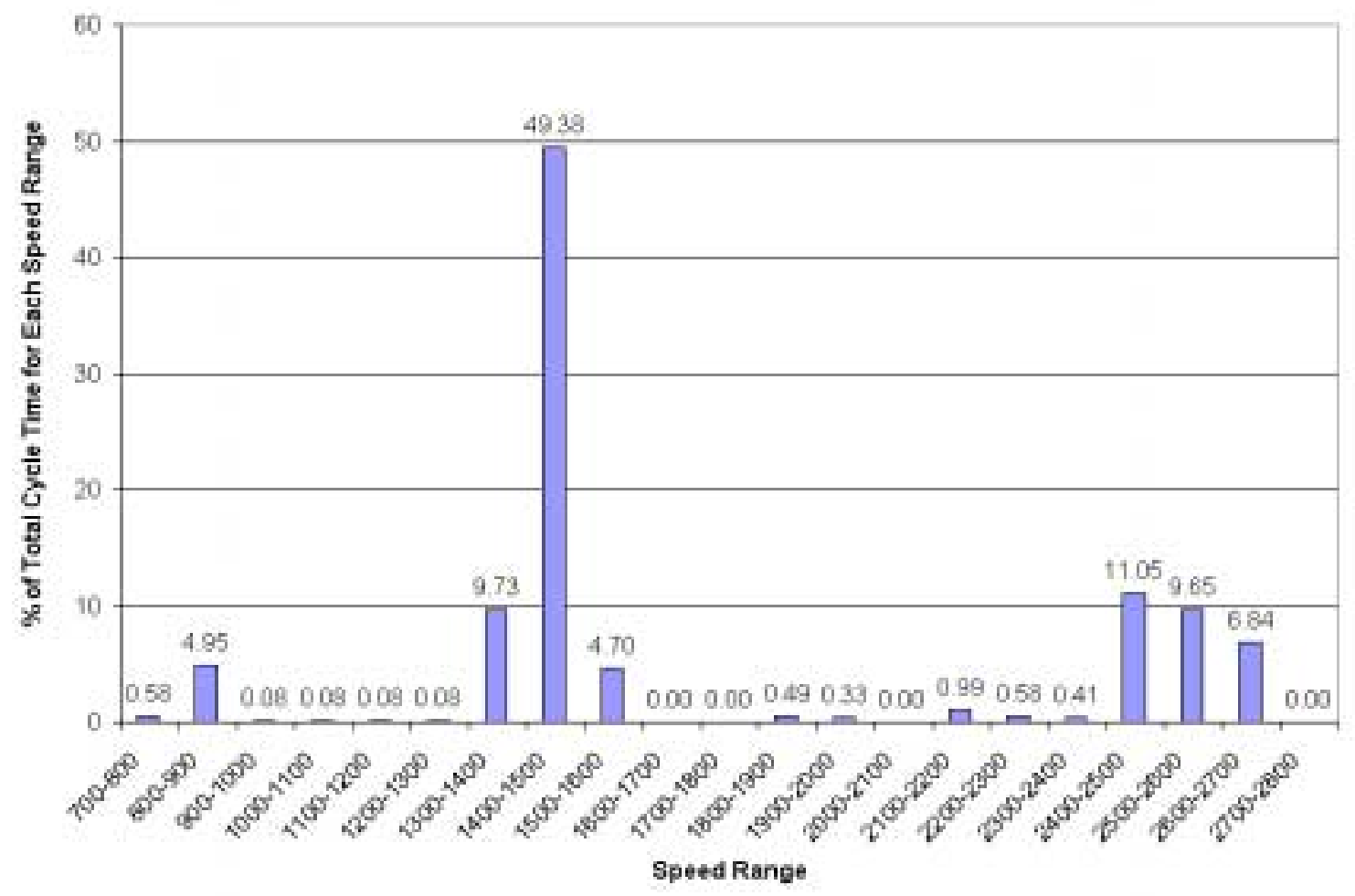

\section{Figure 78 Percentage of Total Cycle Time Spent in each Speed Range.}

The speed discretization indicates a "tri-modal" distribution with idle, intermediate, and rated engine speed operating peaks. The data of Figure 78 was then examined for an approximate rated and intermediate speed range for the streetsweeper. Due to the local maximas at 1400-1500rpm and 2400-2500rpm, these were chosen to be representative of intermediate and rated speed conditions for comparative purposes. Both the intermediate and rated speed ranges were then discretized from 0 to $100 \%$ load in increments of 5\% and the percentage of the selected speed range time the vehicle spent at each load range was plotted. Other speed ranges before and after the selected intermediate and rated speed ranges were also discretized for the percentage of time spent in each load range to see how they compared to the intermediate and rated load range 
time percentages. The results of this operation for the intermediate speed range can be seen in Figure 79 while the rated speed range is illustrated in Figure 80.

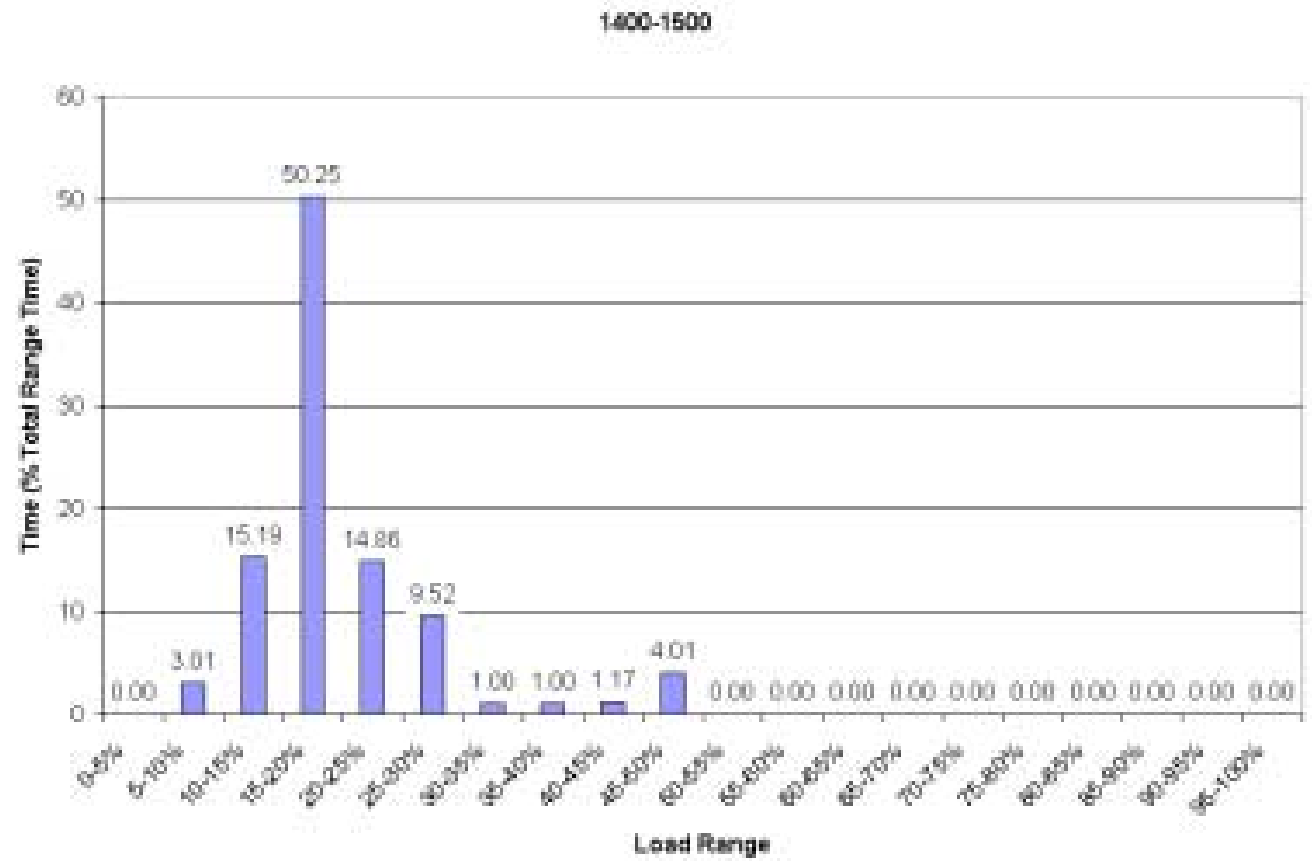

\section{Figure 79 Percent Load vs. Percent Total Intermediate Speed Time for the John Deere 4039T Engine.}

It can be seen from Figure 79 that the load range the engine operated at the most in the field for the intermediate speed range (1400-1500rpm) was $15-20 \%$. By multiplying the time spent in the intermediate speed range by the time spent in the desired load ranges, one can arrive at an approximate weighting factor for the mode. For example, by multiplying the percentage of time the sweeper operated in the intermediate range $(49.38 \%)$ by the percentage of time the streetsweeper spent at a desired "mode," say Intermediate 50, (20\%) one could arrive at a percentage factor of approximately $10 \%$, which equates to a weighting factor of about 0.22 . The weighting factor for intermediate 75 and intermediate 100 should also be assigned values of zero for the case of the streetsweeper. In the 8-mode cycle, the weighting factor for intermediate 50, 
intermediate 75 , and intermediate 100 are all 0.1 . This illustrates why the 8 -mode data may not be representative of actual "real world" load levels and, therefore, emissions data would not provide an accurate picture emissions contributions.

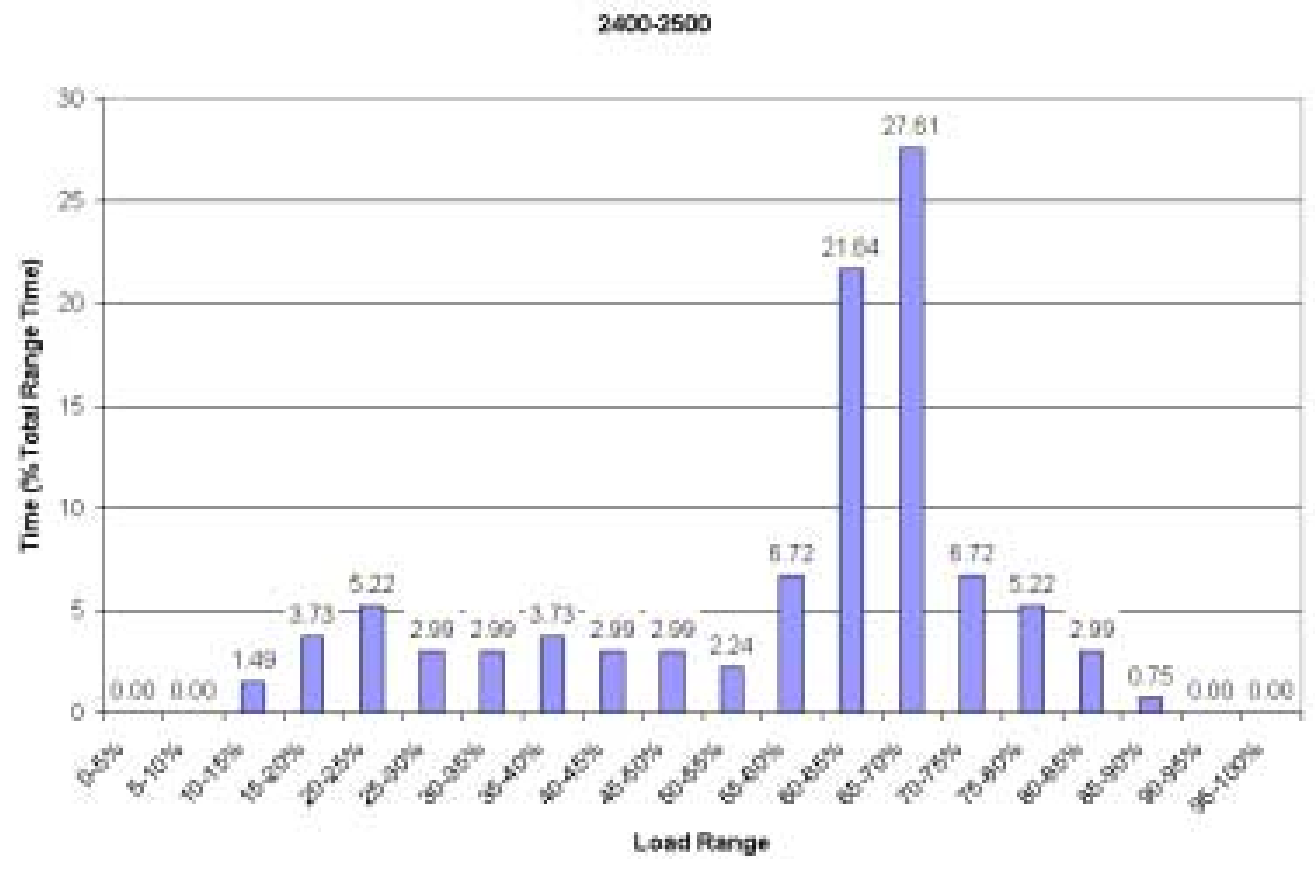

\section{Figure 80 Percent Load vs. Percent Total Rated Speed Time for the John Deere 4039T Engine.}

It can be deduced from Figure 80 that the range the range the streetsweeper most operated in during the infield testing was the rated speed range (2400-2500rpm) and was primarily around $75 \%$ load. The approximate calculated rated speed weighting factors for the streetsweeper would be 0.12 for rated $10,0.06$ for rated $50,0.56$ for rated 75 , and 0.0 for rated 100 . In contrast, the actual weighting factors for the rated conditions of the 8-mode cycle are 0.10 for rated 10 , and 0.15 for rated 50,75 , and 100 . This illustrates that the rated speed percent load points in the 8-mode cycle may be unrepresentative of actual "real world" load levels and, therefore, emissions data would also be unrepresentative. A comparison of the newly weighted 8-mode results with the 
integrated transient results can be seen in Table 25 below. It can be deduced from a

comparison of the percent difference data of Table 24 and Table 25 that the new

weighting factors produce a more accurate prediction of actual in-use emissions from the steady-state 8-mode data.

Table 25 Comparison of Transient and Newly Weighted 8-Mode Results for the John Deere 4039T Streetsweeper Engine (g/bhp-hr).

\begin{tabular}{|c|c|c|c|}
\hline Mode Number & $\begin{array}{c}\text { New Weighted 8- } \\
\text { Mode Results }\end{array}$ & $\begin{array}{c}\text { Transient } \\
\text { Results }\end{array}$ & \% Difference \\
\hline HC & 0.42 & 0.50 & -16.0 \\
\hline CO & 1.03 & 1.85 & -44.3 \\
\hline CO $_{2}$ & 552.4 & 626.0 & -11.8 \\
\hline NO $_{\mathbf{x}}$ & 7.17 & 5.59 & 28.3 \\
\hline PM & 0.137 & 0.245 & -44.1 \\
\hline
\end{tabular}

It should be noted that the transient cycle setpoint file was used for this analysis rather than the actual measured speed/load data. A regression was performed between the speed/load commanded by the setpoint file and the actual speed/load levels achieved. The CFR 40 Part 86 [1] provides regression analysis criteria to assess the validity of a transient cycle with respect to its setpoint file. These criteria can be seen in Table 26.

Table 26 Regression Criteria for Transient Certification Test Validity Analysis as Outlined in the Code of Federal Regulations.

\begin{tabular}{|c|c|c|}
\hline Criteria & Speed & Torque \\
\hline Slope of Regression Line, $\mathbf{m}$ & $0.970-1.030$ & $0.83-1.03$ \\
\hline Coefficient of Determination, $\mathbf{R}^{\mathbf{2}}$ & 0.9700 & 0.8800 \\
\hline Regression line y intercept, $\mathbf{b}$ & $+-50 \mathrm{rpm}$ & $+-15 \mathrm{ft}-\mathrm{lb}$ \\
\hline
\end{tabular}

It can be concluded from viewing Figure 81 that the streetsweeper engine met the criteria for torque outlined in Table 26. The coefficient of determination for the torque was 0.954 , the slope of the regression line was 0.97 , and the y-intercept was $2.36 \mathrm{ft}-\mathrm{lb}$. For the speed regression analysis performed, the results did not meet the criteria. The 
coefficient of determination for the speed was 0.9271 , the slope of the regression line was 0.951 , and the $y$-intercept was $80.0 \mathrm{rpm}$. The speed regression criteria could not be achieved with the eddy-current dynamometer and throttle controller setup used for the transient testing. The criteria listed in Table 26 are meant for engine certification purposes and were merely used as guidelines in this research as they did not have to be strictly adhered to.

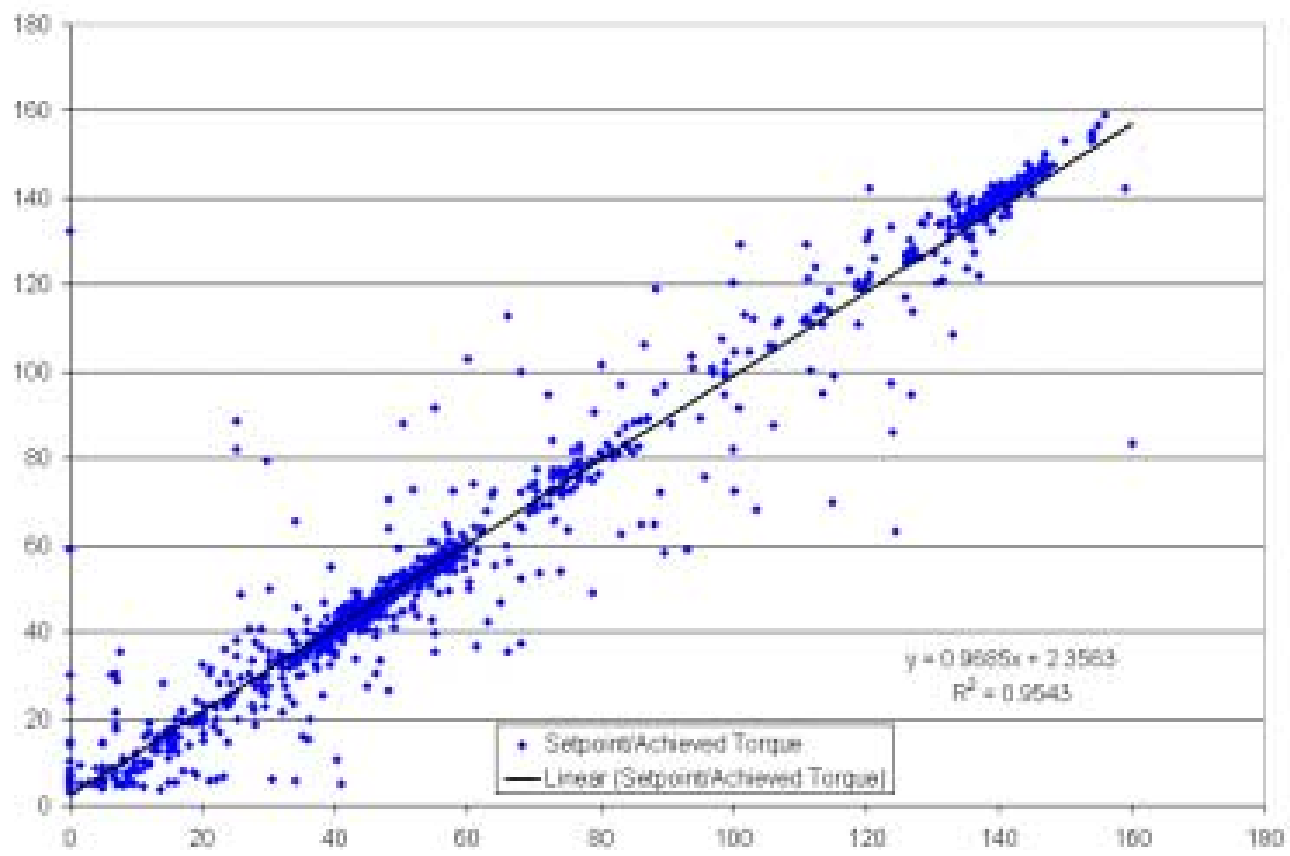

Figure 81 Regression Analysis for the Input vs. Achieved Torque for the John Deere 4039T Engine. 


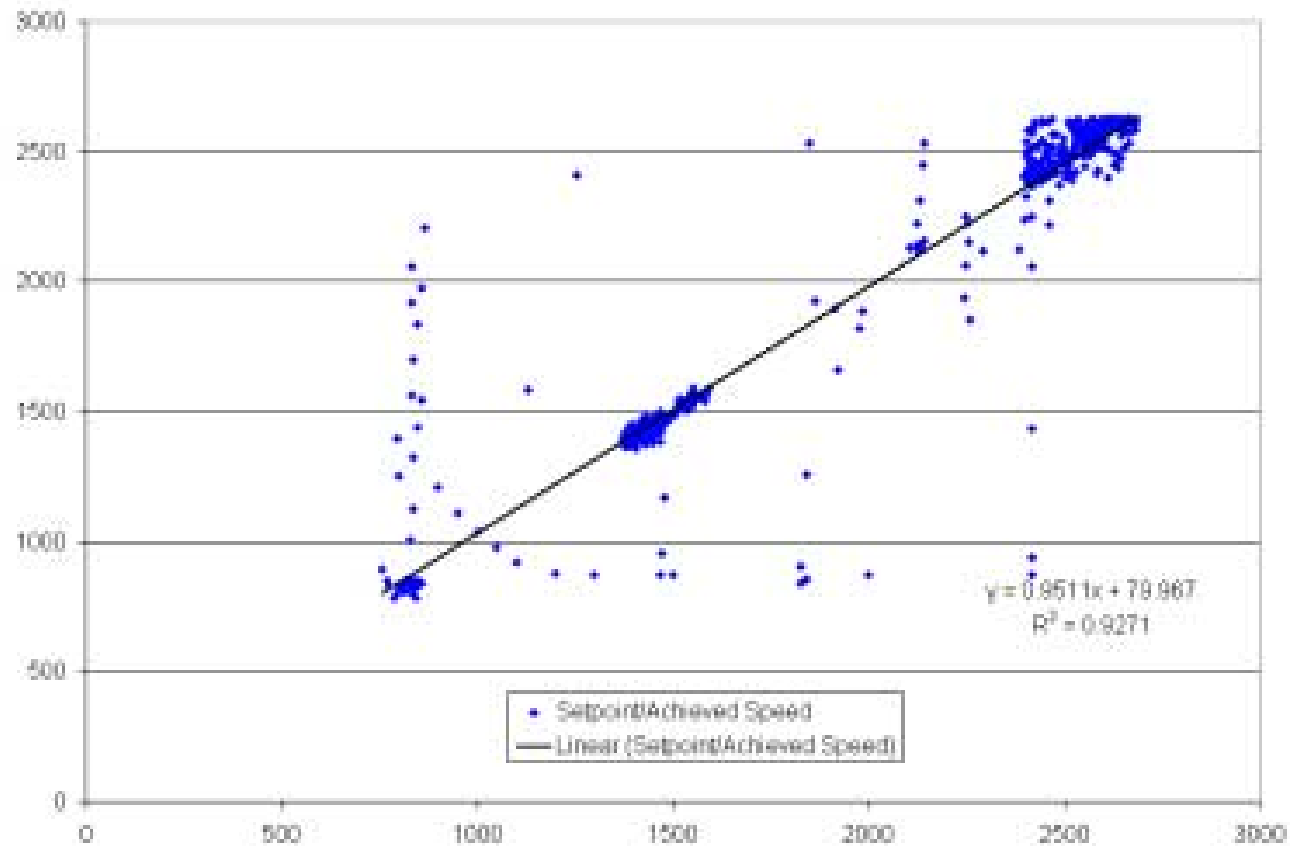

Figure 82 Regression Analysis for the Input vs. Achieved Engine Speed for the John Deere 4039T Engine. 


\section{Chapter 5. Conclusions and Recommendations}

\subsection{Overview}

Additional means to provide a more detailed view of contributors to air inventories are in demand due to increasingly more stringent air quality standards. The need to develop test cycles that accurately represent real "in-use" conditions for offhighway vehicles has fueled research and development of many portable emissions testing systems capable of logging data in the field. Though off-highway vehicles are known to be major contributors to air inventories, the diverse range of application of diesel engines in off-highway equipment has made individual test cycle development a tremendous undertaking. New methods are being explored that provide pathways for development of testing guidelines and protocols for the evaluation of these off-highway vehicles.

The results of this study have focused on only two of the vast number of dieselpowered off-highway vehicles in use today. Care must be taken when attempting to apply data presented in this document to other off-highway equipment, regardless of engine size, power output, etc. Testing has shown that the nature of the test cycle has the largest effect on the emissions levels emitted, and different testing cycles are needed for each type of equipment (loader, scraper, streetsweeper, dozer, etc.) being evaluated to obtain an accurate assessment of their contributions to air quality issues in the future.

\subsection{Conclusions}

The emissions testing and cycle development work performed for this study provides additional information needed for the development of testing protocols for diesel-powered off-highway equipment. The data produced through this research could 
be used to promulgate and develop requirements and standards for the testing of dieselpowered off-highway vehicles and equipment.

Steady-state data was collected during this study with the ISO-8178 Type C 8Mode Cycle. Weighted 8-Mode emissions (in g/bhp-hr) for the John Deere 6059 rubbertired loader engine were 4.765 for $\mathrm{HC}, 8.910$ for $\mathrm{CO}, 1118.0$ for $\mathrm{CO}_{2}, 26.51$ for $\mathrm{NO}_{\mathrm{x}}$, and 0.5015 for PM. For the John Deere 4039T streetsweeper engine, weighted emissions results were 1.954 for $\mathrm{HC}, 5.649$ for $\mathrm{CO}, 1111.0$ for $\mathrm{CO}_{2}, 11.67$ for $\mathrm{NO}_{\mathrm{x}}$, and 0.4739 for PM.

Table 27 Comparison of Steady-State Results with the Current Off-Road Diesel Emissions Standards.

\begin{tabular}{|c|c|c|c|c|}
\hline & $\begin{array}{c}\text { PM } \\
(\mathbf{g} / \mathbf{b h p}-\mathbf{h r})\end{array}$ & $\begin{array}{c}\text { CO } \\
(\mathbf{g} / \mathbf{b h p}-\mathbf{h r})\end{array}$ & $\begin{array}{c}\text { HC } \\
(\mathbf{g} / \mathbf{b h p}-\mathbf{h r})\end{array}$ & $\begin{array}{c}\mathbf{N O}_{\mathbf{x}} \\
(\mathrm{g} / \mathbf{b h}-\mathbf{h r})\end{array}$ \\
\hline 1996 Std. & 0.40 & 8.5 & 1.0 & 6.9 \\
\hline Streetsweeper & 0.47 & 5.65 & 1.95 & 11.67 \\
\hline Loader & 0.50 & 8.91 & 4.77 & 26.51 \\
\hline
\end{tabular}

It can be seen in Table 27 that the loader did not meet any of the current emissions standards and the streetsweeper passed only the current CO standard. Both vehicles were manufactured well before 1996, so they did not have to meet any standards when they were built.

The ISO-8178 Type C 8-Mode Cycle is the standard test used for the emissions evaluation of off-road diesel-powered equipment today. It is evident that the "real world" brake-specific emissions collected from the engine operating according to the transient test cycles differed significantly from the weighted brake-specific emissions collected during the running of the 8-Mode cycle. For both vehicles, all brake-specific emissions levels were reported much higher by the 8-Mode tests than by the transient tests. For the 
John Deere 6059 engine, the transient test result for $\mathrm{HC}$ was $544.6 \%$ lower, CO was $310.6 \%$ lower, $\mathrm{CO}_{2}$ was $104.6 \%$ lower, $\mathrm{NO}_{\mathrm{x}}$ was $227.3 \%$ lower, and $\mathrm{PM}$ was $177.3 \%$ lower than the weighted brake-specific results collected during the 8 -mode testing. For the John Deere 4039T streetsweeper engine, the transient test result for HC was $290.0 \%$ less, $\mathrm{CO}$ was $295.4 \%$ less, $\mathrm{CO}_{2}$ was $77.5 \%$ less, $\mathrm{NO}_{\mathrm{x}}$ was $108.8 \%$ less, and $\mathrm{PM}$ was 93.5\% less than the weighted brake-specific results collected during 8-mode testing. These characteristically large differences indicate that the testing of off-road equipment with a steady-state cycle may drastically over-estimate the contributions to air inventories by these vehicles.

Data were collected during the running of both engines on their respective transient cycles developed by WVU. Full-flow emissions data were collected for both engines in the laboratory using the final transient cycle iterations. Cycle-averaged results for the John Deere 6059 Loader engine (in $\mathrm{g} / \mathrm{bhp}-\mathrm{hr}$ ) were 546.4 for $\mathrm{CO}_{2}, 0.742$ for $\mathrm{HC}$, 2.168 for CO, 8.096 for $\mathrm{NO}_{\mathrm{x}}$, and 0.170 for PM. Results (g/bhp-hr) for the John Deere 4039T streetsweeper engine were 561.8 for $\mathrm{CO}_{2}, 0.367$ for $\mathrm{HC}, 3.569$ for $\mathrm{CO}, 7.359$ for $\mathrm{NO}_{\mathrm{x}}$, and 0.370 for PM. The comparable brake-specific average $\mathrm{CO}_{2}$ results indicate that similar work was performed in each cycle. For comparative purposes, full-flow data was also collected on the streetsweeper during the running of the first transient cycle iteration to investigate the impact that the accuracy of infield cycle recreation had on emissions results. Streetsweeper testing showed that the very labor intensive and time consuming process of cycle iteration changed cycle-averaged $\mathrm{CO}_{2}$ emissions by only $0.68 \%, \mathrm{HC}$ by $1.83 \%, \mathrm{CO}$ by $-4.83 \%, \mathrm{NO}_{\mathrm{x}}$ by $-1.51 \%$, and $\mathrm{PM}$ by $-7.53 \%$ between the first and final cycle iterations. Clearly, this is not a large change in the data for the 
amount of effort that was put into the accurate recreation of the infield cycle. Therefore, one could conclude that you could obtain infield $\mathrm{CO}_{2}$ continuous data and manufacturersupplied brake-specific fuel consumption versus load information and have a sufficiently accurate cycle approximation, as is explained in Section 5.3.1.

A test was run during this study to determine the effect that cycle suitability has on emissions levels. Running the streetsweeper engine on the cycle developed for the rubber-tired loader illustrated the important role that an appropriate vehicle-specific cycle has on emissions. When the streetsweeper engine was exercised according to the rubbertired loader cycle $\mathrm{CO}_{2}$ emissions decreased by $10.26 \%$, $\mathrm{HC}$ decreased by $26.54 \%, \mathrm{CO}$ increased by $92.61 \%, \mathrm{NO}_{\mathrm{x}}$ increased by $31.60 \%$, and PM increased by $51.19 \%$. This illustrates the need for a representative cycle to be derived for each type of equipment being tested to get an accurate estimation of emissions contributions.

\subsection{Recommendations}

In the future, continued testing of off-highway diesel-powered equipment will escalate as air quality standards become ever more stringent. The evolution of testing procedures and standards for off-highway diesels will continue to accelerate in the years to come. Additional research will add to the already expanding database of testing procedures for the off-highway arena. The future efforts suggested by the results of this study focus on additional labor saving techniques that would greatly reduce the amount of effort required for the recreation of the infield cycle. A section is also devoted to refinements that could be made to test procedures followed in this study. 


\subsubsection{Future Research}

It has been shown that the laborious process of cycle iteration did not produce a large difference in cycle averaged emissions results. The close accuracy of the laboratory transient cycle continuous $\mathrm{CO}_{2}$ traces to the infield cycle traces did not make a significant difference in the overall cycle-averaged emissions levels. However, with second-bysecond data some factors such as rate of acceleration/deceleration could be significantly different. The elimination of the cycle iteration process would dramatically reduce the amount of time spent in the development of new transient emissions test cycles for offhighway diesel engines

A method that should be explored in future test cycle creation work is to utilize manufacturer-supplied brake-specific fuel consumption (BSFC) data to directly estimate engine torque based on the gaseous emissions. The procedure for the estimation of fuel consumed from the measured exhaust emissions is outlined in the CFR 40, Part 89 [1].

To obtain brake-specific mass emissions from a mechanically injected diesel engine it is necessary to infer the work done by the engine over a cycle from BSFC data supplied by the engine manufacturer. A means would have to be used to determine the mass flow rate of the exhaust stream. The simplest method would be to measure the intake air flow rate with a laminar flow element or equivalent flow device and measure the mass flow rate of the fuel with a rotometer or similar fluid flow rate measuring device. Temperatures could be taken to determine densities of the intake air and fuel during testing to allow the determination of mass flow rates. The process used to infer total cycle work would involve the following steps: 1) Measure the raw concentration of $\mathrm{CO}_{2}$ and the exhaust flow rate over the cycle period. 2) Integrate the continuous raw $\mathrm{CO}_{2}$ 
concentration data to arrive at an average concentration over the cycle period. A Tedlar bag sample could also be used to determine the cycle-averaged $\mathrm{CO}_{2}$ concentration using laboratory-grade instruments. Calculate the BSFC of the engine from the average $\mathrm{CO}_{2}$ concentration with the manufacturer-supplied information. Determine the mass of HC, $\mathrm{CO}$, and $\mathrm{CO}_{2}$ emitted from the raw exhaust concentration and the exhaust mass flow rate. Calculate the mass of fuel consumed with the following equation:

$$
\mathrm{M}=\frac{\mathrm{G}_{S}}{\mathrm{R}_{2}},
$$

Eqn. 5.1

where

$$
\mathrm{G}_{\mathrm{s}}=R_{2} \cdot \mathrm{HC}_{\text {mass }}+0.429 \cdot \mathrm{CO}_{\text {mass }}+0.273 \cdot \mathrm{CO}_{2 \text { mass }}
$$

Eqn. 5.2

and

$$
\mathrm{R}_{2}=\frac{12.011}{12.011+1.008 \cdot \alpha}
$$

Eqn. 5.3

Where,

$\alpha=$ The Hydrogen to Carbon Ratio of the Fuel

The integrated work over the cycle can be inferred as:

$$
\text { Work }=\frac{\mathrm{M}}{\mathrm{BSFC}}
$$

Eqn. 5.4

The resulting brake-specific mass emission is obtained by dividing the calculated integrated mass by the calculated work: 


$$
\mathrm{BSCO}_{2}=\frac{\mathrm{CO}_{2 \text { mass }}}{\text { Work }}
$$

Eqn. 5.5

The above method could also be used to directly estimate continuous cycle torque based on the calculated BSFC of the engine. Manufacturer-supplied BSFC vs. dry $\mathrm{CO}_{2}$ (\%) data could be cross-referenced to determine the continuous torque trace derived solely from the $\mathrm{CO}_{2}$ continuous emissions data. This method would be much less time consuming, as it would eliminate the laborious cycle iteration process performed for this study. The accuracy of the manufacturer-supplied data would ultimately determine the accuracy that could be achieved for the recreation of the cycle for any future testing in a laboratory setting. Results of this study have shown that emissions data obtained during the running of the recreated cycle are not largely affected by very accurate recreation but, rather, by the basic transient nature of the test cycle itself.

To reiterate and break the previous method into basic steps, the first thing needed would be manufacturer-supplied BSFC plots based upon engine speed and some engine torque parameter (MEP, torque, power, raw $\mathrm{CO}_{2}$ in \%vol or PPM, etc.). The engine speed, raw $\mathrm{CO}_{2}$ concentration, and the exhaust flow rate would all have to be measured and recorded in the field. From the recorded infield data, the BSFC could be determined with the manufacturer-supplied data. The $\mathrm{CO}_{2}$ mass could then be calculated from the exhaust flowrate and the raw $\mathrm{CO}_{2}$ data. The next step is to perform a carbon balance of the $\mathrm{CO}_{2}$ in the exhaust (neglecting $\mathrm{HC}$ and $\mathrm{CO}$ contributions) to determine the amount of fuel consumed. From the fuel consumed, the amount of engine power produced can be determined from manufacturer-supplied data. The torque can then be determined based on the calculated horsepower and the measured engine speed. The major obstacle 
encountered when utilizing this method for transient torque estimation is the problem of time aligning all of the measured parameters. The method is more suitable for steadystate testing where the parameters can be averaged and "smoothed" over a longer period of time.

The current trend indicated by the off-highway vehicle manufacturers is to incorporate electronic engine controls, which will make the task of data collection and torque estimation very easy. A computer interface can retrieve important data from the ECU such as engine fueling rate and intake air temperature, as well as engine speed. Testing an electronically controlled engine would eliminate the need for secondary engine speed acquisition and would allow the estimation of torque based directly on ECU fueling rate data. With the torque already estimated throughout the infield cycle, the laborious task of cycle iteration undertaken in this study could be eliminated. Theoretically, all testing of the vehicle could be performed in the field and the ECUestimated torque and engine speed data could be used for the development of transient testing cycles. A portable system has been developed by WVU that allows the continuous collection of PM in the field. Using this sampling system and a mobile gaseous emissions measurement system could eliminate the dependency on laboratory testing. A detailed description of the portable PM sampling system can be found in Emily Cirillo's Thesis entitled “Development of a Micro-Dilution Tunnel System for InUse, On-Board Heavy Duty Vehicle Particulate Matter Emission Measurement [7]." Dynamometer power-absorbing limitations will force WVU to investigate these infield collection methods in the testing of the final vehicle for the CARB project... an off- 
highway vehicle with an engine producing over 500hp. Testing procedures and results for this vehicle will be found in future reports by WVU.

\subsubsection{Test Procedure Refinement}

A number of refinements in test procedure could be implemented in future evaluation of off-highway equipment. The most troublesome problem encountered during testing was the acquisition of the engine speed signal from the two vehicles' alternators. Difficulty with signal noise and the resultant spikes in the data made it necessary to manually go through the continuous engine speed information and determine if a spike was a result of noise alone by examining the points directly before and after the point in question. If the values differed by a significant amount, the point was considered erroneous due to signal noise and was replaced with the average of the values directly before and after it in the data stream. The alternator signal acquired by the Sensors AMB-II had only six pulses per revolution of the alternator to count, which resulted in relatively poor resolution. A better method of acquiring the engine speed signal in the future would be to use a multiple-toothed wheel mounted directly to the engine's crankshaft to trigger a Hall effect sensor. Better resolution could be obtained with the suggested setup by increasing the number of teeth on the trigger wheel. Mounting the trigger wheel directly on the engine's crankshaft also eliminates the possibility of belt slippage and any consequential errors in engine speed information.

Another problem encountered during testing was the varying time stamp of the data collection rate of the Sensors AMB-II Multigas analyzer. Not only was the sampling rate not an evenly timed event, such as $1 \mathrm{~Hz}$, but it would vary from test to test. This made it difficult to align the AMB-II data with the $1 \mathrm{~Hz}$ laboratory data for cycle 
comparison purposes. A Visual Basic program was written that converted the collected data to an evenly-timed $1 \mathrm{~Hz}$ format through interpolation. A different analyzer with a constant even sampling rate would have made testing easier. Other analyzers should be explored for future testing or software should be developed for the Sensors AMB-II that would remedy the uneven time stamp issue. 


\section{References}

1. “Code of Federal Regulations," CFR 40 Parts 86 to 99, Washington, D.C., 1994

2. Bentz, A. P. and Weaver, E., "Marine Diesel Exhaust Emissions Measured by Portable Instruments," SAE Technical Paper No. 941784, 1994.

3. Bentz, A. P., "Final Summary Report on Project 3310, Marine Diesel Exhaust Emissions (Alternative Fuels)," United States Department of Transportation United States Coast Guard Systems, Report No. CG-D-08-98, 1997.

4. Butler, J. W., Gierczac, C. A., Jesion, G., Stedman, D. H., and Lesko, J. M., "OnRoad $\mathrm{NO}_{\mathrm{x}}$ Emissions Intercomparison of On-Board Measurement and Remote Sensing," Final Report, Coordinating Research Council, Inc., Atlanta, GA, CRC Report No. VE-11-6, 1994.

5. Butler, J. W., Korniski, T. J., Reading, A. R., and Kotenko, T. L., "Dynamometer Quality Data On-Board Vehicles for Real-World Emission Measurements," Proceedings of the Ninth CRC On-Road Vehicle Workshop, April 19-21, San Diego, CA, 1999.

6. Carder, D. K., "Performance Evaluation of Exhaust Aftertreatment Devices Used for Emissions Control On Diesel Engines Employed in Underground Coal Mines," M.S. Thesis, Department of Mechanical and Aerospace Engineering, West Virginia University, Morgantown, WV, 1999.

7. Cirillo, E.,'Development of a Micro-Dilution Tunnel System for In-Use, On-Board Heavy Duty Vehicle Particulate Matter Emission Measurement," M.S. Thesis, Department of Mechanical and Aerospace Engineering, West Virginia University, Morgantown, WV, 2001.

8. Comments on EPA's NPRM for the Control of Emissions of Air Pollution from Nonroad Diesel Engines, August 1998.

9. Emissions Standards: USA-Heavy Duty Truck and Bus Engines/Off-Road Diesel Engines. www.dieselnet.com., EcoPoint Inc., April 2000.

10. Gierczac, C. A., Jesion, G., Piatak, J. W., and Butler, J. W., "On-Board Vehicle Emissions Measurement Program,” Final Report, Coordinating Research Council, Inc., Atlanta, GA, CRC Report No. VE-11-1, 1994. 
11. Howes, P., "Final Report for the City of Houston Concerning the Municiple Waste Truck running on PuriNO ${ }_{x}$ Fuel,"'Environmental Research and Measurement Division, Gloucester, Ontario, 2000.

12. Human, D. M. and Ullman, T. L., "Development of an I/M Short Emissions Test for Buses," SAE Technical Paper No. 920727, 1992.

13. Kelly, N.A. and Groblicki, P. J., "Real-world Emissions from a Modern Production Vehicle Driven in Los Angeles," Journal of Air and Waste Management Association, Vol. 43, No. 10, 1993.

14. Mackay, G. I., Nadler, S. D., Karecki, D. R., Schiff, H. I., Butler, J. W., Gierczac, C. A., and Jesion, G., "Dynamometer Intercomparison of Automobile Exhaust Gas $\mathrm{CO} / \mathrm{CO}_{2}$ Ratios and Temperature Between On-Board Measurements and a Remote Sensing Near Infrared Diode Laser System,"Phase 1b Report to the Coordinating Council and National Renewable Energy Laboratory, 1994.

15. Mackay, G. I., Nadler, S. D., Karecki, D. R., Schiff, H. I., Butler, J. W., Gierczac, C. A., and Jesion, G., "Dynamometer Intercomparison of Automobile Exhaust Gas $\mathrm{CO} / \mathrm{CO}_{2}$ Ratios and Temperature Between On-Board Measurements and a Remote Sensing Near Infrared Diode Laser System,"Phase 1c Report to the Coordinating Council and National Renewable Energy Laboratory, 1994.

16. Pei, Y., "Development of Software for the Heavy-Duty Engine Testing at Engine Research Center, West Virginia University,” M.S. Thesis, Department of Mechanical and Aerospace Engineering, West Virginia University, Morgantown, WV, 1993.

17. Reschke, G. D., "Optimization of a Flame Ionization Detector for the Determination of Hydrocarbon in Diluted Automotive Exhausts," SAE 770141, 1977.

18. Shade, B. C., " A Performance Evaluation of the MEMS - An On-Road Emissions Measurement System Study," M.S. Thesis, Department of Mechanical and Aerospace Engineering, West Virginia University, Morgantown, WV, 2000.

19. Summary Report: "Construction Equipment Retrofit Project,"Northeast States for Coordinated Air Use Management, Boston, Mass., 1997.

20. Technical Report: "Selection Criteria For Diesel Particulate Trap Systems: Vert Experience." www.dieselnet.com, Ecopoint Inc., December 1998. 
21. Technical Report: "VERT: Curtailing Emissions of Diesel Engines in Tunnel Sites." www.dieselnet.com., EcoPoint Inc., April 1998.

22. Vojtisek-Lom, M. and Cobb, Jr., J. T., "On-Road Light-Duty Vehicle Mass Emission Measurements Using a Novel Inexpensive On-Board Portable System,"Proceedings of the Eighth CRC On-Road Vehicle Workshop, San Diego, CA, April 20-22, 1998. 
Appendix A-Additional Data for the John Deere 6059 Loader Engine. 


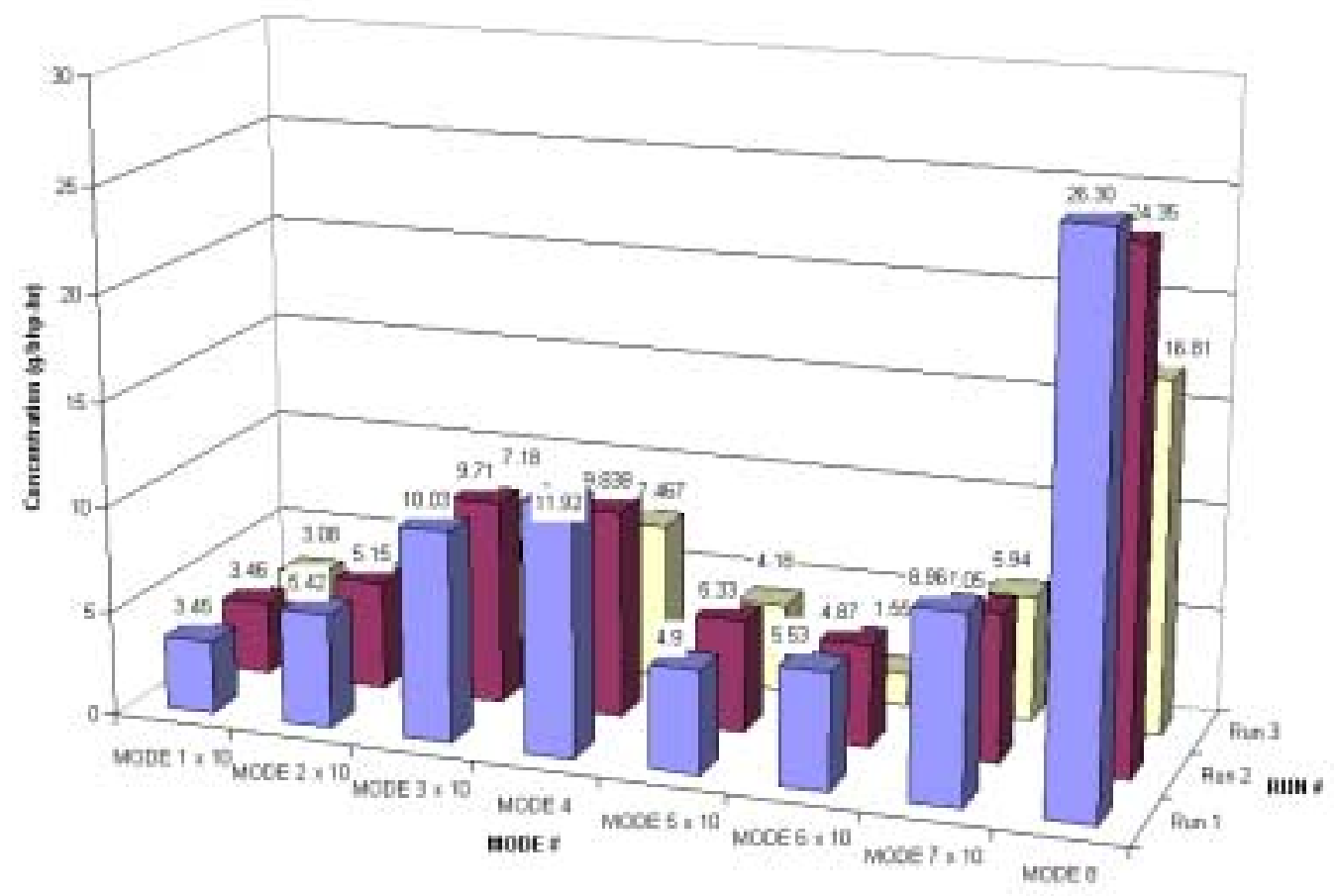

Figure A.83 HC 8-Mode Results for the John Deere 6059 (g/bhp-hr).

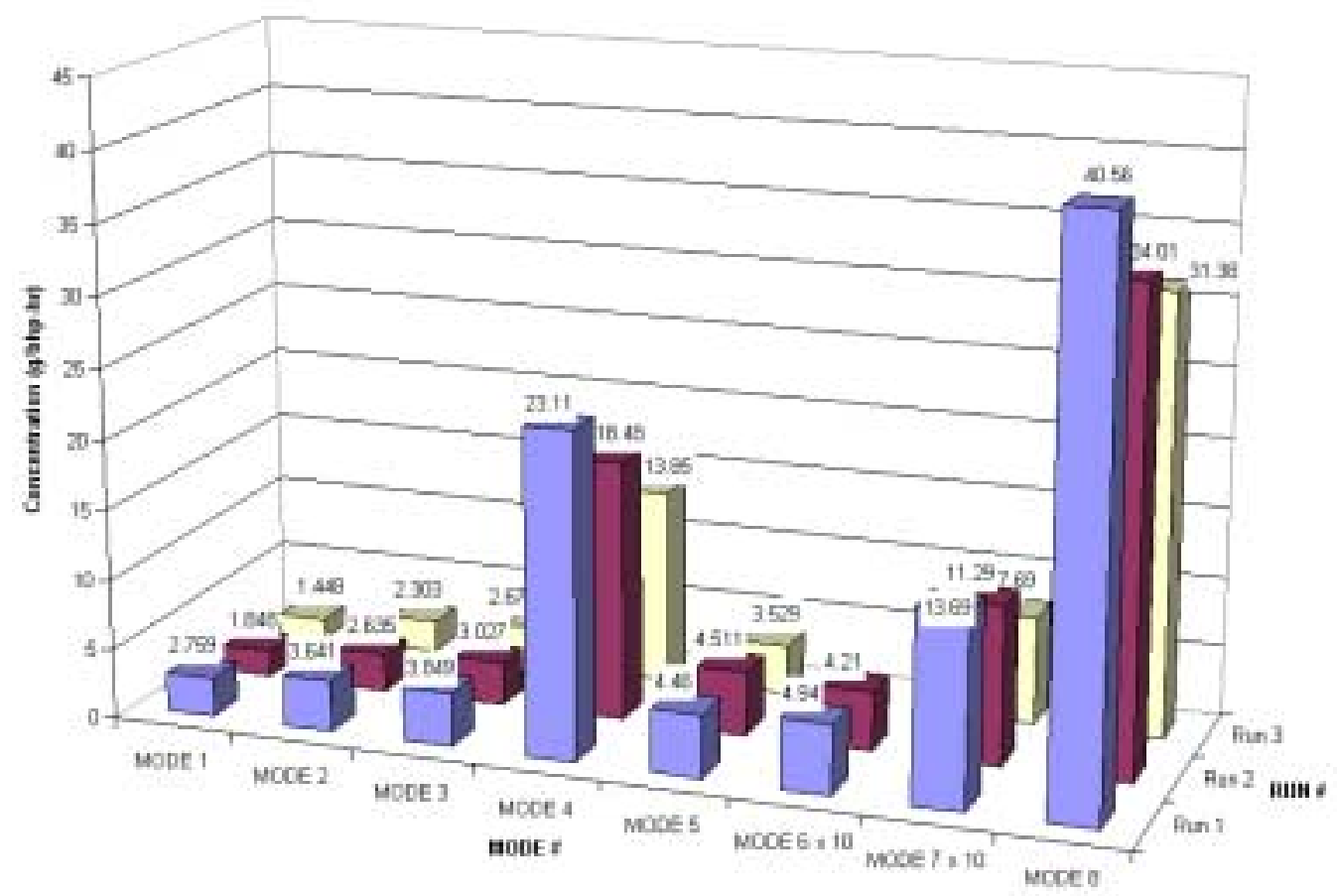

Figure A.84 CO 8-Mode Results for the John Deere 6059 (g/bhp-hr). 


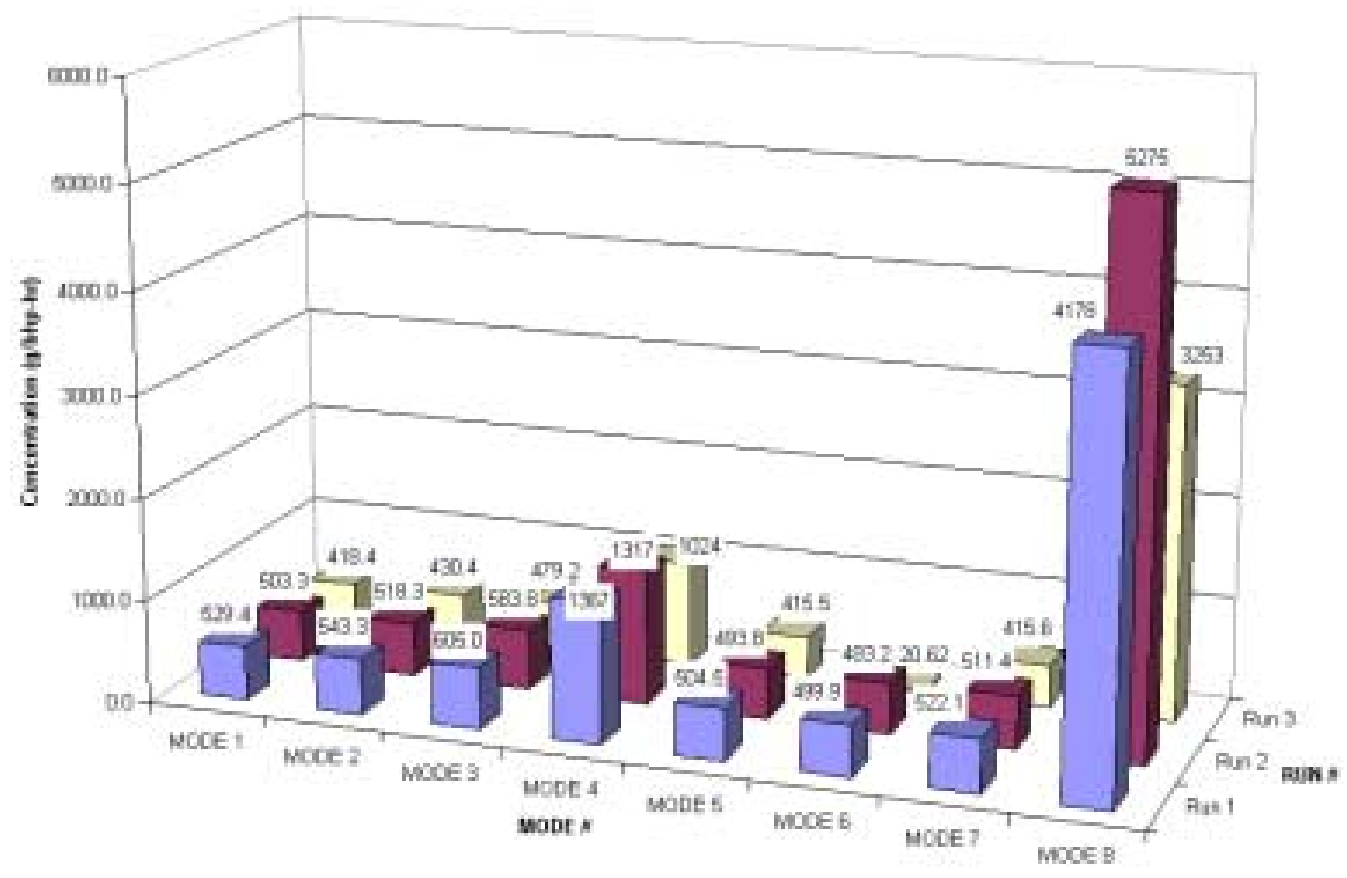

Figure A.85 $\mathrm{CO}_{2}$ 8-Mode Results for the John Deere 6059 (g/bhp-hr).

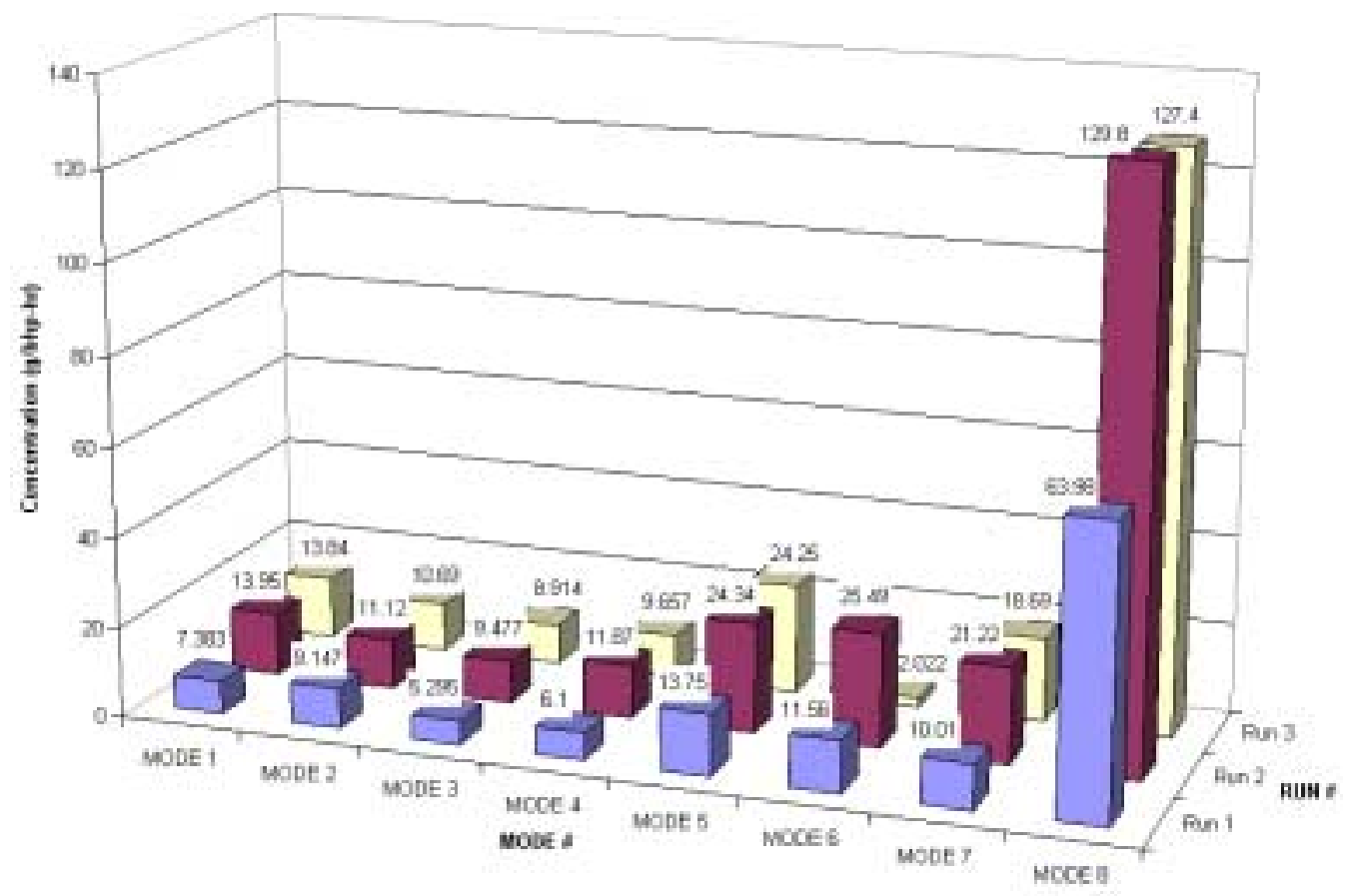

Figure A.86 NO $_{x}$ 8-Mode Results for the John Deere 6059 (g/bhp-hr). 


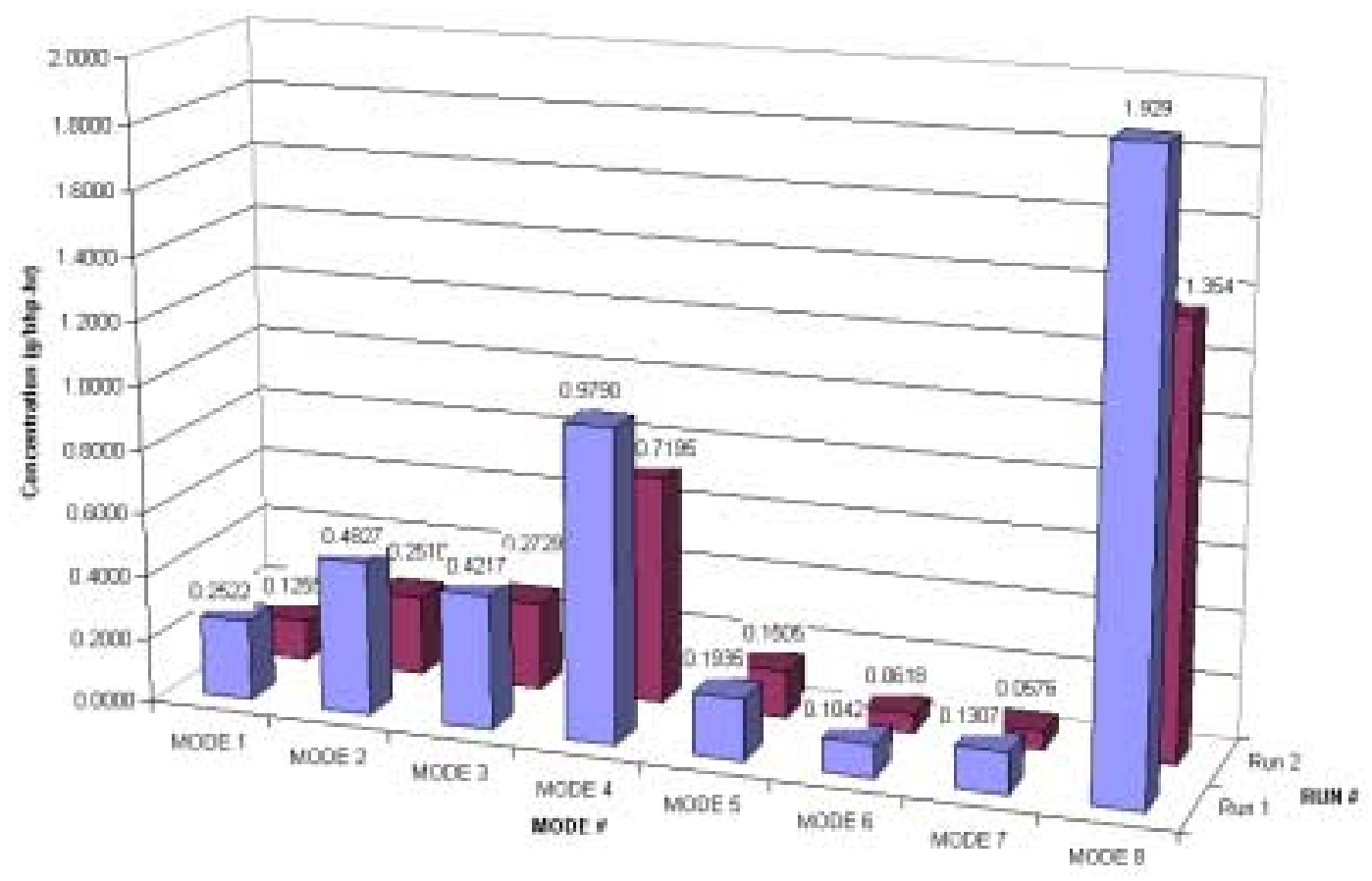

Figure A.87 PM 8-Mode Results for the John Deere 6059 (g/bhp-hr). 
Appendix B-Additional Data for the John Deere 4039T Streetsweeper Engine. 


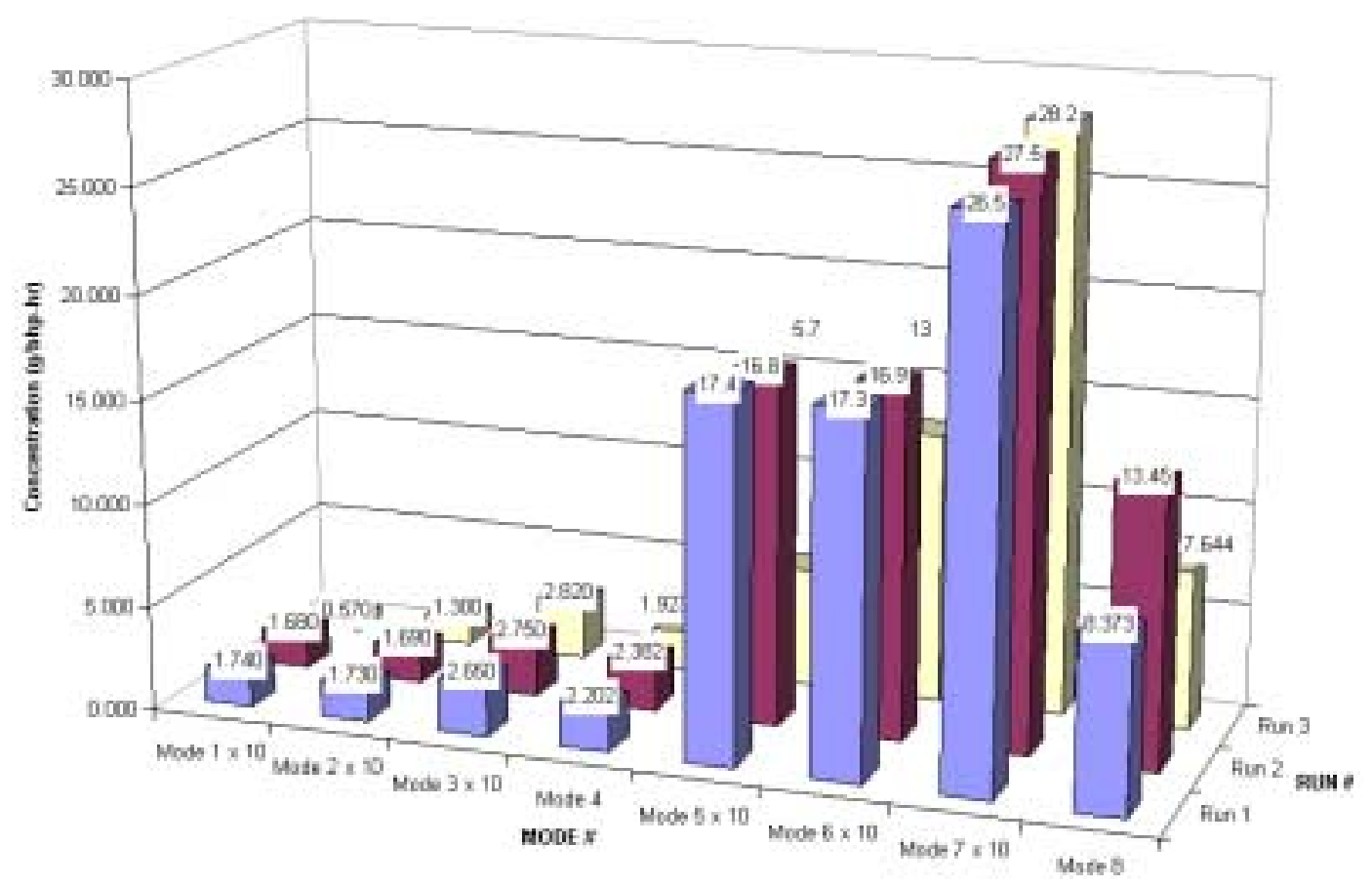

Figure B.88 HC 8-Mode Results for the John Deere 4039T (g/bhp-hr).

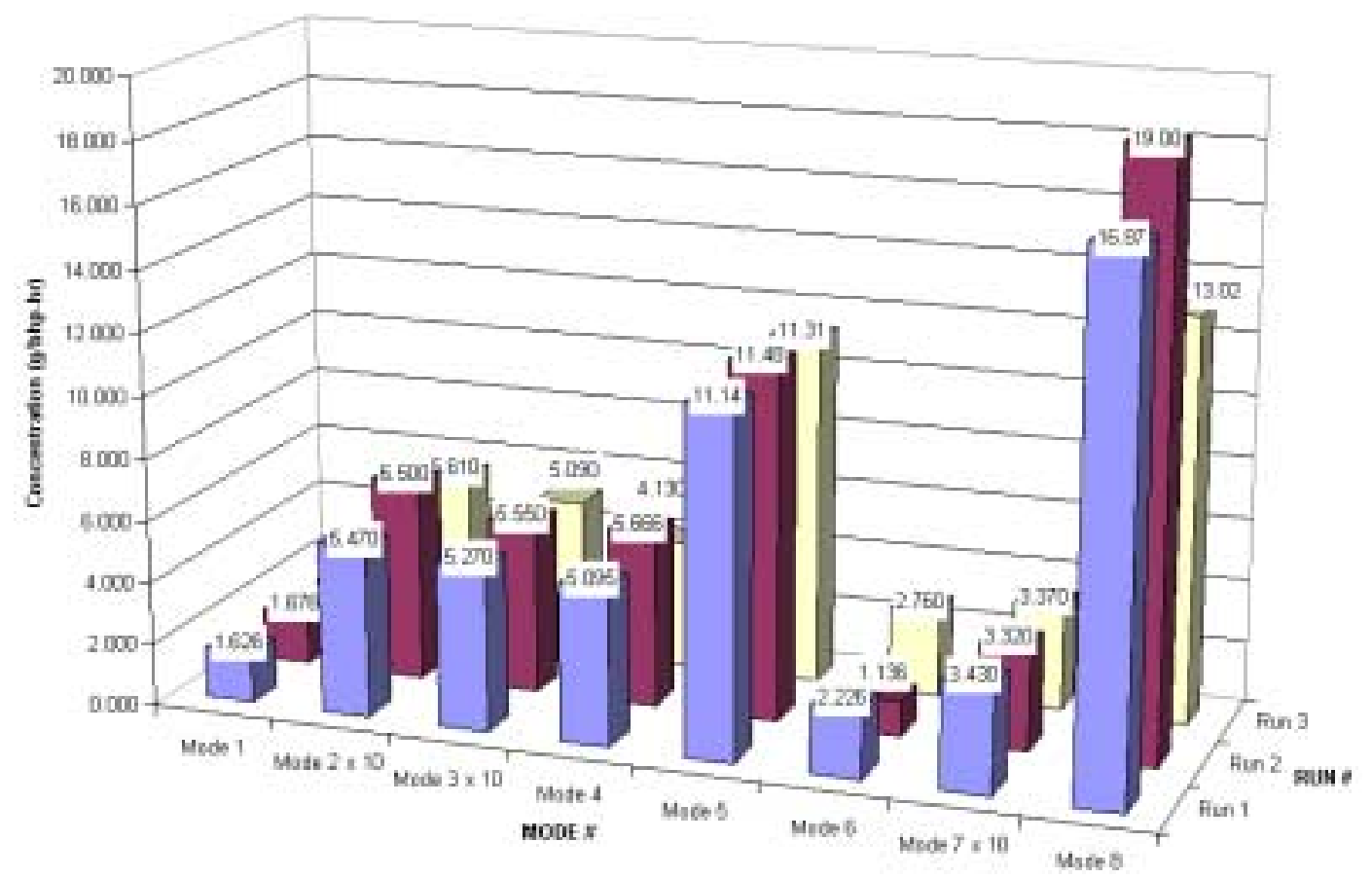

Figure B.89 CO 8-Mode Results for the John Deere 4039T (g/bhp-hr). 


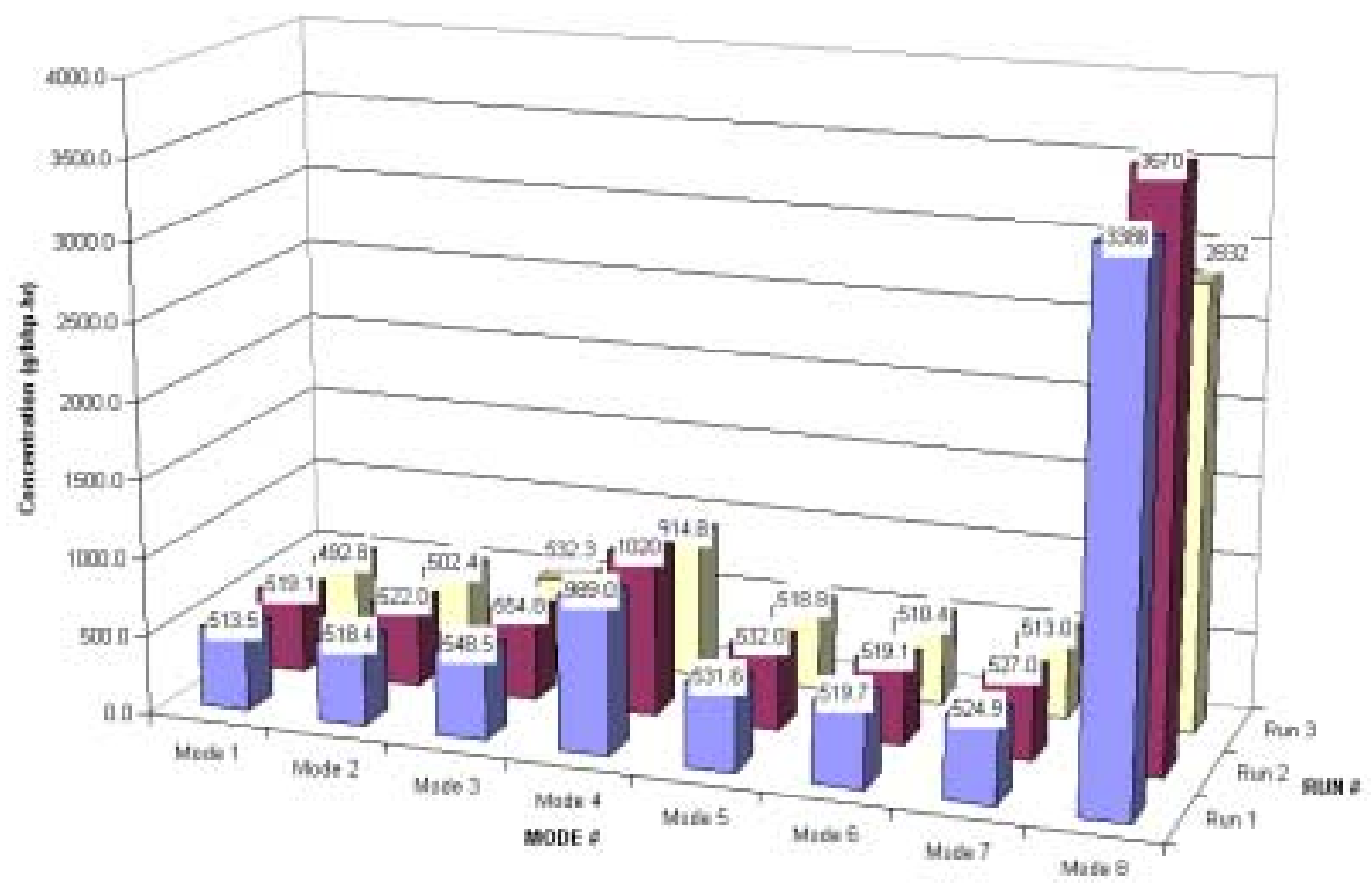

Figure B.90 $\mathrm{CO}_{2}$ 8-Mode Results for the John Deere 4039T (g/bhp-hr).

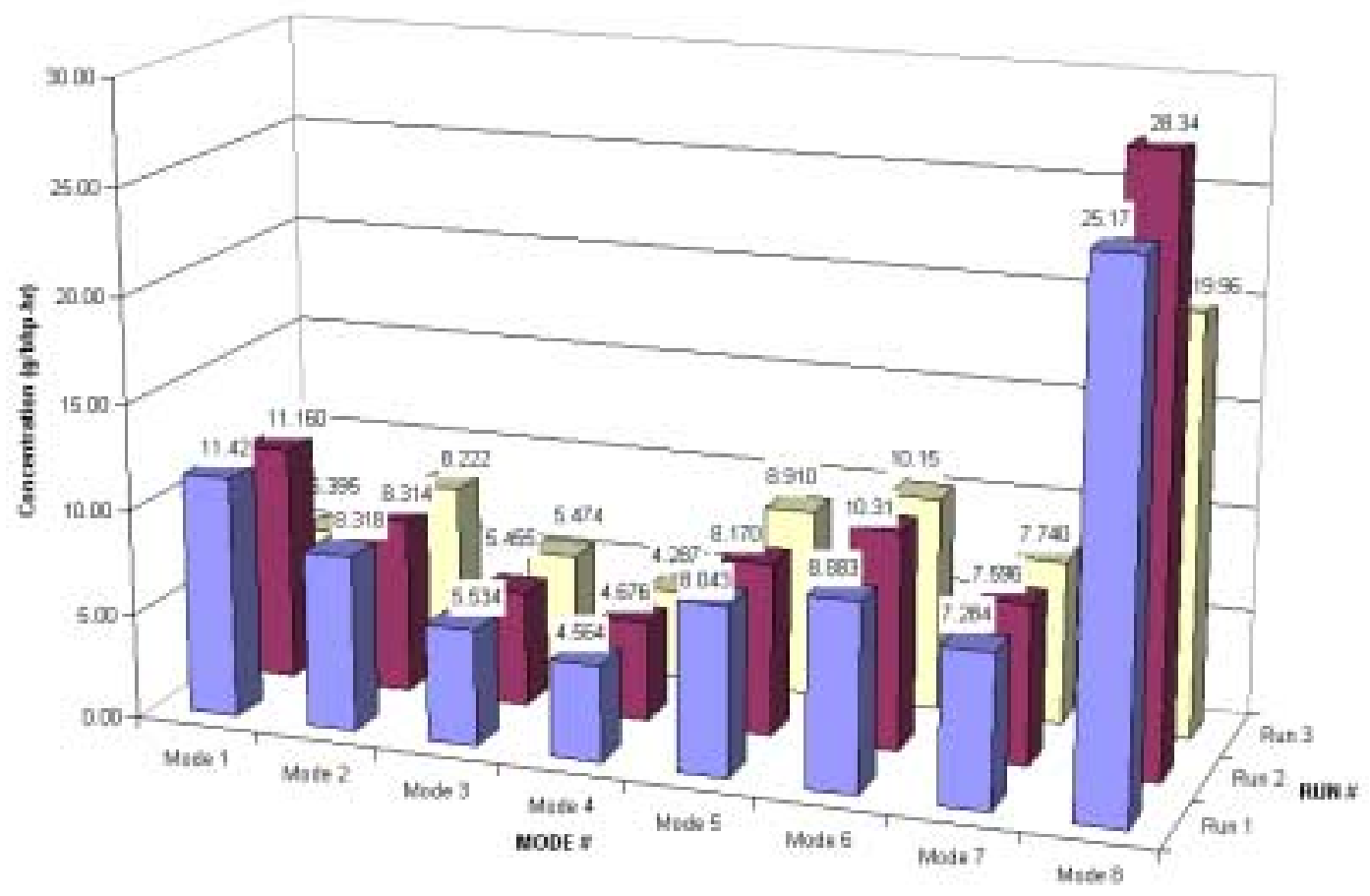

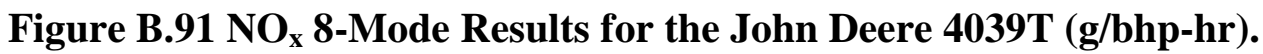




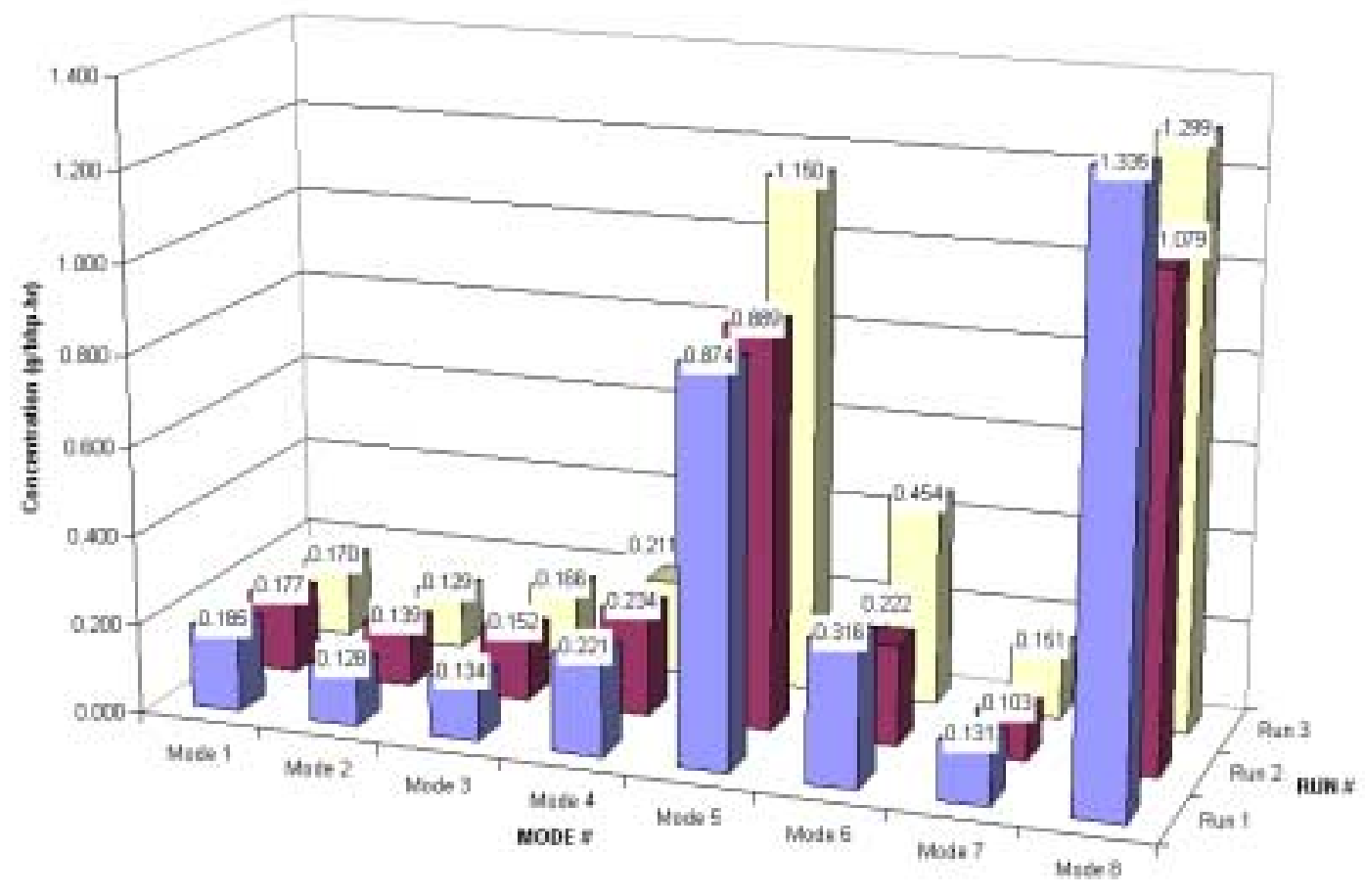

Figure B.92 PM 8-Mode Results for the John Deere 4039T (g/bhp-hr). 